\title{
Physical fitness, fatigue and physical training in sarcoidosis
}

Citation for published version (APA):

Strookappe, E. W. (2017). Physical fitness, fatigue and physical training in sarcoidosis. [Doctoral Thesis, Maastricht University]. Datawyse / Universitaire Pers Maastricht. https://doi.org/10.26481/dis.20170124ews

Document status and date:

Published: 01/01/2017

DOI:

10.26481/dis.20170124ews

Document Version:

Publisher's PDF, also known as Version of record

\section{Please check the document version of this publication:}

- A submitted manuscript is the version of the article upon submission and before peer-review. There can be important differences between the submitted version and the official published version of record.

People interested in the research are advised to contact the author for the final version of the publication, or visit the DOI to the publisher's website.

- The final author version and the galley proof are versions of the publication after peer review.

- The final published version features the final layout of the paper including the volume, issue and page numbers.

Link to publication

\footnotetext{
General rights rights.

- You may freely distribute the URL identifying the publication in the public portal. please follow below link for the End User Agreement:

www.umlib.nl/taverne-license

Take down policy

If you believe that this document breaches copyright please contact us at:

repository@maastrichtuniversity.nl

providing details and we will investigate your claim.
}

Copyright and moral rights for the publications made accessible in the public portal are retained by the authors and/or other copyright owners and it is a condition of accessing publications that users recognise and abide by the legal requirements associated with these

- Users may download and print one copy of any publication from the public portal for the purpose of private study or research.

- You may not further distribute the material or use it for any profit-making activity or commercial gain

If the publication is distributed under the terms of Article $25 \mathrm{fa}$ of the Dutch Copyright Act, indicated by the "Taverne" license above, 


\section{PHYSICAL FITNESS, FATIGUE AND PHYSICAL TRAINING IN SARCOIDOSIS}


(C) Copyright Egbert Willem (Bert) Strookappe, Maastricht 2017

\author{
Layout Tiny Wouters \\ Cover design Thesisexpert.nl \\ Print Datawyse | Universitaire Pers Maastricht
}

ISBN/EAN 978-90-78076-10-0

Financial support for the printing of this thesis was kindly provided by Chiesi; Boehringer Ingelheim B.V.; Scientific College Physical Therapy (WCF) of the Royal Dutch Society for Physical Therapy (KNGF), Hospital Gelderse Vallei Ede and ild care foundation.

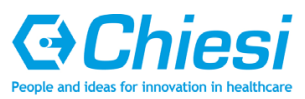

\title{
ild care
}

foundation
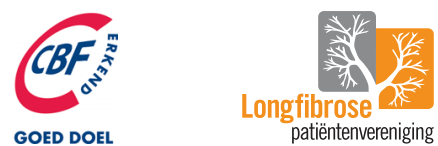

The research published in this thesis was financially supported by the ild care foundation and the Sarcoidosis Belangenvereniging Nederland.

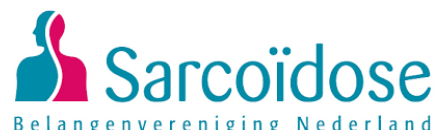




\section{Physical fitness, fatigue and physical training in sarcoidosis}

\section{PROEFSCHRIFT}

Ter verkrijging van de graad van doctor aan de Universiteit Maastricht, op gezag van de Rector Magnificus, Prof. dr. Rianne M. Letschert, volgens het besluit van het College van Decanen,

in het openbaar te verdedigen op dinsdag 24 januari 2017 om 14.00 uur

door

Egbert Willem (Bert) Strookappe 
Promotores:

Prof. dr. M. Drent

Prof. dr. J. De Vries (Universiteit Tilburg)

Beoordelingscommissie:

Prof. dr. R.A. de Bie (voorzitter)

Prof. dr. A. Bast

Prof. dr. J.C. Grutters (Universiteit Utrecht)

Prof. dr. H. Kuipers

Prof. dr. W. Wuyts (Universitair Ziekenhuis Leuven, België) 


\section{Contents}

$\begin{array}{lll}\text { Chapter } 1 & \text { General introduction } & 7\end{array}$

$\begin{array}{llr}\text { Chapter } 2 \text { Consequences of sarcoidosis } & 19\end{array}$

Chapter 3 Validation of the King's Sarcoidosis Questionnaire (KSQ) 39 in a Dutch sarcoidosis population

Chapter 4 Predictors of fatigue in sarcoidosis: the value of exercise testing

Chapter 5 Benefits of physical training in patients with idiopathic or end-stage sarcoidosis-related pulmonary fibrosis: a pilot study

Chapter 6 Benefits of physical training in sarcoidosis

Chapter 7 Physical activity and training in sarcoidosis: review and experience-based recommendations

Chapter 8 Summary and general discussion

Valorisatie

Samenvatting (summary in Dutch)

Dankwoord

Curriculum vitae

List of publications 



\section{Chapter 1}

General introduction 



\section{General introduction}

\section{Sarcoidosis}

Sarcoidosis is a multisystemic disease of unknown cause characterized by cellular immunity activity with formation of noncaseating granuloma in various organ systems. ${ }^{1,2}$ Although sarcoidosis can affect people of all ages, it commonly starts in young and middle-aged adults. The peak incidence occurs between twenty and forty years of age in both sexes. The disease appears to be more common in women than in men. ${ }^{3,4}$ Sarcoidosis is prevalent throughout the world, but the incidence and phenotype differs according to specific regions and race. Löfgren's syndrome is the most frequent type of presentation in the Scandinavian countries and is defined by the presence of acute onset symptoms with fever, arthralgias, erythema nodosum, and bilateral hilar lymphadenopathy. In Japan, cardiac involvement and uveitis are more common. ${ }^{5}$

\section{Clinical presentation}

The clinical presentation is highly variable and unpredictable. The disease primarily affects the lungs $(90 \%)^{5}$ and the lymphatic system, but it may also affect the skin, eye, heart, liver, nervous and musculoskeletal system. Virtually every organ system can be involved. ${ }^{2}$ Patients may suffer from a wide spectrum of organ specific symptoms, in relation to the organ system involved. In addition to symptoms related to the specific organ involvement (dyspnea on exertion, breathlessness and cough accompanying lung involvement e.g.) patients often have non-specific complaints such as exercise intolerance ${ }^{6}$, arthralgia, depressive symptoms, cognitive failure ${ }^{7}$, muscle weakness and fatigue. 6,8

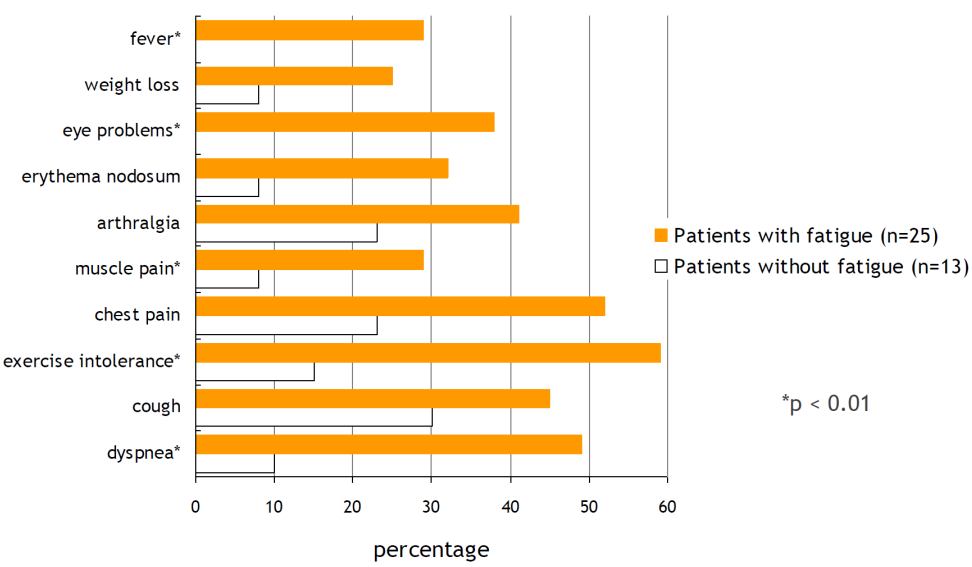

Figure 1.1 Most relevant reported symptoms in sarcoidosis. Group I ( $n=13)$ : patients without fatigue, and group II $(n=25)$ : patients suffering from fatigue. ${ }^{*}$ : $p<0.05$ group I versus group II. 
The impact of the symptoms on patients' lives depends on the specific organ involvement, disease activity, duration and severity of the illness. ${ }^{9}$ The most common symptoms include fatigue, respiratory symptoms like coughing or dyspnea, and symptoms related to extrapulmonary involvement. ${ }^{5}$

Since any organ may be affected, a multidisciplinary approach is needed in the majority of the patients. ${ }^{10}$

\section{Pulmonary involvement}

Involvement of the pulmonary parenchyma and mediastinal lymphadenopathy is present in approximately $90 \%$ of the sarcoidosis patients; hence the pulmonologist is often the prominent physician in the management of the disease. Deterioration of lung function is regarded as an indicator of disease activity in sarcoidosis. ${ }^{11} \mathrm{~A}$ wide spectrum of lung function abnormalities can be present, including an obstructive pattern, restriction, a mixed obstructive and restrictive ventilatory effect, and a decreased diffusion capacity of the lungs for carbon monoxide (DLCO). ${ }^{12}$ Abnormal lung function tests, especially forced expiratory volume in one second (FEV1), forced vital capacity (FVC), and DLCO are traditionally used as an indication for treatment. ${ }^{11}$ Baseline lung function tests are not related to the probability of disease progression and cannot distinguish between reversible granulomatous lesions and irreversible fibrotic changes. ${ }^{11}$ In $80 \%$ of sarcoidosis patients presenting with abnormal spirometric findings, values return normal within two years. ${ }^{13}$ No obvious correlation between lung function test results and chest X-ray (CXR) findings exists, although prominent lung restriction occurs especially in patients with CXR stages III-IV (this staging system is described below). ${ }^{11,12}$ Due to the wide-ranging variety of possible lung function abnormalities in sarcoidosis, depicting a single lung function test as primary measure of change is difficult.

\section{Chest X-ray stages}

Between 85 and $95 \%$ of sarcoidosis patients have abnormalities on chest radiographs. According to the Scadding radiographic staging system, five stages of radiographic abnormality can be recognized: stage 0 (normal CXR), stage I (bilateral hilar lymphadenopathy $(\mathrm{BHL})$ ), stage II (BHL and parenchymal abnormalities), stage III (parenchymal abnormalities without $\mathrm{BHL}$ ) and stage IV (advanced lung fibrosis with evidence of honeycombing, hilar retraction, bullae, cysts and/or emphysema) (Figure 1.2). ${ }^{2,14,15}$ Patients initially present with CXR stage 0 in 5-15\%, stage I in $45-65 \%$, stage II in $30-40 \%$, stage III in $10-15 \%$ and stage IV in $15-25 \%$, respectively. As mentioned before, there is no strong relationship between CXR stages and lung function test results. However, in general, patients with a lower radiographic stage are more likely to experience resolution of symptoms and CXR abnormalities. ${ }^{12}$ 
a

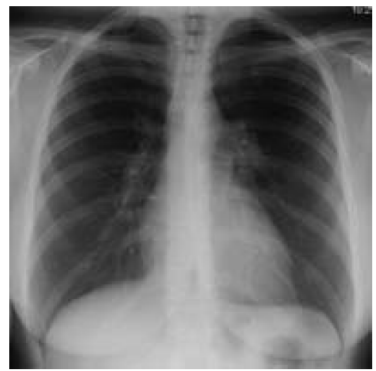

b

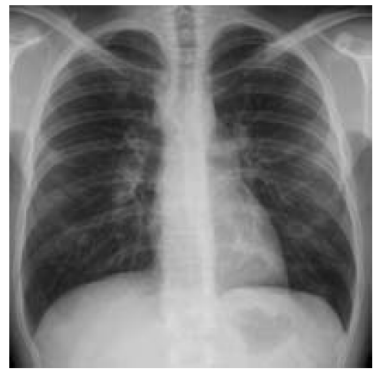

C



d

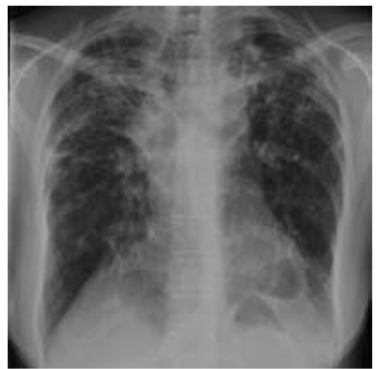

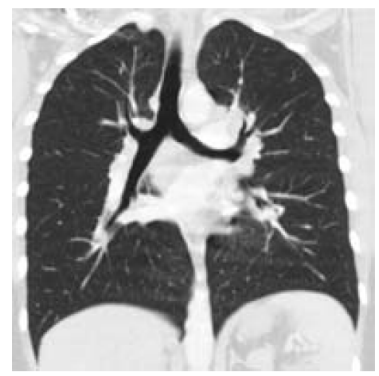
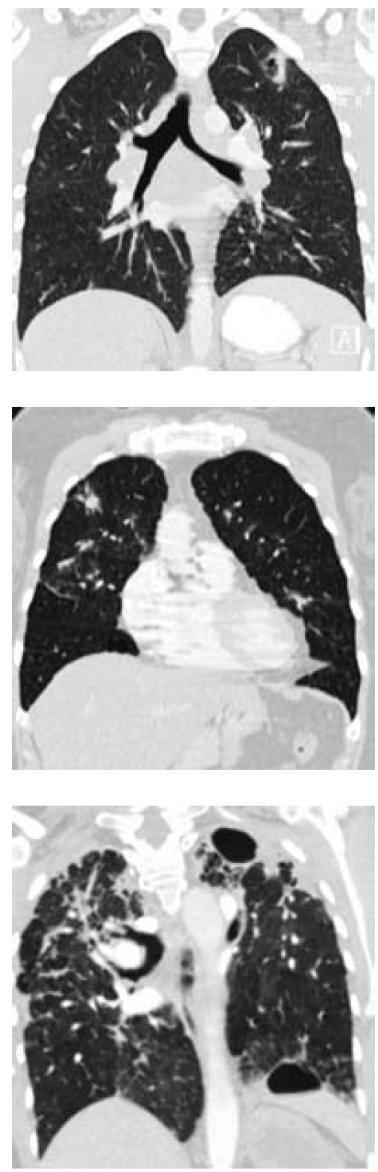

Figure 1.2 Chest radiographic staging system in sarcoidosis. a. Stage I : CXR (left) and coronal high-resolution computed tomography scan (HRCT; right) showing bilateral hilar lymphadenopathy, without parenchymal abnormalities. b. Stage II: CXR (left) and coronal HRCT image (right) showing both lymphadenopathy and parenchymal abnormalities (nodular and reticulonodular opacities). c. Stage III: CXR (left) and coronal HRCT image (right) showing parenchymal abnormalities without hilar lymphadenopathy. d. Stage IV: CXR (left) and coronal HRCT image (right) showing signs of lung fibrosis with hilar retraction and architectural distortion of the pulmonary parenchyma. 


\section{Fatigue}

Despite the fact that fatigue is a common problem and a clear hallmark in sarcoidosis patients that affects quality of life (QOL), it still remains underestimated and poorly understood. ${ }^{16}$ The reported prevalence varies from 60 to $90 \%$ of sarcoidosis patients, and up to $25 \%$ of the fatigued patients report extreme fatigue. ${ }^{8,17,18}$ Sarcoidosis patients may suffer from substantial fatigue even in the absence of other symptoms or diseaserelated abnormalities. For example, fatigue and general weakness may persist even after routine clinical test results have returned to normal. ${ }^{8}$ De Vries et al. found no relationship between fatigue in sarcoidosis patients and a number of clinical variables, including lung function, metabolic variables, laboratory parameters of inflammation and T-cell activation and granuloma formation. ${ }^{19} \mathrm{~A}$ recent study showed that, although exercise intolerance and muscle weakness are frequent problems in sarcoidosis, fatigue was not predicted by the presence of these and other clinical characteristics. ${ }^{20}$ In a study by Fleischer et al. extrapulmonary involvement in addition to pulmonary manifestation correlates with a higher fatigue level. ${ }^{18}$ The fatigue assessment scale (FAS) has been shown to be an easy, reliable and valid scale for assessing fatigue in sarcoidosis patients. ${ }^{21}$ When evaluating sarcoidosis patients suffering from fatigue, it is important to exclude disorders that may interact with fatigue in sarcoidosis, i.e. obstructive sleep apnea syndrome, hypothyroidism and depression. ${ }^{19,22}$

\section{Multifactorial etiology of fatigue}

Fatigue is the most frequently described and devastating symptom in sarcoidosis. The etiology of fatigue remains elusive and is usually multifactorial. Disease treatment (corticosteroid therapy), the disease itself (granuloma formation and cytokine release), comorbidities (depression, anxiety, hypothyroidism e.g.) may all contribute to fatigue. $8,18,19,23$ The diagnosis of sarcoidosis-associated fatigue requires an extensive evaluation to identify and treat potentially reversible causes. Besides pharmacological treatment, non-pharmacological interventions should also be considered. ${ }^{8}$

\section{Muscle involvement}

As mentioned before sarcoidosis may affect any organ system, this also includes the skeletal muscles. In a retrospective study, Cremers et al. found muscle involvement in only $12 \%$ of the PET (positron emission tomography) positive cases $(n=118){ }^{24}$ This number is probably underestimated, as it only gives information about PET-positive cases. Asymptomatic myopathy is present in $50-80 \%$ of patients with sarcoidosis, whereas clinical symptoms are present in less than $5 \% .{ }^{25}$ 

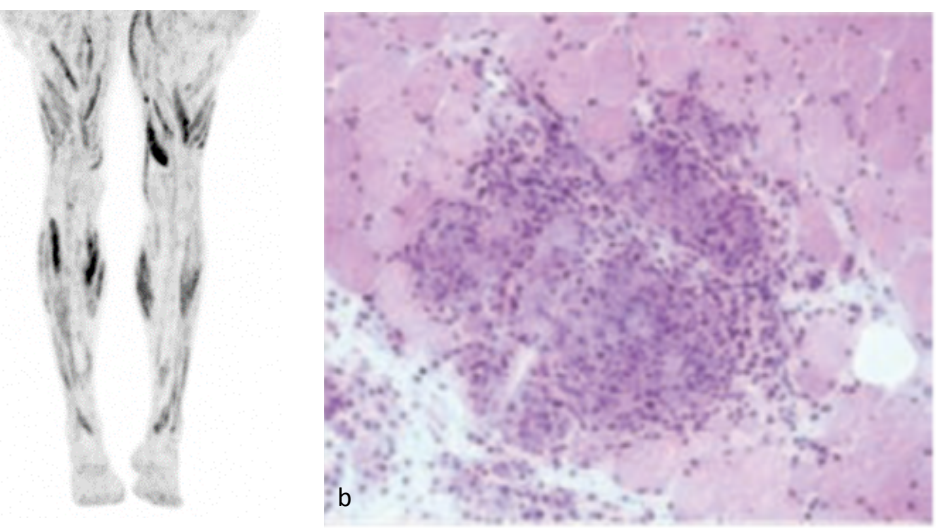

Figure 1.3 a. Fluorine-18 fluorodexyglocose position emission tomography (18F-FDG PET) metabolic activity in the muscles of the lower limbs of a patient with sarcoidosis. b. Biopsy from the left quadriceps muscle of the patient with sarcoidosis showing noncaseating granuloma (with courtesy of Dr. Ruth Keijsers).

Muscle function testing appeared to have additional value in the management of other chronic diseases. ${ }^{26}$ Several tests and instruments can be applied to assess skeletal muscle functions. Some examples evaluating skeletal muscle functions are the Jamar (hand grip strength), hand-held dynamometer, and Biodex System.

\section{Exercise capacity}

A substantial number of patients with symptomatic sarcoidosis display exercise intolerance (45\%), as well as muscle weakness (prevalence rates of $12-27 \%$ ). Patients with impaired peripheral muscle strength are more fatigued and demonstrate impaired lung function test results, six-min walk distance (6MWD), and QOL compared with patients without reduced peripheral muscle strength. ${ }^{20}$ Another cause of exercise intolerance can be the presence of pulmonary hypertension, which occurs in 6-23\% of patients at rest and in more than $40 \%$ of patients during exercise. ${ }^{27}$ Pulmonary hypertension complicates pulmonary sarcoidosis more frequently in advanced parenchymal disease and significantly worsens prognosis. ${ }^{28}$

In clinical practice, several tests are used to evaluate the concept exercise capacity. Exercise tests can be subdivided in maximal exercise tests and submaximal exercise tests. The 'gold standard' in determining exercise capacity is the cardiopulmonary exercise test (CPET, measuring maximal oxygen uptake).$^{29}$ The most used submaximal exercise test used in pulmonary diseases is the six-minute walking test (6MWT), assessing the submaximal level of functional capacity. ${ }^{30}$ Despite the fact that maximal and submaximal exercise tests are very different in nature and assess different aspect of the general construct exercise capacity, exercise responses show similarities in patients with interstitial lung disease (ILD). ${ }^{31}$ 


\section{Fatigue, muscle strength and physical activity}

The relationship between decreased muscle strength, exercise limitation and fatigue is not studied extensively. Fatigue may be explained by skeletal muscle weakness and exercise intolerance, and both may be caused by multiple factors, such as sarcoidosis located in the skeletal muscle, negative vicious circle of physical deconditioning, decreased pulmonary function and corticosteroid-induced myopathy. ${ }^{20,32}$ Several studies found decreased muscle strength in sarcoidosis patients ${ }^{20,32-34}$, with prevalence rate between $12-27 \%{ }^{20}$

Marcellis et al. and Spruit et al. found a correlation between skeletal muscle strength and exercise capacity and fatigue. ${ }^{20,32}$ However, muscle strength only appears to account for a small proportion of the variance regarding fatigue in sarcoidosis patients. ${ }^{20}$ Exercise intolerance and muscle weakness are present in both fatigued and non-fatigued patients. ${ }^{20,22}$ However, patients with impaired skeletal muscle strength were more fatigued and demonstrated impaired pulmonary function test results, exercise capacity and quality of life compared to patients without reduced muscle strength. $^{20,32}$

Skeletal muscle weakness may also be related with physical inactivity. Physical inactivity may result in decreased muscle wasting ('use it or lose it'). Inversely, muscle weakness due to general inflammation ${ }^{35-37}$, sarcoid muscle involvement ${ }^{38}$ or corticosteroid-induced myopathy ${ }^{32,39}$ may lead to lower activity levels and further deconditioning.

\section{Treatment}

Most patients require no treatment, but several pharmacologic options exist for those patients with an indication for therapy. ${ }^{1}$ Nevertheless, none of these drugs are curative. Non-steroidal anti-inflammatory drugs (NSAIDs) can be efficient for symptom relief in patients with arthralgia/arthritis. ${ }^{40}$ Topical treatment can be very effective in cutaneous involvement. Decisions on whether to start systemic immunosuppressive treatment or not are based on clinical features, like organ dysfunction or, in selected cases, symptoms that affect quality of life, i.e. severe cutaneous involvement that does not respond to topical treatment. Although not so strict anymore the drug of first choice is still prednisone, limited evidence is available for the use of other immunosuppressive drugs like methotrexate, azathioprine, leflunomide or hydroxychloroquine and, more recently, TNF- $\alpha$ inhibitors. ${ }^{41-43}$

\section{Non-pharmacological treatment fatigue and exercise limitations}

Emerging evidence suggests that muscle impairment of respiratory and skeletal muscles is associated with functional limitations and fatigue in sarcoidosis. ${ }^{20,32,44}$ Patients suffering from fatigue may reduce their physical activities, causing more perceived physical impairments. This mechanism is also called the negative vicious circle of physical deconditioning. Therefore, this deconditioning may explain fatigue 
partially. ${ }^{32}$ Rehabilitation or physical training has many benefits for patients chronic respiratory disease, including improving exercise capacity, maintaining levels of activity, psychological well-being and social participation. ${ }^{45-47}$ Rehabilitation or physical training may also have comparable benefits in sarcoidosis patients. Only few studies have shown that physical training in sarcoidosis improves exercise capacity, muscle strength, functional status, quality of life and reduces sarcoidosis-associated fatigue. ${ }^{44,48,49}$ Nevertheless, it is likely that improvement of physical functioning might have a positive effect on patients QOL.

\section{Scopes and aims of the study}

The aims of the studies presented in this thesis were to outline the consequences of the symptoms of sarcoidosis on the patients' lives. Furthermore, the possible relationship between fatigue, the most frequently described and most devastating symptom in sarcoidosis, and exercise capacity, muscle function and clinical parameters were assessed. Additionally, the benefits of physical training on exercise capacity, muscle function and fatigue were studied. Finally, recommendations regarding the use of physical training were established based on a literature search and expert opinion.

Chapter 2 provides an overview of the current literature regarding the wide ranging consequences of sarcoidosis. The most frequent described symptoms and their impact on patients daily life are outlined. Treatment options, both pharmacologic and non-pharmacologic treatment options are discussed.

Chapter $\mathbf{3}$ describes the validation process in a Dutch sarcoidosis population of the King's Sarcoidosis Questionnaire (KSQ). The KSQ is a brief questionnaire assessing health status using five modules (general health status, Lung, Medication, Skin and Eyes) in patients with sarcoidosis. Construct validity, internal consistency and repeatability were also determined.

Chapter 4 describes the relationship between fatigue, and both exercise capacity and clinical characteristics in the cohort of patients evaluated between November 2012 and September 2014 at the Department of Physical Therapy of Gelderse Vallei Hospital, Ede, NL. Used exercise tests were the Steep Ramp Test (SRT: maximal effort) and the 6 minute walk test (6MWT: submaximal exercise test).

Chapter $\mathbf{5}$ presents the results of a pilot-study in patients with idiopathic pulmonary fibrosis (IPF) and end-stage sarcoidosis with pulmonary fibrosis following a 12-week physical training program (including skeletal muscle and aerobic endurance training). The impact on exercise capacity, muscle strength and fatigue is determined.

Chapter 6 shows the impact of a 12-week physical training program (including skeletal muscle and aerobic endurance training) for one hour, twice a week, on fatigue, pulmonary function, exercise capacity and muscle strength in 90 sarcoidosis patients. In this cohort study ninety patients underwent baseline testing and returned for repeat testing at three months in the interim, 49 patients completed the training program, and 41 chose not to participate. 
Chapter 7 provides an overview on the available literature regarding physical training and rehabilitation in sarcoidosis. In addition, sarcoidosis experts from all over the world were asked to give their detailed opinion on the indications, contraindications, content and evaluation measures in physical training. Recommendations were established with the use of available data and expert consensus.

Chapter $\mathbf{8}$ gives a summary of the findings presented in this thesis and a general discussion. Additionally, the implications of the study outcomes for clinical practice are argued and suggestions for future research are briefly discussed 


\section{References}

1. Valeyre D, Prasse A, Nunes H, Uzunhan Y, Brillet PY, Muller-Quernheim J. Sarcoidosis. Lancet 2014;383:1155-1167.

2. Statement on sarcoidosis. Joint Statement of the American Thoracic Society (ATS), the European Respiratory Society (ERS) and the World Association of Sarcoidosis and Other Granulomatous Disorders (WASOG) adopted by the ATS Board of Directors and by the ERS Executive Committee, February 1999. Am J Respir Crit Care Med 1999;160:736-755.

3. Hillerdal G, Nou E, Osterman K, Schmekel B. Sarcoidosis: epidemiology and prognosis. A 15-year European study. Am Rev Respir Dis 1984;130:29-32.

4. Ungprasert P, Carmona EM, Utz JP, Ryu JH, Crowson CS, Matteson EL. Epidemiology of Sarcoidosis 1946-2013: A Population-Based Study. Mayo Clin Proc 2016;91:183-188.

5. Baughman RP, Lower EE, Gibson K. Pulmonary manifestations of sarcoidosis. Presse Med 2012;41: e289-302.

6. Marcellis RG, Lenssen AF, Kleynen S, De Vries J, Drent M. Exercise capacity, muscle strength, and fatigue in sarcoidosis: a follow-up study. Lung 2013;191:247-256.

7. Elfferich MD, Nelemans PJ, Ponds RW, De Vries J, Wijnen PA, Drent M. Everyday cognitive failure in sarcoidosis: the prevalence and the effect of anti-TNF-alpha treatment. Respiration 2010;80:212-219.

8. Drent M, Lower EE, De Vries J. Sarcoidosis-associated fatigue. Eur Respir J 2012;40:255-263.

9. Baughman RP, Nagai S, Balter M, et al. Defining the clinical outcome status (COS) in sarcoidosis: results of WASOG Task Force. Sarcoidosis Vasc Diffuse Lung Dis 2011;28:56-64.

10. Drent M. Sarcoidosis: benefits of a multidisciplinary approach. Eur J Intern Med 2003;14:217-220.

11. Consensus conference: activity of sarcoidosis. Third WASOG meeting, Los Angeles, USA, September 811, 1993. Eur Respir J 1994;7:624-627.

12. Keir G, Wells AU. Assessing pulmonary disease and response to therapy: which test? Semin Respir Crit Care Med 2010;31:409-418.

13. Judson MA, Baughman RP, Thompson BW, et al. Two year prognosis of sarcoidosis: the ACCESS experience. Sarcoidosis Vasc Diffuse Lung Dis 2003;20:204-211.

14. Scadding JG. Prognosis of intrathoracic sarcoidosis in England. A review of 136 cases after five years' observation. Br Med J 1961;2:1165-1172.

15. Costabel U, Hunninghake GW. ATS/ERS/WASOG statement on sarcoidosis. Sarcoidosis Statement Committee. American Thoracic Society. European Respiratory Society. World Association for Sarcoidosis and Other Granulomatous Disorders. Eur Respir J 1999;14:735-737.

16. De Vries J, Rothkrantz-Kos S, van Dieijen-Visser MP, Drent M. The relationship between fatigue and clinical parameters in pulmonary sarcoidosis. Sarcoidosis Vasc Diffuse Lung Dis 2004;21:127-136.

17. Marcellis RG, Lenssen AF, de Vries J, Drent M. Reduced muscle strength, exercise intolerance and disabling symptoms in sarcoidosis. Curr Opin Pulm Med 2013;19:524-530.

18. Fleischer M, Hinz A, Brahler E, Wirtz H, Bosse-Henck A. Factors associated with fatigue in sarcoidosis. Respir Care 2014;59:1086-1094.

19. De Vries J, Drent M. Relationship between perceived stress and sarcoidosis in a Dutch patient population. Sarcoidosis Vasc Diffuse Lung Dis 2004;21:57-63.

20. Marcellis RG, Lenssen AF, Elfferich MD, et al. Exercise capacity, muscle strength and fatigue in sarcoidosis. Eur Respir J 2011;38:628-634.

21. De Vries J, Michielsen H, Van Heck GL, Drent M. Measuring fatigue in sarcoidosis: the Fatigue Assessment Scale (FAS). Br J Health Psychol 2004;9:279-291.

22. Drent M, Wirnsberger RM, de Vries J, van Dieijen-Visser MP, Wouters EF, Schols AM. Association of fatigue with an acute phase response in sarcoidosis. Eur Respir J 1999;13:718-722.

23. Korenromp IH, Grutters JC, van den Bosch JM, Heijnen CJ. Post-inflammatory fatigue in sarcoidosis: personality profiles, psychological symptoms and stress hormones. J Psychosom Res 2012;72:97-102.

24. Cremers JP, Van Kroonenburgh MJ, Mostard RL, et al. Extent of disease activity assessed by $18 \mathrm{~F}-$ FDG PET/CT in a Dutch sarcoidosis population. Sarcoidosis Vasc Diffuse Lung Dis 2014;31:37-45.

25. Wieers G, Lhommel R, Lecouvet F, Van den Bergh P, Lambert M. A tiger man. Lancet 2012;380:1859.

26. Spruit MA, Singh SJ, Garvey C, et al. An official American Thoracic Society/European Respiratory Society statement: key concepts and advances in pulmonary rehabilitation. Am J Respir Crit Care Med 2013;188:e13-64. 
27. Huitema MP, Grutters JC, Rensing BJ, Reesink HJ, Post MC. Pulmonary hypertension complicating pulmonary sarcoidosis. Neth Heart J 2016;24:390-399.

28. Baughman RP, Engel PJ, Nathan S. Pulmonary Hypertension in Sarcoidosis. Clin Chest Med 2015;36: 703-714.

29. De Jesus AM, Chabrol J, Aguilaniu B, Wallaert B. [Cardiopulmonary exercise testing and dyspnea in patients with chronic respiratory diseases]. Rev Mal Respir 2014;31:754-764.

30. ATS statement: guidelines for the six-minute walk test. Am J Respir Crit Care Med 2002;166:111-117.

31. Blanco I, Villaquiran C, Valera JL, et al. [Peak oxygen uptake during the six-minute walk test in diffuse interstitial lung disease and pulmonary hypertension]. Arch Bronconeumol 2010;46:122-128.

32. Spruit MA, Thomeer MJ, Gosselink R, et al. Skeletal muscle weakness in patients with sarcoidosis and its relationship with exercise intolerance and reduced health status. Thorax 2005;60:32-38.

33. Baughman RP, Sparkman BK, Lower EE. Six-minute walk test and health status assessment in sarcoidosis. Chest 2007;132:207-213.

34. Miller A, Brown LK, Sloane MF, Bhuptani A, Teirstein AS. Cardiorespiratory responses to incremental exercise in sarcoidosis patients with normal spirometry. Chest 1995;107:323-329.

35. Cicoira M, Bolger AP, Doehner W, et al. High tumour necrosis factor-alpha levels are associated with exercise intolerance and neurohormonal activation in chronic heart failure patients. Cytokine 2001;15:80-86.

36. Gleeson M, Bishop NC, Stensel DJ, Lindley MR, Mastana SS, Nimmo MA. The anti-inflammatory effects of exercise: mechanisms and implications for the prevention and treatment of disease. Nat Rev Immunol 2011;11:607-615.

37. Baydur A, Alavy B, Nawathe A, Liu S, Louie S, Sharma OP. Fatigue and plasma cytokine concentrations at rest and during exercise in patients with sarcoidosis. Clin Respir J 2011;5:156-164.

38. Nessrine A, Zahra AF, Taoufik H. Musculoskeletal involvement in sarcoidosis. J Bras Pneumol 2014;40:175-182.

39. Meyer KC. Immunosuppressive agents and interstitial lung disease: what are the risks? Expert Rev Respir Med 2014;8:263-266.

40. Hoitsma E, De Vries J, van Santen-Hoeufft M, Faber CG, Drent M. Impact of pain in a Dutch sarcoidosis patient population. Sarcoidosis Vasc Diffuse Lung Dis 2003;20:33-39.

41. Drent $\mathrm{M}$, Cremers JP, Jansen TL, Baughman RP. Practical eminence and experience-based recommendations for use of TNF-alpha inhibitors in sarcoidosis. Sarcoidosis Vasc Diffuse Lung Dis 2014;31:91-107.

42. Cremers JP, Drent M, Bast A, et al. Multinational evidence-based World Association of Sarcoidosis and Other Granulomatous Disorders recommendations for the use of methotrexate in sarcoidosis: integrating systematic literature research and expert opinion of sarcoidologists worldwide. Curr Opin Pulm Med 2013;19:545-561.

43. Vorselaars AD, Cremers JP, Grutters JC, Drent M. Cytotoxic agents in sarcoidosis: which one should we choose? Curr Opin Pulm Med 2014;20:479-487.

44. Karadalli MN, Bosnak-Guclu M, Camcioglu B, Kokturk N, Turktas H. Effects of Inspiratory Muscle Training in Subjects With Sarcoidosis: A Randomized Controlled Clinical Trial. Respir Care 2016;61: 483-494.

45. Nici L, ZuWallack R, Wouters E, Donner CF. On pulmonary rehabilitation and the flight of the bumblebee: the ATS/ERS Statement on Pulmonary Rehabilitation. Eur Respir J 2006;28:461-462.

46. McCarthy B, Casey D, Devane D, Murphy K, Murphy E, Lacasse Y. Pulmonary rehabilitation for chronic obstructive pulmonary disease. Cochrane Database Syst Rev 2015:CD003793.

47. Rochester CL, Vogiatzis I, Holland AE, et al. An Official American Thoracic Society/European Respiratory Society Policy Statement: Enhancing Implementation, Use, and Delivery of Pulmonary Rehabilitation. Am J Respir Crit Care Med 2015;192:1373-1386.

48. Marcellis R, Van der Veeke M, Mesters I, et al. Does physical training reduce fatigue in sarcoidosis? Sarcoidosis Vasc Diffuse Lung Dis 2015;32:53-62.

49. Huppmann P, Sczepanski B, Boensch M, et al. Effects of inpatient pulmonary rehabilitation in patients with interstitial lung disease. Eur Respir J 2013;42:444-453. 


\section{Chapter 2}

Consequences of sarcoidosis

M Drent, B Strookappe, E Hoitsma, J De Vries

Clin Chest Med 2015;36:727-37 


\section{Abstract}

\section{Background}

Sarcoidosis is a multisystem disorder of unknown cause(s). Less specific disabling symptoms, including fatigue and physical impairments, may have a major influence on the daily activities and the social and professional lives of the patients, resulting in a reduced quality of life.

\section{Considerations}

A multidisciplinary approach focusing on somatic and psychosocial aspects is recommended. Patients self-perceived knowledge about the importance of exercise and lifestyle should be improved.

\section{Recommendations}

Developing the most appropriate therapeutic approach for sarcoidosis requires careful consideration of the possible impact of fatigue, small fiber neuropathy related symptoms, pain, cognitive functioning, and coping strategies.

\section{Conclusion}

Personalized medicine and appropriate communication are beneficial. 


\section{Introduction}

The clinical expression, natural history, and prognosis of sarcoidosis are highly variable and its course is often unpredictable. ${ }^{1}$ Clinical manifestations vary with the organs involved. ${ }^{1,2}$ The lungs are affected in approximately $90 \%$ of patients with sarcoidosis, and the disease frequently also involves the lymph nodes, skin, and eyes. Remission occurs in more than half of patients within 3 years of diagnosis, and within 10 years in two-thirds, with few or no remaining consequences. ${ }^{2}$ Unfortunately, up to one-third of patients have persistent disease, leading to significant impairment of their quality of life (QoL). ${ }^{3}$ Interpretation of the severity of the sarcoidosis can be complicated by its heterogeneity. Several major concerns of sarcoidosis patients include symptoms that cannot be explained by granulomatous involvement of a particular organ. ${ }^{4}$ Apart from lung-related symptoms (e.g. coughing, breathlessness, and dyspnea on exertion), patients may suffer from a wide range of rather nonspecific disabling symptoms. ${ }^{2,5}$ These symptoms, such as fatigue, fever, anorexia, arthralgia, muscle pain, general weakness, muscle weakness, exercise limitation, and cognitive failure, often do not correspond with objective physical evidence of disease., ${ }^{2,5-9}$ These issues are often troubling to pulmonologists and other sarcoidologists because they do not relate directly to a physiologic abnormality, are difficult to quantify and hence to monitor, and are challenging to treat. ${ }^{4}$

Symptoms such as fatigue can be nonspecific and difficult to objectify. Moreover, absence of evidence does not mean evidence of absence. ${ }^{5,7}$ Sarcoidosis-related complaints, including fatigue, may become chronic and affect patients' QoL even after all other signs of disease activity have disappeared. ${ }^{7,10,11}$ Hence, patients consult their physician not only with organ-specific symptoms - directly related to the organ(s) involved - but also with nonspecific health complaints, such as fatigue, cognitive failure, exercise intolerance, and muscle weakness. ${ }^{12}$ These impairments in sarcoidosis are disabling, especially when they become chronic. ${ }^{13,14}$ Sarcoidosis consists of several overlapping clinical syndromes ('the sarcoidoses'), each with its own specific pathogenesis. A complete evaluation of sarcoidosis could make use of a panel with four disease domains or dimensions: extent of disease, severity, activity and impact. ${ }^{15-17}$ Severity of sarcoidosis in each organ is defined as the degree of organ damage sustained from sarcoidosis. The interpretation of the severity of sarcoidosis can be complicated by its heterogeneity. The organ damage can be estimated subjectively by the intensity of symptoms, objectively as a percentage decline from normal capacity (e.g. percentage of the predicted normal value on pulmonary function testing) or by critical location of lesions (e.g. cardiac block). However, pulmonary function test results do not always represent changes in the severity of pulmonary sarcoidosis, ${ }^{18}$ which illustrates that the demonstration of sarcoid activity remains an enigma. Assessment of inflammatory activity in sarcoidosis patients without deteriorating lung function or radiological deterioration but with unexplained persistent disabling symptoms is an important and often problematic issue. Historically, evaluation of the various available 
tools for the assessment of inflammatory activity has been hampered by the lack of a gold standard.

This section focuses on the impact of the broad range of sarcoidosis-related problems on patients' lives.

\section{Symptoms}

In addition to symptoms related to the organs involved, patients may suffer from all kinds of less specific symptoms. These sarcoidosis-related disabling symptoms can significantly reduce a person's quality of life (QoL), especially in chronic sarcoidosis. ${ }^{19}$ All these symptoms may have major consequences and impact on the patients' lives and those of their relatives.

\section{Fatigue}

Fatigue is the most frequently described and devastating symptom in sarcoidosis, and is globally recognized as a disabling symptom. The reported prevalence varies from 60 to $90 \%$ of sarcoidosis patients, ${ }^{5}$ and up to $25 \%$ of fatigued sarcoidosis patients report extreme fatigue. Physicians generally assess disease severity and progression in sarcoidosis on the basis of clinical tests, such as pulmonary function tests, chest radiographs, and serological tests. However, these objective clinical parameters correlate poorly with the patients' subjective sense of well-being. ${ }^{8,20}$ Sarcoidosis patients may suffer from substantial fatigue even in the absence of other symptoms or disease-related abnormalities. For example, fatigue and general weakness may persist even after routine clinical test results have returned to normal. ${ }^{5}$ There is a positive association between symptoms of suspected small fiber neuropathy (SFN) and fatigue, as well as between dyspnea and fatigue ${ }^{13,21,22}$ So far, no organic substrate has been found for the symptoms of sarcoidosis-associated fatigue.

To date, no appropriate definition of fatigue exists. Fatigue can be seen and measured as a unidimensional or multidimensional concept. The multidimensional concept of fatigue can be divided into at least two categories: physical and mental or passive and active fatigue. 5,10

Some sarcoidosis patients are debilitated by the symptoms of their disease and are unable to work; others are underemployed and incapable of achieving their full potential due to their health issues. ${ }^{23}$ Individuals affected by the disease frequently appear completely healthy, so their symptoms are often not taken seriously by family, friends, employers and healthcare professionals. Consequently, some patients lose their desire and ability to effectively socialize with others, causing relationships and family dynamics to ultimately suffer. These combined factors impact on an individual's economic status, interpersonal relationships and family dynamics, increase their stress levels, and induce depression in patients. 
The etiology of this troublesome problem remains elusive and is usually multifactorial. Fatigue can be a consequence of the treatment itself, for instance as a complication of corticosteroid therapy. The diagnosis of sarcoidosis-associated fatigue requires extensive evaluation to identify and treat potentially reversible causes., ${ }^{5,6}$ Its etiology may involve granuloma formation and cytokine release. However, despite effective treatment of the sarcoidosis, many patients continue to experience fatigue. ${ }^{5,24}$ Comorbidities associated with sarcoidosis, including depression, anxiety, hypothyroidism, and altered sleep patterns, may all contribute to fatigue. ${ }^{23,25}$ Despite an exhaustive search for treatable clinical causes of fatigue, most patients' complaints of fatigue are not correlated with clinical parameters of disease activity. ${ }^{5,24}$

\section{Dyspnea}

Dyspnea is, by definition, subjective, but a greater value should be given to its quantification by validated scales in the initial evaluation and follow-up of patients with sarcoidosis. The mechanism for dyspnea in sarcoidosis is multifactorial. ${ }^{12,22,26}$ Research has found that the degree of dyspnea in sarcoidosis does not correlate with lung function tests. ${ }^{27}$ Pulmonary function test results do not always reflect changes in the severity of pulmonary sarcoidosis. Moreover, several studies have reported that neither lung function test results nor chest radiographs correlate with nonspecific health complaints or with QoL. ${ }^{19,28}$ In the follow-up, the level of dyspnea often, but not always, changes in the same direction as the forced vital capacity (FVC). ${ }^{29}$ Spontaneous resolution of radiographic lesions is more common in asymptomatic patients. ${ }^{17}$ The intensity of dyspnea at initial evaluation correlates with the need for long-term treatment. $^{30}$

\section{Small fiber neuropathy and autonomic dysfunction}

In 2002, small fiber neuropathy (SFN) was recognized as a symptom of sarcoidosis. ${ }^{31}$ Unlike granulomatous large neuron involvement, SFN appears to be a common complication occurring in up to $40 \%{ }^{32}$ to $60 \%$ of patients with sarcoidosis. ${ }^{33}$

SFN is a peripheral nerve disorder that selectively affects thinly myelinated $A \delta$ fibers and unmyelinated $C$ fibers. ${ }^{34}$ These fibers are associated with thermal and nociceptive sensations, and pathology of these nerves may lead to a 'painful neuropathy'. However, these nerves also affect the autonomic nervous system, and SFN may also lead to an 'autonomic neuropathy' (see also Table 2.1)..$^{35,36}$

Symptoms of SFN are disabling for patients, have a high impact on QoL and are often difficult to treat. ${ }^{35}$ Damage to or loss of small somatic nerve fibers results in pain, burning or tingling sensations, or numbness, typically affecting the limbs in a distal to proximal gradient. Symptoms can be very severe, are usually worse at night and often affect sleep. People sometimes sleep with their feet uncovered because they cannot bear the touch of the sheets. Walking may be difficult due to severe pain caused by the pressure on the floor. When autonomic fibers are affected, patients may experience 
dry eyes, dry mouth, orthostatic dizziness, constipation, bladder incontinence, sexual dysfunction, trouble sweating, or red or white skin discolorations (see also Table 2.1). ${ }^{34}$ Involvement of cardiac sympathetic nerves might play a role in the prognosis, as indices of autonomic cardiac dysfunction have been identified as strong predictors of cardiovascular morbidity and mortality. ${ }^{34}$

Since routine nerve conduction tests evaluate only large nerve fiber function, and quantitative techniques for the assessment of small nerve fibers are not routinely applied, the diagnosis of SFN can easily be missed. ${ }^{35,37}$ This may lead to frustration for both physician and patient due to the failure to diagnose a neuropathic pain syndrome. There is as yet no gold standard for the diagnosis of SFN. Diagnosis is usually established on the basis of clinical features, in combination with abnormal findings of specialized tests such as the assessment of intra-epidermal nerve fiber density (IENFD) in skin biopsy, temperature sensation tests for sensory fibers, and sudomotor and cardiovagal testing for autonomic fibers. ${ }^{32,33,38}$

The Small Fiber Neuropathy Screening List (SFNSL) was developed in a sarcoidosis population as a first screening tool. ${ }^{21}$

Table 2.1 Symptoms suggestive of small fiber neuropathy

\begin{tabular}{ll}
\hline Sensory symptoms & Pain $^{\text {a }}$ \\
& Paresthesia's \\
& Sheet intolerance \\
& Restless legs syndrome ${ }^{b}$ \\
Symptoms of autonomic dysfunction & \\
& Hyperhidrosis or hyperhidrosis \\
& Diarrhea or constipation \\
& Urinary incontinence or urine retention \\
& Gastroparesis \\
& Sicca syndrome \\
& Blurry vision \\
& Facial flushes \\
& Orthostatic intolerance \\
& Sexual dysfunction \\
\end{tabular}

\footnotetext{
${ }^{a}$ Pain in small fiber neuropathy often has a burning, tingling, shooting or prickling character; ${ }^{b}$ Restless legs syndrome is a disorder characterized by disagreeable leg sensations that usually occur prior to sleep onset and that cause an almost irresistible urge to move.
}

\section{Psychological burden}

\section{Depressive symptoms}

Depressive symptoms in sarcoidosis are at least partly an expression of exhaustion due to the ongoing disease. Depressive symptoms have been found to be negatively associated with and affect patients' fatigue scores. ${ }^{10}$ In addition, the relationship between fatigue and depressive symptoms parallels the findings for other chronic 
illnesses, such as diabetes, chronic obstructive pulmonary disease, cardiac disease, and rheumatoid arthritis. ${ }^{39}$ Moreover, the severity and nature of fatigue moderate anxiety and depressive symptoms in sarcoidosis. Fatigue and autonomic dysfunction are both dominant symptoms and risk factors for depression. ${ }^{40}$ The symptoms may share several neurobiological abnormalities, for example an increase in TNF- $\alpha .{ }^{40}$ The relationship between depressive symptoms and fatigue may also be based on a cytokine imbalance, initiated by an inflammatory immune response in sarcoidosis. ${ }^{39,41}$ The cytokine balance of patients suffering from depression also appears to be disturbed. ${ }^{42}$

Not only fatigue, but also psychological symptoms such as depressive symptoms and anxiety play an important role in sarcoidosis. ${ }^{15,43-46}$ They have been reported in 17 to $66 \%$ of patients with sarcoidosis. Understanding the nature of the relationships between fatigue, depressive symptoms, and anxiety remains difficult, however. The nature of fatigue moderates the relationships between fatigue and anxiety and between fatigue and depressive symptoms in sarcoidosis. In a study by De Kleijn et al., fatigue was often reported with concurrent depressive symptoms (34-36\%) and anxiety $(43-46 \%){ }^{47}$ About one-third of the patients (31\%) reported high-trait anxiety as well as high levels of depressive symptoms at baseline. The study also suggested that the relationship between depressive symptoms and fatigue is bidirectional. Depressive symptoms may indirectly lead to more symptoms, as they are associated with poor selfcare (diet, exercise, giving up smoking, and medication regimens) in patients with chronic diseases in general. ${ }^{39}$ However, physical symptoms and the resulting functional impairments caused by complications of medical illness are also likely to impose a burden on the patient's life and to provoke depression. ${ }^{39}$ Hence, not only fatigue but also depressive symptoms and anxiety should be an integral part of the multidisciplinary management of sarcoidosis patients.

\section{Anxiety and stress}

Several studies have shown that the prevalence of anxiety in sarcoidosis patients is 33$36 \%{ }^{47,48}$ Studies also showed that anxiety was more common in sarcoidosis patients than in the general population and among healthy persons. ${ }^{49,50}$ The percentages for anxiety disorders are obviously lower; for instance $6.3 \%$ of sarcoidosis patients have a panic disorder. ${ }^{51}$ In any case, anxiety is a major problem in sarcoidosis patients. Since fatigue is one symptom that is known to co-occur with anxiety, it is not surprising that anxiety in general and trait anxiety were found to be related to fatigue. ${ }^{5,24,47}$ One study also found that trait anxiety predicted fatigue at follow-up. ${ }^{47}$ Trait anxiety refers to the tendency of persons to react with anxiety in new situations. In contrast, state anxiety is defined as anxiety that is elicited in a particular situation and does not last long. In addition to fatigue, one study found that the severity of sarcoidosis symptoms was also related to anxiety. ${ }^{52}$ Studies of the relation between anxiety and dyspnea reported inconsistent results. ${ }^{49,53}$

Studies examining stress in sarcoidosis are still very scarce. One study found that the magnitude of stressful life events was higher in sarcoidosis patients than in healthy 
controls. $^{54}$ Patients also appeared to use inadequate coping strategies with regard to stress. ${ }^{54}$ Another study reported a relation between increased life stress and impaired lung function. ${ }^{55}$ Finally, one study focusing on perceived stress found it to be high and related to sarcoidosis symptoms. ${ }^{23}$ Perceived/experienced stress is caused by interpreting a situation as threatening. This indicates that the same situation may be perceived as stressful by one person and as a challenge by another. Interpreting a situation as threatening may result in several reactions known as fight-flight or freeze. In each of these, the person is scared, but this translates into different behavior: anger and aggressive behavior (fight), anxiety and escaping from the situation (flight), or no reaction at all (freeze). Fight and flight reactions require a physical reaction.

Anxiety consists of physical or hyperarousal symptoms, such as increased heart rate, perspiration, and dizziness, which are inherent to the reaction of the sympathetic nervous system. ${ }^{56}$ In addition to a physical component, anxiety also has a cognitive component, that is, a thought (or chain of thoughts) that determines the emotion experienced. If someone is confronted with a situation and has thoughts such as 'I can do this' and 'I want to test whether I can overcome this', the situation is regarded as a challenge, and the above physical symptoms will not occur. If the same situation induces thoughts such as 'I cannot handle this' and 'I must do something, but I have no idea what', the situation is perceived as threatening and the physical symptoms related to anxiety will occur. This relationship between stress and anxiety, and the two components of anxiety (cognitive and physical), might explain the relationships found between symptoms and anxiety/stress.

Another aspect to take into consideration is the duration of stress or anxiety. A brief feeling of stress and anxiety is very common and is considered healthy, as the person will use the above fight or flight reactions to cope with the situation. In this sense a parallel can be drawn with pain and fatigue, which are both healthy responses to a stimulus that may harm the body or demand too much of the body, respectively. It becomes unhealthy when the stress and anxiety become persistent, as this will have negative effects on the immune system. In our modern society, physical reactions are often elicited by thoughts that do not require physical action. Think about (recurrent) negative thoughts, such as 'I am a loser', 'My illness makes me a burden to other people', 'Symptoms will probably become worse', and 'I will soon die from this disease'.

From this perspective, various researchers have justly suggested that sarcoidosis patients may benefit from psychological interventions ${ }^{47,51}$ focusing on coping and appraisal, such as stress reduction treatment. ${ }^{23,55}$ In each case, the basis for the interventions should be a type of cognitive behavioral therapy (CBT), including so-called third generation CBT like mindfulness-based cognitive therapy, as this type of therapy has proved to be effective in patients with anxiety disorder. Finally, it is important to realize that anxiety (just like depressive symptoms/depression) is known to be one of the factors prolonging chronic fatigue, and that chronic fatigue can be successfully treated with CBT. 


\section{Cognitive impairment and memory loss}

In addition to organ-specific symptoms and non-specific health complaints such as fatigue and physical impairments, patients also have to deal with side-effects of medical treatment. Patients with sarcoidosis often report everyday cognitive deficits. ${ }^{6}$ There is growing interest in cognitive failure research in populations of patients with various chronic diseases. ${ }^{57,58}$ Functional cognitive impairment, if present, may lead to increased fatigue and low compliance with medical treatment. Currently, however, no data are available on the extent of cognitive underperformance among sarcoidosis patients. Research in multiple sclerosis patients found that memory complaints were not associated with memory performance, but with fatigue complaints. ${ }^{58}$ It is tempting to speculate that this may also be the case in sarcoidosis patients. There is a special interest in sarcoidosis due to the high prevalence of fatigue and everyday cognitive failure, together with the relatively young age of the patients.

\section{Physical impairment}

Sarcoidosis obviously imposes a burden on patients' lives (see Figure 2.1). ${ }^{12,59}$ Symptoms of fatigue and dyspnea induce exercise limitation, while fatigue also leads to physical inactivity, and the specific sarcoidosis symptoms, or the thought of living with a progressive, incurable condition, create anxiety and mood disturbance, and affect emotional well-being. Although less recognized than exertional dyspnea, lack of energy or exhaustion is a very common and frustrating physical symptom in patients with sarcoidosis. Patients with sarcoidosis (as well as other interstitial lung diseases (ILDs)) often have diminished exercise capacity and reduced muscle strength, as demonstrated by reduced oxygen uptake (measured during a maximal cardiopulmonary exercise test) or a shorter-than-predicted distance covered during a six-minute walking test (6MWD). Monitoring which takes muscle strength and exercise capacity into account has been found to improve the routine monitoring of sarcoidosis. ${ }^{28,60,61}$ Like others, Marcellis et al. found exercise intolerance and muscle weakness to be frequent problems in sarcoidosis, both in fatigued and nonfatigued patients. ${ }^{28}$

Exercise intolerance in sarcoidosis is most often multifactorial, involving lungmechanical, musculoskeletal, and gas exchange abnormalities. ${ }^{12,28,62-64}$ Several studies have reported that neither lung function test results nor chest radiographs correlate with these nonspecific health complaints, nor with QoL. ${ }^{11,23,45-47}$ Moreover, pulmonary function test results at rest appear to be poor predictors of exercise capacity. Changes in gas exchange upon exercise can be fairly accurately predicted by diffusing capacity of the lung for carbon monoxide (DLCO)\%, ${ }^{65,66}$ but can be present even with normal DLCO. ${ }^{67}$ Fatigue, which as mentioned above is one of the major problems in sarcoidosis, can reduce patients' day-to-day functioning. ${ }^{5}$ Consequently, reduced physical activity can induce general deconditioning, which in turn contributes to increased perceived fatigue and a sense of dyspnea, as well as insufficient physical activity. ${ }^{60,68}$ Assessment of the presence of physical impairments is recommended, as it provides additional 
information about the patient's functional status, disease severity, and progression. ${ }^{28,60,62-64}$ Since the patients' ability to handle physical activity is clearly decreased, however, the activities should be adjusted, and rehabilitation programs should be carefully designed. ${ }^{61,69,70}$

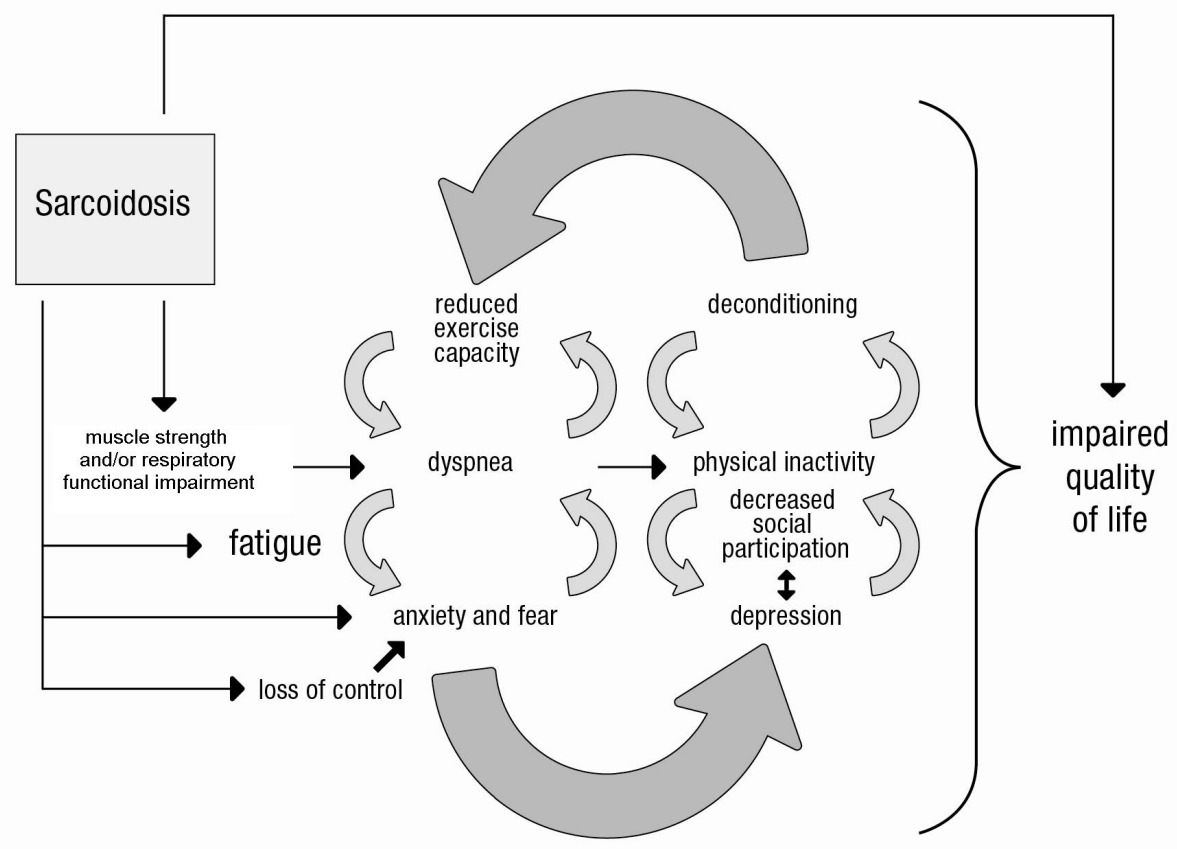

Figure 2.1 Negative vicious circle of physical deconditioning: disabling symptoms in sarcoidosis can reduce daily physical activities, resulting in general deconditioning and a reduced quality of life (adapted from Swigris et al. ${ }^{59}$ and previously published ${ }^{12}$ ).

\section{Overall impact on patients' lives: quality of life}

The impact of any disease depends on the way the patient perceives the disease and modifies his/her activities of daily living. Living with a long-term disease like sarcoidosis significantly affects quality of life (QoL), with negative consequences for general health and social and psychosocial well-being. ${ }^{3,71-73}$ QoL is an important outcome measure of treatment, especially with regard to chronic diseases. It is a concept that concerns patients' evaluation of their functioning in a wide range of domains, but always including the physical, psychological, and social domains. ${ }^{3}$ Assessment covering only these three domains is known as assessment of health-related QoL., ${ }^{3,73}$

QoL is often confused with health status (HS), which concerns patients' physical, psychological, and social functioning. ${ }^{3}$ Psychological factors such as burnout, emotional distress, and work-related social support influence levels of QoL. ${ }^{72}$ A study among 
sarcoidosis patients found that the strongest predictor of all dimensions of QoL was the corresponding QoL at baseline. ${ }^{13}$ This might be explained by the fact that sarcoidosisrelated symptoms remain relatively stable over time. ${ }^{13,47}$ Social support has been described as a buffer against pain and disability, and also as being associated with greater activity levels among individuals with pain. ${ }^{72,74}$ Support from friends and family can also be related to the psychological dimensions of QoL. ${ }^{75}$ A study among people with chronic pain found that a rich social network was related to higher perceived QoL. ${ }^{76}$ Moreover, work-related social support is known to positively predict return to work, while lack of social support at work is a well-known risk factor for development of pain. ${ }^{77}$ In sarcoidosis, there is poor agreement between physicians and patients with regard to the perceived symptoms attributable to the disease, with a particular failure of clinicians to recognize the impact of non-organ-specific features. ${ }^{15,17}$ It has been proposed that assessment of the health status and QoL of sarcoidosis patients would help bridge this gap, aiding communication and treatment, and complementing existing clinical assessments. Various aspects of sarcoidosis, such as the relatively young age at disease onset, the often unpredictable and chronic nature of the disease, the uncertainly about the cause and the broad range of frequently persistent symptoms may account for the aggravating influence on patients' lives as well as those of their families and friends, especially since a really appropriate treatment of sarcoidosis is still lacking.

Fatigue, breathlessness, reduced exercise capacity, and arthralgia are the most frequently reported symptoms. It appears that these sarcoidosis-related symptoms are associated with a lower QoL. ${ }^{8,13,44,47,53,78}$ Women have lower scores on the physical health, psychological health, social relationships, and environmental domains, and the general assessment of overall QoL. Research found that the use of corticosteroids predicted a lower QoL in all domains except spirituality. Having a partner was associated with the QoL domains of psychological health and level of independence, whereas a low educational level predicted better scores for the social relationships domain, while arthralgia predicted poorer scores for this domain. ${ }^{8}$ Fatigue had a negative effect on patients' QoL scores for the physical health, psychological health, and level of independence domains.

\section{Treatment options}

\section{Pharmacological treatment}

There is a lack of standardized management strategies for sarcoidosis. Most sarcoidosis patients show spontaneous resolution of the disease and do not require systemic pharmacological treatment. ${ }^{2}$ Glucocorticoids are the cornerstone therapeutic agent, and have a favorable short-term effect on functional impairments, including respiratory impairment and symptoms. However, the long-term beneficial effect remains uncertain. In view of the limitations we are aware of nowadays, authorization would be 
doubtful if glucocorticoids were to be introduced at present. A subset of patients will require more aggressive treatment. The published data on the different treatment options in sarcoidosis are limited and the treatment therefore still remains mostly empirical. $^{2}$ The decision on whether to start systemic immunosuppressive treatment or not should be based on the patients' symptomatology, including the impact on their QoL, as well as the extent of compromised organ function.

Recent studies have demonstrated the effectiveness of various neurostimulants, including methylphenidate, for the treatment of sarcoidosis-associated fatigue. These and other agents may be useful adjuncts for the treatment of this type of fatigue. There is obviously a need for studies evaluating the causes of, and new therapeutic options for, sarcoidosis-associated fatigue. Psychological interventions should also be examined. Standard sarcoidosis treatments such as those using corticosteroids and other immunosuppressive agents are often ineffective for SFN-related symptoms. ${ }^{4}$ Symptomatic neuropathic pain treatment in sarcoidosis patients is not different from the treatment of neuropathic pain from other causes, and consists of antidepressants, anticonvulsants and prolonged-release opioids. However, in common with their effects in other neuropathic pain states, these agents provide limited pain relief in just $30-60 \%$ of patients, at the cost of considerable side effects. These data indicate that there is an urgent need for analgesic agents with high efficacy for neuropathic pain patients, causing no debilitating side-effects. Case reports mention beneficial effects of intravenous immunoglobulin and anti-TNF-alpha therapy. ${ }^{6,79,80}$ The precise potency of these drugs needs further study however.

\section{Additional alternatives to pharmacological treatment}

Developing the most appropriate therapeutic approach for sarcoidosis, including rehabilitation programs, requires careful consideration of the possible impact of pain, the SFN-related symptoms, the fatigue and coping strategies, as well as all other relevant aspects of this multisystemic disease. ${ }^{3,4,6,49,81}$ Various treatments are available for fatigue with a partly psychological cause, and patients with a clinical depression can be prescribed antidepressants. Some patients may require help to improve their coping and self-management skills, to improve their QoL. Cognitive therapy may be indicated to treat coping problems or stress perception. Sleeping problems should be treated appropriately. ${ }^{25}$ In general, care providers have to raise supportive care issues and provide information about alternative care programs beside medication, which aim to reduce the symptoms and improve the wellbeing of sarcoidosis patients. Patients should be informed about the importance of exercise and they should be encouraged to stay active. 


\section{Rehabilitation}

Patients should be instructed to lead an as active and involved a life as possible as exercise intolerance and muscle weakness are frequent problems in sarcoidosis influencing QoL (Figure 2.1). ${ }^{28}$ Rehabilitation has many benefits for patients with sarcoidosis, including social participation, psychological wellbeing, maintaining levels of activity, learning to use breathing exercises and ways to adapt exercises for the home environment. $69,70,82,83$ In the broader context of medical encounters, physical therapy or rehabilitation can help to avoid a negative vicious circle of deconditioning. ${ }^{61,69}$ Research has found that fatigue in patients with sarcoidosis was reduced after a period of physical training. ${ }^{69,70}$ Moreover, their psychological health and physical functioning also improved. ${ }^{69}$ Sarcoidosis patients generally benefit from additional non-pharmacological treatments, not only physical training but also nutritional supplements and counseling. ${ }^{69,70,84,85}$ Patients should be counseled about their responsibilities in managing their own condition, about ways to engage different services when required, and about lifestyle, e.g. the importance of regular exercise as well as pulmonary rehabilitation programs. Patients self-perceived knowledge about the importance of exercise for their health (in addition to drug therapy) should be improved. Care providers should be able to refer patients to rehabilitation (including pulmonary rehabilitation) by physical therapists or other professionals with awareness/knowledge of sarcoidosis, if they expect these patients to benefit, or if the patients ask for referral. Rehabilitation services or programs led by physical therapists should be available to patients at reasonable cost. Prospective studies should be designed to answer lingering questions about the value of exercise training for patients with sarcoidosis, including what benefits can be expected of maintenance programs and how long these will last. Our own research found that patients reported less feelings of uncertainty and anxiety after a training program (unpublished data). This has promising implications for clinical practice. As sarcoidosis patients may suffer from various impairments, such as arthralgia, muscle pain, and fatigue, the intensity of the training should be personalized to avoid training aggravating these impairments, resulting in high dropout rates. This also argues for a multidisciplinary approach to the routine management of sarcoidosis.

More research is needed to provide evidence for the relationship between physical therapy and recall. Such studies should assess whether awareness of the importance of physical activities in daily life and their consequences for sarcoidosis patients might affect adherence to treatment or medication regimens. The duration, frequency, and intensity of exercise programs are critical to achieve physical benefits. ${ }^{82}$ In general 'high-frequency, low-impact' exercise can be recommended. Future prospective studies are warranted to fine-tune the training parameters, duration, and frequency. 


\section{Communication and patient participation}

Providing information and communication can be hampered by the complexity of sarcoidosis and its heterogeneity. Moreover, management of patients with sarcoidosis requires more than prescribing drugs. It is important for physicians to listen to their patients; it is wise to take what the patient says seriously. Obviously, understanding and remembering medical information is crucial for every patient, as it is a prerequisite for coping with their disease and making informed treatment decisions. Most patients do remember their diagnosis, but have difficulty remembering information about things like treatment plans, recommendations, and side-effects. Patients' information recall may be enhanced by addressing emotions by means of affective communication. Extensive research has shown that physicians' affective communication (i.e., being emotionally supportive; adopting a warm, empathic, and reassuring manner) may improve patients' outcomes, including reduced levels of anxiety and distress. ${ }^{86,87}$ Physicians' affective communication not only tempers emotional arousal, but also enhances recall of medical information. ${ }^{87}$ Research in various disorders has shown that such affective statements improved recall, especially as regards prognostic information and, to some extent, treatment information. Obviously, since sarcoidosis requires a multidisciplinary approach in view of its wide range of symptoms, communication amongst the various health care workers involved and between them and the patients is of great importance. ${ }^{88}$ Although the effect of affective communication has not yet been studied in sarcoidosis, this may be expected to improve patient compliance. Patient participation is increasingly recognized as a key component in the design of health care processes and is also advocated as a means of improving patient compliance. The concept has been successfully applied to various areas of patient care, such as decision making and the management of chronic diseases. Patient participation in shared treatment decision-making is hypothesized to improve treatment adherence and clinical outcomes. Although this has not yet been studied in sarcoidosis, other research findings reveal the significance of patient participation as a key factor in improving treatment adherence and clinical outcome. Quality improvement strategies for sarcoidosis management should therefore emphasize patient participation. Further research is essential to establish key determinants of the success of patient participation in improving efficacy of care for sarcoidosis patients.

Patient participation has promising implications for the multidisciplinary management of sarcoidosis. However, the effect of affective communication on recall should be further established because evidence is lacking, especially for extensive consultations. Other interesting topics for future studies include whether self-perceived medical knowledge about sarcoidosis and its related consequences, including treatment options, is sufficient to achieve beneficial effects. 


\section{Summary}

Sarcoidosis is a multisystem disorder of unknown cause(s) that imposes a burden on patient's lives. In addition to the specific organ-related symptoms, less specific disabling symptoms, including fatigue and physical impairments, may have a major influence on the daily activities and the social and professional lives of the patients, resulting in a reduced quality of life. A multidisciplinary approach is recommended for these patients, one that focuses on somatic as well as psychosocial aspects of this erratic disorder. Patients self-perceived knowledge about the importance of exercise and lifestyle for their health (in addition to drugs) should be improved. Developing the most appropriate therapeutic approach for sarcoidosis, including rehabilitation programs, requires careful consideration of the possible impact of fatigue, small fiber neuropathy symptoms, pain, cognitive functioning, and coping strategies, as well as all other relevant aspects of this multisystemic disease. Hence, personalized medicine and appropriate communication will be beneficial. 


\section{References}

1. Statement on sarcoidosis. Joint Statement of the American Thoracic Society (ATS), the European Respiratory Society (ERS) and the World Association of Sarcoidosis and Other Granulomatous Disorders (WASOG) adopted by the ATS Board of Directors and by the ERS Executive Committee, February 1999. Am J Respir Crit Care Med 1999;160:736-755.

2. Valeyre D, Prasse A, Nunes H, Uzunhan Y, Brillet PY, Muller-Quernheim J. Sarcoidosis. Lancet 2014;383:1155-1167.

3. De Vries J, Drent M. Quality of life and health status in sarcoidosis: a review of the literature. Clin Chest Med 2008;29:525-532.

4. Judson MA. Small fiber neuropathy in sarcoidosis: Something beneath the surface. Respir Med 2011;105:1-2.

5. Drent M, Lower EE, De Vries J. Sarcoidosis-associated fatigue. Eur Respir J 2012;40:255-263.

6. Elfferich MD, Nelemans PJ, Ponds RW, De Vries J, Wijnen PA, Drent M. Everyday cognitive failure in sarcoidosis: the prevalence and the effect of anti-TNF-alpha treatment. Respiration 2010;80:212-219.

7. Korenromp IH, Heijnen CJ, Vogels OJ, van den Bosch JM, Grutters JC. Characterization of chronic fatigue in patients with sarcoidosis in clinical remission. Chest 2011;140:441-447.

8. Michielsen HJ, Peros-Golubicic T, Drent M, De Vries J. Relationship between symptoms and quality of life in a sarcoidosis population. Respiration 2007;74:401-405.

9. Baydur A, Alavy B, Nawathe A, Liu S, Louie S, Sharma OP. Fatigue and plasma cytokine concentrations at rest and during exercise in patients with sarcoidosis. Clin Respir J 2011;5:156-164.

10. de Kleijn WP, Drent M, Vermunt JK, Shigemitsu H, De Vries J. Types of fatigue in sarcoidosis patients. J Psychosom Res 2011;71:416-422.

11. Sharma OP. Fatigue and sarcoidosis. Eur Respir J 1999;13:713-714.

12. Marcellis RG, Lenssen AF, de Vries J, Drent $M$. Reduced muscle strength, exercise intolerance and disabling symptoms in sarcoidosis. Curr Opin Pulm Med 2013;19:524-530.

13. Drent M, Marcellis R, Lenssen A, De Vries J. Association between physical functions and quality of life in sarcoidosis. Sarcoidosis Vasc Diffuse Lung Dis 2014;31:117-128.

14. Morgenthau AS, lannuzzi MC. Recent advances in sarcoidosis. Chest 2011;139:174-182.

15. Cox CE, Donohue JF, Brown CD, Kataria YP, Judson MA. Health-related quality of life of persons with sarcoidosis. Chest 2004;125:997-1004.

16. Judson MA, Costabel U, Drent M, et al. The WASOG Sarcoidosis Organ Assessment Instrument: An update of a previous clinical tool. Sarcoidosis Vasc Diffuse Lung Dis 2014;31:19-27.

17. Pereira CA, Dornfeld MC, Baughman R, Judson MA. Clinical phenotypes in sarcoidosis. Curr Opin Pulm Med 2014;20:496-502.

18. Baughman RP, Lower EE, Gibson K. Pulmonary manifestations of sarcoidosis. Presse Med 2012;41: e289-302.

19. Michielsen HJ, Drent M, Peros-Golubicic T, De Vries J. Fatigue is associated with quality of life in sarcoidosis patients. Chest 2006;130:989-994.

20. Wirnsberger RM, de Vries J, Breteler MH, van Heck GL, Wouters EF, Drent M. Evaluation of quality of life in sarcoidosis patients. Respir Med 1998;92:750-756.

21. Hoitsma E, De Vries J, Drent M. The small fiber neuropathy screening list: Construction and crossvalidation in sarcoidosis. Respir Med 2011;105:95-100.

22. Hinz A, Fleischer M, Brahler E, Wirtz H, Bosse-Henck A. Fatigue in patients with sarcoidosis, compared with the general population. Gen Hosp Psychiatry 2011;33:462-468.

23. De Vries J, Drent M. Relationship between perceived stress and sarcoidosis in a Dutch patient population. Sarcoidosis Vasc Diffuse Lung Dis 2004;21:57-63.

24. Korenromp IH, Grutters JC, van den Bosch JM, Heijnen CJ. Post-inflammatory fatigue in sarcoidosis: personality profiles, psychological symptoms and stress hormones. J Psychosom Res 2012;72:97-102.

25. Verbraecken J, Hoitsma E, van der Grinten CP, Cobben NA, Wouters EF, Drent M. Sleep disturbances associated with periodic leg movements in chronic sarcoidosis. Sarcoidosis Vasc Diffuse Lung Dis 2004;21:137-146.

26. Baughman RP, Sparkman BK, Lower EE. Six-minute walk test and health status assessment in sarcoidosis. Chest 2007;132:207-213. 
27. Baughman RP, Teirstein AS, Judson MA, et al. Clinical characteristics of patients in a case control study of sarcoidosis. Am J Respir Crit Care Med 2001;164:1885-1889.

28. Marcellis RG, Lenssen AF, Elfferich MD, et al. Exercise capacity, muscle strength and fatigue in sarcoidosis. Eur Respir J 2011;38:628-634.

29. Judson MA, Baughman RP, Thompson BW, et al. Two year prognosis of sarcoidosis: the ACCESS experience. Sarcoidosis Vasc Diffuse Lung Dis 2003;20:204-211.

30. Baughman RP, Judson MA, Teirstein A, et al. Presenting characteristics as predictors of duration of treatment in sarcoidosis. QJM 2006;99:307-315.

31. Hoitsma E, Marziniak M, Faber CG, et al. Small fibre neuropathy in sarcoidosis. Lancet 2002;359: 2085-2086.

32. Bakkers M, Merkies IS, Lauria G, et al. Intraepidermal nerve fiber density and its application in sarcoidosis. Neurology 2009;73:1142-1148.

33. Hoitsma $E$, Drent $M$, Verstraete $E$, et al. Abnormal warm and cold sensation thresholds suggestive of small-fibre neuropathy in sarcoidosis. Clin Neurophysiol 2003;114:2326-2333.

34. Hoitsma E, Reulen JP, de Baets M, Drent M, Spaans F, Faber CG. Small fiber neuropathy: a common and important clinical disorder. J Neurol Sci 2004;227:119-130.

35. Hoitsma E, Drent M, Sharma OP. A pragmatic approach to diagnosing and treating neurosarcoidosis in the 21st century. Curr Opin Pulm Med 2010;16:472-479.

36. Tavee J, Zhou L. Small fiber neuropathy: A burning problem. Cleve Clin J Med 2009;76:297-305.

37. Hoitsma E, Faber CG, Drent M, Sharma OP. Neurosarcoidosis: a clinical dilemma. Lancet Neurol 2004;3:397-407.

38. Tavee J, Culver D. Sarcoidosis and small-fiber neuropathy. Curr Pain Headache Rep 2011;15:201-206.

39. Katon $\mathrm{W}$, Lin EH, Kroenke $\mathrm{K}$. The association of depression and anxiety with medical symptom burden in patients with chronic medical illness. Gen Hosp Psychiatry 2007;29:147-155.

40. Freeman R, Komaroff AL. Does the chronic fatigue syndrome involve the autonomic nervous system? Am J Med 1997;102:357-364.

41. Korenromp IH, Grutters JC, van den Bosch JM, Zanen P, Kavelaars A, Heijnen CJ. Reduced Th2 cytokine production by sarcoidosis patients in clinical remission with chronic fatigue. Brain Behav Immun 2011;25:1498-1502.

42. Kim YK, Na KS, Shin KH, Jung HY, Choi SH, Kim JB. Cytokine imbalance in the pathophysiology of major depressive disorder. Prog Neuropsychopharmacol Biol Psychiatry 2007;31:1044-1053.

43. Chang B, Steimel J, Moller DR, et al. Depression in sarcoidosis. Am J Respir Crit Care Med 2001;163: 329-334.

44. De Vries J, Rothkrantz-Kos S, van Dieijen-Visser MP, Drent M. The relationship between fatigue and clinical parameters in pulmonary sarcoidosis. Sarcoidosis Vasc Diffuse Lung Dis 2004;21:127-136.

45. Drent M, Wirnsberger RM, Breteler MH, Kock LM, de Vries J, Wouters EF. Quality of life and depressive symptoms in patients suffering from sarcoidosis. Sarcoidosis Vasc Diffuse Lung Dis 1998;15:59-66.

46. Elfferich MD, De Vries J, Drent M. Type D or 'distressed' personality in sarcoidosis and idiopathic pulmonary fibrosis. Sarcoidosis Vasc Diffuse Lung Dis 2011;28:65-71.

47. de Kleijn WP, Drent M, De Vries J. Nature of fatigue moderates depressive symptoms and anxiety in sarcoidosis. Br J Health Psychol 2013;18:439-452.

48. Ireland J, Wilsher M. Perceptions and beliefs in sarcoidosis. Sarcoidosis Vasc Diffuse Lung Dis 2010;27:36-42.

49. Hinz A, Brähler E, Möde R, Wirtz H, Bosse-Henck A. Anxiety and depression in sarcoidosis: the influence of age, gender, affected organs, concomitant diseases and dyspnea. Sarcoidosis Vasc Diffuse Lung Dis 2012;29:139-146.

50. Spruit MA, Janssen DJ, Franssen FM, Wouters EF. Rehabilitation and palliative care in lung fibrosis. Respirology 2009;14:781-787.

51. Goracci A, Fagiolini A, Martinucci M, et al. Quality of life, anxiety and depression in sarcoidosis. Gen Hosp Psychiatry 2008;30:441-445.

52. Holas P, Krejtz I, Urbankowski T, Skowyra A, Ludwiniak A, Domagala-Kulawik J. Anxiety, its relation to symptoms severity and anxiety sensitivity in sarcoidosis. Sarcoidosis Vasc Diffuse Lung Dis 2013;30: 282-288.

53. de Boer S, Kolbe J, Wilsher ML. The relationships among dyspnoea, health-related quality of life and psychological factors in sarcoidosis. Respirology 2014;19:1019-1024. 
54. Yamada Y, Tatsumi K, Yamaguchi T, et al. Influence of stressful life events on the onset sarcoidosis. Respirology 2003;8:186-191.

55. Klonoff EA, Kleinhenz ME. Psychological factors in sarcoidosis: the relationship between life stress and pulmonary function. Sarcoidosis 1993;10:118-124.

56. Chaturvedi SK, Peter Maguire G, Somashekar BS. Somatization in cancer. Int Rev Psychiatry 2006;18: 49-54.

57. Shin SY, Katz P, Wallhagen M, Julian L. Cognitive impairment in persons with rheumatoid arthritis. Arthritis Care Res 2012;64:1144-1150.

58. Jougleux-Vie C, Duhin E, Deken V, Outteryck O, Vermersch P, Zephir H. Does fatigue complaint reflect memory impairment in multiple sclerosis? Mult Scler Int 2014;2014:692468.

59. Swigris JJ, Brown KK, Make BJ, Wamboldt FS. Pulmonary rehabilitation in idiopathic pulmonary fibrosis: a call for continued investigation. Respir Med 2008;102:1675-1680.

60. Marcellis RG, Lenssen AF, Kleynen S, De Vries J, Drent M. Exercise capacity, muscle strength, and fatigue in sarcoidosis: a follow-up study. Lung 2013;191:247-256.

61. Spruit MA, Thomeer MJ, Gosselink R, et al. Skeletal muscle weakness in patients with sarcoidosis and its relationship with exercise intolerance and reduced health status. Thorax 2005;60:32-38.

62. Baughman RP, Lower EE. Six-minute walk test in managing and monitoring sarcoidosis patients. Curr Opin Pulm Med 2007;13:439-444.

63. Wallaert B, Talleu C, Wemeau-Stervinou L, Duhamel A, Robin S, Aguilaniu B. Reduction of maximal oxygen uptake in sarcoidosis: relationship with disease severity. Respiration 2011;82:501-508.

64. Wirnsberger RM, Drent M, Hekelaar N, et al. Relationship between respiratory muscle function and quality of life in sarcoidosis. Eur Respir J 1997;10:1450-1455.

65. Barros WG, Neder JA, Pereira CA, Nery LE. Clinical, radiographic and functional predictors of pulmonary gas exchange impairment at moderate exercise in patients with sarcoidosis. Respiration 2004;71: 367-373.

66. Medinger AE, Khouri S, Rohatgi PK. Sarcoidosis: the value of exercise testing. Chest 2001;120:93-101.

67. Marcellis RG, Lenssen AF, de Vries GJ, et al. Is there an added value of cardiopulmonary exercise testing in sarcoidosis patients? Lung 2013;191:43-52.

68. Braam AW, de Haan SN, Vorselaars $A D$, et al. Influence of repeated maximal exercise testing on biomarkers and fatigue in sarcoidosis. Brain Behav Immun 2013;33:57-64.

69. Marcellis RG, Veeke MAF, Mesters I, et al. Does physical training reduce fatigue in sarcoidosis? Sarcoidosis Vasc Diffuse Lung Dis 2015;32:in press.

70. Strookappe EW, Elfferich MDP, Swigris JJ, et al. Benefits of physical training in patients with idiopathic or end-stage sarcoidosis-related pulmonary fibrosis: a pilot study. Sarcoidosis Vasc Diffuse Lung Dis 2015;32:in press.

71. De Vries J, Drent M. Quality of life and health status in sarcoidosis: a review. Semin Respir Crit Care Med 2007;28:121-127.

72. Thomten J, Soares JJ, Sundin O. The influence of psychosocial factors on quality of life among women with pain: a prospective study in Sweden. Qual Life Res 2011;20:1215-1225.

73. Patel AS, Siegert RJ, Creamer D, et al. The development and validation of the King's Sarcoidosis Questionnaire for the assessment of health status. Thorax 2013;68:57-65.

74. Holtzman S, Newth S, Delongis A. The role of social support in coping with daily pain among patients with rheumatoid arthritis. J Health Psychol 2004;9:677-695.

75. Goldberg GM, Kerns RD, Rosenberg R. Pain-relevant support as a buffer from depression among chronic pain patients low in instrumental activity. Clin J Pain 1993;9:34-40.

76. Dysvik E, Lindstrom TC, Eikeland OJ, Natvig GK. Health-related quality of life and pain beliefs among people suffering from chronic pain. Pain Manag Nurs 2004;5:66-74.

77. Marhold C, Linton SJ, Melin L. Identification of obstacles for chronic pain patients to return to work: evaluation of a questionnaire. J Occup Rehabil 2002;12:65-75.

78. De Vries J, Wirnsberger RM. Fatigue, quality of life and health status in sarcoidosis. Eur Respir Mon 2005;32:92-104.

79. Parambil JG, Tavee JO, Zhou L, Pearson KS, Culver DA. Efficacy of intravenous immunoglobulin for small fiber neuropathy associated with sarcoidosis. Respir Med 2011;105:101-105.

80. Wijnen PA, Cremers JP, Nelemans PJ, et al. Association of the TNF-alpha G-308A polymorphism with TNF-inhibitor response in sarcoidosis. Eur Respir J 2014;43:1730-1739. 
81. Holland AE, Hill CJ, Conron M, Munro P, McDonald CF. Short term improvement in exercise capacity and symptoms following exercise training in interstitial lung disease. Thorax 2008;63:549-554.

82. Spruit MA, Wouters EFM, Gosselink R. Rehabilitation programmes in sarcoidosis: a multidisciplinary approach. Eur Respir J 2005;32:316-326.

83. Swigris JJ, Fairclough DL, Morrison M, et al. Benefits of pulmonary rehabilitation in idiopathic pulmonary fibrosis. Respir Care 2011;56:783-789.

84. Boots AW, Drent M, de Boer VC, Bast A, Haenen GR. Quercetin reduces markers of oxidative stress and inflammation in sarcoidosis. Clin Nutr 2011;30:506-512.

85. Boots AW, Drent M, Swennen EL, Moonen HJ, Bast A, Haenen GR. Antioxidant status associated with inflammation in sarcoidosis: a potential role for antioxidants. Respir Med 2009;103:364-372.

86. van Osch $M$, Sep $M$, van Vliet $L M$, van Dulmen S, Bensing JM. Reducing patients' anxiety and uncertainty, and improving recall in bad news consultations. Health Psychol 2014;33:1382-1390.

87. Derksen F, Bensing J, Kuiper S, van Meerendonk M, Lagro-Janssen A. Empathy: what does it mean for GPs? A qualitative study. Fam Pract 2015;32:94-100.

88. Drent M. Sarcoidosis: benefits of a multidisciplinary approach. Eur J Intern Med 2003;14:217-220. 



\section{Chapter 3}

\section{Validation of the King's Sarcoidosis Questionnaire (KSQ) in a Dutch sarcoidosis population}

MJG van Manen, M Wapenaar, B Strookappe, M Drent, M Elfferich, J de Vries, HR Gosker, SS Birring, A Patel, L van den Toorn, B van den Blink, K Boomars, E Hoitsma, MS Wijsenbeek Sarcoidosis Vasc Diffuse Lung Dis 2016;33:75-82 


\section{Abstract}

\section{Background}

The King's Sarcoidosis Questionnaire (KSQ) is a brief questionnaire assessing health status using five modules (General Health Status, Lung, Medication, Skin and Eyes) in patients with sarcoidosis. The KSQ was only validated in one English sarcoidosis cohort.

\section{Objective}

The aim of this study was to validate the KSQ in a Dutch sarcoidosis population.

\section{Methods}

The KSQ was translated according to international guidelines and tested in interviews with patients. Consecutive outpatients completed multiple questionnaires twice, two weeks apart. Construct validity, internal consistency and repeatability were determined.

\section{Results}

Of the 98 patients included 85 had lung, 22 skin and 24 eye disease. There was good construct validity of the KSQ General Health Status module against the World Health Organization Quality of Life-BREF questionnaire. The Medication module correlated weak to moderate with most questionnaires. The correlations with organ-specific questionnaires varied from strong for Eyes $(r=0.75)$, Skin ( $r=-0.62)$ to moderate for Lung ( $r=-0.45$ with MRC breathlessness scale). Internal consistency was good for all KSQ modules (Cronbach's $\alpha$ 0.72-0.93). Intraclass correlation coefficients (0.70-0.90) and Bland-Altman plots showed good repeatability of the KSQ.

\section{Conclusion}

The Dutch KSQ is the first translation of the English KSQ, validated in a Dutch sarcoidosis population. 


\section{Introduction}

Sarcoidosis is a heterogeneous multisystem disease with different clinical phenotypes. Sarcoidosis manifests most commonly in the lungs, but can affect skin, eyes, lymphatic nodes and other organs as well. ${ }^{1}$ Health status is impaired in the majority of patients with sarcoidosis due to symptoms such as dyspnea, persistent cough, peripheral pain, fatigue and cognitive dysfunction, leading to limitations in activities, social isolation and depression. ${ }^{1-3}$ Therapy for sarcoidosis often leads to side effects impacting health status. $^{4,5}$ In recent years patient related outcome measures (PROMs) have gained increasing importance in clinical trials and health status is now a standard outcome measure. ${ }^{6}$ Most studies evaluating health status used generic questionnaires such as the World Health Organization Quality of Life-BREF (WHOQOL-BREF) or the MOS 36item Short Form Health Survey (SF-36), both non-disease specific questionnaires. ${ }^{7-12}$ Currently, no sarcoidosis specific instruments measuring health status in patients with sarcoidosis are available in Dutch. In 2012 the King's Sarcoidosis Questionnaire (KSQ) was developed. ${ }^{13}$ This self-administered measure for sarcoidosis covers different domains of health status; General Health Status (GHS), Lung (L), Medication (M), Skin $(\mathrm{S})$ and Eyes (E). The aim of this study was to validate the KSQ in a Dutch sarcoidosis population.

\section{Methods}

\section{Translation validation}

The KSQ was translated from English to Dutch according to a multi-step forwardbackward procedure, following international guidelines, ${ }^{14-16}$ and was reviewed by sarcoidosis experts and the developers (Online Supplement 1). The relevance and applicability of the translated KSQ was tested using ten structured patient interviews.

\section{Psychometric validation}

\section{Subjects}

In July 2014 consecutive sarcoidosis outpatients of the pulmonary department of the Erasmus Medical Center were asked to participate. During the same period sarcoidosis outpatients of the ild care team, Hospital Gelderse Vallei were approached by email. Patients were excluded from the study if they were unable to understand questionnaires due to intellectual impairment or language barrier, when comorbidities that severely impact health status existed (such as malignancies, collagen vascular diseases and cardiac failure other than due to sarcoidosis) or when they had unstable disease as considered by the treating physician. If patients completed less than $85 \%$ of a questionnaire they were withdrawn from the study. Formal consultation with the 
Medical Ethical Committee of the Erasmus Medical Center learnt that, under the Dutch act for medical research involving human subjects (Wet Medisch Onderzoek), approval of this study by the Medical Ethical Committee is not required.

\section{Study procedure}

All patients were asked to complete up to seven questionnaires (depending on organ involvement) in addition to the KSQ: WHOQOL-BREF, ${ }^{7}$ Fatigue Assessment Scale (FAS), ${ }^{17}$ Small Fiber Neuropathy Screening List (SFNSL), ${ }^{18}$ Medical Research Council dyspnea scale (MRC dyspnea scale), ${ }^{19}$ Dermatology Life Quality Index (DLQI), ${ }^{20}$ National Eye Institute Visual Function Questionnaire (NEI-VFQ25) ${ }^{21}$ and Euroqol-5D-5 level (EQ-5D$5 \mathrm{~L}){ }^{22}$ Online Supplement 2 shows the organ specific questionnaires and corresponding KSQ modules. Patients also completed two general health status measurements: Punum Ladders ${ }^{23}$ and Global Rating of Change-Quality of Life (GRC-QoL). ${ }^{24}$ Patients were asked to self-complete the questionnaires at home, two weeks apart.

Results of routinely measured pulmonary function outcomes were gathered from the medical records. The diagnosis of sarcoidosis was established when there was compatible clinical behaviour and pathological or BAL confirmation, according to international guidelines. ${ }^{25}$ Patients were asked about their organ involvement during a short face to face interview or interview by telephone.

\section{Statistical analysis}

Data are presented as mean values ( \pm standard deviation). KSQ scores were calculated on a logit scale as this scale is more linear and has the potential to perform better at the extreme ends of health related QoL. ${ }^{26}$ The validity of the KSQ remains unchanged from the original format. ${ }^{27}$ Construct validity between the general and organ specific domains of $\mathrm{KSQ}$ and the corresponding questionnaires were determined using Pearson's correlation coefficients. A correlation coefficient of $<0.30$ is considered weak, $0.30-0.50$ moderate and $>0.50$ strong. ${ }^{16}$ Cronbach's $\alpha$ coefficient was used to determine the internal consistency of the reliability of the KSQ. A minimum of 0.70 is considered a good internal consistency. Bland-Altman plots and intraclass correlation coefficients were used to evaluate the repeatability at baseline and at two weeks, in patients with stable disease. To assess stable disease we used Punum ladders. ${ }^{23}$ Patients with $\geq 4$ differences in Punum score were excluded in the repeatability analyses. The limits of agreement were calculated as mean $\pm 1.96 \times$ SD of withinsubject differences. Values of $p<0.05$ were considered statistically significant. All data were analyzed with SPSS version 21. 


\section{Results}

\section{Translation validation}

A Dutch version of the $\mathrm{KSQ}$, achieved after forward and backward translation, was approved by the KSQ developers. Following this approval, ten patient interviews with the Dutch version of the KSQ took place (step T3 Online Supplement 1). Discussion of these interview results with the KSQ developers did not necessitate any further adaptations of the translation and resulted in the final Dutch KSQ-version (Online Supplement 3).

\section{Psychometric validation}

One hundred and four consecutive outpatients in the Erasmus Medical Center were evaluated for participation, 89 were interested and 54 participated in this study. At the same time 117 patients of the ild care team, Hospital Gelderse Vallei were approached by email, 60 patients responded and 44 were recruited. Reasons for exclusion were: clinical instability (15), comorbidity that severely impacted quality of life (14), no PA/BAL confirmation (9), not able to read or write Dutch (5) or other reasons (8) (not willing to participate, not reachable by telephone or by email, participating in another study). Thus in total 98 patients were included. Eighty-eight (90\%) of them completed week zero and 83 (85\%) week two (Figure 3.1).

\section{Demographics}

Table 3.1 shows the demographics of the patients included. Patients with two or more organs involved showed a significantly worse health status than patients with singleorgan disease: mean (SEM) KSQ GHS score 53(1.6) versus 68(3.7); mean difference 15; 95\% Confidence Interval (Cl) 7-23; $p=0.001$. No significant difference was found between the KSQ GHS score for females compared with males: mean (SEM) 54(2.5) versus 60(2.3); mean difference $5 ; 95 \% \mathrm{Cl} 1-12, \mathrm{p}=0.115$. Patients with more complaints of fatigue (FAS score $\geq 22$ ) have a significantly worse health status (mean (SEM) KSO GHS 52(1.5)), than those with lower FAS scores (mean (SEM) 76(3.2); mean difference KSQ GHS $-24 ; 95 \% \mathrm{Cl}-30$ to $-17, p=0.000)$. 




Figure 3.1 Study design

\section{Construct validity}

The correlations between the KSQ GHS domain and all generic questionnaires (WHOQOL-BREF and EQ-5D-5L) were strong ( $r=0.50-0.84)$. KSQ organ modules combined with the GHS module all showed a moderate to strong correlation with the WHOQOL-BREF and EQ-5D-5L ( $r=0.44-0.85)$. The Medication module showed a weak to moderate correlation with the generic questionnaires $(r=0.26-0.47)$ (Table 3.2).

All KSQ modules correlated moderately to strongly with the FAS. The relationship between the KSQ organ-specific modules and their corresponding organ-specific questionnaires was also moderate to strong. The Lung module was weakly correlated with the FVC\% predicted ( $r=0.24$ ) (Table 3.2). 
Table 3.1 Patient demographics

\begin{tabular}{|c|c|c|c|c|}
\hline & \multirow[b]{2}{*}{ All patients } & \multicolumn{3}{|c|}{ Organ involvement } \\
\hline & & Lung & Skin & Eyes \\
\hline Number & 88 & 85 & 22 & 24 \\
\hline Age, years, mean (SD) & $52(11)$ & $51(11)$ & $52(11)$ & $52(13)$ \\
\hline Women, n (\%) & $36(41)$ & $35(41)$ & $10(46)$ & $11(46)$ \\
\hline \multicolumn{5}{|l|}{ Ethnicity, n (\%) } \\
\hline Caucasian & $70(80)$ & $67(79)$ & $17(77)$ & $16(67)$ \\
\hline Afro-American & $2(2)$ & $2(2)$ & - & - \\
\hline Surinamese-Hindi & $13(15)$ & $13(15)$ & $4(18)$ & $5(21)$ \\
\hline Morrocan & $2(2)$ & $2(2)$ & $1(5)$ & $2(8)$ \\
\hline Unknown & $1(1)$ & $1(1)$ & - & $1(4)$ \\
\hline \multicolumn{5}{|l|}{ Smoking status, n (\%) } \\
\hline Current & $3(3)$ & $3(4)$ & - & $1(4)$ \\
\hline Ex & $15(17)$ & $15(18)$ & $5(23)$ & $8(33)$ \\
\hline Never & $64(73)$ & $61(72)$ & $15(68)$ & $12(50)$ \\
\hline Unknown & $6(7)$ & $6(7)$ & $2(9)$ & $3(13)$ \\
\hline Time since diagnosis, years, mean (SD) & $8.0(8.8)$ & $8.1(8.9)$ & $7.4(10.5)$ & $8.4(11.2)$ \\
\hline \multicolumn{5}{|l|}{ Organs involved, n (\%) } \\
\hline Lungs & $85(97)$ & & & \\
\hline Skin & $22(25)$ & & & \\
\hline Eyes & $24(27)$ & & & \\
\hline Small nerve fibers & $26(30)$ & & & \\
\hline FVC \% predicted, mean (SD), [n] & $92(20)[84]$ & $91(20)[81]$ & & \\
\hline FEV1/FVC ratio \% predicted, mean, [n] & 76 (13) [74] & 76 (13) [72] & & \\
\hline TLCOc \% predicted, mean (SD) , [n] & $81(21)[73]$ & $81(21)[70]$ & & \\
\hline TLC \% predicted, mean (SD) , [n] & $86(18)[57]$ & $86(18)[56]$ & & \\
\hline
\end{tabular}

FVC, forced vital capacity; FEV1, forced expiratory volume in $1 \mathrm{~s}$; TLCO, diffusing capacity of the lung for carbon monoxide, corrected for hemoglobin level; TLC, total lung capacity as \% predicted.

\section{Reliability}

All domains of the KSQ had good internal consistency, Cronbach $\alpha ; 0.90$ (GHS), 0.91 (Lung), 0.72 (Medication), 0.84 (Skin), and 0.93 (Eyes). With regard to the repeatability (test-retest) 83 patients (lung $n=80$, skin $n=20$ and eyes $n=22$ ) completed the KSQ twice. The following intraclass correlations were found: GHS 0.85, Lung 0.74, Medication 0.70, Skin 0.77, Eyes 0.90, suggesting a good reliability. Twelve patients in the GHS and 13 patients in the Lung module groups were excluded from the analysis for repeatability, because they did not show stability in their Punum scores. The BlandAltman plots in Figure 3.2 and 3.3 show the repeatability of the KSQ GHS and Lung module, respectively. Both plots have a few outliers (outside the $95 \%$ of limits of agreement). We found a mean difference between the first and second measurement of 2.20 in the KSQ GHS module and 2.45 in the Lung module. 


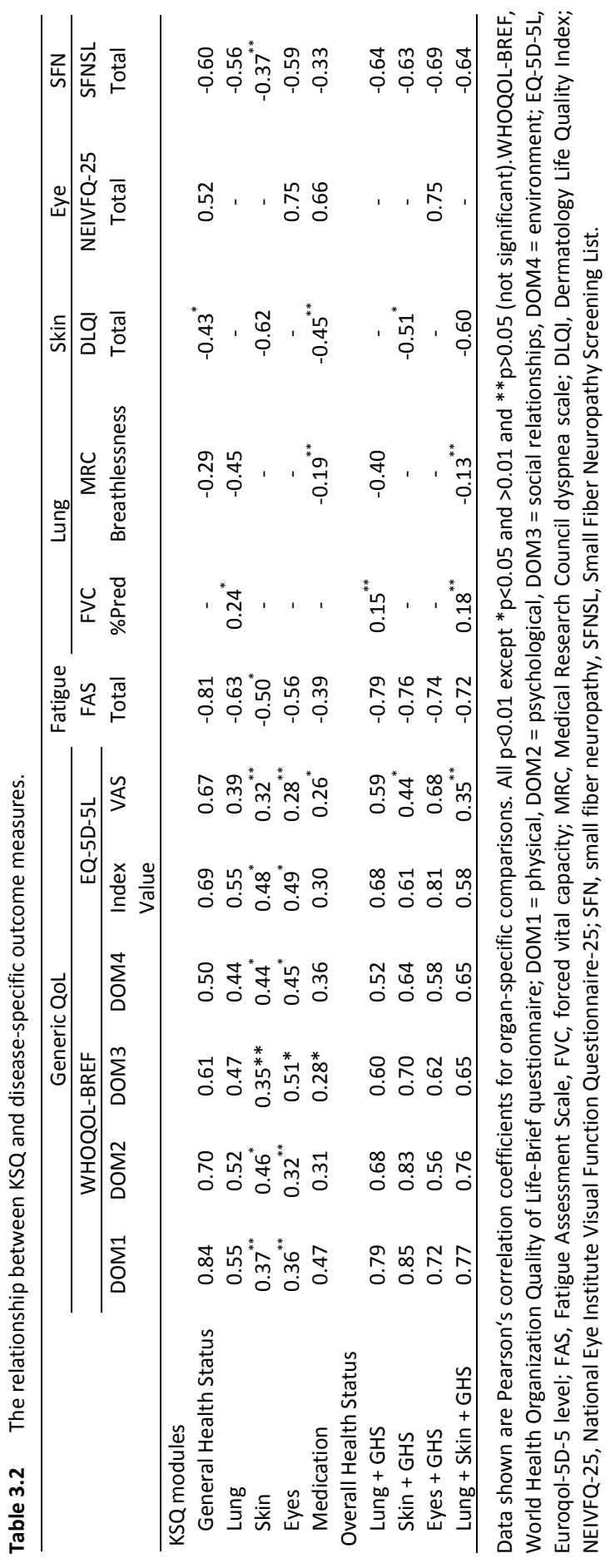




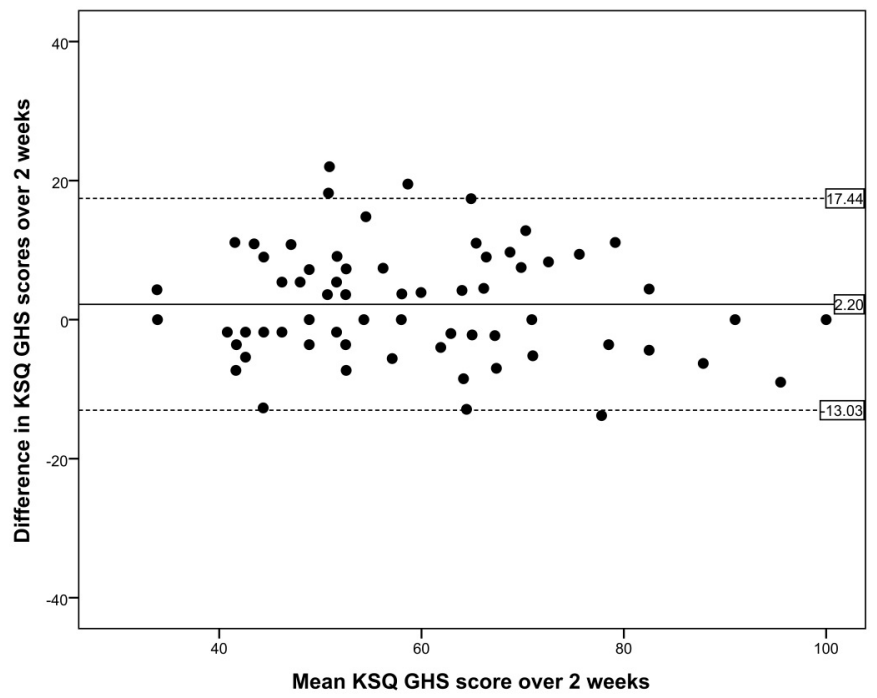

Figure 3.2 Bland Altman plot of repeatability of King's Sarcoidosis Questionnaire General Health Status module. Solid line represents mean difference and dashed lines represent $95 \%$ limits of agreement.



Figure 3.3 Bland Altman plot of repeatability of King's Sarcoidosis Questionnaire Lung module. Solid line represents mean difference and dashed lines represent $95 \%$ limits of agreement. 


\section{Discussion}

The Dutch KSQ is the first health status questionnaire for sarcoidosis in the Netherlands. It is also the first non-English validation of the questionnaire. The KSQ is simple to administer, adaptable to individual organ involvement and shown to be a valid and reliable health status measurement in Dutch patients with sarcoidosis.

PROMs are becoming more important in clinical trials and daily care. ${ }^{6}$ Health status is nowadays a standard outcome measure. Most sarcoidosis studies use non-disease specific questionnaires such as the WHOQOL-BREF and the SF-36. ${ }^{10-12}$ The KSQ is a selfadministered sarcoidosis specific instrument. The KSQ questionnaire was originally developed in the UK and was not available in languages other than English. The availability of the KSQ in other languages could facilitate international collaboration aiming at measuring, comparing and improving health status in patients with sarcoidosis, which is often severely affected. During translation in Dutch and the patient interviews no major cultural difference was noted and the questionnaire was considered comprehensible and relevant by Dutch patients.

The patient demographics of the current Dutch study population were in line with the original study, though there were slightly more Caucasians in our study and lung function was less severely affected. ${ }^{13}$ Quality of life was worse in females similar to Patel et al. but in contrast did not reach statistical significance. ${ }^{13,25}$

The following domains of health status are covered in the KSQ: General Health Status, Lung, Medication, Skin and Eyes. Construct validity of the organ-specific questionnaires with their corresponding modules is similar to the development paper. ${ }^{13}$ The KSQ Lung module showed a weaker correlation with the MRC. In the original article from Patel et al. the MRC dyspnea scale as well as the St. George Respiratory Questionnaire (SGRQ) was used. They found a Pearson's correlation of -0.58 for the MRC dyspnea scale and -0.85 for the SGRQ. It therefore seems that the MRC dyspnea scale is a less reliable tool to assess construct validity in this population. We did not include the SGRQ, because of the high number of questionnaires patients had to complete for validation and we feared this would lead to 'questionnaire fatigue'. Moreover, the SGRQ is a disease-specific questionnaire developed for chronic obstructive pulmonary disease, with 50 items and no questions about skin or eye involvement.

We found a difference in study population between Patel et al. and ours; our population had less patients with a severe impairment of the lungs, which is shown in the difference in TLCOc\% predicted (63 vs. 81 in our group). ${ }^{13}$ This could also explain the weaker correlation found between the Lung module and FVC\% predicted $(r=0.24)$. To date, this lack of correlation between health status questionnaires and lung function has often been reported in other pulmonary diseases as well. ${ }^{28}$ This underlines the idea that health status questionnaires measure different aspects of disease severity and 
therefore are very important additional outcome measures. When combined with the KSQ GHS module all organ-specific KSQ modules showed a better correlation with the generic questionnaires. This supports the use of organ-specific modules in combination with the GHS module.

Fatigue is a major problem in patients with sarcoidosis with an important impact on health status ${ }^{29}$. This was reflected by a strong correlation between the FAS and GHS. This confirms that the KSQ also captures influence on health status caused by fatigue. ${ }^{13}$ Our results are in line with other studies showing the major effect of fatigue on the wellbeing of patients. ${ }^{29}$

Small fiber neuropathy related symptoms, which are disabling and difficult to control, can also significantly reduce health status. ${ }^{30}$ We chose to include the SFNSL questionnaire to evaluate if the $\mathrm{KSQ}$ also captures this problem as this had not been evaluated before. Strong correlations with the SFNSL were found by combining the KSQ GHS and the organ-specific KSQ modules. This suggests that the KSQ captures the small fiber neuropathy related influences on health status.

In line with Patel et al. findings, weak to moderate correlations were found between the optional Medication module and almost all questionnaires. ${ }^{13}$ Therapy for sarcoidosis, as for instance corticosteroids, often causes burdensome side effects. It is tempting to speculate that these side effects may have affected health status more than the symptoms of sarcoidosis. In both Patel et al. and the present study the Medication module does not contribute much. Longitudinal studies are needed with changes in medication to see if the KSQ captures influences of medication on health status.

According to the study of Patel and colleagues, we found that the KSQ has a good internal consistency. ${ }^{13}$ Reliability was also assessed with Bland-Altman plots showing good repeatability (test-retest) in measurements.

At the time of this study, the Sarcoidosis Health Status Questionnaire (SHQ) was the only alternative sarcoidosis health status questionnaire. ${ }^{31}$ In our view this 29 -item instrument, developed in 2001, has some important limitations. It contains only few organ-specific questions, has not been validated for eye and skin disease and can, therefore, not be tailored to individual clinical phenotypes. Furthermore, the SHQ is mostly longer than the $\mathrm{KSQ}$, because most patients do not have to fill in all the organspecific KSQ modules.

Recently, Judson et al. validated a new patient reported outcome measure, the Sarcoidosis Assessment Tool (SAT). ${ }^{30,32}$ The SAT was constructed in a similar way as the KSQ and also consists of organ-specific modules. With 51 questions it is considerably longer than the KSQ. The SAT was validated in an interventional study giving the advantage that the MCID has been calculated. ${ }^{5}$ However, to our knowledge repeatability has not yet fully been assessed making it difficult to conclude if a 
difference in scores indicates a low repeatability or a true change in health status. It would be valuable to compare the different sarcoidosis questionnaires prospectively.

In sarcoidosis any organ can be involved and it remains unclear if the KSQ will also capture the impact of more rare forms of sarcoidosis on health status. Another limitation of our study is the lack of follow-up after two weeks. Responsiveness of the questionnaire can thereby not be assessed. Further research, through longitudinal studies in larger patient cohorts, is warranted to determine the responsiveness, the influence of rarer disease forms and the value of the Medication module.

In conclusion, the Dutch $\mathrm{KSQ}$ is the first translation of the English $\mathrm{KSQ}$, validated in a Dutch sarcoidosis population. 


\section{References}

1. Valeyre D, Prasse A, Nunes H, Uzunhan Y, Brillet PY, Muller-Quernheim J. Sarcoidosis. Lancet 2014;383:1155-1167.

2. Victorson DE, Cella D, Grund H, Judson MA. A conceptual model of health-related quality of life in sarcoidosis. Qual Life Res 2014;23:89-101.

3. Drent M, Wirnsberger RM, Breteler MH, Kock LM, de Vries J, Wouters EF. Quality of life and depressive symptoms in patients suffering from sarcoidosis. Sarcoidosis Vasc Diffuse Lung Dis 1998;15:59-66.

4. Vorselaars AD, Cremers JP, Grutters JC, Drent M. Cytotoxic agents in sarcoidosis: which one should we choose? Current Opinion in Pulmonary Medicine 2014;20:479-487.

5. Judson MA, Baughman RP, Costabel $U$, et al. Safety and efficacy of ustekinumab or golimumab in patients with chronic sarcoidosis. European Respiratory Journal 2014;44:1296-1307.

6. Belkin A, Swigris JJ. Health-related quality of life in idiopathic pulmonary fibrosis: where are we now? Current Opinion in Pulmonary Medicine 2013;19:474-479.

7. Development of the World Health Organization WHOQOL-BREF quality of life assessment. The WHOQOL Group. Psychol Med 1998;28:551-558.

8. Alilovic M, Peros-Golubicic T, Radosevic-Vidacek B, et al. WHOQOL-bREF questionnaire as a measure of quality of life in sarcoidosis. Coll Antropol 2013;37:701-706.

9. Ware JE, Jr., Sherbourne CD. The MOS 36-item short-form health survey (SF-36). I. Conceptual framework and item selection. Med Care 1992;30:473-483.

10. Bourbonnais JM, Malaisamy S, Dalal BD, Samarakoon PC, Parikh SR, Samavati L. Distance saturation product predicts health-related quality of life among sarcoidosis patients. Health Qual Life Outcomes 2012;10:67.

11. Elfferich MD, De Vries J, Drent M. Type D or 'distressed' personality in sarcoidosis and idiopathic pulmonary fibrosis. Sarcoidosis Vasc Diffuse Lung Dis 2011;28:65-71.

12. Heij L, Niesters M, Swartjes M, et al. Safety and efficacy of ARA 290 in sarcoidosis patients with symptoms of small fiber neuropathy: a randomized, double-blind pilot study. Mol Med 2012;18: 1430-1436.

13. Patel AS, Siegert RJ, Creamer D, et al. The development and validation of the King's Sarcoidosis Questionnaire for the assessment of health status. Thorax 2013;68:57-65.

14. Acquadro C, Conway K, Hareendran A, Aaronson N, European Regulatory I, Quality of Life Assessment G. Literature review of methods to translate health-related quality of life questionnaires for use in multinational clinical trials. Value Health 2008;11:509-521.

15. U.S. Department of Health and Human services Food and Drug Administration. Guidance for Industry Patient-Reported Outcome Measures: Use in Medical Product Development to Support Labeling Claims, December 2009

16. Cohen J. Statistical power analysis for the behavioral sciences. Hillsdale, NJ: Lawrence Erlbaum Associates, 1988;

17. Michielsen HJ, De Vries J, Van Heck GL, Van de Vijver FJ, Sijtsma K. Examination of the Dimensionality of Fatigue: The Construction of the Fatigue Assessment Scale (FAS). Eur J Psychol Assess 2004;20:39-48.

18. Hoitsma E, De Vries J, Drent M. The small fiber neuropathy screening list: Construction and crossvalidation in sarcoidosis. Respir Med 2011;105:95-100.

19. Michielsen HJ, Drent M, Peros-Golubicic T, De Vries J. Fatigue is associated with quality of life in sarcoidosis patients. Chest 2006;130:989-994.

20. Finlay AY, Khan GK. Dermatology Life Quality Index (DLQI)--a simple practical measure for routine clinical use. Clin Exp Dermatol 1994;19:210-216.

21. Mangione CM, Lee PP, Gutierrez PR, et al. Development of the 25-item National Eye Institute Visual Function Questionnaire. Arch Ophthalmol 2001;119:1050-1058.

22. Herdman M, Gudex C, Lloyd A, et al. Development and preliminary testing of the new five-level version of EQ-5D (EQ-5D-5L). Qual Life Res 2011;20:1727-1736.

23. Fletcher KE, French CT, Irwin RS, Corapi KM, Norman GR. A prospective global measure, the Punum Ladder, provides more valid assessments of quality of life than a retrospective transition measure. J Clin Epidemiol 2010;63:1123-1131.

24. Kamper SJ, Maher CG, Mackay G. Global rating of change scales: a review of strengths and weaknesses and considerations for design. J Man Manip Ther 2009;17:163-170. 
25. De Vries J, Van Heck GL, Drent M. Gender differences in sarcoidosis: symptoms, quality of life, and medical consumption. Women and Health 1999;30:99-114.

26. Patel AS, Siegert RJ, Bajwah S, et al. Rasch analysis and impact factor methods both yield valid and comparable measures of health status in interstitial lung disease. Journal of Clinical Epidemiology 2015

27. Sinha A, Bajwah S, Gosker HR, et al. A comparison of two scoring methods for the King's Sarcoidosis Questionnaire. Abstract accepted for the ERS 2015

28. Obaseki DO, Erhabor GE, Awopeju OF, Obaseki JE, Adewole OO. Determinants of health related quality of life in a sample of patients with chronic obstructive pulmonary disease in Nigeria using the St. George's respiratory questionnaire. Afr Health Sci 2013;13:694-702.

29. Drent M, Lower EE, De Vries J. Sarcoidosis-associated fatigue. European Respiratory Journal 2012;40:255-263.

30. Judson MA, Costabel U, Drent M, et al. The WASOG Sarcoidosis Organ Assessment Instrument: An update of a previous clinical tool. Sarcoidosis, Vasculitis, and Diffuse Lung Diseases 2014;31:19-27.

31. Cox CE, Donohue JF, Brown CD, Kataria YP, Judson MA. The Sarcoidosis Health Questionnaire: a new measure of health-related quality of life. Am J Respir Crit Care Med 2003;168:323-329.

32. Judson MA, Mack M, Beaumont JL, Watt R, Barnathan ES, Victorson DE. Validation and important differences for the Sarcoidosis Assessment Tool. A new patient-reported outcome measure. American Journal of Respiratory and Critical Care Medicine 2015;191:786-795. 


\section{Online supplement 1}

\section{Translation procedure}

\begin{tabular}{|l|l|}
\hline \multicolumn{2}{|c|}{ King's sarcoidosis questionnaire (KSQ) } \\
$\qquad \begin{array}{l}\text { Forward translation by a translational agency } \\
\text { and a Dutch native speaker }\end{array}$ \\
\hline
\end{tabular}

Dutch King's sarcoidosis health status questionnaires (D-KSQ's): T1 + T2

Evaluation by pneumonologists

Dutch King's sarcoidosis health status questionnaire (D-KSQ): T12

Backward translation by native speakers

ion and approval KSQ developers

Forward translation

Dutch King's sarcoidosis health status questionnaire (D-KSQ): T13

Patient interviews

- 10 patients (Dutch native speakers)

- Different ages, sexes, stages of severity and level of education

- Evaluate (face to face) T3 with a structured questionnaire

Dutch King's sarcoidosis health status questionnaire (D-KSQ): T4

Discuss results patient interviews with KSQ

developers and experts

T4 (D-KSQ) validated 


\section{Online supplement 2}

Depending on their organs affected patients will be asked to complete specific questionnaires

\begin{tabular}{lccccccc}
\hline Questionnaire & $\mathrm{KSQ}(\mathrm{GHS}+\mathrm{M})$ & $\mathrm{KSQ}(\mathrm{L})$ & $\mathrm{KSQ}(\mathrm{S})$ & $\mathrm{KSQ}(\mathrm{E})$ & $\mathrm{MRC}$ & $\mathrm{DLQI}$ & NEI-VFQ25 \\
\hline Organ(s) affected & $\mathrm{X}$ & $\mathrm{X}$ & & & & & \\
$\quad$ Lung & $\mathrm{X}$ & & $\mathrm{X}$ & & & $\mathrm{X}$ & \\
Skin & $\mathrm{X}$ & & & $\mathrm{X}$ & & & $\mathrm{X}$ \\
Eyes & $\mathrm{X}$ & $\mathrm{X}$ & $\mathrm{X}$ & & $\mathrm{X}$ & $\mathrm{X}$ & \\
Lung, Skin & $\mathrm{X}$ & $\mathrm{X}$ & & $\mathrm{X}$ & $\mathrm{X}$ & & $\mathrm{X}$ \\
Lung, Eyes & $\mathrm{X}$ & & $\mathrm{X}$ & $\mathrm{X}$ & & $\mathrm{X}$ & $\mathrm{X}$ \\
Skin, Eyes & $\mathrm{X}$ & $\mathrm{X}$ & $\mathrm{X}$ & $\mathrm{X}$ & $\mathrm{X}$ & $\mathrm{X}$ & $\mathrm{x}$ \\
Lung, Skin, Eyes & $\mathrm{X}$ & & & & & \\
\hline
\end{tabular}

KSQ, King's Sarcoidosis Questionnaire; GHS, General Health Status; M, Medication; L, Lung; E, Eyes; MRC; Medical Research Council; DLQI, Dermatology Life Quality Index; NEIVFQ-25, National Eye Institute Visual Function Questionnaire-25. 


\section{Online supplement 3}

\section{King's Sarcoïdose Vragenlijst (KSQ)}

Invuldatum:

Het doel van deze vragenlijst is het bepalen van de invloed van sarcoïdose op verschillende aspecten van uw leven. Lees elke vraag zorgvuldig door en omcirkel het antwoord dat het meest op $u$ van toepassing is. Beantwoord ALLE vragen zo eerlijk mogelijk. Deze vragenlijst is vertrouwelijk. Alle vragen hebben betrekking op de manier waarop Sarcoïdose uw gezondheid heeft beïnvloed.

\section{ALGEMENE GEZONDHEIDSTOESTAND}

\begin{tabular}{|c|c|c|c|c|c|c|c|c|}
\hline & In de laatste $\mathbf{2}$ weken ... & $\begin{array}{l}\text { De hele } \\
\text { tijd }\end{array}$ & $\begin{array}{c}\text { Het grootste } \\
\text { deel van de } \\
\text { tijd }\end{array}$ & $\begin{array}{c}\text { Een flink } \\
\text { deel van de } \\
\text { tijd }\end{array}$ & \begin{tabular}{|c|} 
Een deel \\
van de \\
tijd
\end{tabular} & \begin{tabular}{|c|} 
Een klein \\
deel van \\
de tijd
\end{tabular} & $\begin{array}{c}\text { Heel } \\
\text { zelden }\end{array}$ & $\begin{array}{l}\text { Helemaal } \\
\text { niet }\end{array}$ \\
\hline 1 & $\begin{array}{l}\text { Heb ik me gefrustreerd } \\
\text { gevoeld }\end{array}$ & 1 & 2 & 3 & 4 & 5 & 6 & 7 \\
\hline 2 & $\begin{array}{l}\text { Heb ik moeite gehad me te } \\
\text { concentreren }\end{array}$ & 1 & 2 & 3 & 4 & 5 & 6 & 7 \\
\hline 3 & $\begin{array}{l}\text { Heb ik onvoldoende } \\
\text { motivatie gehad }\end{array}$ & 1 & 2 & 3 & 4 & 5 & 6 & 7 \\
\hline 4 & Heb ik me moe gevoeld & 1 & 2 & 3 & 4 & 5 & 6 & 7 \\
\hline 5 & Heb ik me zorgen gemaakt & 1 & 2 & 3 & 4 & 5 & 6 & 7 \\
\hline 6 & $\begin{array}{l}\text { Heb ik last of pijn in mijn } \\
\text { spieren/gewrichten gehad }\end{array}$ & 1 & 2 & 3 & 4 & 5 & 6 & 7 \\
\hline 7 & Heb ik me geschaamd & 1 & 2 & 3 & 4 & 5 & 6 & 7 \\
\hline 8 & $\begin{array}{l}\text { Heb ik me zorgen gemaakt } \\
\text { over mijn gewicht }\end{array}$ & 1 & 2 & 3 & 4 & 5 & 6 & 7 \\
\hline \multirow[t]{2}{*}{9} & $\begin{array}{l}\text { Heb ik me zorgen gemaakt } \\
\text { over mijn sarcoïdose }\end{array}$ & 1 & 2 & 3 & 4 & 5 & 6 & 7 \\
\hline & In de laatste $\mathbf{2}$ weken ... & $\begin{array}{l}\text { Zeer } \\
\text { sterk }\end{array}$ & $\begin{array}{l}\text { Behoorlijk } \\
\text { sterk }\end{array}$ & Matig sterk & Enigszins & Weinig & $\begin{array}{c}\text { Zeer } \\
\text { weinig }\end{array}$ & Niet \\
\hline 10 & $\begin{array}{l}\text { Heeft vermoeidheid mij } \\
\text { gehinderd bij mijn normale } \\
\text { sociale activiteiten, zoals } \\
\text { uitgaan met vrienden of } \\
\text { familie }\end{array}$ & 1 & 2 & 3 & 4 & 5 & 6 & 7 \\
\hline
\end{tabular}

The KSQ is protected by copyright, King's College Hospital, U.K. 


\section{LONG}

\begin{tabular}{|c|c|c|c|c|c|c|c|c|}
\hline & In de laatste $\mathbf{2}$ weken ... & $\begin{array}{l}\text { De hele } \\
\text { tijd }\end{array}$ & $\begin{array}{l}\text { Het grootste } \\
\text { deel van de } \\
\text { tijd }\end{array}$ & $\begin{array}{c}\text { Een flink } \\
\text { deel van } \\
\text { de tijd }\end{array}$ & $\begin{array}{c}\text { Een deel } \\
\text { van de tijd }\end{array}$ & $\begin{array}{c}\text { Een klein } \\
\text { deel van de } \\
\text { tijd }\end{array}$ & $\begin{array}{c}\text { Heel } \\
\text { zelden }\end{array}$ & $\begin{array}{l}\text { Helemaal } \\
\text { niet }\end{array}$ \\
\hline 11 & $\begin{array}{l}\text { Heb ik pijn/ongemak } \\
\text { gehad door het hoesten }\end{array}$ & 1 & 2 & 3 & 4 & 5 & 6 & 7 \\
\hline 12 & $\begin{array}{l}\text { Ben ik buiten adem } \\
\text { geraakt als ik de trap op } \\
\text { klom of een flauwe helling } \\
\text { op liep }\end{array}$ & 1 & 2 & 3 & 4 & 5 & 6 & 7 \\
\hline 13 & $\begin{array}{l}\text { Heb ik diep moeten } \\
\text { ademhalen, ook bekend } \\
\text { als "snakken naar adem" }\end{array}$ & 1 & 2 & 3 & 4 & 5 & 6 & 7 \\
\hline 14 & $\begin{array}{l}\text { Heb ik me benauwd op de } \\
\text { borst gevoeld }\end{array}$ & 1 & 2 & 3 & 4 & 5 & 6 & 7 \\
\hline 15 & $\begin{array}{l}\text { Heb ik perioden van } \\
\text { benauwdheid gehad }\end{array}$ & 1 & 2 & 3 & 4 & 5 & 6 & 7 \\
\hline 16 & $\begin{array}{l}\text { Heb ik last gehad van pijn } \\
\text { op de borst }\end{array}$ & 1 & 2 & 3 & 4 & 5 & 6 & 7 \\
\hline
\end{tabular}

\section{MEDICATIE}

\section{Gebruikt u medicatie voor uw sarcoïdose?}

$\mathrm{JAO}$

NEE O (ga naar het volgende onderdeel)

\begin{tabular}{|c|c|c|c|c|c|c|c|c|}
\hline & In de laatste $\mathbf{2}$ weken ... & $\begin{array}{l}\text { Zeer } \\
\text { sterk }\end{array}$ & $\begin{array}{l}\text { Behoorlijk } \\
\text { sterk }\end{array}$ & $\begin{array}{l}\text { Matig } \\
\text { sterk }\end{array}$ & Enigszins & Weinig & $\begin{array}{l}\text { Zeer } \\
\text { weinig }\end{array}$ & Niet \\
\hline 17 & $\begin{array}{l}\text { Heb ik me zorgen gemaakt } \\
\text { over bijwerkingen van } \\
\text { mijn medicijnen }\end{array}$ & 1 & 2 & 3 & 4 & 5 & 6 & 7 \\
\hline 18 & $\begin{array}{l}\text { Heb ik me slechter } \\
\text { gevoeld door mijn } \\
\text { medicijnen voor } \\
\text { sarcoïdose }\end{array}$ & 1 & 2 & 3 & 4 & 5 & 6 & 7 \\
\hline 19 & $\begin{array}{l}\text { Ben ik aangekomen door } \\
\text { mijn medicijnen voor } \\
\text { sarcoïdose }\end{array}$ & 1 & 2 & 3 & 4 & 5 & 6 & 7 \\
\hline
\end{tabular}

The KSQ is protected by copyright, King's College Hospital, U.K. 


\section{HUID}

\begin{tabular}{|c|c|c|c|c|c|c|c|c|}
\hline \multicolumn{2}{|c|}{ In de laatste $\mathbf{2}$ weken ... } & $\begin{array}{l}\text { Zeer } \\
\text { sterk }\end{array}$ & $\begin{array}{l}\text { Behoorlijk } \\
\text { sterk }\end{array}$ & $\begin{array}{l}\text { Matig } \\
\text { sterk }\end{array}$ & Enigszins & Weinig & $\begin{array}{c}\text { Zeer } \\
\text { weinig }\end{array}$ & Niet \\
\hline 20 & $\begin{array}{l}\text { Heb ik last gehad van mijn } \\
\text { huidproblemen }\end{array}$ & 1 & 2 & 3 & 4 & 5 & 6 & 7 \\
\hline 21 & $\begin{array}{l}\text { Heb ik me zorgen gemaakt } \\
\text { over veranderingen in de } \\
\text { kleur van mijn } \\
\text { huidafwijkingen }\end{array}$ & 1 & 2 & 3 & 4 & 5 & 6 & 7 \\
\hline \multicolumn{2}{|c|}{ In de laatste $\mathbf{2}$ weken ... } & $\begin{array}{l}\text { De hele } \\
\text { tijd }\end{array}$ & $\begin{array}{l}\text { Het grootste } \\
\text { deel van de } \\
\text { tijd }\end{array}$ & $\begin{array}{l}\text { Een flink } \\
\text { deel van } \\
\text { de tijd }\end{array}$ & $\begin{array}{c}\text { Een deel } \\
\text { van de tijd }\end{array}$ & $\begin{array}{l}\text { Een klein } \\
\text { deel van de } \\
\text { tijd }\end{array}$ & $\begin{array}{c}\text { Heel } \\
\text { zelden }\end{array}$ & $\begin{array}{c}\text { Helemaal } \\
\text { niet }\end{array}$ \\
\hline 22 & $\begin{array}{l}\text { Heb ik mij geschaamd } \\
\text { vanwege mijn huid }\end{array}$ & 1 & 2 & 3 & 4 & 5 & 6 & 7 \\
\hline
\end{tabular}

\section{OGEN}

\begin{tabular}{|c|c|c|c|c|c|c|c|c|}
\hline & In de laatste 2 weken ... & $\begin{array}{l}\text { De hele } \\
\text { tijd }\end{array}$ & $\begin{array}{l}\text { Het grootste } \\
\text { deel van de } \\
\text { tijd }\end{array}$ & $\begin{array}{l}\text { Een flink } \\
\text { deel van } \\
\text { de tijd }\end{array}$ & $\begin{array}{c}\text { Een deel } \\
\text { van de tijd }\end{array}$ & $\begin{array}{c}\text { Een klein } \\
\text { deel van de } \\
\text { tijd }\end{array}$ & $\begin{array}{c}\text { Heel } \\
\text { zelden }\end{array}$ & $\begin{array}{c}\text { Helemaal } \\
\text { niet }\end{array}$ \\
\hline 23 & Heb ik droge ogen gehad & 1 & 2 & 3 & 4 & 5 & 6 & 7 \\
\hline 24 & $\begin{array}{l}\text { Heb ik problemen gehad } \\
\text { met } \\
\text { fel licht }\end{array}$ & 1 & 2 & 3 & 4 & 5 & 6 & 7 \\
\hline 25 & $\begin{array}{l}\text { Zijn mijn ogen rood } \\
\text { geweest }\end{array}$ & 1 & 2 & 3 & 4 & 5 & 6 & 7 \\
\hline 26 & $\begin{array}{l}\text { Heb ik pijn in of rond mijn } \\
\text { ogen gehad }\end{array}$ & 1 & 2 & 3 & 4 & 5 & 6 & 7 \\
\hline \multirow[t]{2}{*}{27} & $\begin{array}{l}\text { Heb ik moeite gehad met } \\
\text { lezen }\end{array}$ & 1 & 2 & 3 & 4 & 5 & 6 & 7 \\
\hline & In de laatste 2 weken ... & $\begin{array}{l}\text { Zeer } \\
\text { sterk }\end{array}$ & $\begin{array}{l}\text { Behoorlijk } \\
\text { sterk }\end{array}$ & $\begin{array}{l}\text { Matig } \\
\text { sterk }\end{array}$ & Enigszins & Weinig & $\begin{array}{c}\text { Zeer } \\
\text { weinig }\end{array}$ & Niet \\
\hline 28 & $\begin{array}{l}\text { Heb ik last gehad van } \\
\text { wazig zien }\end{array}$ & 1 & 2 & 3 & 4 & 5 & 6 & 7 \\
\hline 29 & $\begin{array}{l}\text { Heb ik me zorgen gemaakt } \\
\text { over mijn } \\
\text { gezichtsvermogen }\end{array}$ & 1 & 2 & 3 & 4 & 5 & 6 & 7 \\
\hline
\end{tabular}

The KSQ is protected by copyright, King's College Hospital, U.K.

Einde vragenlijst

Zie ook: http://www.gosker.nl/temp/ksq-nl.html voor de digitale versie. 



\section{Chapter 4}

Predictors of fatigue in sarcoidosis:

the value of exercise testing

B Strookappe, J De Vries, M Elfferich, P Kuijpers, T Knevel, M Drent

Respir Med 2016;116:49-54 


\section{Abstract}

\section{Background}

Sarcoidosis patients often are troubled by dyspnea, exercise limitation, and fatigue. Many patients (up to $50-81 \%$ ) suffer from sarcoidosis-associated fatigue. The etiology of fatigue in sarcoidosis is still unclear.

\section{Objective}

The aim of this study was to assess the relationship between fatigue and both exercise capacity and clinical characteristics in sarcoidosis patients. Additionally, we studied the predictive value of exercise test results and other relevant clinical characteristics for the independent variable of fatigue.

\section{Methods}

From November 2012 to September 2014, 201 sarcoidosis outpatients were referred to the Dutch ILD care expertise team, 146 of whom were included in this retrospective cohort study. All patients completed the Fatigue Assessment Scale (FAS). Exercise capacity was assessed by the 6-min walking distance (6MWD) and steep ramp test (SRT) result. Clinical data were gathered from the medical records.

\section{Results}

Exercise capacity only showed a weak correlation with fatigue $(r=0.25, p=0.002$ for $6 \mathrm{MWD} \%$ of predicted; $r=0.24, \mathrm{p}=0.003$ for SRT). Fatigue was not correlated with the demographic variables of age, body mass index, or time since diagnosis. Inflammatory markers, lung function tests, and hand grip strength showed no significant correlations with fatigue. Backward multiple regression analysis showed that only female sex $(t=-2,614, p=0.01)$ and 6MWD \% of predicted $(t=-2.773$, $p=0.006$ ) were independent predictors of fatigue. However, the $r^{2}$ indicated that these two variables together explained only $11 \%$ of the FAS score.

\section{Conclusions}

These results show that exercise capacity partly predicts patients' fatigue scores. Fatigue was not explained by lung function test results, inflammatory markers, or other clinical parameters. 


\section{Introduction}

Sarcoidosis is a systemic granulomatous disease of unknown etiology, characterized by the formation of epithelioid cell granuloma without caseation. Patients often exhibit exertional dyspnea, fatigue, muscle weakness, and reduced exercise tolerance, influencing quality of life (QoL). ${ }^{1-4}$

Pulmonary involvement is frequent (90\%). Pulmonary function tests (at rest) and imaging methods are the most commonly used examinations and diagnostic tests in the follow-up and evaluation of the therapeutic response. ${ }^{5}$

Several authors described the discrepancy between reported symptoms and pulmonary function test abnormalities. ${ }^{6,7}$ Marcellis et al. found that the diffusing capacity for carbon monoxide (DLCO) at rest is an inadequate indicator of pulmonary gas exchange abnormalities during exercise. ${ }^{8}$ Cardiopulmonary exercise testing (CPET), in order to define exercise capacity and aerobic performance, appeared to offer added value in detecting impaired gas exchange during exercise. ${ }^{8}$

Many patients suffer from sarcoidosis-associated fatigue, which is reported by up to $50-81 \%$ of the sarcoidosis patients ${ }^{1,9}$. The multifactorial etiology of fatigue in sarcoidosis is still unclear. Possible related factors are general inflammation, sleeping disorders, depression, and small-fiber neuropathy. ${ }^{2}$ Fatigue does not correlate with pulmonary function test results, but it may be explained by peripheral muscle weakness and exercise intolerance. ${ }^{2-4,10,11}$

In turn, both may be explained by multiple factors, such as sarcoidosis located in the skeletal muscle, decreased pulmonary functions, physical deconditioning, and corticosteroid-induced myopathy. ${ }^{2,12,13}$

Cardiopulmonary exercise testing, submaximal exercise testing, and skeletal muscle function tests are therefore potentially important modalities in the follow-up and evaluation of fatigue in sarcoidosis patients.

In clinical practice, several tests are used to evaluate exercise capacity, e.g. the steep ramp test (SRT) and 6-min walk test (6MWT). The SRT is a highly reliable, accessible, and feasible maximal effort cycle ergometer exercise test for patients with pulmonary disease, and exercise responses (including oxygen consumption, minute ventilation, and oxygen saturation) are highly comparable between CPET and SRT in pulmonary patients. ${ }^{14}$

The 6MWT assesses the submaximal level of functional capacity, and since most activities of daily living are performed at submaximal levels of exertion, the 6-min walking distance (6MWD) may more accurately reflect the exercise level for daily physical activity. ${ }^{15}$ Despite the fact that these tests are very different in nature and assess different aspects of the general construct of exercise capacity, exercise responses show similarities in patients with interstitial lung disease (ILD). A study by Blanco et al. found similar peak oxygen uptake values with both 6MWT and CPET in patients with ILD. ${ }^{16}$ Strong correlations between maximal distance walked on 6MWT and maximal oxygen uptake in CPET have been reported for COPD patients. ${ }^{17}$ 
Discrepancies are often seen between test conclusions for patients performing submaximal exercise tests. A fair number of patients present with 6MWT outcomes $<80 \%$ of predicted and yet achieve normal values on the SRT, and vice versa, suggesting that although both tests reflect exercise capacity, they represent different elements/components and are complementary. For this reason it can be useful to use both maximal and submaximal exercise testing in determining the construct of exercise capacity in patients with ILD.

Since the multifactorial etiology of fatigue in sarcoidosis remains unclear, the aim of this study was to assess the relationship between fatigue and both exercise capacity and clinical characteristics. More specifically, we studied the predictive value of exercise testing (including SRT and 6MWT) and other characteristics (lung function tests, body composition, radiographic stages, inflammatory markers) for the independent variable of fatigue.

\section{Materials and methods}

\section{Study design and subjects}

In this retrospective observational study, muscle strength and exercise capacity assessments were routinely performed as part of the baseline evaluation of outpatients with sarcoidosis referred to the ild care expertise team. Assessment was performed by the Department of Physical Therapy of the Gelderse Vallei Hospital, Ede, Netherlands.

Of the 201 patients evaluated between November 2012 and September 2014, 147 underwent the standard baseline evaluation, while 54 did not, for various reasons (no reason given, no combined appointment possible plus problems of traveling distance, etc.; see Figure 4.1, study flow chart). One patient did not complete the baseline physical evaluation due to inability to cycle because of pre-existent knee complaints. Finally, 146 patients were included in this retrospective observational study. None of the patients used supplemental oxygen during any of the tests.

The diagnosis of sarcoidosis was established, in accordance with accepted guidelines, by the multidisciplinary ild care expertise team. ${ }^{18}$ Clinical data were obtained from the medical records. 


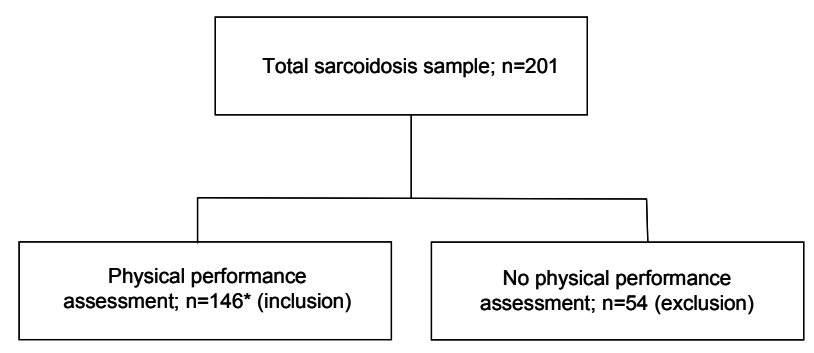

Figure 4.1 Flowchart of the study. During the study period, data of 201 outpatients suffering from sarcoidosis were collected. At baseline, the majority of these patients ( $n=146$; * one excluded due to incomplete physical performance assessment) completed a physical assessment and surveys at the Department of Physical Therapy.

\section{Measures}

\section{Body composition}

Height (in $\mathrm{cm}$ ), weight (in $\mathrm{kg}$ ), and body mass index (BMI) were measured and calculated as reported previously. ${ }^{19}$

\section{Lung function tests}

Forced vital capacity (FVC) and forced expiratory volume in one second (FEV 1 ) were measured with a pneumotachograph (Masterlab, Jaeger, Würzburg, Germany). The diffusing capacity of the lung for carbon monoxide (DLCO) was measured using the single-breath method (Masterlab, Jaeger, Würzburg, Germany). Values were expressed as percentage of the predicted value (i.e., FVC \%, FEV 1 \%, and DLCO \%, respectively).

\section{Exercise capacity}

Maximal oxygen uptake was determined during a cardiopulmonary exercise test using the Steep Ramp Test (SRT) protocol on a cycle ergometer. ${ }^{20}$ After a two-minute unloaded warm-up, the intensity was increased by $25 \mathrm{~W}$ every 10 seconds, with the subject pedaling at a rate of $70-80 \mathrm{rpm}$. The test was terminated when the subject indicated they could no longer continue or if the revolutions per minute fell below 60 . Intermittent standardized encouragement was given to the subject throughout the test. Outcome of the SRT was used to determine estimated $\mathrm{VO}_{2}$ max value according to DeBacker and coworkers. ${ }^{21}$ Reference values determined by Shvartz et al. were used to classify the values obtained. This classification contains the following categories: 'excellent', 'very good', 'good', 'average', 'fair', 'poor', and 'very poor'. Maximal oxygen uptake was defined as reduced when values were classified as 'very poor' or 'poor' in the Shvartz classification. ${ }^{22}$ 
The six-minute walk test (6MWT) was administered according to the American Thoracic Society Guidelines. ${ }^{15}$ The 6MWT is a submaximal exercise test determining the level of functional capacity. The physiologic demand in a walking test appears to be different from that in cycle ergometer tests and may be a better indicator of functioning in normal daily activities. ${ }^{15,23}$ Predicted 6MWD values were calculated using the equation proposed by Gibson and colleagues. ${ }^{24}$ Physical test results (6MWD) below $80 \%$ of the predicted value were assumed to indicate physical impairment. ${ }^{25}$

\section{Muscle strength}

The maximal isometric grip strength of the dominant hand (HGS) was measured with the Jamar dynamometer (Fabrication Enterprises Inc., Irvington, NY, USA) and expressed in kilograms $(\mathrm{kg}){ }^{26}$ Percentage of predicted was calculated using normative data established by Mathiowetz and colleagues. ${ }^{27}$ Biceps brachii strength (elbow flexor muscle strength, EFMS) was assessed during elbow flexion with the microFET (Biometrics, Almere, The Netherlands), an electronic hand-held dynamometer. The 'break' method was used to measure the peak force of the dominant arm in Newton (N). The highest value of at least two measurements was recorded. ${ }^{28}$

Quadriceps performance was assessed by the Chair Rise Time (CRT), which measures the time taken to rise from a chair 10 times with arms folded across the chest. $^{29}$

\section{Questionnaires}

Fatigue was measured with the 10-item Fatigue Assessment Scale (FAS). Each item uses a 5-point rating scale, so the total score range is 10 to 50 . Scores below 22 indicate no fatigue; scores of 22-34 indicate mild-moderate fatigue; and scores of 35 or more indicate severe fatigue. The FAS has acceptable psychometric properties in sarcoidosis. ${ }^{30}$ The minimal clinically important difference in sarcoidosis is 4 points or a $10 \%$ change. $^{31}$

\section{Statistical analysis}

Demographic and clinical data are expressed as mean \pm SD and, where appropriate, in absolute numbers or percentages. The normal distribution of the variables was evaluated with the Kolmogorov-Smirnov analysis.

Patients were subdivided into four groups according to their performance on the exercise tests ( $6 \mathrm{WMT}$ and SRT): group I (6MWD $\geq 80 \%$ of predicted and SRT $\geq$ fair), group II (6MWD $<80 \%$ of predicted and SRT $\geq$ fair), group III (6MWD $\geq 80 \%$ of predicted and SRT 'very poor' / 'poor') and group IV (6MWD < 80\% of predicted and SRT 'very poor' / 'poor').

Statistically significant differences between these groups with regard to demographic, clinical, fatigue, and physical characteristics were investigated by 
analyzing continuous data with one-way ANOVA and examining nominal data using $\chi^{2}$ tests.

Bivariate associations between fatigue and continuous demographic and physical characteristics were calculated using Pearson's correlations, while Spearman's rho was used for ordinal variables.

Variables with significant bivariate association with FAS were included as predictors in the multiple regression analysis. A backward multiple regression analysis was used to develop a model to predict fatigue. A $p<0.05$ was considered statistically significant. Analyses were performed using SPSS 22.0 for Windows (SPSS Inc., Chicago, IL, USA)

\section{Results}

\section{Patient characteristics}

The study included 146 sarcoidosis patients (mean age $47.1 \pm 11.2$ years). The demographic and clinical data, subdivided into the four subgroups according to exercise capacity, are displayed in Table 4.1. The prevalence of reduced exercise capacity was high, with $75 \%$ of the patients showing a reduced 6 MWD (12\%), a reduced SRT VO2max $(13 \%)$, or both (49\%).

In our sarcoidosis patient sample, $62 \%$ of the patients had their $\mathrm{VO}_{2}$ classified as 'very poor' to 'poor', $19 \%$ as 'fair' and $12 \%$ as 'average'. The proportion classified as 'good', 'very good' or 'excellent' was 7\%. Patients with a reduced exercise capacity on both SRT and 6MWT had reduced lung function (FVC) compared with patients with normal exercise capacity. BMI differed between groups I and II, I and IV, and II and IV.

\section{Physical performance}

Muscle strength (expressed as HGS, EFMS, and CRT) was lower in patients with reduced exercise capacity (both SRT and 6MWD) compared with patients with normal exercise capacity (see Table 4.1). Exercise capacity showed low to moderate correlations with muscle strength. Correlation of 6MWD with lower limb muscle strength (CRT) was higher $(r=0.48, p<0.001)$ compared to upper limb strength $(r=0.27, p=0.003)$. Correlation between exercise capacity determined with SRT and lower limb muscle strength (CRT) was also higher $(r=0.56, p<0.001)$ compared to upper limb strength $(r=0.40, p<0.001)$. 
Table 4.1 Demographic and clinical characteristics of the sarcoidosis sample $(n=146)$ studied, subdivided according to performance on exercise test (Steep Ramp Test and 6 minute walk test)

\begin{tabular}{|c|c|c|c|c|c|c|}
\hline & $\begin{array}{c}\text { Group I } \\
++\end{array}$ & $\begin{array}{c}\text { Group II } \\
+-\end{array}$ & $\begin{array}{c}\text { Group III } \\
-+ \\
\end{array}$ & $\begin{array}{c}\text { Group IV } \\
--\end{array}$ & $\begin{array}{c}\text { Group V } \\
\text { (exclusion) }\end{array}$ & Total sample \\
\hline \multicolumn{7}{|l|}{ Demographics } \\
\hline Subjects (n) & 37 & 18 & 19 & 72 & 54 & 146 \\
\hline women, \% & 48.6 & 22.2 & 47.4 & 36.1 & 42.6 & 39.0 \\
\hline age, yrs & $47.7 \pm 9.8$ & $43.1 \pm 9.1$ & $47.4 \pm 13.8$ & $47.4 \pm 11.6$ & $48.9 \pm 11.3$ & $47.1 \pm 11.2$ \\
\hline $\begin{array}{l}\text { time since } \\
\text { diagnosis, yrs }\end{array}$ & $6.0 \pm 6.5$ & $3.6 \pm 4.7$ & $7.7 \pm 9.5$ & $5.9 \pm 6.9$ & $4.7 \pm 6.5$ & $5.9 \pm 7.0$ \\
\hline $\mathrm{BMI}, \mathrm{kg} / \mathrm{m}^{2 \mathrm{a}, \mathrm{c}, \mathrm{e}}$ & $24.3 \pm 2.7$ & $27.8 \pm 4.8$ & $24.4 \pm 4.6$ & $28.8 \pm 4.5$ & $27.0 \pm 5.8$ & $27.0 \pm 4.6$ \\
\hline \multicolumn{7}{|l|}{ Treatment } \\
\hline no treatment, \% & 43.2 & 24.2 & 36.8 & 30.6 & 31.5 & 32.3 \\
\hline glucocorticoids, \% & 32.4 & 38.9 & 26.3 & 40.3 & 42.6 & 38.3 \\
\hline other, \% & 14.4 & 36.9 & 36.3 & 29.1 & 25.9 & 29.4 \\
\hline \multicolumn{7}{|l|}{ Lung function tests } \\
\hline DLCO, \% pred. & $83.6 \pm 15.0$ & $78.9 \pm 17.0$ & $80.3 \pm 21.9$ & $76.9 \pm 18.6$ & $76.8 \pm 17.4$ & $79.3 \pm 18.0$ \\
\hline FEV1, \% pred. & $91.7 \pm 18.8$ & $89.7 \pm 13.7$ & $92.2 \pm 19.1$ & $83.8 \pm 21.1$ & $91.5 \pm 19.5$ & $87.6 \pm 19.7$ \\
\hline FVC, \% pred. ${ }^{c}$ & $103.6 \pm 16.1$ & $94.9 \pm 15.2$ & $94.8 \pm 18.6$ & $90.0 \pm 19.3$ & $98.3 \pm 17.4$ & $94.7 \pm 18.7$ \\
\hline \multicolumn{7}{|c|}{ Chest radiographs stages } \\
\hline O/I/II/III/IV, n & $3 / 7 / 23 / 1 / 2$ & $0 / 5 / 8 / 3 / 2$ & $3 / 6 / 7 / 0 / 3$ & $7 / 18 / 29 / 4 / 14$ & $6 / 18 / 24 / 4 / 2$ & $13 / 36 / 67 / 8 / 21$ \\
\hline \multicolumn{7}{|c|}{ Inflammatory markers } \\
\hline CRP (mg/L) & $6.0 \pm 12.4$ & $3.7 \pm 2.4$ & $2.7 \pm 1.6$ & $5.8 \pm 7.1$ & $11.6 \pm 9.4$ & $5.3 \pm 8.1$ \\
\hline sIL-2R (U/ml) & $4754 \pm 1775$ & $6048 \pm 3781$ & $3522 \pm 991$ & $6413 \pm 9279$ & $5894 \pm 3688$ & $5597 \pm 6821$ \\
\hline \multicolumn{7}{|l|}{ Fatigue measure } \\
\hline $\mathrm{FAS}^{\mathrm{C}}$ & $26.5 \pm 8.5$ & $29.4 \pm 9.4$ & $30.5 \pm 10.6$ & $32.2 .2 \pm 8.2$ & $29.0 \pm 7.8$ & $30.2 \pm 9.0$ \\
\hline FAS physical ${ }^{c}$ & $14.8 \pm 4.9$ & $16.0 \pm 5.2$ & $17.2 \pm 5.5$ & $17.9 \pm 4.3$ & $16.4 \pm 4.3$ & $16.7 \pm 4.9$ \\
\hline FAS mental $^{c}$ & $11.7 \pm 4.7$ & $13.4 \pm 4.4$ & $13.0 \pm 5.4$ & $14.5 \pm 4.6$ & $13.0 \pm 4.2$ & $13.5 \pm 4.7$ \\
\hline \multicolumn{7}{|c|}{ Physical performance } \\
\hline 6MWD, $\mathrm{m}^{\mathrm{b}, \mathrm{c}, \mathrm{d}, \mathrm{e}}$ & $632 \pm 68$ & $624 \pm 46$ & $492 \pm 81$ & $477 \pm 82$ & na & $536 \pm 104$ \\
\hline $\begin{array}{l}\text { 6MWD, } \\
\% \text { pred. }^{\text {b,c,d,e }}\end{array}$ & $91.5 \pm 7.4$ & $86.3 \pm 3.3$ & $71.3 \pm 9.8$ & $67.9 \pm 10.0$ & na & $76.6 \pm 13.6$ \\
\hline $\begin{array}{l}\text { SRT (VO2max } \\
\text { ml.kg.min) }{ }^{a, c, f}\end{array}$ & $32.8 \pm 5.3$ & $26.3 \pm 3.2$ & $29.8 \pm 4.5$ & $23.0 \pm 4.9$ & na & $26.8 \pm 6.3$ \\
\hline HGS, \% pred. & $96.8 \pm 17.4$ & $96.7 \pm 14.2$ & $81.0 \pm 30.6$ & $89.7 \pm 23.5$ & na & $91.1 \pm 22.7$ \\
\hline EFMS, \% pred. ${ }^{c, f}$ & $107.6 \pm 20.6$ & $103.2 \pm 16.4$ & $109.7 \pm 15.1$ & $93.2 \pm 20.4$ & na & $100.5 \pm 20.4$ \\
\hline CRT, female $(s)^{c}$ & $21.0 \pm 3.9$ & $24.3 \pm 7.9$ & $23.7 \pm 5.3$ & $27.0 \pm 7.5$ & na & $24.4 \pm 6.6$ \\
\hline CRT, male $(s)^{c}$ & $16.3 \pm 5.1$ & $19.9 \pm 4.3$ & $22.8 \pm 5.9$ & $22.7 \pm 6.6$ & na & $21.0 \pm 6.4$ \\
\hline
\end{tabular}

Data are expressed as mean \pm SD, absolute numbers or percentages. BMI: body mass index; DLCO: diffusing capacity of the lung for carbon monoxide; \% pred: percentage of predicted value; FVC: forced vital capacity; $\mathrm{FEV}_{1}$ : forced expiratory volume in one second; CRP: C-reactive protein; sIL-2R: soluble interleukin-2 receptor; FAS: Fatigue Assessment Scale; 6MWD: 6 min walking distance; SRT: Steep Ramp Test; HGS: maximal isometric grip strength of dominant hand; EFMS: elbow flexor muscle strength; CRT: Chair Rise Time. ++ both 6MWD and SRT normal, +- normal 6MWD, SRT reduced, -+ reduced 6MWD, SRT normal, -- reduced 6MWD, reduced SRT. P<0.05: a ++ vs +-; b ++ vs -+; c ++ vs --; d +- vs -+; e +- vs --; f -+ vs --

\section{Relationship between fatigue and clinical parameters}

The fatigue score was not correlated with the demographic variables of age, BMI, and time since diagnosis. Clinical data including inflammatory markers, lung function tests, and hand grip strength (HGS) did not show significant correlations with fatigue either. 
The FAS showed a weak bivariate correlation with 6MWD (both in absolute values and percentage of predicted), SRT (both $\mathrm{Wmax}$ and $\mathrm{VO}_{2} \mathrm{max}$ ), EFMS \% of predicted, and CRT (see Table 4.2). Women presented with significantly higher FAS scores than men (33.1 \pm 7.5 vs $28.3 \pm 9.4, p=0.002$ ). The proportion of fatigued patients (FAS $\geq 22$ ) was $93 \%$ in women and $67 \%$ in men in the total population. Correlations between 6MWD and $6 \mathrm{MWD} \%$ of predicted and SRT Rmax and SRT $\mathrm{VO}_{2}$ max were $>0.80$, so the variables $6 \mathrm{MWD} \%$ of predicted and $\mathrm{SRT} \mathrm{VO}_{2}$ max were used in the multiple regression analysis. Age, weight, and sex are taken into account in these variables.

Table 4.2 Correlations with the fatigue assessment scale (FAS).

\begin{tabular}{|c|c|c|}
\hline Variables & Correlations & P-value \\
\hline $\operatorname{Sex}^{b}$ & -0.24 & $p=0.004$ \\
\hline 6MWD, \% pred. ${ }^{a}$ & -0.25 & $p=0.002$ \\
\hline $6 \mathrm{MWD}$, meters ${ }^{\mathrm{a}}$ & -0.27 & $p=0.001$ \\
\hline $\mathrm{SRT} \mathrm{VO}_{2} \max (\mathrm{ml} \cdot \mathrm{kg} \cdot \mathrm{min})^{\mathrm{a}}$ & -0.24 & $p=0.003$ \\
\hline SRT Rmax ${ }^{a}$ & -0.27 & $p=0.001$ \\
\hline EFMS, \% pred. ${ }^{a}$ & -0.23 & $p=0.011$ \\
\hline $\mathrm{CRT}^{\mathrm{a}}$ & -0.21 & $p=0.022$ \\
\hline
\end{tabular}

${ }^{a}$ Pearson's correlation coefficient; ${ }^{b}$ Spearman's rho. 6MWD: 6 min walking distance; SRT: Steep Ramp Test; EFMS: elbow flexor muscle strength; CRT: Chair Rise Time.

Multiple regression analysis showed that female sex $(t=-2,614, p=0.01)$ and 6MWD $\%$ of predicted $(t=-2.773, p=0.006)$ were significant independent predictors of FAS. However, the resulting $r^{2}$ indicated that these two variables explained only $11 \%$ of the FAS score.

These two variables were also found to be independent predictors of the physical component of the FAS. Only the SRT VO2 max appeared to be an independent predictor of the mental component of the FAS (see Table 3).

Table 4.3 Multiple regression analysis: relationship between the Fatigue Assessment Scale (FAS, FAS physical component and FAS mental component) and clinical variables.

\begin{tabular}{|c|c|c|c|c|c|}
\hline \multirow[t]{2}{*}{ Outcome variable } & \multirow[t]{2}{*}{ Independent variables } & \multicolumn{2}{|c|}{ Unstandardized coefficient } & \multirow{2}{*}{$\frac{\text { Standardized coefficients }}{\text { Beta }}$} & \multirow[t]{2}{*}{ P-value } \\
\hline & & $\mathrm{B}$ & Std error & & \\
\hline \multirow[t]{2}{*}{ FAS total } & $\operatorname{sex}$ & -4.015 & 1.536 & -0.223 & $p=0.01$ \\
\hline & 6MWD, \% pred. & -0.152 & 0.055 & -0.246 & $p=0.006$ \\
\hline \multirow[t]{2}{*}{ FAS physical } & $\operatorname{sex}$ & -2.370 & 0.813 & -0.245 & $p=0.004$ \\
\hline & 6MWD, \% pred. & -0.089 & 0.029 & -0.258 & $p=0.003$ \\
\hline FAS mental & $\mathrm{SRT}, \mathrm{VO}_{2} \max$ & -0.182 & 0.063 & -0.251 & $p=0.005$ \\
\hline
\end{tabular}

6MWD: 6 min walking distance; SRT: Steep Ramp Test. 


\section{Discussion}

The aim of this study was to assess the relationship between fatigue and both exercise capacity and clinical characteristics in patients with sarcoidosis. In our cohort, the prevalence of fatigue (FAS $\geq 22$ ) was high (77\%), as was reduced exercise capacity (75\%). Exercise capacity only showed a weak correlation with fatigue. In line with other studies, we found that the level of fatigue was not explained by lung function test results, nor inflammatory markers or other clinical parameters. ${ }^{1,11}$ Female sex and $6 \mathrm{MWD} \%$ of predicted only predicted $11 \%$ of the FAS score.

Women presented with significantly higher FAS scores than men, and more women were fatigued. It has been shown that fatigue is more likely to be present and more severe in patients with extrapulmonary symptoms ${ }^{32}$ and female sarcoidosis patients report more frequent extrapulmonary complaints and musculoskeletal involvement. ${ }^{33}$ This may at least partly explain the differences between male and female patients. There were no differences between the men and women in terms of lung function test results, inflammatory markers, BMI, or chest radiography stages.

Our results support the view that fatigue in sarcoidosis is an entity which is affected by many different variables, since exercise capacity explains only a small proportion of the variance of the reported fatigue. Spruit et al. suggested that fatigue may be explained by muscle weakness and exercise intolerance, due to sarcoidosis located in the skeletal muscle, decreased pulmonary functions, and the negative vicious circle of deconditioning and corticosteroid-induced myopathy. ${ }^{12}$ In a retrospective study, Cremers et al. found muscle involvement in only $12 \%$ of the PET (positron emission tomography) positive cases $(n=118) .{ }^{34}$ This number is probably underestimated, as it only gives information about PET-positive cases. In line with others, our present study found that there is no relationship between fatigue and pulmonary functions. ${ }^{35}$ Although it is highly likely that a negative vicious circle of deconditioning also influences the relation, no studies investigating this have been done.

Fleischer et al. $^{36}$ found associations between medication (prednisolone, methotrexate, and azathioprine) and fatigue, but patients who never used corticosteroids also suffer from fatigue. ${ }^{35,37}$

Few studies on sarcoidosis have reported that perceived fatigue can be decreased by following a physical training program to improve exercise capacity and muscle functions (strength and endurance). ${ }^{3,38-40}$ Some patients may present with impaired exercise capacity, impaired muscle function or both, and a tailored training intervention may then result in a better outcome. Hence, the use of exercise testing and muscle function analysis is important when prescribing, monitoring, and evaluating a physical training program.

The importance of exercise testing in sarcoidosis was highlighted by Marcellis et al.. ${ }^{8}$ The 6MWT has also proven its value in the evaluation of exercise capacity in sarcoidosis. ${ }^{41} \mathrm{~A}$ recent study found that CPET appeared to offer added value in detecting impaired gas exchange during exercise. ${ }^{8}$ Moreover, Lopes et al. found that 
CPET can be helpful in predicting decline in pulmonary functions. ${ }^{42}$ However, CPET requires extensive equipment, is time-consuming and not available in every clinical setting. ${ }^{8}$ The Steep Ramp Test (SRT) is a cardiopulmonary maximal effort test which assesses maximal oxygen uptake. It is a highly reliable, accessible, and feasible instrument for patients with pulmonary disease. ${ }^{14,43}$

In our study we found discrepancies between test conclusions in $25 \%$ of the cases of patients performing (sub)maximal exercise tests (6MWT vs SRT). These outcomes suggest that these two tests represent different elements of exercise capacity, and are complementary. Mainguy and colleagues state that despite a similar physiological demand in terms of $\mathrm{VO}_{2}$ peak, the modality of the exercise test (cycling vs walking) was mainly responsible for the differences in respiratory exchange ratio, locus of symptom limitation, and leg muscle fatigability. ${ }^{44}$

When CPET is not available, the SRT can be a useful alternative, in view of its similar exercise responses. ${ }^{14}$ The SRT can be regularly repeated during the training program, providing the information needed to adjust the training dosage or evaluate the exercise response. ${ }^{21}$ Additionally, the SRT accurately reflects leg muscle capabilities during exercise, whereas CPET may underestimate muscle power due to the attainment of ventilatory limitations. ${ }^{14,43}$ In our present study, correlations between SRT and leg muscle power (CRT) were moderate (data not shown).

Peripheral/skeletal muscle strength is often reduced in sarcoidosis. Patients with impaired muscle strength are more likely to present with lower QoL, lung function test results, and 6MWD. ${ }^{1,12}$ Assessing skeletal muscle function in sarcoidosis is recommended for patients with impaired exercise capacity. It is therefore important to determine the potential influence of muscle function on exercise capacity in each individual patient with impaired exercise capacity. Upper limb strength is often measured as hand grip strength or elbow flexor muscle strength. One option to determine lower limb muscle strength is hand-held dynamometry. However, despite the reduced muscle strength of patients with sarcoidosis, the value of hand-held dynamometry in assessing lower limb muscle strength often appears to be limited, as the patient's strength, especially that of younger male patients, exceeds that of the assessor. ${ }^{45,46}$ The CRT therefore appears to be a valuable alternative. There are strong correlations between several variations of sit-to-stand tests (including CRT) and lower limb muscle strength in pulmonary restricted patients, as shown by our results in this study. ${ }^{47}$

This study has several limitations. Although the choice of tests was carefully considered, ${ }^{23,41}$ other tests might have been useful as well. The voluntary nature of the submaximal exercise tests used in this study may influence the test results, as motivation and will power are important factors, so nonvolitional testing would probably yield more valid results. But in our opinion, as was also stated by Marcellis et al., sarcoidosis patients present with great motivation to participate. ${ }^{1}$ The tests used in our study are generally accepted and have been used in various patient populations, including sarcoidosis patients. ${ }^{12,41}$ Our study population included 146 analyzed patients. 
Groups were created according to the patients' performance on the exercise tests (6MWD and SRT), resulting in groups with rather small numbers, which potentially limits the generalization of the results of our study.

\section{Conclusion}

While it is well known that sarcoidosis-related fatigue is multi-factorial in nature, our study failed to discover any meaningful associations based on the available data for this patient sample. While very small relationships were observed between fatigue and exercise capacity, female sex, and a 6-minute walk test, caution should be used when interpreting these findings given the different limitations described above. Further research to clarify the phenomenon of fatigue in sarcoidosis is important, in order to enhance both medical and paramedical fatigue reduction strategies. 


\section{References}

1. Marcellis RG, Lenssen AF, Elfferich $M D$, et al. Exercise capacity, muscle strength and fatigue in sarcoidosis. Eur Respir J 2011;38:628-634.

2. Drent M, Strookappe B, Hoitsma E, De Vries J. Consequences of Sarcoidosis. Clin Chest Med 2015;36:727-737.

3. Karadalli MN, Bosnak-Guclu M, Camcioglu B, Kokturk N, Turktas H. Effects of Inspiratory Muscle Training in Subjects With Sarcoidosis: A Randomized Controlled Clinical Trial. Respir Care 2016;61: 483-494.

4. Panagiotou M, Polychronopoulos V, Strange C. Respiratory and lower limb muscle function in interstitial lung disease. Chron Respir Dis 2016:doi 10.1177/1479972315626014.

5. Gafa G, Sverzellati N, Bonati E, et al. Follow-up in pulmonary sarcoidosis: comparison between HRCT and pulmonary function tests. Radiol Med 2012;117:968-978.

6. Delobbe A, Perrault H, Maitre J, et al. Impaired exercise response in sarcoid patients with normal pulmonary function. Sarcoidosis Vasc Diffuse Lung Dis 2002;19:148-153.

7. Kollert F, Geck B, Suchy R, et al. The impact of gas exchange measurement during exercise in pulmonary sarcoidosis. Respir Med 2011;105:122-129.

8. Marcellis RG, Lenssen AF, de Vries GJ, et al. Is there an added value of cardiopulmonary exercise testing in sarcoidosis patients? Lung 2013;191:43-52.

9. Drent M, Lower EE, De Vries J. Sarcoidosis-associated fatigue. Eur Respir J 2012;40:255-263.

10. Drent M, Wirnsberger RM, De Vries J, van Dieijen-Visser MP, Wouters EF, Schols AM. Association of fatigue with an acute phase response in sarcoidosis. Eur Respir J 1999;13:718-722.

11. De Vries J, Rothkrantz-Kos S, van Dieijen-Visser MP, Drent M. The relationship between fatigue and clinical parameters in pulmonary sarcoidosis. Sarcoidosis Vasc Diffuse Lung Dis 2004;21:127-136.

12. Spruit MA, Thomeer MJ, Gosselink R, et al. Skeletal muscle weakness in patients with sarcoidosis and its relationship with exercise intolerance and reduced health status. Thorax 2005;60:32-38.

13. Wilsher ML. Psychological stress in sarcoidosis. Curr Opin Pulm Med 2012;18:524-527.

14. Chura RL, Marciniuk DD, Clemens R, Butcher SJ. Test-Retest Reliability and Physiological Responses Associated with the Steep Ramp Anaerobic Test in Patients with COPD. Pulm Med 2012;2012:653831.

15. ATS statement: guidelines for the six-minute walk test. Am J Respir Crit Care Med 2002;166:111-117.

16. Blanco I, Villaquiran C, Valera JL, et al. [Peak oxygen uptake during the six-minute walk test in diffuse interstitial lung disease and pulmonary hypertension]. Arch Bronconeumol 2010;46:122-128.

17. Chuang ML, Lin IF, Wasserman K. The body weight-walking distance product as related to lung function, anaerobic threshold and peak VO2 in COPD patients. Respir Med 2001;95:618-626.

18. Statement on sarcoidosis. Joint Statement of the American Thoracic Society (ATS), the European Respiratory Society (ERS) and the World Association of Sarcoidosis and Other Granulomatous Disorders (WASOG) adopted by the ATS Board of Directors and by the ERS Executive Committee, February 1999. Am J Respir Crit Care Med 1999;160:736-755.

19. Cremers JP, Drent M, Elfferich MD, et al. Body composition profiling in a Dutch sarcoidosis population. Sarcoidosis Vasc Diffuse Lung Dis 2013;30:289-299.

20. Meyer K, Samek L, Schwaibold M, et al. Physical responses to different modes of interval exercise in patients with chronic heart failure--application to exercise training. Eur Heart J 1996;17:1040-1047.

21. De Backer IC, Schep G, Hoogeveen A, Vreugdenhil G, Kester AD, van Breda E. Exercise testing and training in a cancer rehabilitation program: the advantage of the steep ramp test. Arch Phys Med Rehabil 2007;88:610-616.

22. Shvartz E, Reibold RC. Aerobic fitness norms for males and females aged 6 to 75 years: a review. Aviation, space, and environmental medicine 1990;61:3-11.

23. Noonan V, Dean E. Submaximal exercise testing: clinical application and interpretation. Phys Ther 2000;80:782-807.

24. Gibbons WJ, Fruchter N, Sloan S, Levy RD. Reference values for a multiple repetition 6-minute walk test in healthy adults older than 20 years. J Cardiopulm Rehabil 2001;21:87-93.

25. Troosters T, Gosselink R, Decramer M. Six minute walking distance in healthy elderly subjects. Eur Respir J 1999;14:270-274.

26. Werle S, Goldhahn J, Drerup S, Simmen BR, Sprott H, Herren DB. Age- and gender-specific normative data of grip and pinch strength in a healthy adult Swiss population. J Hand Surg Eur Vol 2009;34:76-84. 
27. Mathiowetz V, Wiemer DM, Federman SM. Grip and pinch strength: norms for 6- to 19-year-olds. Am J Occup Ther 1986;40:705-711.

28. Bohannon RW. Make tests and break tests of elbow flexor muscle strength. Phys Ther 1988;68: 193-194.

29. Csuka M, McCarty DJ. Simple method for measurement of lower extremity muscle strength. Am J Med 1985;78:77-81.

30. Michielsen HJ, Drent M, Peros-Golubicic T, De Vries J. Fatigue is associated with quality of life in sarcoidosis patients. Chest 2006;130:989-994.

31. De Kleijn WP, De Vries J, Wijnen PA, Drent M. Minimal (clinically) important differences for the Fatigue Assessment Scale in sarcoidosis. Respir Med 2011;105:1388-1395.

32. Gvozdenovic BS, Mihailovic-Vucinic V, Ilic-Dudvarski A, Zugic V, Judson MA. Differences in symptom severity and health status impairment between patients with pulmonary and pulmonary plus extrapulmonary sarcoidosis. Respir Med 2008;102:1636-1642.

33. Lill H, Kliiman K, Altraja A. Factors signifying gender differences in clinical presentation of sarcoidosis among Estonian population. Clin Resp J 2016;10:282-90.

34. Cremers JP, Van Kroonenburgh MJ, Mostard RL, et al. Extent of disease activity assessed by 18F-FDG $\mathrm{PET} / \mathrm{CT}$ in a Dutch sarcoidosis population. Sarcoidosis Vasc Diffuse Lung Dis 2014;31:37-45.

35. Marcellis RG, Lenssen AF, Kleynen S, De Vries J, Drent M. Exercise capacity, muscle strength, and fatigue in sarcoidosis: a follow-up study. Lung 2013;191:247-256.

36. Fleischer M, Hinz A, Brahler E, Wirtz H, Bosse-Henck A. Factors associated with fatigue in sarcoidosis. Respir Care 2014;59:1086-1094.

37. Elfferich MD, Nelemans PJ, Ponds RW, De Vries J, Wijnen PA, Drent M. Everyday cognitive failure in sarcoidosis: the prevalence and the effect of anti-TNF-alpha treatment. Respiration 2010;80:212-219.

38. Strookappe B, Elfferich M, Swigris J, et al. Benefits of physical training in patients with idiopathic or endstage sarcoidosis-related pulmonary fibrosis: a pilot study. Sarcoidosis Vasc Diffuse Lung Dis 2015;32:43-52.

39. Strookappe B, Swigris J, De Vries J, Elfferich M, Knevel T, Drent M. Benefits of Physical Training in Sarcoidosis. Lung 2015

40. Marcellis RG, Veeke MAF, Mesters I, et al. Does physical training reduce fatigue in sarcoidosis? Sarcoidosis Vasc Diffuse Lung Dis 2015;32:53-62.

41. Baughman RP, Lower EE. Six-minute walk test in managing and monitoring sarcoidosis patients. Curr Opin Pulm Med 2007;13:439-444.

42. Lopes AJ, Menezes SL, Dias CM, Oliveira JF, Mainenti MR, Guimaraes FS. Cardiopulmonary exercise testing variables as predictors of long-term outcome in thoracic sarcoidosis. Braz J Med Biol Res 2012;45:256-263.

43. Rozenberg R, Bussmann JB, Lesaffre E, Stam HJ, Praet SF. A steep ramp test is valid for estimating maximal power and oxygen uptake during a standard ramp test in type 2 diabetes. Scand J Med Sci Sports 2015;25:595-602.

44. Mainguy V, Malenfant S, Neyron AS, et al. Alternatives to the six-minute walk test in pulmonary arterial hypertension. PloS one 2014;9:e103626.

45. Wikholm JB, Bohannon RW. Hand-held Dynamometer Measurements: Tester Strength Makes a Difference. J Orthop Sports Phys Ther 1991;13:191-198.

46. Lu TW, Hsu HC, Chang LY, Chen HL. Enhancing the examiner's resisting force improves the reliability of manual muscle strength measurements: comparison of a new device with hand-held dynamometry. J Rehabil Med 2007;39:679-684.

47. Aguilaniu B, Roth $\mathrm{H}$, Gonzalez-Bermejo J, et al. A simple semipaced 3-minute chair rise test for routine exercise tolerance testing in COPD. Int J Chron Obstruct Pulmon Dis 2014;9:1009-1019. 


\section{Chapter 5}

Benefits of physical training in patients with idiopathic or end-stage sarcoidosis-related pulmonary fibrosis:

a pilot study

B Strookappe, M Elfferich, J Swigris, A Verschoof, J Verschakelen, T Knevel, M Drent Sarcoidosis Vasc Diffuse Lung Dis 2015;32:43-52 


\section{Abstract}

\section{Background}

The natural history of disease in patients with stage IV (fibrotic) sarcoidosis may mirror that of patients with idiopathic pulmonary fibrosis (IPF). Both are bothered by progressive dyspnea, exercise limitation and fatigue. The objective of this study was to establish whether patients suffering from pulmonary fibrosis might benefit from a physical training program.

\section{Methods}

Twenty-four eligible patients referred to the out-patient clinic of the ild care expertise team of Hospital Gelderse Vallei, Ede, The Netherlands between November 2012 and November 2013 were included in this observational pilot study of a 12-week physical training program. Outcomes, including exercise capacity, skeletal muscle strength and symptoms were assessed at two time points: 1) baseline; and 2) after completion of a 12-week physical training program.

\section{Results}

At baseline, the percentage predicted DLCO, FVC, FEV ${ }_{1}$ and exercise capacity (assessed by sixminute walking distance (6MWD) or maximal oxygen uptake) was reduced in both groups. After program completion, exercise capacity improved ( $>10 \%$ improvement $6 \mathrm{MWD})$ in 13 subjects (54.2\%): 7 with IPF and 6 with sarcoidosis subjects. Other secondary endpoints, including pulmonary function tests and patient-reported outcome measures improved in some subjects.

\section{Conclusion}

A 12-week physical training program improved or maintained exercise capacity in patients with IPF (despite disease progression) or fibrotic sarcoidosis. The results from this pilot study could be used to design prospective studies aimed at answering lingering questions about exercise training in patients with these progressive, incurable conditions. 


\section{Introduction}

The interstitial lung diseases (ILD) are a heterogeneous group of lung disorders characterized by physiologic restriction and impaired gas exchange. They induce hypoxemia and activity-limiting dyspnea that often lead to physical deconditioning. ${ }^{1-4}$

In sarcoidosis, morbidity and mortality are driven by the pulmonary aspects of the disease. However, the clinical presentation and disease course of pulmonary sarcoidosis are highly variable. ${ }^{5,6}$ The natural history of stage IV sarcoidosis (by chest radiograph) can mimic idiopathic pulmonary fibrosis (IPF), with a progressive course and early mortality. ${ }^{7,8}$ Complicating matters, some patients with sarcoidosis will develop pulmonary hypertension, and in patients not responding to currently available medical treatment, lung transplantation is considered. ${ }^{6,9}$

IPF is a chronic, progressive and fatal ILD characterized by pulmonary restriction, diminished exercise capacity and symptoms of exertional dyspnea, dry cough and disabling fatigue. Periods of transient clinical stability may occur, however disease progression is the rule. In IPF, lung transplantation is the only therapeutic modality shown to reliably improve survival. ${ }^{10}$ Although IPF is not curable, the results of two recently conducted trials reveal that slowing disease progression is an achievable goal for some patients. ${ }^{11,12}$

In patients with fibrotic sarcoidosis or IPF (as well as other fibrotic ILDs), diminished exercise capacity is demonstrated by reduced oxygen uptake (as measured during a maximal cardiopulmonary exercise test) or a shorter-than-predicted distance covered during a six-minute walk test (6MWD). ${ }^{13-15}$ Although fibrotic ILD - regardless of cause is incurable and often refractory to drug therapy, limited data suggest that pulmonary rehabilitation - the backbone of which is an exercise program that most often includes a combination of aerobic and resistance training - is a safe and effective intervention ${ }^{1-4}$ that improves symptoms, physical functioning and quality of life $(\mathrm{QOL})$. $^{3,16}$

The aim of this study was to expand the data on whether and how patients suffering from sarcoidosis or IPF benefit from a tailored physical training program, as delivered in pulmonary rehabilitation.

\section{Methods}

\section{Subjects}

Twenty-four consecutive patients referred to the out-patient clinic of the ILD care expertise team of Hospital Gelderse Vallei, Ede, The Netherlands between November 
2012 and November 2013 were included as subjects in this study. Diagnoses were confirmed by the multidisciplinary ILD care expertise team in accordance with accepted guidelines. ${ }^{10,17}$

\section{Study design}

In this observational pilot study, there were two time points at which outcome variables were collected: 1 ) baseline; and 2) after completion of a 12-week physical training program. At our center, assessments of muscle strength and exercise capacity are routinely performed as part of the initial evaluation and follow-up of patients with ILD. Within subject, these assessments are made by the same tester at baseline and after 3 months.

\section{Outcome variables}

\section{Body composition}

Height, weight, body mass index (BMI) and fat-free mass (FFM) were measured as reported previously. ${ }^{18}$ FFM was calculated using the Lukaski formula. ${ }^{19}$ To assess the degree of functional tissue depletion, FFM was adjusted for body size by calculating the FFM index (FFMI, FFM/ height ${ }^{2}\left(\mathrm{~kg} \cdot \mathrm{m}^{-2}\right)$ ). Muscle atrophy was defined as FFMI $<15 \mathrm{~kg} / \mathrm{m}^{2}$ for women and $<17 \mathrm{~kg} / \mathrm{m}^{2}$ for men corresponding to $<10^{\text {th }}$ percentile of current reference values established in a large Caucasian group of healthy subjects. ${ }^{20}$

\section{Lung function tests}

Forced vital capacity (FVC) and forced expiratory volume in one second (FEV 1 ) were measured with a pneumotachograph (Masterlab, Jaeger, Würzburg, Germany). The diffusing capacity of the lung for carbon monoxide (DLCO) was measured using the single-breath method (Masterlab, Jaeger, Würzburg, Germany). Values were expressed as percentage of the predicted value (i.e., FVC\%, FEV $\mathrm{FV}_{1} \%$, and DLCO\% respectively).

\section{Muscle strength}

Maximal inspiratory pressure (PImax) was assessed with the MicroRPM (Micro Medical Ltd., Rochester, England) as previously described. ${ }^{21,22}$ The maximal isometric grip strength of the dominant hand was measured with the Jamar dynamometer (Fabrication Enterprises Inc., Irvington, NY, USA) and expressed in kilograms (kgs). ${ }^{23}$ Percentage of predicted was calculated using normative data of Mathiowetz and colleagues. $^{24}$

Quadriceps strength was assessed during knee extension with the microFET (Biometrics, Almere, The Netherlands), an electronic hand-held dynamometer. The 'break' method was used to measure the maximal peak force of the dominant arm or leg in Newton (N). The highest value of at least two measurements was recorded. ${ }^{25}$ 


\section{Exercise capacity}

Maximal oxygen uptake - and other commonly collected variables - were measured during a cardiopulmonary exercise test using the Steep Ramp Test (SRT) protocol on a cycle ergometer. ${ }^{26}$ After a two-minute unloaded warm-up, the intensity was increased by 25 watts every 10 seconds, with the subject pedaling at a rate of 70-80 rpm. The test was terminated when the subject indicated they could no longer continue or if the revolutions per minute fell below 60. Intermittent, standardized encouragement was given to the subject throughout the entire test. The six-minute walk test (6MWT) was administered according to the American Thoracic Society Guidelines. ${ }^{27}$ Predicted $6 \mathrm{MWD}$ values were calculated according to Gibson and colleagues. ${ }^{28}$

\section{Patient-reported outcome instruments}

Fatigue was measured with the 10-item Fatigue Assessment Scale (FAS). Each item uses a 5-point rating scale, so the total score range is 10 to 50 . Scores below 22 indicate no fatigue; scores of 22-34 indicate mild-moderate fatigue; and scores of 35 or more indicate extreme fatigue. In sarcoidosis, the FAS has acceptable psychometric properties. $^{29}$ The minimal clinically important difference in sarcoidosis is 4 points or a $10 \%$ change. $^{30}$

The Borg Rating of Perceived Exertion (RPE) Scale was used to assess perceived exertion. Scores range from 6 to 20, where 6 means "no exertion at all" and 20 means "maximal exertion." The Borg Scale was used to determine the RPE during the 6MWT.

Average breathlessness intensity over a 2-week period was assessed with an 8-point, modified Borg scale (from 0 to 7), for which higher scores connote greater breathlessness. ${ }^{31}$ Subjects also ticked a box to indicate whether their breathlessness was brief, periodic or continuous.

\section{Intervention}

In accordance with American Thoracic Society standards, the exercise program consisted of two major components: aerobic endurance training (stationary cycling, treadmill) and peripheral muscle strengthening. ${ }^{32}$ The program consisted of 24 sessions over 12 weeks. Each session lasted 60 minutes, and both training components were performed at each session.

The aerobic endurance component was started at a level of $50-60 \%$ of peak work achieved during the SRT. ${ }^{26}$ An interval protocol was used while subjects exercised continuously with a goal time of more than 30 minutes. After a 10 minute warm-up period, subjects completed alternating exercise intervals of 40 seconds at high resistance and 60 seconds at low resistance. After completing 10 intervals, subjects cooled down for five minutes. Intensity and duration were gradually increased (both 
within sessions and over time) to build tolerance and confidence. During each session, the targeted exercise intensity was $13-15$ on the Borg RPE Scale. ${ }^{33}$ Pulse-oxymetry was used to monitor peripheral oxygen saturation levels during exercise, and supplemental oxygen use during training was commensurate with current prescriptions.

The strength training component consisted on exercises using Life Fitness Circuit Series equipment (Life Fitness, Barendrecht, The Netherlands). During each training sessions, subjects performed three sets of 15-20 repetitions of 6-8 different exercises some lower- and some upper-body. At least two lower body exercises were performed each training session. The resistance level was individualized for each patient (according to patient preference) and reassessed and adjusted after every session using the Borg Score. The targeted exercise intensity was between 13-15 on the Borg score. ${ }^{33}$

\section{Statistical analysis}

Deviation from normality was tested for each continuous variable using the Kolmogorov-Smirnov test. Comparisons between baseline and follow-up values were performed using the paired $t$-test if data were normally distributed or the MannWhitney rank test if data were not normally distributed. Categorical variables were compared using Chi-square or Fisher's exact test as appropriate. Associations between the pulmonary function tests, 6MWD, FFMI and fatigue of the studied group were calculated using Pearson's correlations. We considered $p<0.05$ to represent statistical significance. All statistical analyses were performed using SPSS statistical software (version 19.0.0 for Windows) (SPSS Inc., Chicago, IL, USA). Descriptive statistics were generated for baseline characteristics.

\section{Results}

All 24 training sessions were completed by 24 subjects: 12 with IPF and 12 with endstage, refractory sarcoidosis. Baseline and post-training data are summarized in Table 5.1. A total of 9 subjects used supplemental oxygen during the training program: 6 with IPF and 3 with sarcoidosis.

\section{Lung function tests}

At baseline, $\mathrm{FVC} \%, \mathrm{FEV}_{1} \%$ and DLCO\% were decreased in both groups. Compared to the sarcoidosis subjects, IPF subjects had a significantly lower DLCO $(p=0.001)$ and FEV 1 (0.003), but the FVC was not different $(p=0.294)$. The 6MWD $(p<0.0001)$, and the SRT (Watt; $p=0.002$ ) were significantly lower in IPF subjects compared with the sarcoidosis subjects. HGF did not differ between IPF and sarcoidosis subjects ( $p=0.991$; Table 5.1 and Figure 5.1). At baseline 15 subjects ( 6 sarcoidosis and 9 IPF, $p=0.223$ for difference) had fatigue (FAS scale score $>22$ ). Mean FAS scores were similar between groups (26.8 
\pm 2.7 vs. $28.5 \pm 5.6, p=0.527)$. The majority of subjects in each group desaturated during a $6 \mathrm{MWT}$ at baseline (Figure 5.1).

Table 5.1 Summary of the demographic, clinical and physical characteristics of studied subjects with idiopathic or end-stage sarcoidosis-related pulmonary fibrosis at baseline and after a 12-weeks training program.

\begin{tabular}{|c|c|c|c|c|}
\hline & $\begin{array}{c}\text { Sarcoidosis } \\
\text { subjects at } \\
\text { baseline }\end{array}$ & $\begin{array}{l}\text { Sarcoidosis } \\
\text { subjects at } \\
\text { follow-up }\end{array}$ & $\begin{array}{l}\text { IPF subjects } \\
\text { baseline }\end{array}$ & $\begin{array}{l}\text { IPF subjects } \\
\text { follow-up }\end{array}$ \\
\hline \multicolumn{5}{|l|}{ Demographics } \\
\hline Subjects, $\mathrm{n}$ & 12 & & 12 & \\
\hline Women/men, $\mathrm{n}$ & $1 / 11$ & & $3 / 9$ & \\
\hline Age, yrs & $53.2 \pm 11.7 \#$ & & $67.3 \pm 11.3$ & \\
\hline Time since diagnosis, yrs & $10.0 \pm 8.2 \#$ & & $3.5 \pm 6.3$ & \\
\hline Nonsmokers/smokers, n & $12 / 0$ & & $12 / 0$ & \\
\hline \multicolumn{5}{|l|}{ Body composition } \\
\hline $\mathrm{BMI}, \mathrm{kg} / \mathrm{m}^{2}$ & $27.8 \pm 5.1$ & & $28.3 \pm 4.6$ & \\
\hline FFMI, $\mathrm{kg} / \mathrm{m}^{2}$ & $17.9 \pm 1.8$ & & $17.4 \pm 2.1$ & \\
\hline \multicolumn{5}{|l|}{ Medication } \\
\hline Prednisone use yes/no, n & $5 / 7$ & $4 / 8$ & $7 / 5$ & $7 / 5$ \\
\hline Methotrexate use yes/no, $\mathrm{n}$ & $1 / 11$ & $8 / 3 *$ & 0 & 0 \\
\hline Anti-TNF- $\alpha$ use yes/no, $n$ & $1 / 11$ & $3 / 9$ & 0 & 0 \\
\hline Pirfenidone & 0 & 0 & 0 & 3 \\
\hline \multicolumn{5}{|l|}{ Dyspnea measure } \\
\hline Borg scale & $4.0 \pm 2.6$ & $3.8 \pm 1.9$ & $4.6 \pm 2.0$ & $5.3 \pm 2.1$ \\
\hline Borg RPE scale & $12.8 \pm 3.0$ & $12.0 \pm 1.9$ & $12.5 \pm 3.0$ & $13.9 \pm 2.6$ \\
\hline \multicolumn{5}{|l|}{ Fatigue measure } \\
\hline FAS-score & $21.9 \pm 5.4 \#$ & $20.7 \pm 5.7$ & $25.1 \pm 5.6$ & $25.9 \pm 9.9$ \\
\hline \multicolumn{5}{|l|}{ Physical functions } \\
\hline SRT, Watt & $270 \pm 69 \#$ & $286 \pm 65$ & $180 \pm 71$ & $190 \pm 68$ \\
\hline Oxygen saturation, start, \% & $96.6 \pm 1.3$ & $97.0 \pm 1.1$ & $96.6 \pm 1.3$ & $93.3 \pm 2.7$ \\
\hline Oxygen saturation, finish, \% & $92.3 \pm 3.9 \#$ & $92.2 \pm 4.5 \#$ & $86.9 \pm 7.1$ & $86.9 \pm 6.4$ \\
\hline \multicolumn{5}{|l|}{ Muscle force } \\
\hline HGF, \% predicted & $89.3 \pm 14.8$ & $99.9 \pm 5.8^{*}$ & $89.2 \pm 14.7$ & $97.4 \pm 17.4$ \\
\hline $\mathrm{Pi}, \mathrm{max}, \%$ predicted & $102.5 \pm 28.8$ & $111.6 \pm 30.7$ & $80.0 \pm 30.5$ & $87.3 \pm 27.3$ \\
\hline
\end{tabular}

Data are expressed as mean \pm standard deviation (SD) or absolute numbers ( $n$ ). IPF = Idiopathic pulmonary fibrosis; $\mathrm{BMI}=$ body mass index; FFMI = fat-free mass index; TNF = tumor necrosis factor; RPE = ratings of perceived exertion; FAS = Fatigue Assessment Scale; SRT = Steep Ramp Test; HGF= hand grip force; QPT: quadriceps peak torques; $\mathrm{Pi}, \max =$ maximal inspiratory pressure. \# all p's <0.05 sarcoidosis vs IPF; all p's $<0.05$ sarcoidosis baseline compared with 3 months later (after the training program) ${ }^{*} p<0.05$ sarcoidosis subjects $(n=12)$ at baseline versus follow-up.

After completion of the training program, in subjects with sarcoidosis, the mean improvement in FVC\% $(\Delta=9.7 \pm 11.4, p=0.075)$, FEV $_{1} \%(\Delta=7.9 \pm 9.6 ; p=0.145)$ and DLCO\% $(\Delta=5.1 \pm 4.5 ; p=0.460)$ were unchanged from baseline. In subjects with IPF, FVC\% $(\Delta=-5.3 \pm 7.8 ; \mathrm{p}=0.386), \mathrm{FEV}_{1} \%(\Delta=-9.0 \pm 7.1 ; \mathrm{p}=0.186)$ were also unchanged from baseline. There was a trend toward decline for DLCO\% $(\Delta=-6.8 \pm 12.0 ; p=0.163)$ among subjects with IPF. A greater proportion of subjects with sarcoidosis had improvements ( $>10 \%$ change from baseline) in pulmonary function tests (Figures 5.2 and Table 5.2). 



Figure 5.1 Individual changes of the oxygen saturation before and after the six minute walking test at baseline of the studied sarcoidosis $(A: n=12)$ and idiopathic pulmonary fibrosis (IPF) subjects ( $B$ : $\mathrm{n}=12$ ).

Table 5.2 Pulmonary function tests and 6 minute walking distance (6MWD) at baseline and after a 12-weeks training program of the studied subjects with idiopathic or end-stage sarcoidosisrelated pulmonary fibrosis.

\begin{tabular}{|c|c|c|c|c|c|c|}
\hline & $\begin{array}{c}\text { Sarcoidosis } \\
\text { patients at } \\
\text { baseline }\end{array}$ & $\begin{array}{l}\text { Sarcoidosis } \\
\text { patients at } \\
\text { follow-up }\end{array}$ & & $\begin{array}{l}\text { IPF patients } \\
\text { baseline }\end{array}$ & $\begin{array}{l}\text { IPF patients } \\
\text { follow-up }\end{array}$ & \\
\hline Lung function tests & & & $p$-value & & & $\mathrm{p}$-value \\
\hline DLCO, \% predicted & $62.7 \pm 16.4 \#$ & $67.8 \pm 16.7 \#$ & 0.460 & $40.9 \pm 12.6$ & $34.1 \pm 10.5$ & 0.163 \\
\hline$\triangle \mathrm{DLCO}$ & & $5.1 \pm 8.5$ & & & $-6.8 \pm 12.0$ & $0.01^{*}$ \\
\hline FVC, \% predicted & $71.3 \pm 12.3 \#$ & $81.0 \pm 13.0 \#$ & 0.075 & $77.0 \pm 13.4$ & $71.7 \pm 14.9$ & 0.368 \\
\hline$\Delta \mathrm{FVC}$ & & $9.7 \pm 11.4$ & & & $-5.3 \pm 7.8$ & $0.001 *$ \\
\hline $\mathrm{FEV}_{1}, \%$ predicted & $63.0 \pm 14.2 \#$ & $70.9 \pm 11.2 \#$ & 0.145 & $83.7 \pm 16.1$ & $74.7 \pm 16.2$ & 0.186 \\
\hline$\triangle 6 \mathrm{MWD}$ & & $7.9 \pm 9.6$ & & & $-9.0 \pm 7.1$ & $<0.001^{*}$ \\
\hline $6 \mathrm{MWD}$, meter & $513 \pm 102 \#$ & $565 \pm 122 \#$ & 0.278 & $305 \pm 137$ & $335 \pm 125$ & 0.588 \\
\hline$\triangle 6 \mathrm{MWD}$, meter & & $51.3 \pm 33.3$ & & & $29.4 \pm 73.6$ & $0.358 *$ \\
\hline 6MWD, \% predicted & $64.8 \pm 9.4 \#$ & $70.9 \pm 11.5 \#$ & 0.198 & $46.0 \pm 18.6$ & $50.0 \pm 15.7$ & 0.706 \\
\hline$\Delta 6 \mathrm{MWD}, \%$ & & $9.5 \pm 5.4$ & & & $9.45 \pm 19.4$ & $0.990 *$ \\
\hline
\end{tabular}

Data are expressed as mean \pm standard deviation (SD). IPF = Idiopathic pulmonary fibrosis; DLCO = diffusing capacity of the lung for carbon monoxide; $F V C=$ forced vital capacity; $F E V_{1}=$ forced expiratory volume in one second; $6 \mathrm{MWD}=$ six-minute walking distance; $\Delta$ difference between follow-up and baseline. ${ }^{\#} p<0.05$ : sarcoidosis subjects $(n=12)$ at baseline and follow-up vs IPF subjects $(n=12)$ at baseline and follow-up *p $\Delta$ sarcoidosis vs IPF

\section{Muscle strength}

The HGF of the dominant hand increased by at least $10 \%$ over the baseline values in 12 subjects ( 7 with sarcoidosis vs. 5 with IPF). There was a trend toward improvement in mean HGF values in the sarcoidosis group $(p=0.081)$ but not in the IPF group 
$(p=0.247)$. Muscle atrophy was present at baseline in a total of 10 subjects (all were male; 5 with sarcoidosis and 5 with IPF). Only one subject was cachectic (BMI<20). At baseline, quadriceps strength was less than $80 \%$ of predicted in one subject with sarcoidosis and six with IPF. Quadriceps strength improved in the subject with sarcoidosis (by $10 \%$, from 74 to $84 \%$ ) and in three subjects with IPF (76\% to $90 \%, 74 \%$ to $111 \%$, and $70 \%$ to $82 \%)$. It remained unchanged in the other three IPF subjects.

\section{Exercise capacity}

Maximal work achieved (Watts from the SRT: $10 \%$ over baseline) improved in 10 subjects ( 6 with sarcoidosis and 4 with IPF). Mean values for change from baseline were unchanged (sarcoidosis group $p=0.488$ and IPF group $p=0.534$ ). The 6MWD increased by $10 \%$ over the baseline value in half of the subjects (6/12 with sarcoidosis and 6/12 with IPF). There was no between-group difference in mean change in 6MWD (\% of predicted value) from baseline to post-program ( $\Delta=9.5 \pm 5.4 \%$ for sarcoidosis vs. $9.5 \pm 19.4 \%$ for IPF; $p=0.990$ for comparison; Table 5.2 and Figure 5.3). As defined by a $>10 \%$ increase from baseline in raw value, 6MWD improved in 13 subjects $(54.2 \%)$ : 6 with sarcoidosis (6/12 or $50 \%)$ and 7 with IPF (7/12 or $54.2 \%)$.
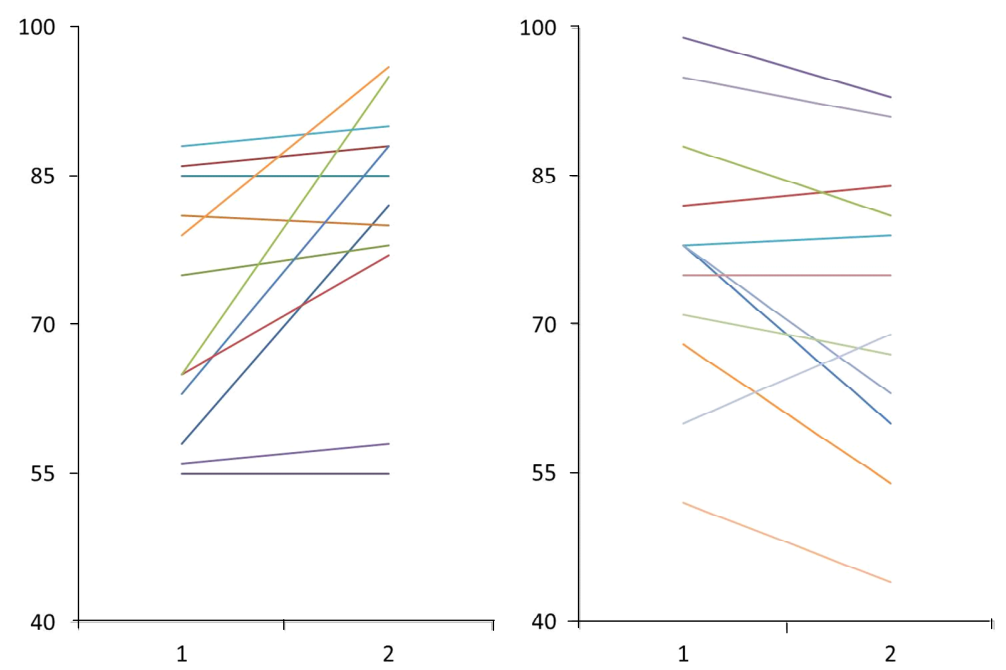

Figure 5.2 Individual changes in forced vital capacity (FVC), percentage predicted after a 12-weeks training program compared to baseline of studied sarcoidosis (A: $n=12)$ and idiopathic pulmonary fibrosis (IPF) subjects (B: $n=12$ ).

\section{Patient-reported outcome instruments}

Of the 15 subjects with an abnormally increased FAS score at baseline, 8 improved ( 4 with sarcoidosis vs. 4 with IPF), 5 remained stable and 2 deteriorated. Breathlessness did not change in either group. 



Figure 5.3 Individual changes in six minute walking distance (6MWD), percentage predicted after a 12weeks training program compared to baseline of studied sarcoidosis ( $A: n=12)$ and idiopathic pulmonary fibrosis (IPF) subjects (B: $n=12$ ).

Table 5.3 Change of pulmonary function tests (DLCO and FVC, percentage of predicted) and 6 minute walking distance (6MWD, percentage of predicted) as well as the Steep ramp test (SRT), Watt; Hand grip force (HGF, percentage predicted) of $\geq 10 \%$ (improvement); between $-10 \%$ and $10 \%$ (stable) and $\geq 10 \%$ deterioration) between baseline and a 12-weeks training program of the studied subjects with idiopathic or end-stage sarcoidosis-related pulmonary fibrosis.

\begin{tabular}{|c|c|c|c|c|c|c|}
\hline & improvement & & stable & & deterioration & \\
\hline \multirow[t]{2}{*}{ DLCO, \% predicted } & 6 & & 11 & & 7 & \\
\hline & 5 Sarcoidosis & $1 \mathrm{IPF}$ & 6 Sarcoidosis & $5 \mathrm{IPF}$ & 1 Sarcoidosis & $6 \mathrm{IPF}$ \\
\hline \multirow[t]{2}{*}{ FVC, \% predicted } & 6 & & 14 & & 4 & \\
\hline & 5 Sarcoidosis & $1 \mathrm{IPF}$ & 7 Sarcoidosis & $7 \mathrm{IPF}$ & 0 Sarcoidosis & $4 \mathrm{IPF}$ \\
\hline \multirow[t]{2}{*}{$6 \mathrm{MWD}, \%$ predicted } & 13 & & 11 & & 2 & \\
\hline & 6 Sarcoidosis & 7 IPF & 6 Sarcoidosis & $3 \mathrm{IPF}$ & 0 Sarcoidosis & $2 \mathrm{IPF}$ \\
\hline \multirow[t]{2}{*}{ SRT, Watt } & 10 & & 12 & & 2 & \\
\hline & 6 Sarcoidosis & $4 \mathrm{IPF}$ & 6 Sarcoidosis & 6 IPF & 0 Sarcoidosis & $2 \mathrm{IPF}$ \\
\hline \multirow[t]{2}{*}{ HGF, \% predicted } & 12 & & 9 & & 3 & \\
\hline & 7 Sarcoidosis & $5 \mathrm{IPF}$ & 3 Sarcoidosis & $6 \mathrm{IPF}$ & 2 Sarcoidosis & $1 \mathrm{IPF}$ \\
\hline
\end{tabular}

IPF = Idiopathic pulmonary fibrosis; DLCO = diffusing capacity of the lung for carbon monoxide; FVC = forced vital capacity; $6 \mathrm{MWD}$ = six-minute walking distance; SRT = Steep Ramp Test; HGF= hand grip force.

\section{Discussion}

In this study, we observed that patients suffering from IPF or severe fibrotic pulmonary sarcoidosis benefited from a 12-week, supervised exercise training program. Mean $6 \mathrm{MWD}$ improved in both groups, and 54.2\% of subjects ( $\mathrm{N}=13 ; 7$ with IPF and 6 with sarcoidosis) experienced a $>10 \%$ improvement in 6MWD. All the more impressive, despite trends toward decline in mean FVC\% and DLCO\% (and slightly less-so for FVC\%), 
in subjects with IPF, mean 6MWD increased. Furthermore, mean values for FVC\% and DLCO\% in subjects with sarcoidosis improved, although differences from baseline did not meet statistical significance.

Peripheral muscle (particularly the quadriceps) weakness is common in patients with sarcoidosis or IPF. Quadriceps force is associated with exercise limitation as well as lung function impairment in IPF patients. ${ }^{34-36}$ Similarly, sarcoidosis patients with reduced peripheral muscle strength (particularly the quadriceps) are more fatigued and more likely to have impaired lung function, 6MWT and QOL. ${ }^{14}$ In our study, fatigue was associated with exercise capacity (as defined by SRT), but not muscle strength (data not shown).

Cremers and colleagues found that muscle atrophy was present in $34 \%$ patients with stage IV sarcoidosis. ${ }^{18}$ Marcellis and co-investigators observed a trend toward lower levels of the FFM index (FFM adjusted for body size) in sarcoidosis patients with reduced leg muscle strength. ${ }^{14}$ In the present study, $41.6 \%$ of subjects had muscle atrophy at base line. The FFMI did not correlate with pulmonary function test results nor with fatigue or the 6MWD (data not shown). Chura and colleagues assessed the use of different exercise tests, including the SRT, in patients with COPD. ${ }^{37}$ They suggested that the SRT is a reliable, practical test of leg muscle anaerobic power, even in the setting of ventilatory limitation. In our study, peak work achieved (i.e., watts generated during the SRT) improved in $42 \%$ and remained stable in $50 \%$ of subjects, thus suggesting that the exercise program delivered in pulmonary rehabilitation has the potential to preserve or improve peripheral muscle strength. Limited data suggest that patients with pulmonary fibrosis have a limited capacity for muscle remodeling after exercise training; this could result from a complex interplay of several factors, including systemic inflammation, arterial and muscular hypoxia and cachexia. In cachectic patients, strengthening exercises may activate anabolic and catabolic pathways simultaneously, thereby limiting the magnitude of the training effect. ${ }^{38}$

Both IPF and fibrotic sarcoidosis create burdens in patients' lives. Symptoms of dyspnea induces exercise limitation, fatigue leads to physical inactivity, and the symptoms themselves, or the thought of living with a progressive, incurable condition, creates anxiety, mood disturbance and impairs emotional well-being. ${ }^{39-44}$ Although less well-recognized than exertional dyspnea and dry cough, fatigue or exhaustion is very common in patients with IPF. As in sarcoidosis, fatigue is a frustrating symptom for IPF patients, perhaps as frustrating as shortness of breath. ${ }^{42}$ Like Elfferich and colleagues, we observed that fatigue was more prevalent among subjects with IPF (9/12) than those with sarcoidosis $(6 / 12) .{ }^{41}$

In both sarcoidosis and IPF, exercise capacity, as measured by 6MWD, is often reduced. ${ }^{14,45,46}$ In both conditions, ventilatory impairment is the main factor contributing to exercise limitation, although gas exchange abnormalities also contribute. $^{14,45,46}$ Recently, Marcellis and colleagues reported that fatigue and 6MWD 
were associated with QOL in sarcoidosis. In particular, the most affected QOL domain physical health - showed strong associations with fatigue and exercise capacity at baseline and follow-up in their study. ${ }^{43}$ The same is true for IPF: 6MWD is associated with health-related QOL. ${ }^{46}$ In our study, although physical training did not improve fatigue at the group level, among the 15 subjects with significant fatigue at baseline (as defined by FAS scores), 8 (53.3\%) had significant improvement in fatigue after completion of the physical training program.

Although we cannot be certain, medical treatment was unlikely to have significantly influenced results: one subject in the sarcoidosis group had discontinued prednisone by the end of the training session. Nine subjects with sarcoidosis started therapy during the training session: seven started MTX, and two started infliximab. The beneficial effects of these medications are not expected before three months. ${ }^{47}$ In the IPF group, the number of subjects taking prednisone at baseline and at the end of the training session was the same. Although three subjects with IPF initiated treatment with pirfenidone during the training program, two discontinued it because of side effects. The one subject who remained on pirfenidone progressed and recently underwent lung transplantation.

The findings of our study should be interpreted in the context of several limitations: first the sample size in this pilot study was small, and we did not include a control group; thus, the results should be interpreted as hypothesis-generating and used predominantly to help design larger, definitive studies. Although subjects used oxygen during training, if they used it at home, oxygen flow rates were not titrated (and oxygen was not initiated to prevent desaturation) during training sessions. Whether training would have a greater impact on improving outcomes if peripheral oxygen saturations were maintained $>90 \%$ during exercise sessions is a question that merits investigation. Two retrospective studies have shown that ambulatory oxygen therapy may significantly improve 6MWT performance and dyspnea in patients with IPF. ${ }^{48,49}$ Likewise, whether exercise training programs could or should be modified to better suit patients with IPF or fibrotic sarcoidosis is a topic in need of exploration.

In conclusion, a 12-week physical training program improved or maintained exercise capacity in patients with IPF (despite disease progression) or fibrotic sarcoidosis, and in certain subjects, other important outcomes improved. The results from this pilot study could be used to design prospective studies aimed at answering lingering questions about exercise training in patients with these progressive, incurable conditions. 


\section{References}

1. Spruit MA, Thomeer MJ, Gosselink R, et al. Skeletal muscle weakness in patients with sarcoidosis and its relationship with exercise intolerance and reduced health status. Thorax 2005;60:32-38.

2. Holland A, Hill C. Physical training for interstitial lung disease. Cochrane Database Syst Rev 2008;(4): CD006322.

3. Swigris JJ, Brown KK, Make BJ, Wamboldt FS. Pulmonary rehabilitation in idiopathic pulmonary fibrosis: a call for continued investigation. Respir Med 2008;102:1675-1680.

4. Braam AW, de Haan SN, Vorselaars $A D$, et al. Influence of repeated maximal exercise testing on biomarkers and fatigue in sarcoidosis. Brain Behav Immun 2013;33:57-64.

5. Baughman RP, Lower EE, Gibson K. Pulmonary manifestations of sarcoidosis. Presse medicale 2012;41 (6 Pt 2):e289-302.

6. Valeyre D, Prasse A, Nunes H, Uzunhan Y, Brillet PY, Muller-Quernheim J. Sarcoidosis. Lancet 2014;383: 1155-1167.

7. Nardi A, Brillet PY, Letoumelin P, et al. Stage IV sarcoidosis: comparison of survival with the general population and causes of death. Eur Respir J 2011;38:1368-1373.

8. Patterson KC, Strek ME. Pulmonary fibrosis in sarcoidosis. Clinical features and outcomes. Ann Am Thorac Soc 2013;10:362-370.

9. Valeyre D, Nunes H, Bernaudin JF. Advanced pulmonary sarcoidosis. Curr Opin Pulm Med 2014;20: 488-495.

10. Travis WD, Costabel U, Hansell DM, et al. An official American Thoracic Society/European Respiratory Society statement: Update of the international multidisciplinary classification of the idiopathic interstitial pneumonias. Am J Respir Crit Care Med 2013;188:733-748.

11. Richeldi L, du Bois RM, Raghu G, et al. Efficacy and safety of nintedanib in idiopathic pulmonary fibrosis. N Engl J Med 2014;370:2071-2082.

12. King TE, Jr., Bradford WZ, Castro-Bernardini S, et al. A phase 3 trial of pirfenidone in patients with idiopathic pulmonary fibrosis. N Engl J Med 2014;370:2083-2092.

13. Du Bois RM, Weycker D, Albera C, et al. Six-minute-walk test in idiopathic pulmonary fibrosis: test validation and minimal clinically important difference. Am J Respir Crit Care Med 2011;183:1231-1237.

14. Marcellis RG, Lenssen AF, Elfferich MD, et al. Exercise capacity, muscle strength and fatigue in sarcoidosis. Eur Respir J 2011;38:628-634.

15. Jackson RM, Gomez-Marin OW, Ramos CF, et al. Exercise limitation in IPF patients: a randomized trial of pulmonary rehabilitation. Lung 2014;192:367-376.

16. Holland AE, Hill CJ, Conron M, Munro P, McDonald CF. Short term improvement in exercise capacity and symptoms following exercise training in interstitial lung disease. Thorax 2008;63:549-554.

17. Statement on sarcoidosis. Joint Statement of the American Thoracic Society (ATS), the European Respiratory Society (ERS) and the World Association of Sarcoidosis and Other Granulomatous Disorders (WASOG) adopted by the ATS Board of Directors and by the ERS Executive Committee, February 1999. Am J Respir Crit Care Med 1999;160:736-755.

18. Cremers JP, Drent M, Elfferich MD, et al. Body composition profiling in a Dutch sarcoidosis population. Sarcoidosis Vasc Diffuse Lung Dis 2013;30:289-299.

19. Lukaski HC, Bolonchuk WW, Hall CB, Siders WA. Validation of tetrapolar bioelectrical impedance method to assess human body composition. J Appl Physiol (1985) 1986;60:1327-1332.

20. Evans WJ, Morley JE, Argiles J, et al. Cachexia: a new definition. Clin Nutr 2008;27:793-799.

21. Black LF, Hyatt RE. Maximal respiratory pressures: normal values and relationship to age and sex. Am Rev Respir Dis 1969;99:696-702.

22. ATS/ERS Statement on respiratory muscle testing. Am J Respir Crit Care Med 2002;166:518-624.

23. Werle S, Goldhahn J, Drerup S, Simmen BR, Sprott H, Herren DB. Age- and gender-specific normative data of grip and pinch strength in a healthy adult Swiss population. J Hand Surg Eur Vol 2009;34:76-84.

24. Mathiowetz V, Wiemer DM, Federman SM. Grip and pinch strength: norms for 6- to 19-year-olds. Am J Occup Ther 1986;40:705-711.

25. Bohannon RW. Make tests and break tests of elbow flexor muscle strength. Physical therapy 1988;68: 193-194.

26. Meyer K, Samek L, Schwaibold M, et al. Physical responses to different modes of interval exercise in patients with chronic heart failure--application to exercise training. Eur Heart J 1996;17:1040-1047. 
27. ATS statement: guidelines for the six-minute walk test. Am J Respir Crit Care Med 2002;166:111-117.

28. Gibbons WJ, Fruchter N, Sloan S, Levy RD. Reference values for a multiple repetition 6-minute walk test in healthy adults older than 20 years. J Cardiopulm Rehabil 2001;21:87-93.

29. Michielsen HJ, Drent M, Peros-Golubicic T, De Vries J. Fatigue is associated with quality of life in sarcoidosis patients. Chest 2006;130:989-994.

30. De Kleijn WP, De Vries J, Wijnen PA, Drent M. Minimal (clinically) important differences for the Fatigue Assessment Scale in sarcoidosis. Respir Med 2011;105:1388-1395.

31. Skevington SM, Pilaar M, Routh D, MaCleod RD. On the language of breathlessness. Psychology \& health 1997;12:677-689.

32. Nici L, Donner C, Wouters E, et al. American Thoracic Society/European Respiratory Society statement on pulmonary rehabilitation. Am J Respir Crit Care Med 2006;173:1390-1413.

33. Borg GA. Psychophysical bases of perceived exertion. Med Sci Sports Exerc 1982;14:377-381.

34. Marcellis RG, Lenssen AF, de Vries GJ, et al. Is There an Added Value of Cardiopulmonary Exercise Testing in Sarcoidosis Patients? Lung 2013;191:43-52.

35. Marcellis RG, Lenssen AF, de Vries J, Drent M. Reduced muscle strength, exercise intolerance and disabling symptoms in sarcoidosis. Curr Opin Pulm Med 2013;19:524-530.

36. Nishiyama $\mathrm{O}$, Taniguchi $\mathrm{H}$, Kondoh $\mathrm{Y}$, et al. Quadriceps weakness is related to exercise capacity in idiopathic pulmonary fibrosis. Chest 2005;127:2028-2033.

37. Chura RL, Marciniuk DD, Clemens R, Butcher SJ. Test-Retest Reliability and Physiological Responses Associated with the Steep Ramp Anaerobic Test in Patients with COPD. Pulm Med 2012;2012:653831.

38. Vogiatzis I, Simoes DC, Stratakos G, et al. Effect of pulmonary rehabilitation on muscle remodelling in cachectic patients with COPD. Eur Respir J 2010;36:301-310.

39. De Vries J, Drent M. Quality of life and health status in sarcoidosis: a review. Semin Respir Crit Care Med 2007;28:121-127.

40. Drent M, Lower EE, De Vries J. Sarcoidosis-associated fatigue. Eur Respir J 2012;40:255-263.

41. Elfferich MD, De Vries J, Drent M. Type D or 'distressed' personality in sarcoidosis and idiopathic pulmonary fibrosis. Sarcoidosis Vasc Diffuse Lung Dis 2011;28:65-71.

42. De Vries J, Kessels BL, Drent M. Quality of life of idiopathic pulmonary fibrosis patients. Eur Respir J 2001;17:954-961.

43. Marcellis RG, Lenssen AF, Drent M, De Vries J. Association between physical functions and quality of life in sarcoidosis. Sarcoidosis Vasc Diffuse Lung Dis 2014;31:117-128.

44. De Vries J, Drent M. Relationship between perceived stress and sarcoidosis in a Dutch patient population. Sarcoidosis Vasc Diffuse Lung Dis 2004;21:57-63.

45. Swigris JJ, Wamboldt FS, Behr J, et al. The 6 minute walk in idiopathic pulmonary fibrosis: longitudinal changes and minimum important difference. Thorax 2010;65:173-177.

46. Verma G, Marras T, Chowdhury N, Singer L. Health-related quality of life and 6 min walk distance in patients with idiopathic pulmonary fibrosis. Can Respir J 2011;18:283-287.

47. Cremers JP, Drent M, Bast A, et al. Multinational evidence-based World Association of Sarcoidosis and Other Granulomatous Disorders recommendations for the use of methotrexate in sarcoidosis: integrating systematic literature research and expert opinion of sarcoidologists worldwide. Curr Opin Pulm Med 2013;19:545-561.

48. Visca D, Montgomery A, de Lauretis A, et al. Ambulatory oxygen in interstitial lung disease. Eur Respir J 2011;38:987-990.

49. Frank RC, Hicks S, Duck AM, Spencer L, Leonard CT, Barnett E. Ambulatory oxygen in idiopathic pulmonary fibrosis: of what benefit? Eur Respir J 2012;40:269-270. 


\section{Chapter 6}

Benefits of physical training in sarcoidosis

B Strookappe, J Swigris, J De Vries, M Elfferich, T Knevel, M Drent

Lung 2015;193:701-708 


\section{Abstract}

\section{Background}

Sarcoidosis patients suffer from fatigue and exercise limitation. The aim of this study was to establish whether a physical training program improves these and other outcomes important to sarcoidosis patients.

\section{Methods}

From 11/2012-9/2014, 201 sarcoidosis patients were referred to the ild care expertise team, Ede, The Netherlands. In our center all patients are routinely recommended to undergo testing at baseline to determine their physical functioning and encouraged to complete a 12-week, supervised physical training program. Ninety patients underwent baseline testing and returned for repeat testing at three months-in the interim, 49 completed the training program (Group I) and 41 chose not to participate (Group II). Change over time (from baseline to 3 months) in fatigue, exercise capacity, and skeletal muscle strength were assessed between the two groups.

\section{Results}

At baseline, there were no between-group differences for fatigue, DLCO\%, FVC\%, or exercise capacity (assessed by percent predicted six-minute walk distance [6MWD\%] and Steep Ramp Test [SRT]). The 6MWD for Group I improved between baseline and three months, while the 6MWD remained the same in Group II $(F=72.2, p<0.001)$. Group I showed a significantly larger decrease of fatigue compared with Group II $(F=6.27, p=0.014)$. Lung function tests did not change in either group.

\section{Conclusion}

A supervised physical training program improves exercise capacity and fatigue among sarcoidosis patients and should be included in their management regimen. 


\section{Introduction}

Sarcoidosis is a multisystem disorder of unknown cause(s) characterized by the formation of immune granulomas in involved organs, most often the lung and lymphatic system (but virtually any organ can be affected). The clinical presentation of sarcoidosis is highly variable: certain patients present acutely, with severe symptoms and/or multi-organ involvement; although, some patients are entirely asymptomatic. Symptoms are generally nonspecific and include general weakness, arthralgias, reduced exercise capacity, dyspnea and fatigue. ${ }^{1-5}$ In addition to the specific organ-related symptoms, these less specific disabling symptoms may have a major influence on the daily activities and the social and professional lives of the patients, resulting in a reduced quality of life (QOL). ${ }^{6}$ Distance covered during the six-minute walk test (6MWD) is often reduced and correlates with forced vital capacity (FVC) and fatigue severity. ${ }^{7,8}$ Fatigue may be explained by peripheral muscle weakness and exercise intolerance - each is influenced by multiple factors, including sarcoidosis-related skeletal muscle abnormalities, decreased pulmonary function, small fiber neuropathy and deconditioning. ${ }^{9-11}$

In several chronic - including lung - diseases, physical training has been shown to improve exercise intolerance and peripheral muscle weakness. ${ }^{12,13}$ Limited data suggest that pulmonary rehabilitation - the backbone of which is an exercise program that most often includes a combination of aerobic and resistance training - or an exercise training program run outside the confines of a formal pulmonary rehabilitation program, is a safe intervention ${ }^{14-17}$ that improves symptoms, physical functioning and quality of life (QoL) in these patients. ${ }^{12,14}$ Recently, Marcellis and colleagues observed that in sarcoidosis patients, fatigue, physical functioning, and psychological health all improved in response to physical training. ${ }^{13}$ Our group showed that a 12 -week physical training program improved or maintained exercise capacity in patients with severe fibrotic sarcoidosis or progressive idiopathic pulmonary fibrosis (IPF). ${ }^{18}$

The aim of this study was to examine whether a physical training program supervised by a physical therapist improves fatigue and exercise capacity in sarcoidosis patients.

\section{Materials and methods}

\section{Study design and subjects}

In this retrospective observational study outcomes were compared between sarcoidosis patients who completed an exercise training program and those who did not. Patients were included in the cohort if they were evaluated by the ild care 
expertise team of Hospital Gelderse Vallei, Ede, The Netherlands from 11/2012-9/2014 and underwent testing at baseline and three months later at the department of physical therapy. The diagnosis of sarcoidosis was confirmed by the multidisciplinary ild care expertise team in accordance with accepted guidelines ${ }^{1}$.

Of the 201 patients evaluated 147 underwent the standard baseline testing; 54 did not complete the baseline testing for various reasons (no reason given, no combined appointment possible along with travel distance, etc.). Of these 147 patients, 90 underwent baseline testing and returned for repeat testing at three months. Finally, 49 out of 90 patients completed the training program (Group I) and 41 chose not to participate (Group II) (see also Figure 6.1). Fatigue, exercise capacity and skeletal muscle strength were measured in all 90 patients by the same tester.



Figure 6.1 During the study period data of 201 out patients suffering from sarcoidosis were collected. At baseline, the majority of these patients $(n=147)$ completed a physical assessment and surveys at the department of physical therapy. These patients received a tailored advice and were encouraged to start a 12 -weeks physical training program supervised by a physical therapist in accordance with their physical performance assessed at baseline. In 90 patients a second physical assessment after a 3 month period follow up was achieved. Between-group evaluation of patients who completed a supervised physical training $(n=49)$ and those who decided not to follow a physical training program $(n=41)$ 


\section{Outcome variables}

\section{Body composition}

Height, weight, body mass index (BMI) were measured as reported previously. ${ }^{19}$

\section{Lung function tests}

Forced vital capacity (FVC) and forced expiratory volume in one second (FEV 1 ) were measured with a pneumotachograph (Masterlab, Jaeger, Würzburg, Germany). The diffusing capacity of the lung for carbon monoxide (DLCO) was measured using the single-breath method (Masterlab, Jaeger, Würzburg, Germany). Values were expressed as percentage of the predicted value (i.e., $\mathrm{FVC}$, $\mathrm{FEV}_{1} \%$, and DLCO\% respectively).

\section{Muscle strength}

The maximal isometric grip strength of the dominant hand was measured with the Jamar dynamometer (Fabrication Enterprises Inc., Irvington, NY, USA) and expressed in kilograms (kgs). ${ }^{20}$ Percentage of predicted was calculated using normative data of Mathiowetz and colleagues. ${ }^{21}$ Biceps brachii strength was assessed during elbow flexion with the microFET (Biometrics, Almere, The Netherlands), an electronic hand-held dynamometer. The 'break' method was used to measure the maximal peak force of the dominant arm in Newton (N). The highest value of at least two measurements was recorded. $^{22}$

\section{Exercise capacity}

Maximal oxygen uptake - and other commonly collected variables - were measured during a cardiopulmonary exercise test using the Steep Ramp Test (SRT) protocol on a cycle ergometer. The protocol as described by Meyer et al. was used. ${ }^{23}$ Outcome of the SRT was used to determine estimated $\mathrm{VO}_{2}$ max value according to DeBacker and coworkers. ${ }^{24}$ Reference values determined by McArdle, Katch and Katch were used to classify obtained values. ${ }^{25}$ Maximal oxygen uptake was defined as reduced when values were classified 'very poor' and 'poor' according to McArdle. The six-minute walk test (6MWT) was administered according to the American Thoracic Society Guidelines. ${ }^{26}$ Predicted 6MWD values were calculated according to Gibson and colleagues. ${ }^{27}$

\section{Questionnaires}

Fatigue was measured with the 10-item Fatigue Assessment Scale (FAS). Each item uses a 5-point rating scale, so the total score range is 10 to 50 . Scores below 22 indicate no fatigue; scores of 22-34 indicate mild-moderate fatigue; and scores of 35 or more indicate extreme fatigue. In sarcoidosis, the FAS has acceptable psychometric properties. $^{28}$ The minimal clinically important difference in sarcoidosis is 4 points or a $10 \%$ change. $^{29}$ 
The Borg Rating of Perceived Exertion (RPE) Scale was used to assess perceived exertion during the 6MWT. Scores range from 6 to 20, where 6 means "no exertion at all" and 20 means "maximal exertion." Average breathlessness intensity over a 2-week period was assessed with an 8-point, modified Borg scale (from 0 to 7), for which higher scores indicate greater breathlessness. ${ }^{30}$ Patients also ticked a box to indicate whether their breathlessness was brief, periodic or continuous.

\section{Intervention}

Patients were encouraged to start a 12-weeks physical training program supervised by a physical therapist in accordance with their physical performance assessed at baseline. In accordance with the American Thoracic Society standards, the exercise program contained two major components: aerobic endurance training (stationary cycling, treadmill) and peripheral muscle strengthening (upper- and lower-body). ${ }^{12} \mathrm{~A}$ physical therapist supervised the training program which consisted of twice-weekly, 60 minute sessions that included both components.

The aerobic endurance component was started at a level of $50-60 \%$ of peak work achieved during the SRT. ${ }^{23}$ An interval protocol was used while subjects exercised continuously with a goal time of more than 30 minutes. After a 10 minute warm-up period, subjects completed alternating exercise intervals of 40 seconds at high resistance and 60 seconds at low resistance. After completing 10 intervals, subjects cooled down for five minutes. Intensity and duration were gradually increased (both within sessions and over time) to build tolerance and confidence. During each session, the targeted exercise intensity was $13-15$ on the Borg RPE Scale. ${ }^{31}$ Pulse-oxymetry was used to monitor peripheral oxygen saturation levels during exercise, and supplemental oxygen use during training was commensurate with current prescriptions.

The strength training component consisted on exercises using Life Fitness Circuit Series equipment (Life Fitness, Barendrecht, The Netherlands). During each training sessions, subjects performed three sets of 15-20 repetitions of 6-8 different exercises some lower- and some upper-body. At least two lower body exercises were performed each training session. The resistance level was individualized for each patient (according to patient preference) and reassessed and adjusted after every session using the Borg Score. The targeted exercise intensity was between 13-15 on the Borg score. ${ }^{31}$

\section{Statistical analysis}

Descriptive statistics were generated for baseline characteristics. To examine differences between the two patient groups who participated in this study at baseline, independent sample t-tests (Mann-Whitney $U$ tests) or Chi-square (or Fisher's exact) tests were performed depending on the type of variables and normality of data. Analyses of variance for repeated measures were performed to examine whether the 
effect of the training on fatigue, the MWD, and perceived exertion, taking (if necessary) variables on which the two patient groups differed at baseline into account. Furthermore, a Chi-square test was performed to examine the difference between groups concerning the MCID of fatigue. We considered $p<0.05$ to represent statistical significance. All statistical analyses were performed using SPSS statistical software (version 19.0 for Windows) (SPSS Inc., Chicago, IL, USA).

\section{Results}

Baseline characteristics for the 147 patients with evaluable data-including the 90 patients who returned at three months-are summarized in Table 6.1. Figure 6.1 displays the flow chart of the study.

Table 6.1 Summary of demographic and clinical features of the sarcoidosis outpatients $(n=201)$ referred to the ild care expertise team: 54 patients had no baseline physical measurements at the department of physical therapy, 57 patients only had a measurement at baseline, 90 patients had a measurement at baseline and after 3 months (Group I: followed a supervised physical training program; Group II: no training).

\begin{tabular}{|c|c|c|c|c|c|}
\hline & $\begin{array}{l}\text { No physical } \\
\text { performance } \\
\text { assessment }\end{array}$ & $\begin{array}{c}\text { Baseline } \\
\text { physical } \\
\text { performance } \\
\text { assessment }\end{array}$ & Group I & Group II & Total population \\
\hline \multicolumn{6}{|l|}{ Demographics } \\
\hline Subjects & 54 & 57 & 49 & 41 & 201 \\
\hline females, \% & 42.6 & 43.9 & 42.9 & 24.4 & 39.3 \\
\hline age, yrs & $48.9 \pm 11.3$ & $45.5 \pm 11.3$ & $47.6 \pm 11.3$ & $49.2 \pm 10.5$ & $47.7 \pm 11.2$ \\
\hline $\begin{array}{l}\text { time since diagnosis, } \\
\text { yrs }\end{array}$ & $4.7 \pm 6.5$ & $6.3 \pm 7.9$ & $5.8 \pm 7.0$ & $5.4 \pm 5.5$ & $5.5 \pm 6.9$ \\
\hline $\mathrm{BMI}, \mathrm{kg} / \mathrm{m}^{2}$ & $27.0 \pm 5.8$ & $25.9 \pm 4.1$ & $27.5 \pm 4.4$ & $27.9 \pm 5.3$ & $27.0 \pm 4.9$ \\
\hline \multicolumn{6}{|l|}{ Treatment } \\
\hline no treatment, $\mathrm{n}$ & $17(31.5 \%)$ & $23(40.4 \%)$ & $12(24.5 \%)$ & $13(31.7 \%)$ & $65(32.3)$ \\
\hline glucocorticoids, $\mathrm{n}$ & $23(42.6 \%)$ & $18(31.6 \%)$ & 21 (42.9\%) & $15(36.6 \%)$ & $77(38.3)$ \\
\hline other\#, n & $14(25.9)$ & $16(28.0 \%)$ & $16(32.7 \%)$ & $13(31.7 \%)$ & $59(29.4 \%)$ \\
\hline \multicolumn{6}{|l|}{ Lung function tests } \\
\hline DLCO, \% pred. & $76.8 \pm 17.4$ & $82.2 \pm 16.4$ & $78.8 \pm 18.2$ & $77.9 \pm 18.9$ & $79.1 \pm 17.7$ \\
\hline $\mathrm{FEV}_{1}, \%$ pred. & $91.5 \pm 19.5$ & $92.5 \pm 17.4$ & $85.3 \pm 18.4$ & $85.7 \pm 21.8$ & $88.9 \pm 19.4$ \\
\hline FVC, \% pred. & $98.3 \pm 17.4$ & $99.5 \pm 17.5$ & $91.2 \pm 16.8$ & $94.8 \pm 18.0$ & $96.0 \pm 17.6$ \\
\hline \multicolumn{6}{|c|}{ Chest radiographs stages } \\
\hline 0/I/II/III/IV & $6 / 18 / 24 / 4 / 2$ & $7 / 17 / 23 / 6 / 4$ & $4 / 11 / 22 / 0 / 4$ & $2 / 10 / 21 / 3 / 5$ & $19 / 56 / 90 / 13 / 23$ \\
\hline \multicolumn{6}{|c|}{ Inflammatory markers } \\
\hline $\mathrm{CRP}(\mathrm{mg} / \mathrm{l})$ & $11.6 \pm 39.4$ & $5.3 \pm 10.1$ & $5.6 \pm 7.7$ & $4.6 \pm 4.0$ & $6.7 \pm 20.3$ \\
\hline sIL-2R (U/ml) & $5894 \pm 3688$ & $5126 \pm 2723$ & $5514 \pm 3595$ & $6467 \pm 11807$ & $5705 \pm 6176$ \\
\hline \multicolumn{6}{|l|}{ Fatigue measure } \\
\hline FAS & $29.0 \pm 7.8$ & $30.3 \pm 9.7$ & $29.8 \pm 8.1$ & $30.2 \pm 9.0$ & $29.8 \pm 8.6$ \\
\hline
\end{tabular}

Data are expressed as absolute number or mean \pm SD. BMI: body mass index; DLCO: diffusing capacity of the lung for carbon monoxide; \% predicted: \% of predicted; FEV $_{1}$ : forced expiratory volume in $1 \mathrm{~s}$; FVC: forced vital capacity; CRP: C-reactive protein; sIL-2R: soluble interleukin-2 receptor; FAS: Fatigue Assessment Scale; \# immunosuppressive treatment: methotrexate with or without glucocorticoids. 
At baseline, there were no between-group differences in demographic or clinical variables (e.g., pulmonary function tests, inflammatory markers, radiological findings, peripheral muscle strength or exercise capacity, or treatment (Table 6.2). There were also no between-group differences with regard to fatigue and perceived exertion.

Table 6.2 Difference of physical measurements, fatigue and dyspnea of the sarcoidosis outpatients referred to the ild care expertise team performed at the department of physical therapy at baseline and follow up between Group I and Group II (Group I: followed a supervised physical training program; Group II: no training).

\begin{tabular}{|c|c|c|}
\hline & Group I & Group II \\
\hline Subjects & 49 & 41 \\
\hline \multicolumn{3}{|l|}{$6 \mathrm{MWD}$, meters } \\
\hline at baseline & $513 \pm 102$ & $530 \pm 104$ \\
\hline at follow up & $583 \pm 104$ & $534 \pm 110$ \\
\hline p-value within Groups & 0.0001 & 0.892 \\
\hline \multicolumn{3}{|l|}{ 6MWD, \% pred. } \\
\hline at baseline & $73.6 \pm 12.9$ & $75.3 \pm 14.3$ \\
\hline at follow up & $83.5 \pm 12.2$ & $76.1 \pm 15.2$ \\
\hline p-value within Groups & $<0.0001$ & 0.832 \\
\hline \multicolumn{3}{|l|}{ SRT, watts } \\
\hline at baseline & $260 \pm 68$ & $286 \pm 75$ \\
\hline at follow up & $285 \pm 67$ & $298 \pm 79$ \\
\hline p-value within Groups & 0.074 & 0.497 \\
\hline \multicolumn{3}{|l|}{$\mathrm{SRT}, \mathrm{VO}_{2} \mathrm{max}, \mathrm{ml} / \mathrm{kg} / \mathrm{min}$} \\
\hline at baseline & $25.4 \pm 4.9$ & $26.2 \pm 6.4$ \\
\hline at follow up & $27.7 \pm 5.5$ & $26.6 \pm 6.7$ \\
\hline p-value within Groups & 0.043 & 0.777 \\
\hline \multicolumn{3}{|l|}{ HGS, \% pred. } \\
\hline \multirow[t]{2}{*}{ at baseline } & $89.6 \pm 23.0$ & $92.2 \pm 20.2$ \\
\hline & $(n=42)$ & $(n=38)$ \\
\hline at follow up & $96.3 \pm 21.8$ & $96.0 \pm 19.2$ \\
\hline p-value within Groups & 0.177 & 0.406 \\
\hline \multicolumn{3}{|l|}{ EFMS, \% pred. } \\
\hline at baseline & $\begin{array}{c}98.5 \pm 18.1 \\
(n=41)\end{array}$ & $\begin{array}{c}100.7 \pm 21.8 \\
(n=31)\end{array}$ \\
\hline at follow up & $106.3 \pm 18.1$ & $103.3 \pm 20.5$ \\
\hline p-value within Groups & 0.049 & 0.623 \\
\hline \multicolumn{3}{|l|}{ FAS } \\
\hline at baseline & $29.8 \pm 8.1$ & $30.3 \pm 9.0$ \\
\hline at follow up & $25.6 \pm 7.5$ & $28.6 \pm 9.0$ \\
\hline p-value within Groups & 0.009 & 0.408 \\
\hline \multicolumn{3}{|l|}{ Borg RPE } \\
\hline at baseline & $11.6 \pm 3.7$ & $11.9 \pm 3.0$ \\
\hline at follow up & $11.7 \pm 3.0$ & $12.5 \pm 3.1$ \\
\hline p-value within Groups & 0.782 & 0.381 \\
\hline \multicolumn{3}{|l|}{ Modified Borg } \\
\hline at baseline & $4.1 \pm 3.1$ & $4.2 \pm 2.6$ \\
\hline at follow up & $3.6 \pm 2.9$ & $4.0 \pm 2.2$ \\
\hline p-value within Groups & 0.381 & 0.782 \\
\hline
\end{tabular}

Data are expressed as absolute number or mean \pm SD; \% pred. : \%predicted; 6MWD: 6 minute walking distance; SRT: Steep Ramp Test; $\mathrm{VO}_{2}$ max: maximal oxygen uptake; HGS: hand grip strength; EFMS: elbow flexor muscle strength; FAS: Fatigue Assessment Scale; DLCO: diffusing capacity of the lung for carbon monoxide; \% predicted: $\%$ of predicted; $\mathrm{FEV}_{1}$ : forced expiratory volume in $1 \mathrm{~s}$; FVC: forced vital capacity; RPE: Rating of Perceived Exertion. 
Concerning fatigue we found an interaction effect of time with group ( $F=6.27$, $p=0.014)$. This indicates that while both groups started with the same level of fatigue, Group I showed a significantly larger decrease of fatigue compared with Group II (see Figure 6.2). The change in fatigue was also found when looking at the cut-off scores. At baseline, the majority of patients were fatigued. At three months, FAS scores improved by 4 or more points (i.e., the minimal clinically important difference or MCID) in $74.4 \%$ of the patients in Group I and $48.5 \%$ of patients in Group II ( $p=0.032)$. Lung function tests did not change in either group (data not shown).



Figure 6.2 Mean Fatigue assessment scale (FAS) scores of Group I who followed a supervised physical training program; Group II: no training. In group I the FAS score improved after the 12-weeks physical training program $(p=0.009)$

An interaction effect was also found with regard to the 6MWD, \% norm ( $F=59.5$, $p<0.001$ ). The 6MWD, \% norm for Group I improved between baseline and three months while the 6MWD remained the same in Group II. As shown in Figure 6.3, similar results were found with regard to 6MWD distance (interaction effect: $F=72.2, p<0.001$ ).

Concerning EFMS, \% predicted no significant interaction effect $(p=0.129)$ was found. There is a significant increase across time in both groups $(F=9.25, p=0.003$, but no difference between the two groups $(p=0.907)$. For HGS $\%$ norm no significant interaction effect $(p=0.933)$ was present, but we did find that the $\%$ decreased significantly across time $(F=446.5, p<0.001)$ in both groups. No group difference was found. 

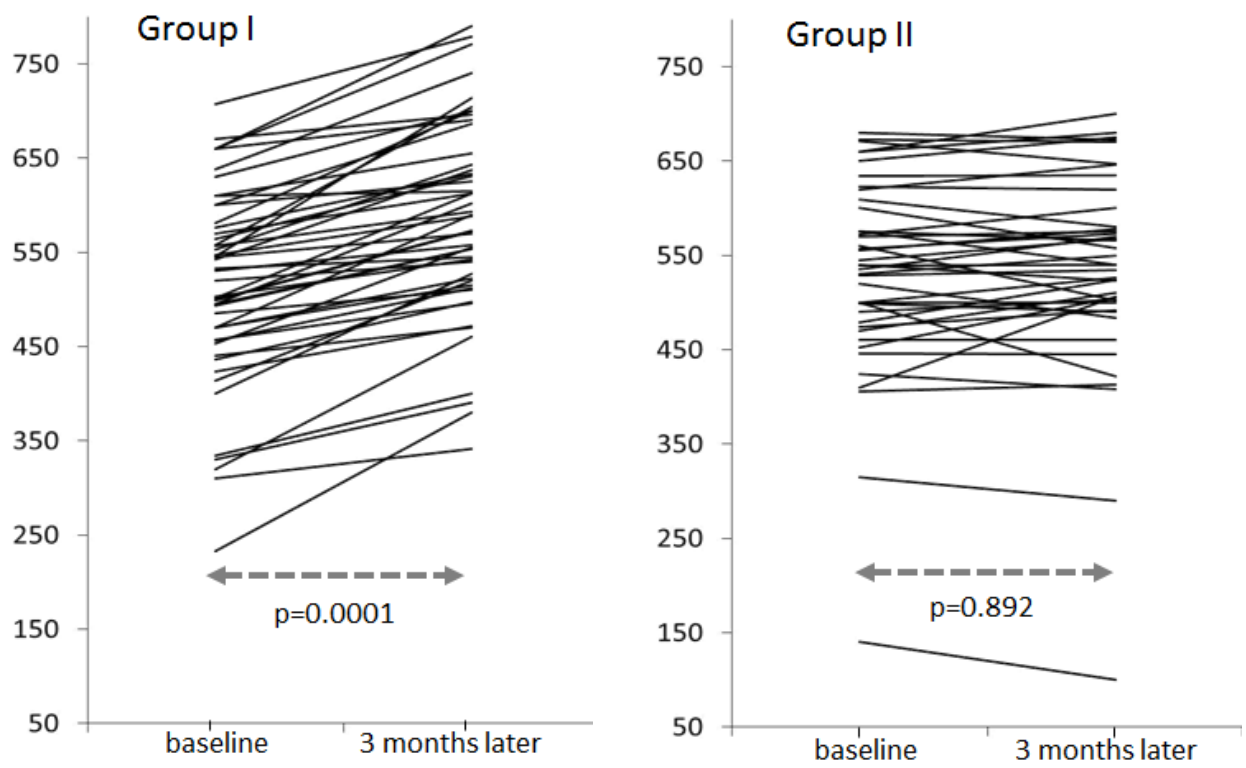

Figure 6.3 Change of the six minute walking distance (meters) between baseline and after three months follow-up: Group I: followed a supervised physical training program; Group II: no training.

With regard to the two types of Borg scores, the Modified Borg and the Borg RPE, no difference was found between the groups and across time.

We did find an interaction effect on the two SRT measures, SRT watts ( $F=4.6$, $\mathrm{p}=0.034)$ and $\mathrm{SRT} \mathrm{VO}_{2} \max , \mathrm{ml} / \mathrm{kg} / \mathrm{min}(\mathrm{F}=6.3, \mathrm{p}=0.014)$ indicating different changes across time for both groups. Although the main effects for both measures showed that the difference between the groups was not significant.

\section{Discussion}

In this study, we observed that a supervised, 12-week, aerobic exercise and strength training program improves exercise performance, strength and fatigue in patients with sarcoidosis. The results were independent of age, gender, time since diagnosis, baseline pulmonary function (and other markers of sarcoidosis severity), inflammatory status or pharmacological interventions. Currently, a program like the one used at our center is not standard of care for patients with sarcoidosis, but we think it should be. The exercise program is similar to those used in pulmonary rehabilitation programs throughout the world; thus, most clinicians caring for sarcoidosis patients have access to this valuable adjunctive therapeutic modality. In fact, we would argue that 
pulmonary rehabilitation should be considered as a first-line therapy for patients suffering from sarcoidosis.

Patients with sarcoidosis are frequently limited by reduced exercise tolerance, muscle weakness and impaired QOL. ${ }^{7,32,33}$ Sarcoidosis imposes a burden on patient's lives and fatigue is ubiquitous among sarcoidosis patients. Exercise programs and pulmonary rehabilitation are beneficial for patients with many respiratory diseases, ${ }^{12}$ and evidence on the benefits of pulmonary rehabilitation (PR) and exercise for sarcoidosis patients is increasing. ${ }^{13,18,34-36}$ Our study builds on the results of a study by Marcellis and co-investigators who observed that fatigue declined and 6MWD and peripheral muscle strength improved after a 13-week physical training program in sarcoidosis patients. ${ }^{13}$ Ryerson and his colleagues found that PR improved exercise capacity in interstitial lung disease (ILD) patients, regardless of baseline 6MWD; and patients with worse baseline functional capacity had greater improvements following PR. ${ }^{37}$ This suggests that motivated patients with relatively severe functional impairment should still be offered PR (unless contraindications exist), because they stand to benefit most.

At baseline, we found strong - but far from perfect - correlations between SRT and both $\mathrm{VO}_{2}$ max and 6MWD. This suggests that the SRT (submaximal exercise test, cycling, not every-day activity in all patients) and 6MWD (submaximal exercise test, walking, every-day activity) assess different aspects of physical functioning. Regardless, the between-groups differences in both variables were significantly greater in the group completing the intervention. Because there is lack of clarity, ${ }^{38}$ future studies are needed to address the issue of which exercise modality (cycle ergometry, walking or both) should be used to assess the effects of interventions aimed at improving physical functional capacity.

Sarcoidosis is a heterogeneous disease, making assessments of disease severity complex. For example, pulmonary function test may not reflect the severity of pulmonary sarcoidosis ${ }^{39}$; thus, incorporating metrics across a broad range of outcomes is needed to generate a comprehensive determination of sarcoidosis severity. This is likely best performed via a multidisciplinary approach ${ }^{5}$ that incorporates the assessment of multiple domains of physical functioning - and because it is so common and intrusive - fatigue. ${ }^{7,40}$ Patients with any chronic illness are at risk for physical inactivity, which in turn can induce general deconditioning. Poor physical conditioning contributes to fatigue, dyspnea and the vicious cycle of more physical inactivity. ${ }^{10,15}$ Our results suggest that physical therapy and exercise are capable of breaking this cycle. Given the complexity of sarcoidosis, and the potential for multi-system involvement, the therapeutic approach to any one patient, including rehabilitation or physical exercise programs, should be comprehensive, well thought-out and tailored to his/her needs. $^{34,41-44}$ 
This study has several limitations. First, it was an observational study, lacking a randomized control group, and blinding was not possible. This could introduce bias. Patients who decided to complete the supervised training program were likely more motivated than the other patients to improve their physical performance. Finally, we did not assess the long term effect of PR. Thus, it is unknown whether these benefits are sustained following a supervised trainings program, and which patients experience the greatest benefits.

In conclusion, a supervised physical training program improves fatigue, exercise capacity and peripheral muscle strength among sarcoidosis patients, these results were independent of age, gender, time since diagnosis, baseline pulmonary function (and other markers of sarcoidosis severity), inflammatory status or pharmacological interventions. Physical training should be included in their management regimen. Further research is required to confirm which patients benefit most from exercise training (including the type offered in pulmonary rehabilitation programs), to determine which components of such a program are most valuable to patients with sarcoidosis, and explore whether there are strategies that can be used to achieve longterm benefits. 


\section{References}

1. Statement on sarcoidosis. Joint Statement of the American Thoracic Society (ATS), the European Respiratory Society (ERS) and the World Association of Sarcoidosis and Other Granulomatous Disorders (WASOG) adopted by the ATS Board of Directors and by the ERS Executive Committee, February 1999. Am J Respir Crit Care Med 1999;160:736-755.

2. Baughman RP, Culver DA, Judson MA. A concise review of pulmonary sarcoidosis. Am J Respir Crit Care Med 2011;183:573-581.

3. Iannuzzi MC, Fontana JR. Sarcoidosis: clinical presentation, immunopathogenesis, and therapeutics. JAMA 2011;305:391-399.

4. Valeyre D, Nunes H, Bernaudin JF. Advanced pulmonary sarcoidosis. Curr Opin Pulm Med 2014;20: 488-495.

5. Valeyre D, Prasse A, Nunes H, Uzunhan Y, Brillet PY, Muller-Quernheim J. Sarcoidosis. Lancet 2014;383:1155-1167.

6. Drent M, Strookappe B, Hoitsma E, De Vries J. Consequences of sarcoidosis. Clin Chest Med 2015;36:727-737.

7. Marcellis RG, Lenssen AF, Elfferich MD, et al. Exercise capacity, muscle strength and fatigue in sarcoidosis. Eur Respir J 2011;38:628-634.

8. Spruit MA, Thomeer MJ, Gosselink R, et al. Skeletal muscle weakness in patients with sarcoidosis and its relationship with exercise intolerance and reduced health status. Thorax 2005;60:32-38.

9. Marcellis RG, Lenssen AF, de Vries J, Drent M. Reduced muscle strength, exercise intolerance and disabling symptoms in sarcoidosis. Curr Opin Pulm Med 2013;19:524-530.

10. Marcellis RGJ, Lenssen AF, Kleynen S, De Vries J, Drent M. Exercise capacity, muscle strength and fatigue in sarcoidosis: a follow-up study. Lung 2013;191:247-256.

11. Drent M, Marcellis R, Lenssen A, De Vries J. Association between physical functions and quality of life in sarcoidosis. Sarcoidosis Vasc Diffuse Lung Dis 2014;31:117-128.

12. Spruit MA, Singh SJ, Garvey C, et al. An official American Thoracic Society/European Respiratory Society statement: key concepts and advances in pulmonary rehabilitation. Am J Respir Crit Care Med 2013;188:e13-64.

13. Marcellis RG, Veeke MAF, Mesters I, et al. Does physical training reduce fatigue in sarcoidosis? Sarcoidosis Vasc Diffuse Lung Dis 2015;32:53-62.

14. Spruit MA, Wouters EFM, Gosselink R. Rehabilitation programmes in sarcoidosis: a multidisciplinary approach. Eur Respir Mon 2005;32:316-326.

15. Braam AW, de Haan SN, Vorselaars $A D$, et al. Influence of repeated maximal exercise testing on biomarkers and fatigue in sarcoidosis. Brain Behav Immun 2013;33:57-64.

16. Holland A, Hill C. Physical training for interstitial lung disease. Cochrane Database Syst Rev 2008:CD006322.

17. Swigris JJ, Brown KK, Make BJ, Wamboldt FS. Pulmonary rehabilitation in idiopathic pulmonary fibrosis: a call for continued investigation. Respir Med 2008;102:1675-1680.

18. Strookappe B, Elfferich MDP, Swigris JJ, et al. Benefits of physical training in patients with idiopathic or end-stage sarcoidosis-related pulmonary fibrosis: a pilot study. Sarcoidosis Vasc Diffuse Lung Dis 2015;32:43-52.

19. Cremers JP, Drent M, Elfferich MD, et al. Body composition profiling in a Dutch sarcoidosis population. Sarcoidosis Vasc Diffuse Lung Dis 2013;30:289-299.

20. Werle S, Goldhahn J, Drerup S, Simmen BR, Sprott H, Herren DB. Age- and gender-specific normative data of grip and pinch strength in a healthy adult Swiss population. J Hand Surg Eur Vol 2009;34:76-84.

21. Mathiowetz V, Wiemer DM, Federman SM. Grip and pinch strength: norms for 6- to 19-year-olds. Am J Occup Ther 1986;40:705-711.

22. Bohannon RW. Make tests and break tests of elbow flexor muscle strength. Phys Ther 1988;68: 193-194.

23. Meyer K, Samek L, Schwaibold M, et al. Physical responses to different modes of interval exercise in patients with chronic heart failure--application to exercise training. Eur Heart J 1996;17:1040-1047.

24. De Backer IC, Schep G, Hoogeveen A, Vreugdenhil G, Kester AD, van Breda E. Exercise testing and training in a cancer rehabilitation program: the advantage of the steep ramp test. Arch Phys Med Rehabil 2007;88:610-616. 
25. McArdle WD, Katch FI, Katch VL. Exercise physiology: Energy, Nutrition, \& Human Performance. Baltimore: Lippincott Williams and Wilkins, 2007

26. ATS statement: guidelines for the six-minute walk test. Am J Respir Crit Care Med 2002;166:111-117.

27. Gibbons WJ, Fruchter N, Sloan S, Levy RD. Reference values for a multiple repetition 6-minute walk test in healthy adults older than 20 years. Journal of cardiopulmonary rehabilitation 2001;21:87-93.

28. Michielsen HJ, Drent M, Peros-Golubicic T, De Vries J. Fatigue is associated with quality of life in sarcoidosis patients. Chest 2006;130:989-994.

29. De Kleijn WP, De Vries J, Wijnen PA, Drent M. Minimal (clinically) important differences for the Fatigue Assessment Scale in sarcoidosis. Respir Med 2011;105:1388-1395.

30. Skevington SM, Pilaar M, Routh D, MaCleod RD. On the language of breathlessness. Psychology \& health 1997;12:677-689.

31. Borg GA. Psychophysical bases of perceived exertion. Med Sci Sports Exerc 1982;14:377-381.

32. Marcellis RG, Lenssen AF, Kleynen S, De Vries J, Drent M. Exercise capacity, muscle strength, and fatigue in sarcoidosis: a follow-up study. Lung 2013;191:247-256.

33. Marcellis RG, Lenssen AF, de Vries GJ, et al. Is there an added value of cardiopulmonary exercise testing in sarcoidosis patients? Lung 2013;191:43-52.

34. Holland AE, Hill CJ, Conron M, Munro P, McDonald CF. Short term improvement in exercise capacity and symptoms following exercise training in interstitial lung disease. Thorax 2008;63:549-554.

35. Huppmann P, Sczepanski B, Boensch M, et al. Effects of inpatient pulmonary rehabilitation in patients with interstitial lung disease. Eur Respir J 2013;42:444-453.

36. Ries AL. Pulmonary rehabilitation: summary of an evidence-based guideline. Respir Care 2008;53: 1203-1207.

37. Ryerson CJ, Garvey C, Collard HR. Pulmonary rehabilitation for interstitial lung disease. Chest 2010;138:240-241; author reply 241-242.

38. Man WD, Soliman MG, Gearing J, et al. Symptoms and quadriceps fatigability after walking and cycling in chronic obstructive pulmonary disease. Am J Respir Crit Care Med 2003;168:562-567.

39. Baughman RP, Lower EE, Gibson K. Pulmonary manifestations of sarcoidosis. Presse Med 2012;41: e289-302.

40. Drent M, Lower EE, De Vries J. Sarcoidosis-associated fatigue. Eur Respir J 2012;40:255-263.

41. De Vries J, Drent M. Quality of life and health status in sarcoidosis: a review of the literature. Clin Chest Med 2008;29:525-532.

42. Hinz A, Brähler E, Möde R, Wirtz H, Bosse-Henck A. Anxiety and depression in sarcoidosis: the influence of age, gender, affected organs, concomitant diseases and dyspnea. Sarcoidosis Vasc Diffuse Lung Dis 2012;29:139-146.

43. Elfferich MD, Nelemans PJ, Ponds RW, De Vries J, Wijnen PA, Drent M. Everyday cognitive failure in sarcoidosis: the prevalence and the effect of anti-TNF-alpha treatment. Respiration 2010;80:212-219.

44. Judson MA. Small fiber neuropathy in sarcoidosis: Something beneath the surface. Respir Med 2011;105:1-2. 


\section{Chapter 7}

Physical activity and training in sarcoidosis: review and experience-based recommendations

B Strookappe, LA Saketkoo, M Elfferich, A Holland, J De Vries, T Knevel, M Drent

Expert Rev Respir Med 2016;10:1057-68 


\section{Abstract}

\section{Introduction}

Sarcoidosis is a multisystemic inflammatory disorder with a great variety of symptoms, including fatigue, dyspnea, pain, reduced exercise tolerance and muscle strength. Physical training has the potential to improve exercise capacity and muscle strength, and reduce fatigue. The aim of this review and survey was to present information about the role of physical training in sarcoidosis and offer practical guidelines.

\section{Areas covered}

A systematic literature review guided an international consensus effort among sarcoidosis experts to establish practice-basic recommendations for the implementation of exercise as treatment for patients with various manifestations of sarcoidosis. International sarcoidosis experts suggested considering physical training in symptomatic patients with sarcoidosis.

\section{Expert commentary}

There is promising evidence of a positive effect of physical training. Recommendations were based on available data and expert consensus. However, the heterogeneity of these patients will require modification and program adjustment of the standard rehabilitation format for e.g. COPD or interstitial lung diseases.

\section{Conclusion}

An optimal training program (types of exercise, intensities, frequency, duration) still needs to be defined to optimize training adjustments, especially reduction of fatigue. Further randomized controlled trials are needed to consolidate these findings and optimize the comprehensive care of sarcoidosis patients. 


\section{Introduction}

Physical training or pulmonary rehabilitation (PR) is an important element of the comprehensive care of people with pulmonary diseases and other chronic diseases, including musculo-skeletal disorders, neurological diseases and psychiatric conditions. ${ }^{1-6}$. Of note, exercise also has a role as treatment in diseases such as those of the locomotive apparatus or respiratory system that do not primarily manifest as organ-specific disorders, but also are accompanied by many other clinical manifestations such as fatigue and other disabling nonspecific symptoms. ${ }^{3,6}$ In selected cases, exercise therapy might be just as effective as medical treatment, and in special situations it might be more effective or add to its effect. ${ }^{6}$

Sarcoidosis, a multi-system inflammatory disorder, has many faces and phenotypes. It may occur at all ages and presents with lung involvement in the majority of cases. ${ }^{7-11}$ Extra-pulmonary manifestations of this disease involve the heart, joints, kidney, liver, eyes, nervous system, and skin. A growing body of evidence has demonstrated the impact of not only organ-specific symptoms but also nonspecific problems, including lack of energy, fatigue, pain, anxiety, depression, and cognitive symptoms, on patients' lives, inducing significant worsening of (health-related) quality of life (HR QoL). ${ }^{10,12-14}$ Multifactorial influences include systemic inflammation, decreased pulmonary function, sleeping disorders, small fiber neuropathy (SFN), sarcoid myopathy, hypoxia or glucocorticoid use, and deconditioning. ${ }^{15-18}$ This can lead to physical inactivity, loss of fitness and muscle strength, and thus increased fatigue. ${ }^{19,20}$ Considerable knowledge has accumulated concerning the significance of exercise as the first-line treatment of several chronic diseases. ${ }^{6}$ To date, no formal consensus exists regarding the role of exercise programs for sarcoidosis.

To collect information about the benefits of physical training in sarcoidosis, a comprehensive literature review was performed, which was then used to guide an international consensus effort among sarcoidosis experts to establish practical recommendations - based on evidence, experience and common sense - for the use of physical training in the management of patients with manifestations of sarcoidosis.

\section{Materials and methods}

This study consisted of four phases.

\section{Phase I}

A computerized comprehensive search of the literature from January 1971 until December 2015 was performed. Results were identified in PubMed, MEDLINE, and CINAHL. Combinations of the following Medical Subject Headings (MeSH) and free text 
words were used: sarcoidosis, interstitial lung disease, physical training, training, physical therapy, exercise, exercise training, exercise capacity, outcome, evaluation.

The following criteria were used to identify relevant studies:

1) Patients: sarcoidosis, interstitial lung disease;

2) Intervention: physical training / exercise training / physical therapy / PR; and

3) Language: English.

We augmented our search by reviewing the reference lists of retrieved articles, including review articles. The initial selection was done by two authors (LAS and BS). Consensus regarding 'title and abstracts' was reached by two authors (MD and BS). Data was extracted by BS and checked by MD, see Figure 7.1. A descriptive summary of studies included presents the study design, participant and treatment characteristics, as well as objective and patient-reported outcomes (see also Table 7.1).

The study quality was assessed by using appropriate instruments, viz. the STROBE Statement ${ }^{21}$ for observational studies and PEDro scale ${ }^{22,23}$ for randomized trials.

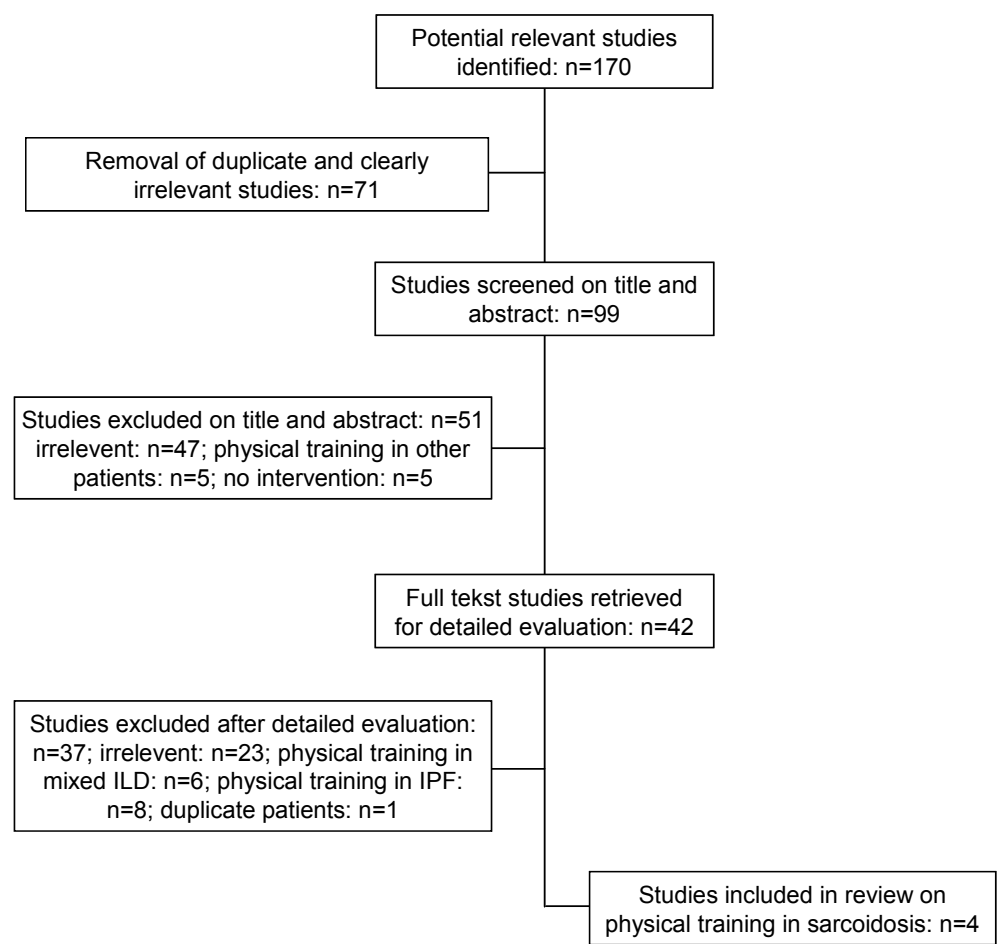

Figure 7.1 Flow-chart of the literature review. 


\section{Phase II}

The results and conclusions from the literature review in Phase I provided key concepts regarding PR and physical training in interstitial lung disease (ILD) and in sarcoidosis. These concepts reflect the scientific efforts and experienced opinion of the expert community.

Thus, Phase II involved content analysis of the literature review (LAS, BS), deconstructing the text of each paper into individual topics and reassembling them into a non-redundant and categorized item list. Each item from Phase II was directly translated into a representative survey question, which together formed the questionnaire used in Phase III of the study.

\section{Phase III}

Phase III comprised an evaluation of physical training in sarcoidosis by international sarcoidosis experts. The active data collection occurred during six weeks in August and September 2015; 165 international sarcoidosis experts were invited by email to complete a web-based survey on physical training in sarcoidosis. The experts selected were members of the World Association of Sarcoidosis and Other Granulomatous Disorders (WASOG) or the American Association of Sarcoidosis and Other Granulomatous Disorders (AASOG), or identified by authorship in peer-reviewed journals in related studies. Additionally, the respondents were subdivided by region: Europe, United States \& Canada, \& other (including Russia, Asia, Australia).

\section{Survey}

The survey consisted of two parts. All participants were asked to complete Part I of the survey, which collected sarcoidosis-specific demographic data including specialty, degree of clinical experience, and perceptions and regional availability of physical training.

Part II of the survey included only participants self-defined as being familiar with physical training in sarcoidosis. Items were divided into two major areas: (1) potential sarcoidosis manifestations (e.g. pulmonary, cardiac) and symptoms (e.g. fatigue, dyspnea) as indications for physical training; and (2) potential domains and tools to monitor the impact of physical training (e.g. fatigue or dyspnea scales, lung function).

The survey items were rated on a 10-point Likert scale from 1 (not at all) to 10 (absolutely) anchored in either useful or appropriate depending on the item content. This included the degree of appropriateness of physical function testing (e.g. exercise capacity, muscle function, activities of daily living) as part of the standard assessment of any patient with sarcoidosis. Additionally, open-ended questions were posed, such as those querying relative contraindications of physical training in sarcoidosis. Finally, participants ranked the top three domains for monitoring physical training in sarcoidosis. 


\section{Phase IV}

In Phase IV, results obtained during phases I and III were assembled to prepare 10 recommendations (MD, LAS, BS). Finally, the recommendations were submitted to a panel of 15 leading international sarcoidosis experts familiar with exercise in sarcoidosis who each saw over 100 new sarcoidosis patients a year. The experts indicated their level of agreement on a 10-point Likert scale from 1 (no agreement) to 10 (full agreement) ${ }^{24}$. The experts were also asked to comment on each recommendation. The specific comments on the recommendations were gathered and grouped (by BS and MD), and recommendations were refined on the basis of these comments. Recommendations with an agreement level less than $75 \%$ were excluded from the final selection.

\section{Statistical analysis}

Standard proportional analyses were performed on aggregate responses. Chi-square analyses were used to assess regional differences. Descriptive statistics were used for the recommendations of Phase IV. All statistical analyses were performed using SPSS statistical software (version 22.0 for Windows, SPSS Inc., Chicago, IL, USA).

\section{Results}

\section{Phase I}

A systematic literature review (Figure 7.1) yielded 42 studies on pulmonary rehabilitation (PR) or physical training in ILD. Twenty-three were irrelevant after detailed evaluation, eight studied patients suffering from idiopathic pulmonary fibrosis (IPF), six patients with mixed ILD aetiology, and one study analyzed patients also included in one of the other included studies. Therefore, finally only four studies were included. Average observational study quality, assessed by the STROBE checklist, was 25 out of 34 points (range 20-30). The quality of the randomized trial, assessed by the PEDro scale, was 9/11, see also Table 7.1.

Two of the four included studies were retrospective cohort studies, ${ }^{25,26}$ one was a prospective cohort study, ${ }^{27}$ and one was a randomized controlled trial. ${ }^{28}$ Specific information regarding patient characteristics for the sarcoidosis subpopulation in the study by Huppmann et al. could not be determined from the paper nor from personal correspondence with the authors. ${ }^{25,29}$ Information regarding the outcomes for the sarcoidosis subpopulation was presented by the authors in personal correspondence. ${ }^{29}$

The age of the patients was similar across all other studies (average 48 years), and the percentage of women in the studies was also similar (ranging from $42 \%$ to $66 \%$ ). However, the study by Marcellis et al. had a smaller proportion of women (22\%). ${ }^{27}$ 
Chest radiographic stages showed some variance across the study populations. The sarcoidosis patients in the study by Karadalli et al. all had chest X-ray stage I or II. ${ }^{28}$ In the other two studies most patients had stage II or III (50-66\%). ${ }^{26,27}$

The majority of patients were outpatients who performed their specific training regimen two to three times a week. ${ }^{26,27}$ Patients in the study by Huppmann et al. trained four to five times a week on an inpatient basis. ${ }^{25}$ The interventions consisted of endurance training, peripheral muscle training ${ }^{26,27}$ and inspiratory muscle training, ${ }^{28}$ exercise training, breathing training and education. ${ }^{25}$

Each study suggested benefits in the areas of exercise capacity, fatigue, and QoL. $^{25-28}$

In all studies, exercise capacity (6-minute walking distance, 6MWD) improved, ranging from 34 to $70 \mathrm{~m}$ improvement. In the study of Marcellis et al. and Strookappe et al. fatigue decreased significantly, -2.7 points $(\mathrm{Cl}-4.4$ to 1.1$)$ and $-4.2(\mathrm{Cl}-5.4$ to -2.7$)$ points on the Fatigue Assessment Scale (FAS), respectively. ${ }^{26,27}$ Huppmann et al. and Marcellis et al. found improvement of health status. ${ }^{25,27}$ Marcellis et al. also showed improvement of quadriceps femoris muscle strength (+10.7 kg; $\mathrm{Cl} 5.5$ to 15.9$).{ }^{27}$ In the RCT of Karadalli et al. patients who performed the inspiratory muscle training program improved their inspiratory strength significantly compared with the controls (PImax $+45.9 \mathrm{cmH} 2 \mathrm{O}, \mathrm{Cl} 39.3$ to $52.8, \mathrm{p}<0.001)^{28}$

More information is provided in Table 7.1.

\section{Phase II}

Content analysis of the literature review resulted in 28 draft recommendations, 10 of which were related to specified symptoms or organ manifestations that justified indications for physical training, 15 to clinical endpoints in physical training, and three to general assessment in sarcoidosis. These were further deconstructed and translated into discrete survey items with 28 questions and 15 suggestions for rating and priority ranking.

\section{Phase III}

In phase III of the study, 165 of the world's leading sarcoidosis experts of varying specialties were consulted with a web-based survey, of whom 108 (65\%) participated. The great majority of the participants were pulmonologists (82\%). Other specialists and healthcare workers included: rheumatologists (7\%), internists (4\%), cardiologists (3\%), neurologists (2\%), and other specialists (all $<1 \%$, including immunologists, physical therapists, and oncologists). More than half (55\%) had more than 15 years' experience with sarcoidosis $(70 \%>10$ years). Of the overall patient populations seen by the participants $61 \%$ had severe pulmonary sarcoidosis and $49 \%$ had severe extrapulmonary sarcoidosis. Participant demographics are shown in Table 7.2. 


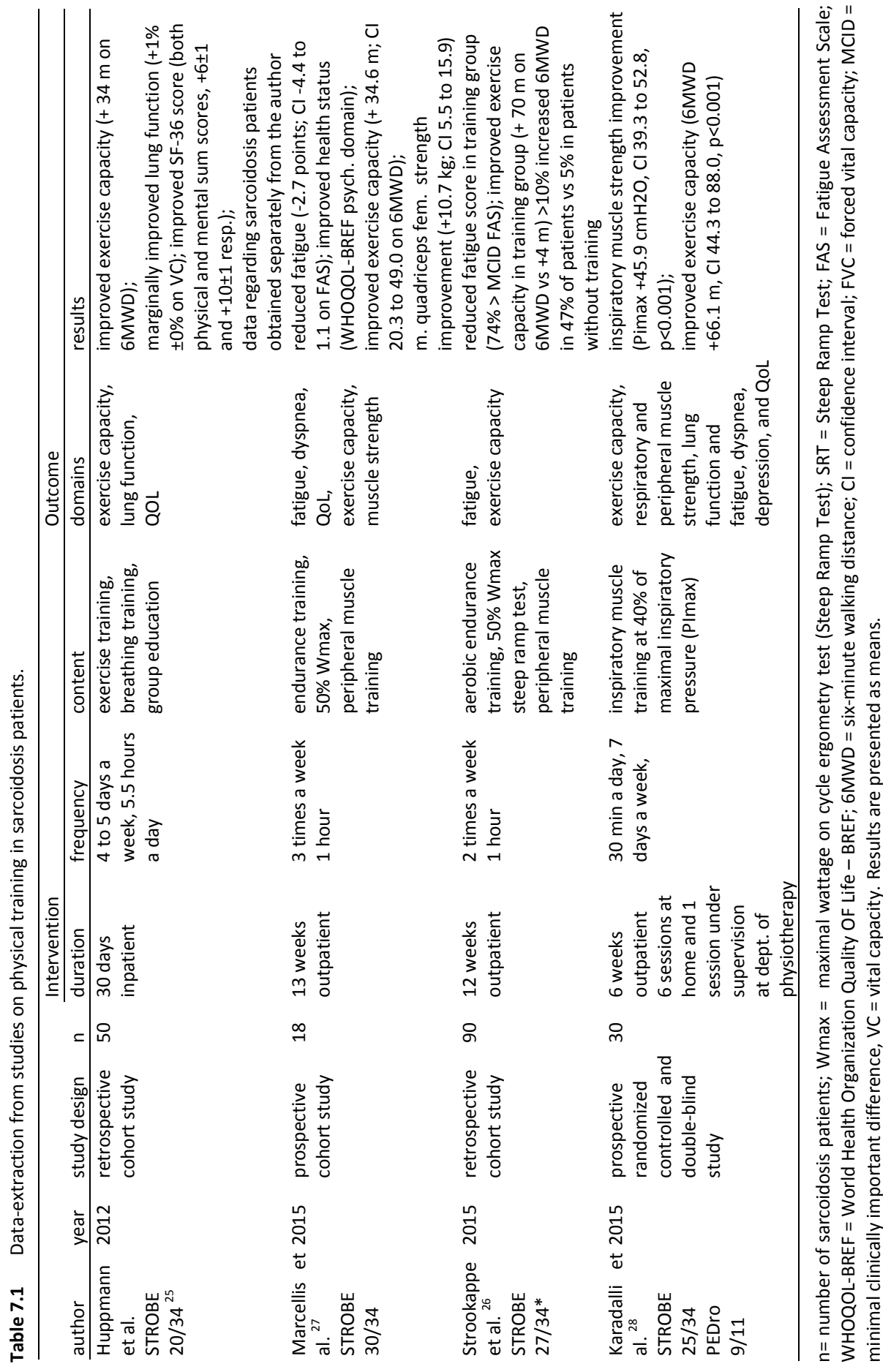


Table 7.2 Demographics of respondents to the survey ${ }^{79-81}$.

\begin{tabular}{|c|c|c|c|c|}
\hline & $\begin{array}{c}\text { Europe } \\
n=54\end{array}$ & $\begin{array}{l}\text { US \& Canada } \\
n=27\end{array}$ & $\begin{array}{l}\text { Other } \\
\mathrm{n}=27\end{array}$ & $\begin{array}{c}\text { Total population } \\
\mathrm{n}=108 \\
\end{array}$ \\
\hline \multicolumn{5}{|l|}{ Age, years } \\
\hline $31-45 / 46-60 />60, \%$ & $26 / 54 / 20$ & $41 / 37$ / 22 & $55 / 30 / 15$ & $36 / 45 / 19$ \\
\hline \multicolumn{5}{|l|}{ Specialty } \\
\hline Pulmonologist, \% & 85 & 74 & 82 & 82 \\
\hline \multicolumn{5}{|l|}{ Experience, years } \\
\hline $0-5 / 5-10 / 1015 / 15 / 25 />25, \%$ & $6 / 15 / 18 / 28 / 33$ & $15 / 26 / 7 / 19 / 33$ & $4 / 37 / 11 / 26 / 22$ & $7 / 23 / 14 / 25 / 31$ \\
\hline \multicolumn{5}{|l|}{$\begin{array}{l}\text { Percentage of patients with } \\
\text { pulmonary sarcoidosis }\end{array}$} \\
\hline $\begin{array}{l}\text { less severe (chest X-ray } \\
\text { stage } 0-I), \%\end{array}$ & $37 \pm 24$ & $32 \pm 25$ & $47 \pm 26$ & $38 \pm 25$ \\
\hline $\begin{array}{l}\text { severe (chest X-ray } \\
\text { stage II-IV), \% }\end{array}$ & $61 \pm 25$ & $68 \pm 24$ & $53 \pm 26$ & $61 \pm 25$ \\
\hline \multicolumn{5}{|l|}{$\begin{array}{l}\text { Percentage of patients with } \\
\text { extra-pulmonary sarcoidosis }\end{array}$} \\
\hline less severe , \% & $45 \pm 26$ & $41 \pm 24$ & $60 \pm 31$ & $48 \pm 27$ \\
\hline severe, $\% *$ & $54 \pm 27$ & $59 \pm 23$ & $30 \pm 25$ & $49 \pm 28$ \\
\hline
\end{tabular}

*Severe: clinically relevant lesions for which treatment is recommended

The majority of participants rated physical training as valuable in sarcoidosis $(81 \%$, $n=87)$. Only $3 \%(n=4)$ considered it not valuable and $16 \%(n=17)$ expressed being uncertain about this. These latter respondents also indicated being unfamiliar with physical training in sarcoidosis. The majority of respondents $(69 \%, n=75)$ reported that their patients generally had access to physical training. However, insurance coverage of and access to physical training for sarcoidosis were available only in some regions (see Table 3). Most respondents $(62 \%, n=67)$ would refer patients 'regularly, often or always' if physical training was available for sarcoidosis, with pulmonary involvement and fatigue being the most prominent indications for referral (see Table 7.3).

Respondents familiar with physical training in sarcoidosis $(n=60)$ also completed part II of the survey. In their assessment of physical training, several domains were rated as important (median Likert 1-10, range for all respondents): QoL (9; range 2-10), exercise capacity (9; range 2-10), activity level (9; range $3-10)$, fatigue (8.5; range $0-10)$, health status (8; range 2-10), muscle strength (8; range 2-10), dyspnea (8; range 0-10), and mental health (8; range $2-10)$. The highest levels of agreement on indications for physical training were pulmonary involvement, fatigue, and muscular and extrapulmonary involvement (see Table 7.4). Sarcoidosis experts from Europe reported a higher likelihood of physical training referral for extra-pulmonary sarcoidosis than respondents from other regions. 
Table 7.3 Questions on physical training in sarcoidosis.

\begin{tabular}{|c|c|c|c|c|}
\hline & $\begin{array}{c}\text { Europe } \\
\mathrm{n}=54\end{array}$ & $\begin{array}{l}\text { US \& Canada } \\
\qquad n=27\end{array}$ & $\begin{array}{l}\text { Other } \\
\mathrm{n}=27\end{array}$ & $\begin{array}{c}\text { Total population } \\
\mathrm{n}=108 \\
\end{array}$ \\
\hline \multicolumn{5}{|l|}{$\begin{array}{l}\text { Are you familiar with physical } \\
\text { training in sarcoidosis? }\end{array}$} \\
\hline yes / no, \% & $65 / 35$ & $70 / 30$ & $41 / 59$ & $60 / 40$ \\
\hline $\begin{array}{l}\text { Do you consider physical } \\
\text { training valuable in sarcoidosis? }\end{array}$ & & & & \\
\hline $\begin{array}{l}\text { yes / no / not sufficiently } \\
\text { familiar, } \%\end{array}$ & 89 / 4 / 7 & $78 / 0 / 22$ & $67 / 4 / 30$ & $81 / 3 / 16$ \\
\hline \multicolumn{5}{|l|}{$\begin{array}{l}\text { Physical training is available in } \\
\text { the region where I work for } \\
\text { sarcoidosis patients. }\end{array}$} \\
\hline $\begin{array}{l}\text { yes / no / not sufficiently } \\
\text { familiar, \% } \\
\text { If you do have access to physical } \\
\text { training are you likely to refer } \\
\text { sarcoidosis patients? }\end{array}$ & 72 / 20 / 8 & $67 / 26 / 7$ & $56 / 33$ / 11 & $67 / 25 / 8$ \\
\hline regularly / often / always, \% & 67 & 59 & 67 & 65 \\
\hline $\begin{array}{l}\text { never / occasionally, \% } \\
\text { Physical training is reimbursed } \\
\text { by health insurers for } \\
\text { sarcoidosis patients in my } \\
\text { country. }\end{array}$ & 33 & 41 & 33 & 35 \\
\hline $\begin{array}{l}\text { yes / sometimes/ not sufficiently } \\
\text { familiar, \% }\end{array}$ & $26 / 32$ / 41 & $7 / 56 / 37$ & 19 / 22 / 59 & $20 / 36 / 44$ \\
\hline $\begin{array}{l}\text { Regional restrictions have kept } \\
\text { me from referring patients to } \\
\text { physical training. }\end{array}$ & & & & \\
\hline $\begin{array}{l}\text { yes / no / not sufficiently } \\
\text { familiar, } \%\end{array}$ & 41 / 46 / 13 & 44 / 44 / 12 & 44 / 41 / 15 & 43 / 44 / 13 \\
\hline
\end{tabular}

Table 7.4 Indications for physical training in sarcoidosis.

\begin{tabular}{lcccc}
\hline $\begin{array}{l}\text { Do you perceive physical } \\
\text { training to be beneficial in } \\
\text { sarcoidosis patients with: }\end{array}$ & $\begin{array}{c}\text { Europe } \\
\mathrm{n}=32\end{array}$ & $\begin{array}{c}\text { US \& Canada } \\
\mathrm{n}=15\end{array}$ & $\begin{array}{c}\text { Other } \\
\mathrm{n}=13\end{array}$ & $\begin{array}{c}\text { Total population } \\
\mathrm{n}=60\end{array}$ \\
\hline Pulmonary involvement & $8.2 \pm 1.7$ & $8.2 \pm 1.2$ & $7.9 \pm 1.7$ & $8.1 \pm 1.6$ \\
Mild pulmonary involvement & $6.7 \pm 2.7$ & $6.3 \pm 3.0$ & $6.7 \pm 2.8$ & $6.6 \pm 2.7$ \\
No pulmonary involvement ${ }^{a}$ & $7.7 \pm 1.9$ & $6.8 \pm 2.2$ & $5.9 \pm 2.9$ & $7.1 \pm 2.3$ \\
Fatigue & $8.2 \pm 1.7$ & $7.5 \pm 2.1$ & $7.3 \pm 2.8$ & $7.8 \pm 2.2$ \\
Small fiber neuropathy & $6.4 \pm 2.5$ & $5.9 \pm 2.7$ & $6.8 \pm 2.8$ & $6.4 \pm 2.6$ \\
Arthritis & $6.2 \pm 2.4$ & $6.6 \pm 2.4$ & $5.3 \pm 2.2$ & $6.1 \pm 2.4$ \\
Muscular involvement & $7.3 \pm 2.5$ & $6.9 \pm 2.6$ & $7.0 \pm 2.5$ & $7.1 \pm 2.5$ \\
Neurosarcoidosis & $6.2 \pm 2.4$ & $5.7 \pm 3.0$ & $6.7 \pm 2.4$ & $6.2 \pm 2.5$ \\
Cardiac involvement & $5.7 \pm 2.0$ & $6.7 \pm 2.9$ & $5.6 \pm 2.6$ & $6.0 \pm 2.4$ \\
\hline
\end{tabular}

Likert 0-10. Data are expressed as mean \pm SD. $p<0.05:^{a}$ Europe vs Other.

Half of the respondents considered physical training a safe intervention in sarcoidosis without need for restrictions. Almost $50 \%$ of respondents (29/60) indicated 
situations of potential harm from physical training, e.g. for patients with cardiac involvement (e.g. untreated arrhythmias $(n=17,28 \%)$ ) or sarcoidosis associated pulmonary hypertension.

\section{Phase IV}

In Phase IV, results obtained during phases I and III were assembled to prepare 10 recommendations (MD, LAS, BS). (see section 2.5) The recommendations were reviewed by 15 leading international sarcoidosis experts familiar with exercise in sarcoidosis. Recommendations with an agreement level less than $75 \%$ were excluded from the final selection. This review process lead to the exclusion of two recommendations, resulting in the final eight recommendations.

The eight key remaining recommendations are presented in Table 7.5, with their levels of agreement. The mean level of agreement for the total set of these initial recommendations among the 15 leading sarcoidologists was $7.8 \pm 0.8$.

Table 7.5 International experts' recommendations for the use of physical training in sarcoidosis.

\begin{tabular}{|c|c|c|c|}
\hline & Recommendation & $\begin{array}{l}\text { agreement* } \\
\text { (mean } \pm \text { SD) }\end{array}$ & $\begin{array}{l}\mathrm{LoE}^{* * \&} \\
\mathrm{GoR}^{* *}\end{array}$ \\
\hline 1 & $\begin{array}{l}\text { The cause of fatigue in sarcoidosis patients can be multifactorial. Therefore } \\
\text { other causes beside sarcoidosis-associated fatigue should be excluded. }\end{array}$ & $9.7 \pm 0.6$ & $\begin{array}{c}2 B \\
C\end{array}$ \\
\hline 2 & $\begin{array}{l}\text { Standardized fatigue assessment (with a validated instrument, e.g. FAS) is } \\
\text { recommended in the work-up of sarcoidosis patients. }\end{array}$ & $7.0 \pm 2.4$ & $\begin{array}{c}2 \mathrm{~B} \\
\mathrm{~B}\end{array}$ \\
\hline 3 & $\begin{array}{l}\text { In the assessment of the severity and extent of the disease in symptomatic } \\
\text { sarcoidosis patients with fatigue and/or exercise limitation, evaluation of } \\
\text { exercise capacity (submaximal or maximal exercise test, e.g. 6MWD, CPET) as } \\
\text { well as muscle strength assessment should be considered. }\end{array}$ & $7.2 \pm 2.4$ & $\begin{array}{c}2 B \\
C\end{array}$ \\
\hline 4 & $\begin{array}{l}\text { To achieve improvement of sarcoidosis-associated fatigue, a physical training } \\
\text { program is recommended in symptomatic sarcoidosis patients, } \\
\text { complementary to the medical treatment. }\end{array}$ & $7.7 \pm 2.9$ & $\begin{array}{c}2 B \\
C\end{array}$ \\
\hline 5 & $\begin{array}{l}\text { Symptomatic sarcoidosis patients with fatigue and/or exercise limitation } \\
\text { suffering from various manifestations might benefit from a supervised } \\
\text { physical training program, not only patients with pulmonary manifestations. }\end{array}$ & $7.6 \pm 3.1$ & $\begin{array}{c}2 B \\
C\end{array}$ \\
\hline 6 & $\begin{array}{l}\text { A correctly monitored supervised physical training program in sarcoidosis is } \\
\text { safe and has no absolute contraindications based on its acceptable safety } \\
\text { profile. However, manifestations of pulmonary hypertension and cardiac } \\
\text { involvement should be considered as relative contraindications and caution } \\
\text { should be exercised by the qualified supervisors. }\end{array}$ & $7.7 \pm 2.4$ & $\begin{array}{l}5 \\
D\end{array}$ \\
\hline 7 & $\begin{array}{l}\text { When starting physical training in symptomatic sarcoidosis, standardized } \\
\text { evaluation of exercise capacity (e.g. } 6 \mathrm{MWD} \text { ), muscle strength and fatigue, } \\
\text { (e.g. FAS) is recommended at baseline and after completion of the program. }\end{array}$ & $7.5 \pm 2.9$ & $\begin{array}{c}3 B \\
C\end{array}$ \\
\hline 8 & $\begin{array}{l}\text { Aerobic endurance training and peripheral muscle strengthening are both } \\
\text { recommended in a supervised physical training program for sarcoidosis } \\
\text { patients. }\end{array}$ & $7.6 \pm 2.8$ & $\begin{array}{c}3 B \\
C\end{array}$ \\
\hline
\end{tabular}

LoE = Levels of Evidence; GoR = Grade of Recommendations. FAS=Fatigue Assessment Scale; 6MWD= sixminute walking distance; $\mathrm{CPET}=$ cardio-pulmonary exercise test. ${ }^{*}$ The level of agreement was measured on a on a 10-point Likert scale (from 1, no agreement, to 10 , full agreement). ** Level of Evidence and Grade of Recommendation according to Oxford Centre for Evidence-Based Medicine. 


\section{Discussion}

Physical activity brings health benefits. ${ }^{31,32}$ However, the best way to implement this awareness into the care of sarcoidosis patients to reduce physical inactivity and fatigue has to be explored. A comprehensive literature review was performed regarding the role of physical training in sarcoidosis patients, to guide an international consensus effort among sarcoidosis experts to establish practical recommendations for the use of physical training in the management of various manifestations of sarcoidosis. Although relatively few studies have been done so far, there is encouraging evidence of a positive effect of physical training on the devastating symptoms of sarcoidosis. Despite the paucity of studies, available data and scientific rationale induced a multinational committee of sarcoidosis experts to recommend that sarcoidosis patients might benefit from supervised tailored physical training with serial assessment of muscle strength and exercise capacity. Physical training was recognized as a strategy to reduce fatigue and dyspnea, as well as to improve QoL.

\section{Heterogeneity of sarcoidosis}

Due to the heterogeneity of the disease and the diversity in severity, sarcoidosis patients may present with a variety of organ-related symptoms and functional impairments. Moreover, they are often affected by rather nonspecific disabling symptoms. In addition to the impact of inflammation and treatment on muscles on the one hand, there is a well-described relationship between reduced physical activity/deconditioning, fatigue and exercise intolerance with peripheral muscle integrity, comparable to that in other chronic diseases, not only respiratory disorders on the other hand. ${ }^{3,6,26}$ This underlines that the treatment should be individualized and tailored to the personal needs, and cover all clinically relevant symptoms (see also Table 7.5). Due to its complexity, sarcoidosis requires a multidisciplinary approach. ${ }^{10,33}$

\section{Fatigue and dyspnea}

Fatigue is the most frequently described and disabling symptom in sarcoidosis and can be nonspecific and difficult to characterize for both patients and clinicians. ${ }^{20,34}$ Sarcoidosis-associated fatigue and exercise capacity have important associations with QoL, especially in the domain of physical health ${ }^{17,35-38}$. Even so, the fatigue associated with systemic inflammation is multi-dimensional and can be sub-classified as general, mental, physical, or motivational fatigue. Inflammation-related fatigue exerts cytokine/chemokine influences on the hypothalamus, muscle (including respiratory muscles), nerve and bone, leading to mental exhaustion, sleep disorders, loss of muscle and bone mass and autonomic dysfunction, as well as the exhausting psychological burden of pain in addition to that of living with a chronic illness. In patients with sarcoidosis, sarcoidosis-associated pulmonary hypertension, and sleep apnea are important disease aspects that are potential causes of fatigue, which need to be 
excluded. ${ }^{20,39-41}$ Fatigue can also be a consequence of the treatment itself, such as corticosteroid therapy, which also affects the hypothalamic axis as well as other endocrine functions and muscle health ${ }^{7}$. Like fatigue, dyspnea is a significant symptom and multifactorial phenomenon in sarcoidosis. ${ }^{39,42-47}$ Dyspnea appears to be related to fatigue, low levels of energy, and chest pain. ${ }^{27,44,47,48}$ However, the degree of dyspnea in sarcoidosis does not correlate with lung function tests. ${ }^{49}$

In line with the studies done so far, practical recommendations (Table 7.5) show that fatigue was considered by the sarcoidosis experts to be a key element in the management of sarcoidosis patients. This makes assessment of fatigue an important metric in addition to objective clinical and laboratory data. Accordingly, it was recommended by 15 leading sarcoidologists that measurement of patient-reported fatigue in combination with assessment of physical activity and functional performance may offer useful clinical information in the evaluation of fatigue in patients with sarcoidosis. Moreover, it was recognized that - as the etiology of fatigue is elusive and may be multi-factorial - the diagnosis of sarcoidosis-associated fatigue requires extensive evaluation to identify and treat potentially reversible causes including nondisease related causes such as hypothyroidism (Table 7.5).,

\section{Muscle strength and deconditioning}

Patients with sarcoidosis may experience respiratory as well as limb muscle dysfunction, and the ensuing deconditioning, inactivity and exercise tolerance. ${ }^{3,5,11,19,26,50}$ Wirnsberger et al. found reduced respiratory muscle strength and endurance time in a small population of sarcoidosis patients with normal lung function. ${ }^{51}$ More recently, it was demonstrated that not only fatigue but also exercise intolerance and muscle weakness were frequently reported, with substantial reduction of maximal inspiratory pressure $(\mathrm{PI}, \mathrm{max}){ }^{11}$ Interestingly, maximal inspiratory and expiratory mouth pressures in sarcoidosis patients demonstrated a more consistent gradual decline with increasing dyspnea and diminishing activity levels than lung volumes and gas transfer. ${ }^{52}$

However, the assessment of muscle strength is variable in clinical practice. The Biodex System 3 Pro Dynamometer (Biodex Medical Systems, Shirley, New York, USA), which is the gold standard in muscle strength testing, was used to assess muscle function in sarcoidosis. However, this system is quite expensive, not portable, and has limited availability in clinical practice, which limits its practical usability. The microFET (Biometrics, Almere, The Netherlands), used in the study of Marcellis et al. and Strookappe et al., is a hand-held dynamometer and could offer a reliable alternative to measure peripheral muscle strength. ${ }^{26,27,53}$

Although asymptomatic muscle involvement in sarcoidosis has been reported in up to $80 \%$ of cases, symptomatic involvement is thought to be less frequent. ${ }^{7,54-57}$ Symptomatic muscle involvement may include palpable nodules, acute myositis, and chronic myopathy with or without functional impairment. ${ }^{58}$ According to the results reported in the literature, respiratory as well as limb muscle dysfunction are also 
important in considering when to start a physical training program. These latter considerations were appreciated by the experts as recommendation (Table 7.5). Whether impaired respiratory muscle function impacts on morbidity and mortality, in sarcoidosis as in other ILDs, needs to be further investigated. ${ }^{59}$

\section{Small fiber neuropathy}

Small fiber neuropathy (SFN) has been recognized as a serious phenomenon in sarcoidosis. ${ }^{60}$ Symptoms affecting the autonomic nervous system generally take the form of pain, constipation, incontinence, and in some cases erectile dysfunction and orthostatic hypotension. Patients also experience insomnia and depression at an advanced stage of the disease, with some patients experiencing memory problems and a lack of concentration and initiative. ${ }^{61}$ There is a positive association between SFNassociated symptoms and fatigue. ${ }^{17,62}$ Moreover, SFN may at least partly explain muscle dysfunction and exercise limitations. Since symptoms of SFN are disabling for patients, they can also significantly reduce their health status. ${ }^{62-64}$ To date, SFN itself is often difficult to treat. ${ }^{10,65}$

\section{Side effects of medical treatment}

Medical treatment for sarcoidosis is often associated with burdensome side-effects, with glucocorticoids being known to cause myopathy, ${ }^{66}$ fatigue, psychological burden, and sleeping problems. ${ }^{40,45,67}$ In a study among 25 patients with sarcoidosis only in the patients who received oral corticosteroid treatment $(n=11)$ was the quadriceps peak torque was inversely related to the mean daily dose of corticosteroids received in the 6 months before testing. ${ }^{18}$ Thus, steroid myopathy may be a clinically relevant entity in sarcoidosis, especially with intensified corticosteroid treatment. However, two studies found that the medication did not contribute much and does not impact on the health status more than the symptoms of sarcoidosis. ${ }^{14,47}$ Sarcoidosis-related muscle effects at the tissue, cellular, and molecular levels require further investigation.

\section{Quality of life}

The majority of patients with sarcoidosis have impaired QoL and health status due to the burden of the disease, leading to limitations in activities of daily living, social isolation and depression. ${ }^{10,13-15}$ In line with others, Salligan demonstrated in a small study that sarcoidosis patients were more fatigued, more depressed, more dyspneic, and less physically active, and had lower physical performance than their age- and racematched controls. ${ }^{68}$

Sarcoidosis-related complaints, including fatigue, may become chronic and affect patients' QoL even after all other signs of disease activity have disappeared; this appears to be unique to sarcoidosis-related fatigue as compared to other inflammatory conditions. $^{34,69}$ Physicians generally assess disease severity and progression in sarcoidosis on the basis of so-called 'objective measures' such as pulmonary function 
tests, chest radiographs, and serologic tests. However, these parameters correlate poorly with the patients' subjective sense of well-being. Marcellis et al. demonstrated that fatigue and QoL were closely correlated over a 2-year follow-up period, suggesting that reduced muscle strength and exercise intolerance underlie fatigue in sarcoidosis. ${ }^{43}$ Inspiratory muscle endurance and quadriceps strength each correlated strongly with Medical Outcomes Study 36-item Short Form Health Survey (SF-36) scores, especially the physical subscales. ${ }^{70}$ In recent years patient-related outcome measures (PROMs) have gained increasing recognition in terms of their value in clinical trials to quantify patient-perceived health status, which is now a standard outcome measure. ${ }^{13}$ Moreover, patient involvement can influence the priorities of clinical care. In the management of sarcoidosis, therapeutic approaches should include strategies to restore QoL, with special emphasis on energy and fatigue. ${ }^{9,36}$ In terms of the impact on patients' lives, lack of energy, physical impairment, and fatigue are the most important QoL domains affecting them. Therefore, in line with the results of earlier studies, the experts agreed on recommending a physical training program in sarcoidosis patients suffering from substantial symptoms, complementary to the medical treatment (Table 7.5).

\section{Physical training in sarcoidosis}

The literature review revealed that the evidence for the role of physical training is limited but promising (Table 7.1). ${ }^{25-28}$ The only three currently available observational non-randomized studies and one randomized controlled trial evaluating physical training in sarcoidosis found significant and clinically relevant benefits. ${ }^{25-28}$ Two studies reported that a physical training program improved exercise capacity and muscle strength and reduced fatigue in sarcoidosis, and recommended that physical training be included as a first-line therapy in sarcoidosis. ${ }^{26,27}$ Both Marcellis et al. and Strookappe et al. found a significantly greater decrease of fatigue in physical training groups compared with the patients who did not complete a physical training program. These findings show consistent observational relationships between fatigue and reduced $6 \mathrm{MWD}$, respiratory muscle weakness, and reduced peripheral muscle strength, as well as significant tandem improvement in sarcoidosis-associated fatigue, psychological health, and physical functioning after a period of physical training. ${ }^{26,27}$ Huppmann et al. described that an inpatient PR program had a positive impact on the functional status and HR QoL of patients with ILD, including sarcoidosis patients ( $n=50 ; 12 \%){ }^{25,29}$ In the original article, data on the sarcoidosis patients was not presented separately. ${ }^{25}$ Specifically, Karadalli et al. demonstrated that inspiratory muscle training improves functional capacity, maximal exercise capacity, and respiratory muscle strength, while reducing severe perceived fatigue and dyspnea in the early stages of sarcoidosis, and could be safely added to rehabilitation programs. ${ }^{28}$ Early referral to physical training should be considered, as less severe physiological limitation may provide greater opportunity to successfully undertake training, ${ }^{50}$ But several studies found that patients with very low functional exercise capacity and severe symptoms should be offered the 
opportunity to undertake a training program and may experience clinically important benefits. $^{1,71}$

In one of the studies excluded of final analysis (due to duplicate patients with an included study) ${ }^{30}$ patients $(n=12)$ with severe respiratory involvement (stage IV fibrotic sarcoidosis) were analyzed after a 12-week training program. Exercise capacity and muscle strength were improved in half of the patients. An increased 6MWD of $>10 \%$ was found in $50 \%$ of the patients and $58 \%$ of the patients improved their hand grip strength by $>10 \%$. There was also a trend regarding improvement of the forced vital capacity (FVC) \% of predicted $(\Delta=9.7 \pm 11.4 ; p=0.075)$.

\section{Survey}

Eight recommendations for the practical use of physical training in sarcoidosis were developed by integrating evidence from both our systematic literature review and the experiential opinions of sarcoidosis experts worldwide (Table 7.5). In the consensus process, the knowledge and experience of 108 international sarcoidosis experts were harnessed to bridge the gaps in the available evidence. The agreement by this large expert group provides a valuable platform for the implementation and adjustment of these physical training recommendations for sarcoidosis. Such strength of consensus is anticipated to increase the awareness and availability of physical training as a safe and cost-effective strategy in the management of sarcoidosis. The present study was also a first attempt to increase the awareness that sarcoidosis patients might benefit from physical training, like many other patients suffering from any kind of chronic disease ${ }^{6}$. Further studies are urgently needed.

\section{Effect of physical training}

Physical activity increases aerobic capacity and muscle strength, and thus physical wellbeing.

Rehabilitation has many benefits for patients with sarcoidosis, including social participation, psychological well-being, maintaining levels of activity, learning to use breathing exercises, and ways to adapt exercises to the home environment..$^{5,27,30,72}$ In the broader context of medical management, physical therapy or rehabilitation can help to avoid a negative vicious circle of deconditioning, and improve coping with the disease. $^{18,27}$

\section{Optimizing physical therapy}

The duration, frequency, and intensity of exercise programs are critical to achieve physical benefits. ${ }^{12,26,50}$ Although physical training interventions described for ILD show great similarities with interventions used in other chronic lung diseases, e.g., COPD, ${ }^{2,73}$ lessons learned from other disorders, like neurological and rheumatologic disorders, should be taken into account as well. ${ }^{6}$ Studies carried out so far involving subjects with 
sarcoidosis carried out so far have shown that physical activity can reduce their symptoms. The positive effect of physical training in sarcoidosis is believed to be multifactorial. The physical training program in sarcoidosis must be individualized and should focus on the patients' needs and symptoms. Generally speaking, 'highfrequency, low-impact' exercise can be recommended. Further prospective studies are warranted to fine-tune the training parameters, duration, frequency and ways to achieve an optimal and long-lasting effect.

\section{Safety and other considerations}

Emerging evidence suggests that in a disease with severe functional impairment, exercise training may serve as a safe, feasible, and beneficial adjunct therapy., ${ }^{3,5,26,50}$ The suggested indications for initiating physical training in sarcoidosis are broad, but due to the heterogeneity of manifestations and symptomatology, the management of sarcoidosis patients is complex and indications as well as relative contraindications should be taken carefully into account. Moreover, the impact of disease severity on the response to exercise training in sarcoidosis is still unclear. Multi-factorial sarcoidosisrelated pulmonary hypertension is a serious concern in severe sarcoidosis, however current international guidelines by the American Thoracic Society and the European Respiratory Society support exercise training within the context of PR for pulmonary arterial hypertension (PAH). ${ }^{74}$ The recommended forms of exercise include light or moderate aerobic and light resistive training in patients with stable disease. ${ }^{3,19,50}$ The recommendations endorsed by the experts indicate that supervision in these cases is beneficial (Table 7.5).

Future studies need to include larger and more homogeneous samples in terms of sarcoidosis phenotypes, disease severity and duration, age, nutritional status, comorbidities, and treatments. This may help reveal possible variations in fatigue, muscle function, and exercise capacity while drawing attention to the most severely affected phenotypes.

\section{Expert commentary}

\section{Indications for physical therapy in sarcoidosis}

The indications for physical training and rehabilitation in sarcoidosis are broad, but still have to be defined. So far, no studies have evaluated this extensively. The unique clinical picture and underlying pathophysiology of sarcoidosis may require sarcoidosisspecific exercise prescription. Furthermore, organ-specific manifestations, such as joint pain and stiffness, may require modification of the standard pulmonary rehabilitation program, ${ }^{2}$ including reduction of weight-bearing exercise. ${ }^{50}$ 


\section{Tailored physical training program}

The heterogeneity of patients with sarcoidosis, representing different phenotypes who may or may not have lung parenchymal involvement, pain, fatigue and/or muscle impairment, may require modification and program adjustment of the standard physical training format. The intensity of the training should be personalized, tailored to the individual - which might also include adjustments for daily fluctuations in energy levels - to avoid aggravating the impairments, which would result in high dropout rates. $^{2}$ Besides, as with other chronic cardiopulmonary diseases, exercise limitation in sarcoidosis is most likely to be multifactorial, meaning that exercise capacity is not limited by any single component of the disease process, but rather by their collective quantitative interaction(s). This reinforces the need for clinicians to tailor all components of the rehabilitation program to the specific needs of people with sarcoidosis. Despite the limited studies, the initial results are promising, providing sufficient justification for further investigation with multi-center randomized trials. Challenges for future research include patient selection, along with the specific components of physical training to optimize the benefits. The consensus results presented here are a first attempt to produce recommendations for the use of physical training for various manifestations of sarcoidosis. In view of the paucity of data, an optimal training program (types of exercises, intensities, frequency, and duration) still needs to be defined to optimize training adjustments, especially regarding the reduction of fatigue. Again, characterization of disease phenotypes may provide the guidance that is necessary for a structured tailored physical training and lifestyle intervention program, with an emphasis on determinants of modifiable lifestyle habits. ${ }^{75}$ Moreover, psychological aspects and coping with the disease should be covered as well. Prospective studies should be designed to answer lingering questions about the value of exercise training for patients with sarcoidosis, including finding the optimal type and dosage of exercise, the benefits that can be expected from maintenance programs, and how long these benefits will last. The accumulated knowledge about the importance of physical training in symptomatic sarcoidosis patients is promising enough for it to be implemented.

\section{Five-year view}

Sarcoidosis patients generally benefit from additional non-pharmacologic treatments, not only physical training but also nutritional supplements and counseling. ${ }^{54,76}$ Therefore, patients should be aware of their opportunities for managing their own condition, including ways to engage different services when required, and lifestyle, for example, the importance of regular exercise as well as physical training programs. Patients' knowledge about the importance of exercise for their health (in addition to drug therapy) should be improved. ${ }^{10}$ 


\section{Evidence-based guidelines and implementation in health care}

A growing body of evidence has demonstrated the exercise-limiting effects of sarcoidosis, suggesting that in general, patients with sarcoidosis may indeed benefit from an exercise program. However, evidenced-based guidelines have to be established. A thorough patient assessment at entry into rehabilitation will assist in tailoring the exercise program to their individual needs. Health education, using selfadministered modules and continued supervised home practice of physical training for chronic symptomatic sarcoidosis-associated fatigue will add significant and sustained benefits to conventional therapy while reducing costs. ${ }^{77}$

\section{Directions for future studies}

The phenomenon of muscle dysfunction in sarcoidosis demands a wider appreciation and deeper understanding. The pathogenesis, molecular basis, and extent of muscle dysfunction should be further explored. Larger, robustly designed studies can help establish whether both respiratory and limb muscles are affected. Whether the demonstrated muscle defects represent the consequences of systemic abnormalities stemming from the primary pathobiology and multisytemic character of sarcoidosis, or constitute manifestations of a primary myopathic process, remains to be explored. The role of inflammation, oxidative stress, physical inactivity and the possible effect of sarcoidosis-specific therapy are likely to be better characterized. Finally, studies exploring sarcoidosis-specific treatment influences on aspects of skeletal muscle function, morphology, and enzyme activities should provide the required insights. Ultimately, all aspects of muscle alterations in sarcoidosis should be considered and interpreted within the context of disease heterogeneity, duration, and severity, with disease phenotypes identified and physical training targeted appropriately to these differing needs.

\section{New directions and innovation of the health care system}

Studies in idiopathic pulmonary fibrosis (IPF) and Parkinson's disease have reported increased awareness of the benefits of home-based physical training, supervised by physical therapists on-line and/or by phone calls, in terms of reduction of burden of disease (muscle strength, exercise capacity, fatigue, mental status, and QoL), and the same benefits may be achieved in patients with sarcoidosis. ${ }^{6,77,78}$ These findings could guide a feasibility study outlining 'best practice' in other chronic disorders, in which home-based supervised physical training programs are expected to improve QoL and reduce the burden of disease. The results can be used to stimulate broader initiatives to promote supervised physical training in sarcoidosis as well as other ILDs, and help develop national and international guidelines. Just as in many other chronic diseases, it is now time for the health care systems to create the necessary infrastructure to ensure that supervised exercise can be prescribed as treatment. Moreover, it is important that society in general supports a physically active lifestyle. People do not exercise when 
you just tell them to; people start to exercise when the context compels them to do so. In order to enhance the physical activity level of a population, accessibility is important. There is a need for political statements and regulations about 'health consequences'. Politicians should also consider health aspects, including how infrastructure and architecture may influence the population's physical activity levels.

\section{Conclusion}

Sarcoidosis has many faces and many phenotypes as well as a wide spectrum of symptoms. This justifies the fact that the treatment strategies should be tailored to the specific needs of the individual sarcoidosis patient including use of training modalities. Emerging evidence suggests that sarcoidosis involves adverse alterations of respiratory and peripheral skeletal muscle morphology and function. These alterations are clinically relevant and appear to be associated with functional limitations, dyspnea, and fatigue. Ultimately, muscle dysfunction is a useful indication for therapeutic intervention, as it seems partially reversible by exercise training. Observational studies have shown that sarcoidosis patients benefit from physical training by improving their exercise capacity as well as reducing sarcoidosis-associated fatigue and dyspnea. An exercise-based rehabilitation program should be offered to all sarcoidosis patients suffering from fatigue, dyspnea and/or exercise intolerance. Expected outcomes are improvements in muscle strength and endurance, reduction in fatigue, and ultimately improvement in QoL. A thorough patient assessment should be performed at the beginning and end of rehabilitation to evaluate program outcomes, including assessment of fatigue, muscle strength and exercise capacity. Addressing these issues in the management of sarcoidosis patients enables clinicians to tailor their therapies. Even more importantly it helps the patients in their struggle with this devastating disease and to gain more understanding. The present study developed practical recommendations for the use of physical training, based on available data and expert consensus. This review provides further justification to prioritize the promotion of regular physical activity as part of a comprehensive management strategy of symptomatic sarcoidosis patients to reduce physical inactivity and fatigue. However, further randomized controlled trials are needed to consolidate these findings into specific recommendations for including physical training and exercise rehabilitation in the comprehensive care of patients with sarcoidosis. 


\section{Key issues}

- Sarcoidosis is a systemic heterogenic disease affecting the lungs in most cases. The evolution (progression, improvement, or stability) and impact of sarcoidosis are variable.

- Sarcoidosis patients often present with non-specific symptoms, such as reduced exercise capacity, peripheral and respiratory muscle strength impairment, and dyspnea. The hallmark and most frustrating symptom of sarcoidosis is fatigue.

- International sarcoidosis experts suggest considering physical training in patients suffering from sarcoidosis-associated fatigue. Important indications for initiating physical training by fatigued sarcoidosis patients were considered to be the presence of pulmonary, muscular, as well as other extra-pulmonary involvement.

- The heterogeneity of patients with sarcoidosis will require modification and program adjustments to the standard rehabilitation format for e.g. COPD, ILD or other chronic diseases.

- In view of the paucity of data, an optimal training program (types of exercises, intensities, frequency, duration) still needs to be defined in order to optimize training specifications, especially with the aim reducing fatigue.

- A thorough characterization of the sarcoidosis phenotypes in terms of manifestations and limitations is necessary to find determinants of physical activities that are modifiable by changing lifestyle habits and to develop structured tailored exercise training and lifestyle interventions.

- Randomized controlled trials are needed to consolidate the limited data into specific recommendations for physical training in patients with sarcoidosis. 


\section{References}

1. Holland AE, Hill CJ, Glaspole I, Goh N, McDonald CF. Predictors of benefit following pulmonary rehabilitation for interstitial lung disease. Respir Med 2012;106:429-435.

2. Holland $A E$, Wadell $K$, Spruit MA. How to adapt the pulmonary rehabilitation programme to patients with chronic respiratory disease other than COPD. Eur Respir Rev 2013;22:577-586.

3. Spruit MA, Singh SJ, Garvey C, et al. An official American Thoracic Society/European Respiratory Society statement: key concepts and advances in pulmonary rehabilitation. Am J Respir Crit Care Med 2013;188:e13-64.

4. Swigris JJ, Brown KK, Make BJ, Wamboldt FS. Pulmonary rehabilitation in idiopathic pulmonary fibrosis: a call for continued investigation. Respir Med 2008;102:1675-1680.

5. Swigris JJ, Fairclough DL, Morrison M, et al. Benefits of pulmonary rehabilitation in idiopathic pulmonary fibrosis. Respir Care 2011;56:783-789.

6. Pedersen BK, Saltin B. Exercise as medicine - evidence for prescribing exercise as therapy in 26 different chronic diseases. Scandinavian journal of medicine \& science in sports $2015 ; 25$ Suppl 3: 1-72.

7. Valeyre D, Prasse A, Nunes H, Uzunhan Y, Brillet PY, Muller-Quernheim J. Sarcoidosis. Lancet 2014;383:1155-1167.

8. Judson MA, Mack M, Beaumont JL, Watt R, Barnathan ES, Victorson DE. Validation and important differences for the Sarcoidosis Assessment Tool. A new patient-reported outcome measure. Am J Respir Crit Care Med 2015;191:786-795.

9. Judson MA. The Clinical Features of Sarcoidosis: A Comprehensive Review. Clin Rev Allergy Immunol 2015;49:63-78.

10.* Drent M, Strookappe B, Hoitsma E, De Vries J. Consequences of sarcoidosis. Clin Chest Med 2015;36:727-737.

* This review focuses on the impact of sarcoidosis on patient's lives.

11.** Marcellis RG, Lenssen AF, Elfferich MD, et al. Exercise capacity, muscle strength and fatigue in sarcoidosis. Eur Respir J 2011;38:628-634.

** This study showed that exercise intolerance, muscle weakness, and fatigue are frequent problems in both fatigued and nonfatigued sarcoidosis patients. Fatigue was predicted neither by exercise capacity nor by muscle strength.

12. De Vries J, Drent M. Quality of life and health status in sarcoidosis: a review of the literature. Clin Chest Med 2008;29:525-532.

13. Judson MA. Quality of Life Assessment in Sarcoidosis. Clin Chest Med 2015;36:739-750.

14.* Patel AS, Siegert RJ, Creamer D, et al. The development and validation of the King's Sarcoidosis Questionnaire for the assessment of health status. Thorax 2013;68:57-65.

* This study presented the King's Sarcoidosis Questionnaire, a brief, valid and easy to administer health status measure in sarcoidosis.

15. De Vries J, Wirnsberger RM. Fatigue, quality of life and health status in sarcoidosis. Eur Respir Mon 2005;32:92-104.

16. De Vries J, Drent M. Relationship between perceived stress and sarcoidosis in a Dutch patient population. Sarcoidosis Vasc Diffuse Lung Dis 2004;21:57-63.

17. Drent M, Marcellis R, Lenssen A, De Vries J. Association between physical functions and quality of life in sarcoidosis. Sarcoidosis Vasc Diffuse Lung Dis 2014;31:117-128.

18. Spruit MA, Thomeer MJ, Gosselink R, et al. Skeletal muscle weakness in patients with sarcoidosis and its relationship with exercise intolerance and reduced health status. Thorax 2005;60:32-38.

19.* Panagiotou M, Polychronopoulos V, Strange C. Respiratory and lower limb muscle function in interstitial lung disease. Chron Respir Dis 2016;13:162-72.

* This article reviews the impact of exercise rehabilitation on the morphologic, metabolic, and functional muscle profile and outcomes in PAH. Ultimately, muscle dysfunction offers a potentially fruitful field for therapeutic interventions, as it seems partially reversible by exercise training.

20. Drent M, Lower EE, De Vries J. Sarcoidosis-associated fatigue. Eur Respir J 2012;40:255-263.

21. Vandenbroucke JP, von Elm E, Altman DG, et al. Strengthening the Reporting of Observational Studies in Epidemiology (STROBE): explanation and elaboration. Int J Surg 2014;12:1500-1524. 
22. Schulz KF, Altman DG, Moher D. CONSORT 2010 statement: updated guidelines for reporting parallel group randomised trials. PLoS Med 2010;7:e1000251.

23. Verhagen AP, de Vet HC, de Bie RA, et al. The Delphi list: a criteria list for quality assessment of randomized clinical trials for conducting systematic reviews developed by Delphi consensus. J Clin Epidemiol 1998;51:1235-1241.

24. Roddy E, Zhang W, Doherty M, et al. Evidence-based clinical guidelines: a new system to better determine true strength of recommendation. J Eval Clin Pract 2006;12:347-352.

25. Huppmann P, Sczepanski B, Boensch M, et al. Effects of inpatient pulmonary rehabilitation in patients with interstitial lung disease. Eur Respir J 2013;42:444-453.

26.* Strookappe B, Swigris J, De Vries J, Elfferich M, Knevel T, Drent M. Benefits of Physical Training in Sarcoidosis. Lung 2015;193:701-708.

* Study including largest sarcoidosis population so far, describing the benefit of physical training in sarcoidosis.

27. Marcellis RG, Veeke MAF, Mesters I, et al. Does physical training reduce fatigue in sarcoidosis? Sarcoidosis Vasc Diffuse Lung Dis 2015;32:53-62.

28. Karadalli MN, Bosnak-Guclu M, Camcioglu B, Kokturk N, Turktas H. Effects of Inspiratory Muscle Training in Subjects With Sarcoidosis: A Randomized Controlled Clinical Trial. Respir Care 2015;61:483-94.

29. Huppmann P. Personal communication of data., 2016

30. Strookappe B, Elfferich M, Swigris J, et al. Benefits of physical training in patients with idiopathic or end-stage sarcoidosis-related pulmonary fibrosis: a pilot study. Sarcoidosis Vasc Diffuse Lung Dis 2015;32:43-52.

31. Lee IM, Shiroma EJ, Lobelo F, Puska P, Blair SN, Katzmarzyk PT. Effect of physical inactivity on major non-communicable diseases worldwide: an analysis of burden of disease and life expectancy. Lancet 2012;380:219-229.

32. Ding D, Lawson KD, Kolbe-Alexander TL, et al. The economic burden of physical inactivity: a global analysis of major non-communicable diseases. Lancet 2016

33. Drent M. Sarcoidosis: benefits of a multidisciplinary approach. Eur J Intern Med 2003;14:217-220.

34. Korenromp IH, Heijnen CJ, Vogels OJ, van den Bosch JM, Grutters JC. Characterization of chronic fatigue in patients with sarcoidosis in clinical remission. Chest 2011;140:441-447.

35. Michielsen HJ, Peros-Golubicic T, Drent M, De Vries J. Relationship between symptoms and quality of life in a sarcoidosis population. Respiration 2007;74:401-405.

36. De Vries J, Rothkrantz-Kos S, van Dieijen-Visser MP, Drent M. The relationship between fatigue and clinical parameters in pulmonary sarcoidosis. Sarcoidosis Vasc Diffuse Lung Dis 2004;21:127-136.

37. de Boer S, Kolbe J, Wilsher ML. The relationships among dyspnoea, health-related quality of life and psychological factors in sarcoidosis. Respirology 2014;19:1019-1024.

38. Wirnsberger RM, De Vries J, Jansen TL, Van Heck GL, Wouters EF, Drent M. Impairment of quality of life: rheumatoid arthritis versus sarcoidosis. Neth J Med 1999;54:86-95.

39. Bosse-Henck A, Wirtz H, Hinz A. Subjective sleep quality in sarcoidosis. Sleep Med 2015;16:570-576.

40. Verbraecken J, Hoitsma E, van der Grinten CP, Cobben NA, Wouters EF, Drent M. Sleep disturbances associated with periodic leg movements in chronic sarcoidosis. Sarcoidosis Vasc Diffuse Lung Dis 2004;21:137-146.

41. Baughman RP, Engel PJ, Nathan S. Pulmonary Hypertension in Sarcoidosis. Clin Chest Med 2015;36:703-714.

42. Baughman RP, Sparkman BK, Lower EE. Six-minute walk test and health status assessment in sarcoidosis. Chest 2007;132:207-213.

43. Marcellis RG, Lenssen AF, de Vries J, Drent M. Reduced muscle strength, exercise intolerance and disabling symptoms in sarcoidosis. Curr Opin Pulm Med 2013;19:524-530.

44. Jastrzebski D, Ziora $D$, Lubecki $M$, et al. Fatigue in sarcoidosis and exercise tolerance, dyspnea, and quality of life. Adv Exp Med Biol 2015;833:31-36.

45.** Hinz A, Brähler E, Möde R, Wirtz H, Bosse-Henck A. Anxiety and depression in sarcoidosis: the influence of age, gender, affected organs, concomitant diseases and dyspnea. Sarcoidosis Vasc Diffuse Lung Dis 2012;29:139-146.

** This study found that dyspnea is an important symptom in the prediction of anxiety and depression. 
46. Kabitz HJ, Lang F, Walterspacher S, Sorichter S, Muller-Quernheim J, Windisch W. Impact of impaired inspiratory muscle strength on dyspnea and walking capacity in sarcoidosis. Chest 2006;130:14961502.

47. Van Manen MJ, Wapenaar M, Strookappe B, et al. Validation of the King's Sarcoidosis Questionnaire (KSQ) in a Dutch sarcoidosis population. Sarcoidosis Vasc Diffuse Lung Dis 2016;33:75-82.

48. Wirnsberger RM, de Vries J, Breteler MH, van Heck GL, Wouters EF, Drent M. Evaluation of quality of life in sarcoidosis patients. Respir Med 1998;92:750-756.

49. Baughman RP, Teirstein AS, Judson MA, et al. Clinical characteristics of patients in a case control study of sarcoidosis. Am J Respir Crit Care Med 2001;164:1885-1889.

50.** Holland AE, Dowman LM, Hill CJ. Principles of rehabilitation and reactivation: interstitial lung disease, sarcoidosis and rheumatoid disease with respiratory involvement. Respiration 2015;89:89-99.

** Interesting review about rehabilitation in ILD.

51. Wirnsberger RM, Drent $\mathrm{M}$, Hekelaar $\mathrm{N}$, et al. Relationship between respiratory muscle function and quality of life in sarcoidosis. Eur Respir J 1997;10:1450-1455.

52. Baydur A, Alsalek M, Louie SG, Sharma OP. Respiratory muscle strength, lung function, and dyspnea in patients with sarcoidosis. Chest 2001;120:102-108.

53. Bohannon RW. Test-retest reliability of hand-held dynamometry during a single session of strength assessment. Phys Ther 1986;66:206-209.

54. Cremers JP, Drent M, Elfferich MD, et al. Body composition profiling in a Dutch sarcoidosis population. Sarcoidosis Vasc Diffuse Lung Dis 2013;30:289-299.

55. Cremers JP, Van Kroonenburgh MJ, Mostard RL, et al. Extent of disease activity assessed by 18F-FDG PET/CT in a Dutch sarcoidosis population. Sarcoidosis Vasc Diffuse Lung Dis 2014;31:37-45.

56. Silverstein A, Siltzbach LE. Muscle involvement in sarcoidosis. Asymptomatic, myositis, and myopathy. Arch Neurol 1969;21:235-241.

57. Wirnsberger RM, de Vries J, Wouters EF, Drent M. Clinical presentation of sarcoidosis in The Netherlands an epidemiological study. Neth J Med 1998;53:53-60.

58. Costabel U. Skeletal muscle weakness, fatigue and sarcoidosis. Thorax 2005;60:1-2.

59. Walterspacher S, Schlager D, Walker DJ, Muller-Quernheim J, Windisch W, Kabitz HJ. Respiratory muscle function in interstitial lung disease. Eur Respir J 2013;42:211-219.

60. Hoitsma E, Marziniak M, Faber CG, et al. Small fibre neuropathy in sarcoidosis. Lancet 2002;359:2085-2086.

61. Elfferich MD, Nelemans PJ, Ponds RW, De Vries J, Wijnen PA, Drent M. Everyday cognitive failure in sarcoidosis: the prevalence and the effect of anti-TNF-alpha treatment. Respiration 2010;80:212-219.

62. Hoitsma E, De Vries J, Drent M. The small fiber neuropathy screening list: Construction and crossvalidation in sarcoidosis. Respir Med 2011;105:95-100.

63. Judson MA. Small fiber neuropathy in sarcoidosis: Something beneath the surface. Respir Med 2011;105:1-2.

64. Hoitsma E, Drent M, Sharma OP. A pragmatic approach to diagnosing and treating neurosarcoidosis in the 21st century. Curr Opin Pulm Med 2010;16:472-479.

65. Tavee J, Culver D. Sarcoidosis and small-fiber neuropathy. Curr Pain Headache Rep 2011;15:201-206.

66. Baughman RP, Nunes H. Therapy for sarcoidosis: evidence-based recommendations. Expert Rev Clin Immunol 2012;8:95-103.

67. Elfferich MD, De Vries J, Drent M. Type D or 'distressed' personality in sarcoidosis and idiopathic pulmonary fibrosis. Sarcoidosis Vasc Diffuse Lung Dis 2011;28:65-71.

68. Saligan LN. The relationship between physical activity, functional performance and fatigue in sarcoidosis. J Clin Nurs 2014;23:2376-2378.

69. Michielsen HJ, Drent M, Peros-Golubicic T, De Vries J. Fatigue is associated with quality of life in sarcoidosis patients. Chest 2006;130:989-994.

70. Brancaleone P, Perez T, Robin S, Neviere R, Wallaert B. Clinical impact of inspiratory muscle impairment in sarcoidosis. Sarcoidosis Vasc Diffuse Lung Dis 2004;21:219-227.

71. Ryerson CJ, Cayou C, Topp F, et al. Pulmonary rehabilitation improves long-term outcomes in interstitial lung disease: a prospective cohort study. Respir Med 2014;108:203-210.

72. Spruit MA, Wouters EFM, Gosselink R. Rehabilitation programmes in sarcoidosis: a multidisciplinary approach. Eur Respir Mon 2005;32:316-326. 
73. Holland AE, Hill CJ, Conron M, Munro P, McDonald CF. Short term improvement in exercise capacity and symptoms following exercise training in interstitial lung disease. Thorax 2008;63:549-554.

74. Panagiotou M, Peacock AJ, Johnson MK. Respiratory and limb muscle dysfunction in pulmonary arterial hypertension: a role for exercise training? Pulm Circ 2015;5:424-434.

75. Hebestreit H, Kriemler S, Radtke T. Exercise for all cystic fibrosis patients: is the evidence strengthening? Curr Opin Pulm Med 2015;21:591-595.

76. Boots AW, Drent M, de Boer VC, Bast A, Haenen GR. Quercetin reduces markers of oxidative stress and inflammation in sarcoidosis. Clin Nutr 2011;30:506-512.

77. Rammaert B, Leroy S, Cavestri B, Wallaert B, Grosbois JM. Home-based pulmonary rehabilitation in idiopathic pulmonary fibrosis. Rev Mal Respir 2011;28:e52-57.

78. Lingner H, Grosshennig A, Flunkert K, et al. ProKaSaRe Study Protocol: A Prospective Multicenter Study of Pulmonary Rehabilitation of Patients With Sarcoidosis. JMIR Res Protoc 2015;4:e134.

79. Baughman RP, Drent M, Culver DA, et al. Endpoints for clinical trials of sarcoidosis. Sarcoidosis Vasc Diffuse Lung Dis 2012;29:90-98.

80. Judson MA, Baughman RP, Costabel U, et al. Efficacy of infliximab in extrapulmonary sarcoidosis: results from a randomised trial. Eur Respir J 2008;31:1189-1196.

81. Judson MA, Costabel U, Drent M, et al. The WASOG Sarcoidosis Organ Assessment Instrument: An update of a previous clinical tool. Sarcoidosis Vasc Diffuse Lung Dis 2014;31:19-27. 



\section{Chapter 8}

Summary, general discussion and suggestions for future research 



\section{Summary}

Sarcoidosis is a multisystemic disease of unknown cause characterized by cellular immunity activity with formation of noncaseating granuloma in various organ systems. ${ }^{1,2}$ Sarcoidosis can affect any organ system, so patients can suffer from a wide spectrum of organ-specific symptoms. In addition to symptoms related to the specific organ involved, patients often have non-specific complaints such as exercise intolerance, general weakness, and fatigue. ${ }^{2-5}$ Pharmacological treatment options aim to treat the disease and preserve organ function. Despite effective treatment of their sarcoidosis, many patients continue to experience fatigue and exercise intolerance., Exercise training is a generally accepted treatment strategy in chronic lung diseases to reduce physical impairments, dyspnea, and fatigue. ${ }^{7}$ However, evidence regarding the benefits of physical training in sarcoidosis is scarce, ${ }^{8-10}$ and mostly comes from observational studies with rather small patient populations.

The aims of the studies presented in this thesis were to examine the consequences of sarcoidosis-related problems for patients' lives, and determine relationships between clinical characteristics and sarcoidosis-related problems such as fatigue, limited exercise capacity, and decreased muscle strength. In line with this, we explored the influence of a physical training program on exercise capacity, muscle strength, and most importantly, fatigue. Sarcoidosis patients included in these studies were referred to the former ILD (interstitial lung disease) care team of the Gelderse Vallei Hospital in Ede, The Netherlands. Over a period of 22 months, patients underwent exercise testing and muscle testing and completed questionnaires before and after a physical training program. This was first examined in a pilot study, after which we conducted a twogroup observational study. Finally, recommendations regarding physical training in sarcoidosis were drawn up with the help of a systematic literature overview and a survey of expert opinion regarding the use of physical training in sarcoidosis. The present chapter offers an overview of the main findings, as well as practical implications and recommendations for future research.

\section{Overview of the main findings}

Chapter 1, the general introduction, provides a summary of the pathogenesis, epidemiology, clinical presentation, and non-organ-specific symptoms of the disease. These non-specific complaints, e.g. fatigue, exercise intolerance, and arthralgia, impose a burden on patients' lives. The roles of both pharmacological and non-pharmacological interventions in the management of sarcoidosis are outlined.

Chapter 2 presents an overview of the literature regarding the wide-ranging consequences of sarcoidosis. In addition to the specific organ-related symptoms, less specific disabling symptoms, including fatigue, exercise intolerance, small fiber neuropathy (SFN), depressive symptoms, anxiety and cognitive impairment, can have a 
major influence on the daily activities and the social and professional lives of the patients, resulting in a reduced quality of life (QoL). A multidisciplinary approach is generally recommended by experts for these patients, one that focuses on the somatic as well as psychological aspects of this erratic disorder. As regards pharmacological treatment, glucocorticoids are the cornerstone therapeutic agent and have a favorable short-term effect on functional impairments. Some patients, however, require more aggressive treatment. The decision to start systemic immunosuppressive treatment or not should be based on the patients' symptomatology, including the impact on their QoL, as well as the extent of compromised organ function. Sarcoidosis patients may also benefit from non-pharmacological (additional) treatment options. Developing the most appropriate therapeutic approach for sarcoidosis, including rehabilitation programs, requires consideration of the possible impact of fatigue, SFN symptoms, pain, cognitive functioning, sleep disorders, as well as other relevant aspects of this multisystem disease. Therefore, personalized medicine is key.

Chapter 3 reports on the process of validating King's Sarcoidosis Questionnaire (KSQ) in a Dutch sarcoidosis population. The KSQ is a brief questionnaire assessing the health status of patients with sarcoidosis, using five modules (General health status, Lung, Medication, Skin and Eyes). Previously it was only validated in one English sarcoidosis cohort. The KSQ was translated according to international guidelines and tested in interviews with patients. In addition, consecutive outpatients completed multiple questionnaires twice, two weeks apart. Of the 98 patients included, 85 had lung, 22 skin and 24 eye disease. The findings showed good construct validity of the KSQ General Health Status (GHS) module against the World Health Organization Quality of Life-BREF questionnaire. The Medication module correlated weakly to moderately with most questionnaires, including the Fatigue Assessment Scale (FAS) ( $r=0.39)$. The correlations with organ-specific questionnaires varied from strong for Eyes $(r=0.75)$ and Skin ( $r=-0.62$ ) to moderate for Lung ( $r=-0.45$ with the MRC breathlessness scale). The correlations between the KSQ GHS domain $(r=0.81)$ and generic questionnaires (Euroqol-5D-5 level [EQ-5D-5L], Global Rating of Change - Quality of Life [GRC-QoL], and WHOQOL-BREF) were strong, especially for the Energy and Fatigue aspect $(r=0.84))$. All KSQ modules correlated moderately to strongly with the FAS ( $r=0.50-0.81)$. The organ-specific 'Lung' module of the KSQ did not show any relationship with lung function test results, except for a weak correlation with FVC \% of predicted ( $r=0.24)$. Internal consistency was good for all KSQ modules (Cronbach's $\alpha$ 0.72-0.93). Intraclass correlation coefficients (0.70-0.90) and Bland-Altman plots showed good repeatability of the KSQ. This Dutch KSQ is the first health status questionnaire for sarcoidosis in the Netherlands. Our validation also represents the first non-English validation of the questionnaire. The $\mathrm{KSQ}$ is simple to administer, adaptable to individual organ involvement and has proved to be a valid and reliable health status measurement for Dutch patients with sarcoidosis.

Chapter 4 presents the findings of a study into the relationship between fatigue and both exercise capacity and clinical characteristics (age, sex, time since diagnosis, 
body mass, lung function tests, and inflammatory markers) in sarcoidosis patients. Additionally, it outlines the predictive value of exercise test results and other relevant clinical characteristics for the independent variable fatigue. All patients underwent exercise testing (six minute walk test [6MWT], the Steep Ramp Test [SRT]) and skeletal muscle function testing (hand grip strength [HGS], chair rise time [CRT], and elbow flexor muscle strength [EFMS]). Fatigue was measured with the FAS in all patients. In total, 146 patients were included in this cohort study. Prevalences of fatigue (77\%) and exercise intolerance (75\%) were high. Exercise capacity only showed a weak correlation with fatigue ( $r=0.25, p=0.002$ for 6 MWD \% of predicted; $r=0.24, p=0.003$ for SRT). Fatigue was not correlated with the demographic variables of age, body mass index, or time since diagnosis. Nor did inflammatory markers, lung function tests, or hand grip strength show any significant correlations with fatigue. Backward multiple regression analysis showed that only female sex $(t=-2.614, p=0.01)$ and 6MWD \% of predicted $(t=-2.773, p=0.006)$ were independent predictors of fatigue. However, the $r(2)$ value indicated that these two variables together explained only $11 \%$ of the FAS score. In conclusion, this study showed that fatigue and exercise intolerance are substantial problems among sarcoidosis patients. While it is well known that sarcoidosis-related fatigue is multi-factorial in nature, our study failed to discover any meaningful associations based on the available data for this patient sample. Further research to clarify the phenomenon of fatigue in sarcoidosis is important, in order to enhance both medical and allied health care strategies to reduce fatigue.

Chapter $\mathbf{5}$ addresses the use of a tailored physical training program by patients suffering from idiopathic or end-stage-sarcoidosis-related pulmonary fibrosis. The natural history of disease in patients with stage IV (fibrotic) sarcoidosis may mirror that of patients with idiopathic pulmonary fibrosis (IPF), as both are affected by progressive dyspnea, exercise limitation and fatigue. All 24 patients referred to the ILD care expertise team of the Gelderse Vallei Hospital underwent exercise testing (6MWT, SRT), skeletal muscle function testing (HGS, EFMS), and pulmonary function tests (DLCO, $\mathrm{FEV}_{1}, \mathrm{FVC}$ ) at baseline and after completion of a 12-week physical training program. At baseline, the percentage of predicted DLCO, FVC, FEV1 and exercise capacity (assessed by six-minute walking distance [6MWD] or maximal oxygen uptake) was reduced in both groups. After program completion, exercise capacity had improved $(>10 \%$ improvement on 6MWD) in 13 subjects (54.2\%): 7 with IPF and 6 with sarcoidosis. Other secondary endpoints, including pulmonary function tests and patient-reported outcome measures, improved in some subjects. A 12-week physical training program improved or maintained exercise capacity in the majority of patients with IPF (despite disease progression) or fibrotic sarcoidosis. The results from this pilot study could be used to design prospective studies aimed at answering lingering questions about exercise training in patients with these progressive, incurable conditions.

Chapter 6 discusses the results of sarcoidosis patients following a physical training program. The aim of the study was to establish whether a physical training program improves exercise capacity and reduces fatigue. At our center, all sarcoidosis patients 
were routinely recommended to undergo physical testing at the Department of Physical Therapy. Exercise capacity (6MWT, SRT), skeletal muscle function (HGS, EFMS, CRT), fatigue (FAS) and pulmonary function tests (DLCO, FEV $1, F V C)$ were applied at baseline and after a 12-week physical training program. Ninety patients underwent baseline testing, 49 of them completed the training program (group I), and 41 chose not to participate (group II). At baseline, there were no between-group differences regarding fatigue, pulmonary function, or exercise capacity. The 6MWD for Group I improved between baseline and 3 months, while the 6MWD remained unchanged in Group II $(\mathrm{F}=72.2, \mathrm{p}<0.001)$. Group I showed a significantly larger decrease in fatigue compared with Group II ( $F=6.27, p=0.014)$. Lung function tests did not change in either group. Our findings indicate that a supervised, 12-week, aerobic exercise and strength training program improves exercise performance and strength, and reduces fatigue in patients with sarcoidosis. The results were independent of age, gender, time since diagnosis, baseline pulmonary function (and other markers of sarcoidosis severity), inflammatory status, or pharmacological interventions. We would argue that physical training should be considered as a first-line therapy for patients suffering from sarcoidosis.

Chapter 7 presents a systematic literature overview (phase I) on physical training and pulmonary rehabilitation in patients with sarcoidosis. An extensive search strategy resulted in four publications on this topic. Each study suggested benefits in the areas of exercise capacity, fatigue, and QoL. Although relatively few studies have been done so far, there is encouraging evidence of a positive effect of physical training on the devastating symptoms of sarcoidosis. Our systematic literature review guided an international consensus effort among sarcoidosis experts to establish recommendations for the implementation of exercise as a treatment for patients with various manifestations of sarcoidosis (phases II and III). Most experts were pulmonologists (>82\%) and the majority $(70 \%)$ had more than 10 years of experience with sarcoidosis patients. They considered physical training to be a valuable and safe intervention. Pulmonary involvement, fatigue, and muscular and extra-pulmonary involvement were considered the most important indications for physical training. Almost $50 \%$ of the respondents indicated situations where physical training could potentially harm patients, e.g. patients with untreated arrhythmias. Results obtained during phases I and III were assembled to prepare ten recommendations regarding physical training in sarcoidosis. Finally, the recommendations were submitted to a panel of 15 leading international sarcoidosis experts familiar with the subject of exercise in sarcoidosis. Recommendations with an agreement level below $75 \%$ were excluded from the final selection. This process resulted in eight key recommendations, regarding indications, standardized assessment, content of physical training program, safety considerations, and monitoring.

\section{General conclusion}

Exercise is a well-documented safe and effective intervention for the prevention and rehabilitation of chronic diseases. Sarcoidosis has many faces and many phenotypes, as 
well as a wide spectrum of symptoms, including exercise intolerance, muscle weakness, fatigue, and diminished QoL. This justifies tailoring the treatment strategies to the specific needs of individual sarcoidosis patients, including the use of training modalities. In the short term, supervised exercise training programs have demonstrated clinical benefits in improving exercise capacity, fatigue, dyspnea, and QoL in patients with sarcoidosis. An exercise-based rehabilitation program should be offered to all sarcoidosis patients suffering from these problems. Expected outcomes are improvements in muscle strength and endurance, reduction of fatigue and dyspnea, and ultimately improvement of QoL. A thorough patient assessment should be performed at the beginning and end of rehabilitation to evaluate the program outcomes, including assessment of fatigue, dyspnea, muscle strength, and exercise capacity. Addressing these issues in the management of sarcoidosis patients enables clinicians to tailor their therapies. Even more importantly, it helps patients in their struggle with this devastating disease. The available data underscore the importance of implementing training principles to target the pathophysiological impairments due to sarcoidosis, in order to optimize training adoption and enhance the outcomes. The current exercise training data regarding sarcoidosis provide sufficient evidence of clinical benefit to recommend exercise-based pulmonary rehabilitation as a standard of care for sarcoidosis.

\section{General discussion}

Sarcoidosis patients often present with complaints specifically related to the organ systems involved. The majority of these patients also suffer from non-specific health complaints, like fatigue, SFN and exercise intolerance. Fatigue in sarcoidosis is a problem which is affected by many different variables. Deconditioning of skeletal muscle plays a key role, although systemic effects of sarcoidosis on muscle have not yet been studied extensively. Fatigue may be explained not only by decreased pulmonary functions and the negative vicious cycle of deconditioning, but also by muscle weakness and exercise intolerance, due to sarcoidosis located in the skeletal muscle itself. ${ }^{11}$

The prevalence and impact of these non-specific complaints was outlined in studies by Marcellis et al. ${ }^{4,12,13}$ They also found that these non-specific complaints have a stable and persistent character. ${ }^{4}$ These non-specific health complaints correlate poorly with objective clinical parameters (e.g. chest X-ray, pulmonary function tests). ${ }^{14,15}$ Patients may suffer from substantial fatigue even in the absence of other symptoms or diseaserelated abnormalities. ${ }^{5}$

The cause of fatigue in sarcoidosis patients is multifactorial, and fatigue has a great impact on patients' lives, so the evaluation and treatment of sarcoidosis-associated fatigue needs a comprehensive evaluation. Researchers have recommended identifying reversible causes of fatigue related to metabolic disorders (diabetes, thyroid dysfunction, anemia), psychological conditions (depression, anxiety) and organ-related 
conditions (SFN, sleep disturbances). Sarcoidosis patients may continue to experience persistent fatigue despite appropriate identification and treatment of these reversible causes. For these patients, neurostimulant therapy may be helpful, as well as cognitive behavioral therapy. ${ }^{5}$

In line with other studies, we found that the level of sarcoidosis-associated fatigue was not explained by lung function test results, nor inflammatory markers or other clinical parameters. In addition, our study found only weak relationships between fatigue and exercise capacity. ${ }^{12,16}$ De Kleijn et al. described several significant predictors of fatigue, e.g. cognitive failure, depressive symptoms, symptoms of suspected SFN and dyspnea. ${ }^{17,16}$ Cognitive therapy may be indicated to improve coping strategies or stress perception and antidepressants can be considered in patients with a clinical depression. ${ }^{18,19}$ Sleeping problems as well as other causes of fatigue should also be evaluated and treated appropriately. ${ }^{20-25}$ Sarcoidosis-associated fatigue may either improve or worsen with therapy., ${ }^{422-25}$ Persistence of fatigue or new-onset fatigue during therapy may be an adverse effect of corticosteroids. ${ }^{26}$ Various neuro-stimulants, including methylphenidate and tumor necrosis factor-alpha (TNF- $\alpha$ ) inhibitors have been found to be effective for the treatment of sarcoidosis-associated fatigue. ${ }^{5,18,27-29}$ These agents and other therapeutic options (e.g. psychological interventions) may be useful for the treatment of this fatigue. ${ }^{5}$

Pharmacological treatment alone may be not sufficient for the treatment of sarcoidosis-associated fatigue and exercise limitations. ${ }^{5}$ Several drugs (e.g. corticosteroids) used in the management of sarcoidosis may have adverse effects on exercise capacity and muscle function. ${ }^{11}$ Impaired exercise capacity and muscle function will result in further deconditioning and decreasing activity levels of patients. ${ }^{12,13}$ To interrupt this vicious circle it is important to be aware of this lack of effect and the negative side effects, and to initiate additional therapies, such as physical training, to restore or improve exercise capacity and muscle function. ${ }^{13}$

Rehabilitation is considered a useful therapeutic option in other chronic diseases (including lung diseases). ${ }^{30}$ So far the available studies found significant and clinically relevant clinical benefits regarding exercise capacity, muscle strength, and fatigue. ${ }^{8-}$ $10,31,32$

The reasons why rehabilitation may be effective in treating non-specific sarcoidosis-related complaints has to do with the characteristics of the disease. The main characteristic of sarcoidosis is the formation of granuloma, which is hallmarked by an immune response, releasing chemokines and cytokines (e.g. interferon- $\gamma$, interleukin (IL)-2, IL-12, IL-18, and TNF- $\alpha$ ). This process is suggested to induce persistent inflammation and subsequent tissue damage. ${ }^{2}$ Systemic inflammation can be a trigger for oxidative stress, which may contribute to muscle dysfunction in chronic diseases. ${ }^{33}$ ${ }^{34}$ Furthermore, treatments such as corticosteroids may also adversely impact on 
muscle function, causing e.g. myopathy, fatigue, and psychological burden, as well as sleeping problems. ${ }^{19,35,36}$ In a study among 25 patients with sarcoidosis, only for those patients who received oral corticosteroid treatment $(n=11)$ was the quadriceps peak torque inversely related to the mean daily dose of corticosteroids received in the 6 months before testing. ${ }^{11}$

Physical inactivity leads to the accumulation of visceral fat and consequently to the activation of a network of inflammatory pathways. Chronic inflammation promotes the development of insulin resistance, atherosclerosis, neurodegeneration, and tumor growth, $^{37,38}$ and is associated with the development of several diseases. ${ }^{39,40}$ Physical activity, or exercise, mediates anti-inflammatory effects via the reduction of visceral fat mass and the establishment of an anti-inflammatory environment with each bout of exercise. ${ }^{38,41-43}$ Several studies have shown that muscle fibers express the myokine IL-6 in response to muscle contractions. This IL- 6 then exerts its effect both locally within the muscle and, when released into the circulation, in a hormone-like fashion in a number of organs. ${ }^{41}$

The mechanism by which exercise rehabilitation improves outcomes in sarcoidosis is not clearly understood. It is most likely that this type of rehabilitation ameliorates peripheral muscle dysfunction by providing an effective training stimulus to the muscle. It may also improve cardiovascular fitness, improve disease self-management and provide effective psychosocial support. ${ }^{9,31,32,44}$ There is no evidence that rehabilitation impacts on the progression of the disease. We showed that exercise capacity (6MWD $+70 \mathrm{~m}$ vs $+4 \mathrm{~m}$ ) and muscle strength improved, and fatigue decreased, in 49 patients who attended a physical training program, compared to 41 patients who did not take part in the training program. ${ }^{32}$ In line with the information presented above we suggest that physical training (or exercise rehabilitation) is a valuable treatment option, in addition to pharmaceutical treatment strategies, to reduce chronic systemic inflammation, visceral fat, and oxidative stress, thereby improving muscle strength and exercise capacity and reducing sarcoidosis-associated fatigue. These strategies are all intended to improve patients' quality of life and make them feel more comfortable. ${ }^{45}$

Since rehabilitation delivers relevant gains in patient-centered outcomes, it is a treatment recommended for people with ILD by the American Thoracic Society (ATS) / European Respiratory Society (ERS) guidelines for IPF management and the ATS/ERS pulmonary rehabilitation statement. ${ }^{46,47}$

The suggested indications for initiating physical training in sarcoidosis are broad, but the heterogeneity of manifestations and symptomatology mean that the management of sarcoidosis patients is complex, and indications as well as relative contraindications should be carefully taken into account. Although multi-factorial sarcoidosis-related pulmonary hypertension is a serious concern in severe sarcoidosis, current international guidelines by the ATS and the ERS nevertheless support exercise training within the context of pulmonary rehabilitation for pulmonary arterial hypertension (PAH). ${ }^{48}$ Manifestations of pulmonary hypertension and cardiac 
involvement should be considered as relative contraindications and caution should be exercised by the qualified supervisors (chapter 7 of this thesis).

\section{Practical implications}

As stated above, patients may suffer from all kinds of non-organ-specific symptoms in addition to symptoms specifically related to the organs involved. Since these problems are frequent and may have a major influence on patients' daily activities and their social and professional lives, it is important to recognize and quantify these problems in the evaluation of sarcoidosis patients. We therefore recommend standardized fatigue assessment, with a validated instrument, in the work-up of sarcoidosis patients.

Physical training may be an important non-pharmacological intervention to reduce sarcoidosis-associated fatigue. Symptomatic sarcoidosis patients with fatigue and/or exercise limitation suffering from various manifestations might benefit from a supervised physical training program.

Evaluation of exercise capacity as well as muscle strength assessment should be considered in the evaluation of the severity and extent of the disease in symptomatic sarcoidosis patients with fatigue and/or exercise limitation.

\section{Key issues}

- The management of symptomatic sarcoidosis patients should focus not only pharmacological treatment strategies, but should combine all relevant aspects of a healthy life style to promote physical fitness.

- A better understanding of the principles of exercise training and the pathophysiology of sarcoidosis is essential for effective exercise program delivery.

- Despite the complexity of the signs and symptoms presented in sarcoidosis, supervised exercise training is a feasible and effective treatment for clinical improvement.

- Emerging research findings show significant enhancements of exercise capacity, fatigue and QoL among sarcoidosis patients after exercise training interventions.

\section{Suggestions for future research}

The multifactorial nature of sarcoidosis-related fatigue warrants further research to identify the different phenotypes of sarcoidosis-associated fatigue. The phenomenon of fatigue must be clarified in order to enhance medical as well as psychological and allied health care strategies to reduce fatigue.

Future research should focus on the effectiveness of physical training in symptomatic sarcoidosis patients, i.e. patients who have limited exercise capacity and decreased muscle strength and suffer from fatigue. The studies presented in this thesis showed short-term benefits of physical training in sarcoidosis, independent of age, 
gender, time since diagnosis, and baseline pulmonary functions. Long-term benefits of this intervention should be investigated. Larger, randomized controlled studies are necessary to further build up the body of knowledge. It is also valuable to gather information to find out which patients will benefit most from this intervention. The assessment of factors that distinguish responders from non-responders is a challenging issue in sarcoidosis.

\section{Muscle involvement and exercise limitations}

Reduced muscle strength is a problem in a substantial number of sarcoidosis patients, regardless of their phenotype and clinical presentation. Therefore, the phenomenon of muscle dysfunction in sarcoidosis demands a wider appreciation and deeper understanding. The pathogenesis, molecular basis, and extent of muscle dysfunction should be further explored. Larger, robustly designed studies can help establish whether any muscle defects found represent consequences of systemic abnormalities stemming from the primary pathobiology and multisystemic character of sarcoidosis, or constitute manifestations of a primary myopathic process. The role of inflammation, oxidative stress, and physical inactivity, and the possible effect of sarcoidosis-specific therapy, should be better characterized. Finally, studies exploring the influence of sarcoidosis-specific treatment on aspects of skeletal muscle function, morphology, and enzyme activities should provide the required insights.

\section{Lifestyle, food, and nutrition}

Little research to date has focused on the relationship between diet, nutrition, and sarcoidosis. Functional foods and/or supplements may be used in the context of a healthy lifestyle. Inflammation is considered to be one of the major causes of the initiation of various chronic diseases such as asthma, cancer, cardiovascular disease, diabetes, obesity, inflammatory bowel disease, and osteoporosis, as well as neurological diseases like Parkinson's disease. Increasing evidence suggests that inflammatory markers, such as TNF- $\alpha$, are the major factors regulating these inflammatory diseases. In addition to the benefits of pharmacological treatment and physical training, food may also play a role in the management of sarcoidosis, as foodderived anti-oxidants may provide subtle, but substantial effects reducing oxidative stress and inflammation. Anti-oxidant capacities of food and food-derived components (e.g. quercetin) have health promoting benefits and may prove a valuable addition. Future studies should investigate the benefit of combining all relevant aspects of a healthy life style in order to promote physical fitness.

\section{Diagnostic work-up}

Standardized assessment of non-specific symptoms (e.g. fatigue, SFN, exercise intolerance, muscle weakness, general weakness) is important. Since no standardized 
assessment battery is as yet available, future studies should focus on the standardization and optimization of this assessment in sarcoidosis. Ultimately, it is of great interest to assess not only fatigue, but also the activity levels in daily life of patients with sarcoidosis. In the evaluation of treatment effect in general, it is important to compare activity levels at baseline and at follow-up. Patients who have attended a physical training program may experience persistent fatigue complaints even though their activity level has improved significantly. It is also interesting to investigate the relationship between fatigue and activity levels. More detailed information on patients' activity levels may facilitate tailoring the physical training program and providing advice regarding increased physical activity. Some patients may need a closely supervised physical training program, while for others, tailored advice and coaching 'at a distance' (e.g. by email or telephone) may be sufficient for them to exercise independently. A few studies have shown that e-health coaching is effective in patients with chronic illnesses, including COPD and diabetes mellitus, in terms of promoting health status and physical activity. ${ }^{49-51}$ Evidence for the effectiveness of ehealth in the management of sarcoidosis is lacking, so prospective randomized controlled trials are necessary to examine this.

\section{Physical training in sarcoidosis: who, when, how, and how long?}

Implementing physical training in the standard of care for sarcoidosis urgently requires guidelines. The heterogeneity of patients with sarcoidosis, representing different phenotypes which may or may not include lung parenchymal involvement, pain, fatigue, and/or muscle impairment, may require modification and program adjustment of the standard physical training format. The research described in this thesis constitutes a first step towards establishing guidelines by expanding the body of knowledge on the effectiveness of physical training and establishing recommendations regarding physical training in sarcoidosis. It remains unknown, however, which training parameters are to be used in sarcoidosis. Which patients will or will not respond to the intervention? What modalities are most effective in improving physical impairments and reducing sarcoidosis-related fatigue? Nor do we know the optimal frequency, intensity, and duration of the training program. These matters should be addressed in future research, in order to optimize treatment strategies. 


\section{References}

1. Valeyre D, Prasse A, Nunes H, Uzunhan Y, Brillet PY, Muller-Quernheim J. Sarcoidosis. Lancet 2014;383:1155-1167.

2. Statement on sarcoidosis. Joint Statement of the American Thoracic Society (ATS), the European Respiratory Society (ERS) and the World Association of Sarcoidosis and Other Granulomatous Disorders (WASOG) adopted by the ATS Board of Directors and by the ERS Executive Committee, February 1999. Am J Respir Crit Care Med 1999;160:736-755.

3. Ungprasert P, Carmona EM, Utz JP, Ryu JH, Crowson CS, Matteson EL. Epidemiology of Sarcoidosis 1946-2013: A Population-Based Study. Mayo Clin Proc 2016;91:183-188.

4. Marcellis RG, Lenssen AF, Kleynen S, De Vries J, Drent M. Exercise capacity, muscle strength, and fatigue in sarcoidosis: a follow-up study. Lung 2013;191:247-256.

5. Drent M, Lower EE, De Vries J. Sarcoidosis-associated fatigue. Eur Respir J 2012;40:255-263.

6. Korenromp IH, Grutters JC, van den Bosch JM, Heijnen CJ. Post-inflammatory fatigue in sarcoidosis: personality profiles, psychological symptoms and stress hormones. J Psychosom Res 2012;72:97-102.

7. McCarthy B, Casey D, Devane D, Murphy K, Murphy E, Lacasse Y. Pulmonary rehabilitation for chronic obstructive pulmonary disease. Cochrane Database Syst Rev 2015:CD003793.

8. Huppmann P, Sczepanski B, Boensch M, et al. Effects of inpatient pulmonary rehabilitation in patients with interstitial lung disease. Eur Respir J 2013;42:444-453.

9. Marcellis $\mathrm{R}$, Van der Veeke $M$, Mesters I, et al. Does physical training reduce fatigue in sarcoidosis? Sarcoidosis Vasc Diffuse Lung Dis 2015;32:53-62.

10. Karadalli MN, Bosnak-Guclu M, Camcioglu B, Kokturk N, Turktas H. Effects of Inspiratory Muscle Training in Subjects With Sarcoidosis: A Randomized Controlled Clinical Trial. Respir Care 2016;61: 483-494.

11. Spruit MA, Thomeer MJ, Gosselink R, et al. Skeletal muscle weakness in patients with sarcoidosis and its relationship with exercise intolerance and reduced health status. Thorax 2005;60:32-38.

12. Marcellis RG, Lenssen AF, Elfferich MD, et al. Exercise capacity, muscle strength and fatigue in sarcoidosis. Eur Respir J 2011;38:628-634.

13. Marcellis RG, Lenssen AF, de Vries J, Drent M. Reduced muscle strength, exercise intolerance and disabling symptoms in sarcoidosis. Curr Opin Pulm Med 2013;19:524-530.

14. Michielsen HJ, Peros-Golubicic T, Drent M, De Vries J. Relationship between symptoms and quality of life in a sarcoidosis population. Respiration 2007;74:401-405.

15. Wirnsberger RM, de Vries J, Breteler MH, van Heck GL, Wouters EF, Drent M. Evaluation of quality of life in sarcoidosis patients. Respir Med 1998;92:750-756.

16. Strookappe B, De Vries J, Elfferich M, Kuijpers P, Knevel T, Drent M. Predictors of fatigue in sarcoidosis: The value of exercise testing. Respir Med 2016;116:49-54.

17. de Kleijn WP, Drent M, De Vries J. Nature of fatigue moderates depressive symptoms and anxiety in sarcoidosis. Br J Health Psychol 2013;18:439-452.

18. Elfferich MD, Nelemans PJ, Ponds RW, De Vries J, Wijnen PA, Drent M. Everyday cognitive failure in sarcoidosis: the prevalence and the effect of anti-TNF-alpha treatment. Respiration 2010;80:212-219.

19. Elfferich MD, De Vries J, Drent M. Type D or 'distressed' personality in sarcoidosis and idiopathic pulmonary fibrosis. Sarcoidosis Vasc Diffuse Lung Dis 2011;28:65-71.

20. Verbraecken J, Hoitsma E, van der Grinten CP, Cobben NA, Wouters EF, Drent M. Sleep disturbances associated with periodic leg movements in chronic sarcoidosis. Sarcoidosis Vasc Diffuse Lung Dis 2004;21:137-146.

21. Lal C, Medarov BI, Judson MA. Interrelationship between sleep-disordered breathing and sarcoidosis. Chest 2015;148:1105-1114.

22. Baydur A, Alavy B, Nawathe A, Liu S, Louie S, Sharma OP. Fatigue and plasma cytokine concentrations at rest and during exercise in patients with sarcoidosis. Clin Respir J 2011;5:156-164.

23. Fleischer $M$, Hinz A, Brahler E, Wirtz H, Bosse-Henck A. Factors associated with fatigue in sarcoidosis. Respir Care 2014;59:1086-1094.

24. Korenromp IH, Heijnen CJ, Vogels OJ, van den Bosch JM, Grutters JC. Characterization of chronic fatigue in patients with sarcoidosis in clinical remission. Chest 2011;140:441-447.

25. de Kleijn WP, Elfferich MD, De Vries J, et al. Fatigue in sarcoidosis: American versus Dutch patients. Sarcoidosis Vasc Diffuse Lung Dis 2009;26:92-97. 
26. Aggarwal AN, Sahu KK, Gupta D. Fatigue and health-related quality of life in patients with pulmonary sarcoidosis treated by oral Corticosteroids. Sarcoidosis Vasc Diffuse Lung Dis 2016;33:124-129.

27. Lower EE, Harman S, Baughman RP. Double-blind, randomized trial of dexmethylphenidate hydrochloride for the treatment of sarcoidosis-associated fatigue. Chest 2008;133:1189-1195.

28. Lower EE, Malhotra A, Surdulescu V, Baughman RP. Armodafinil for sarcoidosis-associated fatigue: a double-blind, placebo-controlled, crossover trial. J Pain Symptom Manage 2013;45:159-169.

29. Wijnen PA, Cremers JP, Nelemans PJ, et al. Association of the TNF-alpha G-308A polymorphism with TNF-inhibitor response in sarcoidosis. Eur Respir J 2014;43:1730-1739.

30. Pedersen BK, Saltin B. Exercise as medicine - evidence for prescribing exercise as therapy in 26 different chronic diseases. Scand J Med Sci Sports 2015;25 Suppl 3:1-72.

31. Strookappe B, Elfferich M, Swigris J, et al. Benefits of physical training in patients with idiopathic or endstage sarcoidosis-related pulmonary fibrosis: a pilot study. Sarcoidosis Vasc Diffuse Lung Dis 2015;32:43-52.

32. Strookappe B, Swigris J, De Vries J, Elfferich M, Knevel T, Drent M. Benefits of Physical Training in Sarcoidosis. Lung 2015;193:701-708.

33. Boots AW, Drent M, Swennen EL, Moonen HJ, Bast A, Haenen GR. Antioxidant status associated with inflammation in sarcoidosis: a potential role for antioxidants. Respir Med 2009;103:364-372.

34. Lawler JM, Song W. Specificity of antioxidant enzyme inhibition in skeletal muscle to reactive nitrogen species donors. Biochem Biophys Res Commun 2002;294:1093-1100.

35. Baughman RP, Nunes H. Therapy for sarcoidosis: evidence-based recommendations. Expert Rev Clin Immunol 2012;8:95-103.

36. Hinz A, Brahler E, Mode R, Wirtz H, Bosse-Henck A. Anxiety and depression in sarcoidosis: the influence of age, gender, affected organs, concomitant diseases and dyspnea. Sarcoidosis Vasc Diffuse Lung Dis 2012;29:139-146.

37. Handschin C, Spiegelman BM. The role of exercise and PGC1alpha in inflammation and chronic disease. Nature 2008;454:463-469.

38. Walsh NP, Gleeson M, Shephard RJ, et al. Position statement. Part one: Immune function and exercise. Exerc Immunol Rev 2011;17:6-63.

39. Pedersen BK. The diseasome of physical inactivity--and the role of myokines in muscle--fat cross talk. J Physiol 2009;587:5559-5568.

40. Lee IM, Shiroma EJ, Lobelo F, Puska P, Blair SN, Katzmarzyk PT. Effect of physical inactivity on major non-communicable diseases worldwide: an analysis of burden of disease and life expectancy. Lancet 2012;380:219-229.

41. Gleeson M, Bishop NC, Stensel DJ, Lindley MR, Mastana SS, Nimmo MA. The anti-inflammatory effects of exercise: mechanisms and implications for the prevention and treatment of disease. Nat Rev Immunol 2011;11:607-615.

42. Karstoft K, Pedersen BK. Exercise and type 2 diabetes: focus on metabolism and inflammation. Immunol Cell Biol 2016;94:146-150.

43. Allen J, Sun Y, Woods JA. Exercise and the Regulation of Inflammatory Responses. Prog Mol Biol TransI Sci 2015;135:337-354.

44. Swigris JJ, Fairclough DL, Morrison M, et al. Benefits of pulmonary rehabilitation in idiopathic pulmonary fibrosis. Respir Care 2011;56:783-789.

45. Holland AE, Fiore JF, Jr., Goh N, et al. Be honest and help me prepare for the future: What people with interstitial lung disease want from education in pulmonary rehabilitation. Chron Respir Dis 2015;12: 93-101.

46. Raghu G, Collard HR, Egan JJ, et al. An official ATS/ERS/JRS/ALAT statement: idiopathic pulmonary fibrosis: evidence-based guidelines for diagnosis and management. Am J Respir Crit Care Med 2011;183:788-824.

47. Spruit MA, Singh SJ, Garvey C, et al. An official American Thoracic Society/European Respiratory Society statement: key concepts and advances in pulmonary rehabilitation. Am J Respir Crit Care Med 2013;188:e13-64.

48. Panagiotou M, Peacock AJ, Johnson MK. Respiratory and limb muscle dysfunction in pulmonary arterial hypertension: a role for exercise training? Pulm Circ 2015;5:424-434. 
49. Tabak M, Brusse-Keizer M, van der Valk P, Hermens $H$, Vollenbroek-Hutten M. A telehealth program for self-management of COPD exacerbations and promotion of an active lifestyle: a pilot randomized controlled trial. Int J Chron Obstructive Pulm Dis 2014;9:935-944.

50. Dennis SM, Harris M, Lloyd J, Powell Davies G, Faruqi N, Zwar N. Do people with existing chronic conditions benefit from telephone coaching? A rapid review. Aust Health Rev 2013;37:381-388.

51. van der Weegen S, Verwey R, Spreeuwenberg M, Tange H, van der Weijden T, de Witte L. It's LiFe! Mobile and Web-Based Monitoring and Feedback Tool Embedded in Primary Care Increases Physical Activity: A Cluster Randomized Controlled Trial. J Med Internet Res 2015;17:e184. 

Valorisatie 



\section{Inleiding}

Sarcoïdose is een stoornis van het afweersysteem. Het is een multisysteemaandoening, die gekenmerkt wordt door ontstekingsactiviteit met de vorming van niet-verkazende granulomen. Granulomen zijn ophopingen van afweercellen die in het gehele lichaam kunnen voorkomen en op den duur kunnen leiden tot functievermindering van de betrokken organen. Het behoort tot de groep interstitiële longaandoeningen. Anders dan de term 'interstitiële longaandoeningen' doet vermoeden, zijn bij sarcoïdose niet uitsluitend de longen betrokken. In principe kan sarcoïdose zich in alle organen van het menselijk lichaam manifesteren. Betrokkenheid van de longen komt het meest voor, maar ook de ogen, huid, het lymfe- en spier-skeletsysteem zijn veelvuldig aangedaan. Sarcoïdosepatiënten kunnen zich zowel met orgaan-specifieke symptomen als met niet orgaan-specifieke symptomen, zoals pijn, vermoeidheid, algehele malaise en inspanningsintolerantie presenteren. Deze symptomen hebben veelal een subjectief en vaag karakter, waardoor deze moeilijk te diagnosticeren zijn. Daarnaast is aangetoond dat fysieke beperkingen en vermoeidheid bij een substantieel aantal sarcoïdosepatiënten een rol speelt. Deze problemen blijken ook grote gevolgen te hebben voor het dagelijks leven en daarmee voor de kwaliteit van leven (KvL). Medicamenteuze behandeling leidt lang niet altijd tot een verbetering van deze klachten en problemen. Daarom is men opzoek naar andere behandelopties voor fysieke beperkingen en het verminderen van vermoeidheid bij sarcoïdose. Een mogelijkheid ter verbetering van de fysieke fitheid en verminderen van vermoeidheid is een (fysiotherapeutisch) trainingsprogramma. De evidentie met betrekking tot de effectiviteit van deze behandeloptie bij sarcoïdose is beperkt en internationale richtlijnen ontbreken tot op heden. $\mathrm{Er}$ is dan ook dringend behoefte aan verdere wetenschappelijke onderbouwing hiervan.

Een aanzienlijk deel van de sarcoïdosepatiënten heeft last van verminderde inspanningsintolerantie, spierzwakte en vermoeidheid. Deze beperkingen blijken veelal een aanhoudend en chronisch karakter te hebben. Fysieke testen vormen dan ook een belangrijk onderdeel in de work-up en follow-up, aangezien deze in staat zijn om de voorheen relatief subjectieve klachten te objectiveren. Zo sluit een normale diffusie capaciteit (DLCO) van de longen gemeten in rust een eventuele pulmonale gaswisselingsstoornis tijdens maximale inspanning niet uit. Een cardiopulmonale inspanningstest lijkt hiervoor een betere voorspeller te zijn. Daarnaast blijkt de KvL resultaten eerder onderzoek van onze groep - in grote mate voorspeld te worden door de ernst van vermoeidheid en inspanningscapaciteit. Deze resultaten geven aan dat dit belangrijke interventieparameters zijn voor het verbeteren van de $\mathrm{KvL}$ en belastbaarheid. Vanwege bovenstaande onderzoeksresultaten is aanbevolen om fysieke testen deel uit te laten maken van de multidisciplinaire begeleiding van patiënten met sarcoïdose.

Hoofdstuk vijf en zes van dit proefschrift geven een weergave van de effecten van een door fysiotherapeuten begeleid fysiek trainingstraject bij patiënten met sarcoïdose 
en longfibrose. Hierin komt naar voren dat deze patiëntgroepen trainbaar zijn. Dit uit zich onder meer in verbetering van hun fitheid in een drie maanden durend trainingstraject. Daarnaast nemen vermoeidheidsklachten significant en klinisch relevant af. Hoofdstuk vijf laat bovendien zien dat deze klinische verbeteringen ook haalbaar zijn bij patiënten met ernstiger longfunctionele afwijkingen (patiënten met stadium IV longsarcoïdose met fibrotische kenmerken). Het is interesant om te zien dat zij vergelijkbare respons vertonen op de trainings-interventie.

In het laatste hoofdstuk van dit proefschrift wordt een systematisch overzicht van beschikbare literatuur ten aanzien van fysieke training bij sarcoïdose weergegeven. De uitkomsten van dit systematische literatuuroverzicht zijn leidend geweest bij het verkrijgen van consensus tussen sarcoïdose-experts over aanbevelingen ten aanzien van fysieke training als interventie bij sarcoïdosepatiënten met verschillende manifestaties van de ziekte. Dit heeft uiteindelijk geresulteerd in acht aanbevelingen ten aanzien van indicaties voor fysieke training, gestandaardiseerde evaluatie, inhoud van het trainings-programma, veiligheidsoverwegingen en monitoring tijdens de training.

\section{Maatschappelijk relevantie}

Sarcoïdose komt over de hele wereld voor, bij zowel mannen als vrouwen. De aandoening kan zich voordoen op iedere leeftijd, maar komt vaker voor bij jong volwassenen in de leeftijdscategorie van 25-45 jaar. Na astma is het de tweede meest voorkomende aandoening bij jong volwassenen. De incidentie van sarcoïdose in Nederland wordt geschat op 20 per 100.000 inwoners en de prevalentie op 50 per 100.000 inwoners, dat komt dus neer op een geschat aantal van 8000 sarcoïdosepatiënten in Nederland. Sarcoïdosepatiënten staan over het algemeen volop in het leven, waarbij op verscheidene gebieden veel van hen wordt gevraagd. Hierbij valt te denken aan studeren, opbouwen van een carrière en participeren in een gezin. Fysieke klachten kunnen grote gevolgen hebben voor het dagelijks functioneren en de KvL. Deze klachten kunnen zelfs leiden tot geheel of gedeeltelijke arbeidsongeschiktheid met financiële consequenties voor zowel de patiënt als de werkgever tot gevolg. Dit kan een lager maandinkomen tot gevolg hebben voor de patiënt, problemen bij het afsluiten van een hypotheek opleveren, maar ook tot een toename van zorgkosten leiden. De werkgever kan te maken krijgen met arbeidsverzuim- en gerelateerde kosten.

Fysieke klachten, als vermoeidheid en verminderd inspanningsvermogen, zorgen er bijvoorbeeld regelmatig voor dat patiënten hun huidige baan niet (goed) kunnen vervullen. Regelmatig wordt gezien dat patiënten al ruim voor het uiteindelijk verzuim moeite hebben hun taken te vervullen. Dit geeft veel bijkomende problemen als onzekerheid, frustratie, verlies van controle en stress. Veelal wordt gezocht naar oplossingen, zoals meer slapen en rust nemen, minder participatie in sociale 
activiteiten om er voor te zorgen het werk niet te hoeven verzuimen. Ook wordt er vaak (gedwongen) voor gekozen de werkzaamheden of het takenpakket aan te passen. Uiteindelijk resulteren deze strategieën regelmatig in lagere werkvreugde, verminderde sociale activiteiten en veelal uiteindelijk toch verzuim. Ter illustratie: bovenstaand scenario zag ik onlangs terug bij een jonge, voorheen sportieve, vrouw. Reeds enkele jaren erg gelukkig werkzaam in haar droombaan, als politieagente op straat. Twee jaar geleden werd bij haar sarcoïdose geconstateerd. In het begin van de ziekte had ze veel hinder van vermoeidheid, verminderd inspanningsvermogen en gewrichtsklachten. $\mathrm{Na}$ adequate medische behandeling verdween de 'actieve' sarcoïdose, klinische tests lieten verbetering van ziekte-parameters en vermindering van de ziekteactiviteit zien. Echter, de vermoeidheid en het verminderde inspanningsvermogen vertoonde een persisterend karakter, resulterend in matige, onvolledige re-integratie in haar werkzaamheden. Dit leidde tot veel frustratie, teleurstelling en verdriet bij haar zelf, maar ook tot onbegrip bij haar collega's en leidinggevende. Ze zag er immers niet ziek uit en in normale dagelijkse omgang was niets te bemerken van haar klachten.

In veel gevallen komen de ervaren fysieke klachten van de patiënt niet overeen met de resultaten van standaard uitgevoerde medische onderzoeken. Dit leidt bij veel patiënten tot een gevoel van onbegrip. Veelal wordt de verminderde orgaanfunctie (meestal longfunctie) en ziekteactiviteit gebruikt om de ernst van de ziekte te bepalen en het beloop te monitoren. Hoewel in $70-90 \%$ van de patiënten de longen betrokken zijn, kunnen de uitslagen van longfunctietesten een normaal beeld laten zien. Bij een normale diffusiecapaciteit in rust, treedt bij ongeveer $15 \%$ van de patiënten desaturatie op bij inspanning. Ondanks dat veel patiënten een normale longfunctie hebben, wordt toch vaak bij deze patiënten een verminderd inspanningsvermogen en verminderde perifere spierkracht gezien. Ook patiënten met herstelde of niet afwijkende longfunctietesten blijven vaak hinder houden van forse vermoeidheidsklachten, zonder tekenen van ziekteactiviteit. Dit fenomeen staat bekend als het post-sarcoïdose moeheidssyndroom. Het blijft van belang het klachtenpatroon minutieus te inventariseren, kwantificeren en te monitoren.

Om erkenning te krijgen voor de klachten dienen medisch specialisten zich bewust te zijn van het feit dat sarcoïdosepatiënten te maken kunnen krijgen met fysieke beperkingen en dit ook zorgvuldig laten onderzoeken. Het tijdig opsporen van fysieke beperkingen en het op de juiste wijze behandelen of begeleiden van deze patiënten kan een positieve werking hebben op de fysieke klachten, het psychosociaal welzijn, het dagelijks functioneren en de KvL van de patiënt en daarmee ook op financiële en arbeid gerelateerde factoren. Veel patiënten zijn verminderd belastbaar door de aanwezigheid van verschillende fysieke beperkingen (verminderd inspanningsvermogen, verminderde spierkracht, vermoeidheid). Het komt regelmatig voor dat patiënten niet kunnen voldoen aan de eisen van hun eerdere fulltime functie. Veelal dient het werk aangepast 
te worden (meer rust, minder zwaar, minder uren) om verzuim te vermijden. Dit resulteert regelmatig in onbegrip bij collega's, werkgevers en ook arbo-artsen.

Bovenstaande klachten zijn niet altijd, of worden niet altijd, goed in kaart gebracht. Dit bemoeilijkt het krijgen van erkenning voor het feit dat er bij sarcoïdosepatiënten vaak sprake kan zijn van een verminderde belastbaarheid. Erkenning en herkenning kan helpen bij het zoeken naar een juiste aanpak om de employability van de patiënt zo goed mogelijk te blijven benutten. Richtlijnen voor het gestandaardiseerd in kaart brengen van eerder genoemde fysieke beperkingen zijn noodzakelijk voor het vaststellen van belastbaarheid bij keuringen en bepaling van de mate van arbeidsgeschiktheid. In het begeleidingstraject dient ook aandacht te komen voor het optimaliseren van de balans tussen werk gerelateerde belasting en belastbaarheid.

Onze onderzoeksresultaten hebben aangetoond dat de frequent voorkomende fysieke beperkingen bij sarcoïdose met de juiste begeleiding door een fysiotherapeut, met ervaring met ILD-patiënten, positief beïnvloedbaar zijn. Alhoewel vervolgonderzoek nog steeds noodzakelijk is, laat ons onderzoek zien dat fysieke training een belangrijk onderdeel is bij het beïnvloeden van deze klachten. Daarom is een eerste aanzet gedaan tot het opstellen van richtlijnen samen met internationale sarcoïdose experts. Vervolgonderzoek blijft wenselijk om dit nog beter te onderbouwen.

\section{Doelgroepen}

Klinisch onderzoek dient (in-)direct altijd in het teken te staan van de patiënt, door verbetering te bewerkstelligen in de zorgverlening en daarmee tot verbeteringen in het patiënten welzijn te creëren. De belangrijkste doelgroep waarvoor deze onderzoeken zijn uitgevoerd betreft de patiënten met sarcoïdose en ander ILD waaronder longfibrose. Longfibrose is een ernstige, chronische en progressieve longziekte. Een fysiek trainingsprogramma zorgt voor een verbetering of stabilisering van het inspanningsvermogen. Ondanks de progressie van de ziekte, gekenmerkt door achteruitgang van de longfunctie (DLCO, FVC), zorgt een fysiek trainingsprogramma voor verbetering of stabilisering van het inspanningsvermogen. Longfibrose is niet te genezen, alleen een longtransplantatie kan de ziekte wegnemen. Om de patiënt goed voor te bereiden op de operatie en de kans op postoperatieve pulmonale complicaties te verkleinen speelt ook fysieke training een belangrijke rol.

De onderzoeksresultaten in dit proefschrift dienen tevens de medisch specialisten meer bewust te maken van het bestaan van vermoeidheid en fysieke beperkingen bij patiënten met sarcoïdose en de wijze waarop deze in kaart gebracht kunnen worden. Ook benadrukken de uitkomsten dat niet-medicamenteuze behandelopties overwogen dienen te worden bij de behandeling van vermoeidheid en fysieke beperkingen bij deze patiënten. 
Aangezien alle organen van het menselijk lichaam betrokken kunnen zijn bij het ziekteproces is een multidisciplinaire teambenadering van sarcoïdosepatiënten noodzakelijk. Zowel voor het in kaart brengen van fysieke beperkingen en vermoeidheid, als het trainen van sarcoïdosepatiënten, is een gekwalificeerde fysiotherapeut de aangewezen persoon. Begeleiding van sarcoïdosepatiënten met hun verscheidenheid aan klachten vereist immers specifieke kennis van het menselijk bewegingsapparaat, de pathologie sarcoïdose en trainingsleer. Richtlijnen over fysieke training bij chronische longaandoeningen zijn veelal gebaseerd op onderzoeken bij COPD-patiënten. Voor sarcoïdosepatiënten, met name voor degenen met een chronisch karakter, zijn $\mathrm{KvL}$ en een zo optimaal mogelijke participatie in de maatschappij heel belangrijk. Internationale experts geven ook aan dat meer onderzoek op dit gebied noodzakelijk is om de effectiviteit van een trainingsprogramma te onderzoeken en het programma af te stemmen op voor sarcoïdosepatiënten specifieke klachten en behoeftes. Derhalve dient in de opleiding van fysiotherapeuten naast COPD ook ILD aandacht te krijgen.

\section{Kennisdeling}

Implementatie van onderzoeksresultaten verloopt veelal niet vanzelf. In tegenstelling tot fundamenteel onderzoek is het voordeel van toegepast onderzoek, waarbij klinische vraagstellingen aan de basis liggen, dat relevante bevindingen van directe waarde zijn voor de behandelaars van sarcoïdosepatiënten. Dit proefschrift bevat dan ook uitsluitend toegepast onderzoek. Gestreefd wordt om de onderzoeks-resultaten te implementeren in de zorg met als hoger doel verbetering van de zorgverlening aan de sarcoïdosepatiënt. Een voorwaarde voor het implementeren van de onderzoeksresultaten is dat zowel behandelaars als sarcoïdosepatiënten op de hoogte zijn van de nieuwste ontwikkelingen en wetenschappelijke inzichten. Aangezien het begeleiden van sarcoïdosepatiënten een multidisciplinair karakter heeft is het de uitdaging om zoveel mogelijk disciplines te bereiken.

Alle onderzoeken in dit proefschrift zijn momenteel gepubliceerd in internationale tijdschriften. Tevens hebben de onderzoeksresultaten geleid tot wetenschappelijke voordrachten op zowel nationale (Koninklijk Nederlands Genootschap voor Fysiotherapie (KNGF)) als internationale (European Respiratory Society (ERS), American Association of Sarcoidosis and other Granulomatous Disorders (AASOG), World Association of Sarcoidosis and other Granulomatous Disorders (WASOG)) congressen met een verscheidenheid aan (para-) medische disciplines. Middels refereerbijeenkomsten zijn de onderzoeksresultaten teruggekoppeld naar de directe collega's van de afdeling fysiotherapie van Ziekenhuis Gelderse Vallei te Ede, het ILD Expertisecentrum van het St. Antoniusziekenhuis, locatie Nieuwegein, maar ook naar collega fysiotherapeuten elders in het land. Mede hierdoor zijn de resultaten beschikbaar gekomen voor behandelaars betrokken bij de zorg van sarcoïdose- 
patiënten. Vanuit de expertisecentra dienen fysiotherapeuten en andere zorgverleners betrokken bij de zorg voor sarcoïdosepatiënten optimaal te worden geïnformeerd en middels voorlichting en scholing op de hoogte te worden gesteld van nieuwe ontwikkelingen. De organisatie van masterclasses voor fysiotherapeuten is in voorbereiding.

\section{Patiënt empowerment}

De patiënt anno 2016 is over het algemeen een patiënt die actief betrokken wil zijn bij zijn/haar behandeling en op de hoogte wil blijven van de nieuwste medische ontwikkelingen. Dit hebben we getracht na te streven door lezingen te verzorgen voor de leden van de Sarcoïdose Belangenvereniging Nederland (SBN), de Longfibrose Patiëntenvereniging en door een lezing te verzorgen op de patiënten conferentie in New Orleans (US). Tijdens deze bijeenkomsten werden de onderzoeksbevindingen besproken en kritisch bediscussieerd en na afloop waren de patiënten en hun partners in de gelegenheid tot het stellen van vragen. Naast het informeren van patiënten is een belangrijk doel van deze bijeenkomsten om ervoor te zorgen dat patiënten een centrale rol kunnen innemen binnen hun eigen zorgproces. Daarbij is een goed geïnformeerde patiënt beter gemotiveerd.

\section{Innovatie}

Op dit moment ontbreken aanbevelingen over het gebruik van fysieke testen en fysieke training in nationale en internationale richtlijnen vanwege het gebrek aan wetenschappelijke onderbouwing.

De onderzoeken in dit proefschrift dragen bij aan het verschaffen van inzicht in de impact van fysieke beperkingen (verminderd inspanningsvermogen, verminderde spierkracht, vermoeid-heid) en hun onderlinge relaties, bij sarcoïdosepatiënten. Bij het in kaart brengen van (de gevolgen van) de ziekte door de arts worden in de huidige situatie veelal deze fysieke beperkingen niet meegenomen.

Daarnaast is ook uitgebreid gekeken naar de effecten van een fysiek trainingsprogramma op deze fysieke beperkingen bij deze patiëntengroep. Fysieke training kan een belangrijke (aanvullende) rol spelen bij het verminderen van vermoeidheid, verbeteren van het inspanningsvermogen en spierkracht en hiermee vergroten van de KvL. Deze interventie wordt nog weinig toegepast bij deze patiëntengroep, getuige de beperkte hoeveelheid wetenschappelijke literatuur aangaande dit onderwerp.

Voor het uitvoeren van de onderzoeken in dit proefschrift hebben wij gebruik gemaakt van bestaande meetinstrumenten en trainingsapparatuur. Het belang van bewegen en 
de invloed van lifestyle wordt bij chronische ziekten als sarcoïdose steeds belangrijker. Patiënten hebben een eigen verantwoordelijkheid en ook wordt benadrukt dat ze zelf een belangrijke rol kunnen spelen in het bevorderen van het gezondheidsproces en het genezingsproces in relatie tot hun omgeving (zelfeffectiviteit).

\section{Toekomstvisie}

De uitkomsten van de onderzoeken hebben geresulteerd in een achttal aanbevelingen ten aanzien van indicaties voor fysieke training, gestandaardiseerde evaluatie, inhoud van het trainingsprogramma, veiligheidsoverwegingen en monitoring tijdens de training. $\mathrm{Nu}$ is het van groot belang dat deze uitkomsten worden opgenomen in internationale medische en paramedische richtlijnen en hiermee hun weg naar de dagelijkse praktijk vinden. Hiervoor dienen onze aanbevelingen gesteund te worden door de diverse beroepsorganisaties, zoals de Nederlandse Vereniging van Artsen voor Longziekten en Tuberculose (NVALT) en het KNGF, die betrokken zijn bij de zorg van sarcoïdosepatiënten.

Moeheid is een van de grootste problemen van sarcoïdosepatiënten en daarbij moeilijk behandelbaar. Uit onze onderzoeksresultaten blijkt dat moeheid, fysieke functies en KvL bij sarcoïdose mogelijk beïnvloedbaar zijn met een trainingsprogramma. Ondanks dat de wetenschappelijke bewijskracht met betrekking tot de effectiviteit van fysieke training bij sarcoïdose beperkt is en meer onderzoek vereist is (bijvoorbeeld een gerandomiseerd effectonderzoek), kan dit een mogelijke behandeloptie zijn bij patiënten met vermoeidheidsklachten en fysieke beperkingen.

Toekomstig onderzoek dient zich te richten op de frequentie, duur, intensiteit en lange termijn effecten van training bij sarcoïdose. Maar ook de meerwaarde van een multidisciplinair revalidatieprogramma dient onderzocht te worden en tevens de inzet van e-health faciliteiten binnen de revalidatie.

Naast de mogelijke gezondheidswinst dient middels een kosten-effectiviteitsstudie onderzocht te worden of ook nog een economisch belang in de vorm van kostenbesparing kan worden bereikt. Immers de verwachting is dat fysieke training een goedkopere behandeloptie is voor vermoeidheidsklachten in vergelijking met medicamenteuze therapie. De keuze voor de behandeling hangt af van symptomen en ernst van functionele stoornissen en wordt in overleg tussen arts en patiënt bepaald. Met andere woorden is de klacht daadwerkelijk een probleem? Medicamenteuze therapie is in veel gevallen ontoereikend voor adequate behandeling van fysieke beperkingen. Training kan een goede aanvulling zijn op de huidige standaard behandelopties. 
Om deze bevindingen uiteindelijk toe te kunnen voegen aan het standaard zorgpakket van sarcoïdosepatiënten dient vervolgonderzoek plaats te vinden, waarna implementatie in de klinische praktijk kan plaatsvinden. Hiervoor is het essentieel om duidelijke afspraken te maken met de zorgverzekeraars. Zij bepalen of fysiotherapeutische interventies worden opgenomen in het chronisch zorgpakket voor sarcoïdosepatiënten en andere patiënten met ILD, zoals longfibrose, en daarmee in aanmerking komen voor financiële vergoeding. Dit is voor de patiënten en het uiteindelijke effect van groot belang. 
Samenvatting 



\section{Samenvatting}

Sarcoïdose is een multisysteem aandoening waarvan de oorzaak nog onbekend is. De ziekte wordt gekarakteriseerd door ontstekingsactiviteit en vorming van granulomen. Sarcoïdose kan zich in alle orgaansystemen presenteren, met functievermindering van het betreffende orgaansysteem gepaard gaan en een heel divers klachtenpatroon geven. Naast orgaanspecifieke klachten hebben patiënten regelmatig veel hinder van niet orgaanspecifieke klachten, zoals verminderde inspanningstolerantie, kortademigheid bij inspanning, algemene zwakte en vermoeidheid.

Farmacologische behandelopties zijn gericht op het behandelen van de ziekte (onderdrukking van de inflammatie) en behoud van orgaanfunctie. Ondanks effectieve behandeling van de sarcoïdose en uitdoven van de ziekteactiviteit houden veel patiënten last van vermoeidheid en beperkte inspanningstolerantie. Medicatie is dan ook geen oplossing voor deze klachten. Voor het verbeteren van conditie en spierkracht is fysieke training noodzakelijk.

Fysieke training is een effectief gebleken interventie bij de behandeling van fysieke beperkingen bij chronische (long)ziekten, gericht op verminderen van vermoeidheid en kortademigheid bij inspanning en tevens verbetering van de inspanningstolerantie. Wetenschappelijke bewijs voor de effectiviteit van deze interventie bij sarcoïdosepatiënten is beperkt. De aanwezige kennis komt veelal voort uit observationele studies met kleine patiëntenpopulaties.

De studies die beschreven worden in dit proefschrift hebben tot doel de gevolgen van sarcoïdose, de relaties tussen vermoeidheid, de karakteristieken van de patiënten en het inspanningsvermogen te beschrijven. Daaropvolgend is ook de invloed van fysieke training op het inspanningsvermogen, spierkracht en bovenal vermoeidheid onderzocht.

De sarcoïdosepatiënten die geïncludeerd zijn in deze studies waren verwezen naar het (voormalig) ild (interstitial lung disease) care team van Ziekenhuis Gelderse Vallei te Ede. Gedurende een periode van 22 maanden voerden alle patiënten één of meerdere malen inspanningstesten en spiertesten uit, daarnaast werden vragenlijsten afgenomen, voor en na een fysiek trainingsprogramma. Aan de hand van deze gegevens, een uitgebreid literatuuronderzoek en een survey onder sarcoïdose experts, werden aanbevelingen opgesteld ten aanzien van het inzetten van fysieke training bij sarcoïdose.

\section{Weergave van de belangrijkste bevindingen}

Hoofdstuk 1, geeft een algemene inleiding en overzicht van de pathogenese, epidemiologie, klinische presentatie en niet-specifieke klachten bij sarcoïdose. Deze niet orgaan-specifieke klachten, zoals vermoeidheid, verminderde inspanningstolerantie, gewrichtsklachten hebben forse invloed op het dagelijks leven van de 
patiënt. De rol van zowel farmacologische als niet-farmacologische behandelopties worden behandeld.

In hoofdstuk 2, wordt een overzicht van de literatuur gegeven ten aanzien van de uiteenlopende gevolgen voor de patiënt van de ziekte. Naast de orgaan-specifieke klachten hebben niet orgaan-specifieke klachten, zoals vermoeidheid, verminderde inspanningstolerantie, dunne vezelneuropathie, depressieve klachten en cognitieve stoornissen een grote invloed op het dagelijks (sociale en professionele) leven van patiënten. Dit leidt tot een verminderde kwaliteit van leven (KvL). Daarom wordt een multidisciplinaire behandeling aanbevolen voor deze patiënten met zowel aandacht voor de somatische als de psychologische aspecten van deze grillige ziekte. Glucocorticoïden worden nog steeds meestal als eerste ingezet als medicamenteuze behandeling wenselijk is. Echter, sommige patiënten hebben een meer agressieve behandelvorm nodig. Het besluit om te starten met immunosuppressieve behandeling moet worden gebaseerd op zowel de ernst van de symptomen, als de impact van deze symptomen op de KvL van de patiënt, als de mate van verminderde orgaanfunctie en/of schade. Sarcoïdosepatiënten kunnen ook baat hebben bij niet-farmacologische behandelopties. Het is van belang de impact van vermoeidheid, dunne vezelneuropathie, cognitieve stoornissen, pijn, slaapstoornissen en andere relevantie aspecten van deze multisysteem ziekte te kennen om een optimaal behandelregime te kunnen bieden. Behandeling op maat is hierbij essentieel.

Hoofdstuk 3, geeft een weergave van het validatie proces van de King's Sarcoidosis Questionnaire (KSQ) in een Nederlandse sarcoïdosepopulatie. De KSQ is een compacte vragenlijst die de gezondheidstoestand van de sarcoïdosepatiënt in vijf modules in kaart brengt (Algemene gezondheidstoestand, Longen, Medicatie, Huid en Ogen). De KSQ is eerder in één Engels cohort gevalideerd. De KSQ werd vertaald aan de hand van internationale richtlijnen en werd getest in interviews met patiënten. Patiënten vulden meerdere vragenlijsten tweemaal in, twee weken na elkaar. Van de 98 patiënten hadden er 85 long, 22 huid en 24 oogklachten. De construct validiteit van de KSQ Algemene Gezondheidstoestand module in relatie tot World Health Organization Quality of Life-Bref vragenlijst was sterk. De Medicatiemodule toonde een zwakke correlatie met de meeste vragenlijsten, waaronder de FAS (Fatigue Assesment Scale (FAS): vermoeidheidsvragenlijst; $r=0.39)$. De correlaties met orgaan-specifieke vragenlijsten varieerden van sterk voor Ogen $(r=0.75)$, Huid $(r=0.62)$ tot matig voor Long ( $r=-0.45$ met MRC dyspnoe schaal). De correlaties tussen het domein KSQ Algemene gezondheidstoestand $(r=0.81)$ en alle generieke vragenlijsten (Euroqol-5D-5 level (EQ-5D-5L), Global Rating of Change - Quality of Life (GRC-QoL), and WHOQOLBref waren sterk: vooral het domein Energie en Vermoeidheid $(r=0.84)$. Alle modules van de KSQ correleerden matig tot sterk met de FAS ( $r=0,50-0.81)$. De orgaanspecifieke module Long van de KSQ liet geen relatie zien met longfuncties, behalve een zwakke relatie met FVC \% van voorspeld $(r=0.24)$. De interne consistentie was goed voor alle 
KSQ modules (Cronbach's $\alpha$ 0.72-0.93). Intraclass correlatie coëfficiënten (0.70-0.90) en Bland-Altman plots lieten goede herhaalbaarheid zien van de KSQ. De Nederlandse KSQ is de eerste Gezondheidstoestand vragenlijst voor sarcoïdosepatiënten in Nederland. Daarnaast is het ook de eerste niet-Engelse validatie van de vragenlijst. De KSQ is gemakkelijk in te vullen en aan te passen op individuele orgaan betrokkenheid. De KSQ is een betrouwbaar en valide instrument om gezondheidstoestand van Nederlandse sarcoïdosepatiënten te bepalen.

Hoofdstuk 4, geeft de relatie tussen vermoeidheid, inspanningsvermogen en patiëntkarakteristieken (leeftijd, geslacht, tijd sinds diagnose, body mass index (BMI), longfunctie en ontstekingsparameters) bij sarcoïdosepatiënten weer. Daarnaast wordt de voorspellende waarde van uitkomsten van inspanningstesten en andere relevante patiëntkarakteristieken ten opzichte van de onafhankelijke variabele vermoeidheid weergegeven. Alle patiënten voerden inspanningstesten (6 minuten wandeltest (6MWT), Steep Ramp Test (SRT)) en spierkrachttesten (handknijpkracht: HGS, chair rise time (CRT), kracht van de elleboogbuigers (EFMS)) uit. Vermoeidheid werd gemeten met behulp van de FAS bij alle patiënten. In totaal werden 146 patiënten geïncludeerd in deze cohortstudie. Het inspanningsvermogen liet een zwakke correlatie met vermoeidheid zien $(r=0.25, p=0.002$ bij 6MWD \% van voorspeld; $r=0.24, p=0.003$ bij SRT). Vermoeidheid correleerde niet met demografische variabelen (leeftijd, BMI, tijd sinds diagnose). Ontstekingsparameters, longfunctie en handknijpkracht lieten ook geen significante correlaties met vermoeidheid zien. Meervoudige regressie analyse liet zien dat alleen vrouwelijk geslacht $(t=-2,614, p=0.01)$ en 6MWD $\%$ van voorspeld $(t=-2.773, p=0.006)$ onafhankelijke voorspellers van vermoeidheid waren. Echter, de $r(2)$ gaf aan dat deze twee variabelen samen slechts $11 \%$ van de FAS score verklaarden. Concluderend naar aanleiding van deze studie kan gesteld worden dat vermoeidheid (prevalentie 77\%) en verminderd inspanningsvermogen (prevalentie 75\%) substantiële problemen zijn bij patiënten met sarcoïdose. Het is algemeen geaccepteerd dat sarcoïdose-gerelateerde vermoeidheid multifactorieel van aard is. Deze studie slaagde er niet in op basis van de vergaarde data belangrijke associaties met vermoeidheid te vinden. Verder onderzoek om het fenomeen vermoeidheid te ontrafelen bij sarcoïdosepatiënten is belangrijk, om zowel farmacologische en non-farmacologische behandelstrategieën verbeteren.

Hoofdstuk 5, geeft inzicht is het gebruik van een fysiek trainingsprogramma op maat bij patiënten met idiopathische pulmonale fibrose (IPF), of eind-stadiumsarcoïdose-gerelateerde longfibrose. In beide gevallen hebben patiënten veel hinder van toenemende kortademigheid, verminderde inspanningstolerantie en vermoeidheid. Alle vierentwintig patiënten die werden verwezen naar het ild care expertiseteam van Ziekenhuis Gelderse Vallei, te Ede voerden inspanningstesten (6MWT, SRT), spierkrachttesten (HGS, EFMS) en longfunctietesten (FVC, DLCO, FEV 1 ) uit. Deze metingen werden gedaan bij aanvang en na het afronden van een 12 -weken 
durend fysiek trainingsprogramma. Bij aanvang bleek bij beide groepen het percentage van het voorspelde longfunctietest (FVC, DLCO, FEV $_{1}$ ) en inspanningstolerantie (6MWT, $\mathrm{VO}_{2} \max$ ) verminderd. $\mathrm{Na}$ het afronden van het trainingsprogramma was het inspanningsvermogen verbeterd ( $>10 \%$ verbetering op 6MWT) bij 13 patiënten $(54.2 \%)$ : bij zeven patiënten met IPF en zes met sarcoïdose. Ook andere, secundaire, uitkomstmaten, zoals longfunctietesten vertoonden verbetering bij sommige patiënten. Een 12-weken durend fysiek trainingsprogramma kan ervoor zorgen dat het inspanningsvermogen verbeterd of stabiel blijft bij patiënten met idiopathische pulmonale fibrose (IPF) (ondanks ziekteprogressie) en sarcoïdose met longfibrose. De resultaten van deze pilotstudie kunnen gebruikt worden om prospectieve studies op te zetten gericht op het beantwoorden van de vragen ten aanzien van het effect van fysieke training bij patiënten met deze progressieve, niet te genezen, ziekte.

In hoofdstuk 6, worden de resultaten weergegeven van sarcoïdosepatiënten die een fysiek trainingsprogramma hebben gevolgd. Het doel van deze studie was te bepalen of een fysiek trainingsprogramma inspanningsvermogen verbeterd en vermoeidheid verminderd. In ons centrum worden alle sarcoïdosepatiënten routinematig doorverwezen naar Afdeling Fysiotherapie om inspanningsvermogen en spierkracht te bepalen. Aan het begin en na het volgen van een 12-weken durend fysiek trainingsprogramma werden inspanningsvermogen (6MWT, SRT), spierkracht (HGS, EFMS, CRT), vermoeidheid (FAS) en longfunctietesten (FVC, DLCO, FEV1) uitgevoerd. Negentig patiënten voerden deze testen uit, 49 patiënten (groep I) volgden het trainingsprogramma en 41 kozen ervoor dit niet te doen (groep II). Ten aanzien van vermoeidheid, longfunctie en inspanningsvermogen verschilden deze twee groepen bij aanvang niet van elkaar. De 6MWD in groep I verbeterde in 12-weken tijd, terwijl deze in groep II niet veranderde $(F=72.2, p<0.001)$. Groep I liet een significant grotere afname van vermoeidheid zien vergeleken met groep $\| \quad(F=6.27, p=0.014)$. De longfunctie veranderde in beide groepen niet. In deze studie vonden we dat door een gesuperviseerd 12-weken durend fysiek trainingsprogramma inspanningsvermogen, spierkracht toeneemt en vermoeidheid afneemt bij patiënten met sarcoïdose. De resultaten waren onafhankelijk van leeftijd, geslacht, tijd sinds diagnose, longfunctie bij aanvang, ontstekingswaarden en farmacologische interventies. Onze aanbeveling is dat fysieke training als eerste lijn therapie bij sarcoïdosepatiënten dient te worden overwogen, vooral bij patiënten met verminderd inspanningsvermogen, verminderde spierkracht en/of vermoeidheid.

Hoofdstuk 7, bestaat uit een systematisch literatuuroverzicht (fase I) ten aanzien van fysieke training bij patiënten met sarcoïdose. Een uitgebreide zoekstrategie resulteerde in vier publicaties. Al deze studies lieten positieve resultaten zien ten aanzien van het verbeteren van inspanningsvermogen, verminderen van vermoeidheid en verbeteren van KvL. Ondanks het feit dat er nog weinig onderzoek is gedaan ten aanzien van dit onderwerp is er een duidelijke aanwijzing dat fysieke training een 
positieve bijdrage kan leveren bij het beïnvloeden van deze zeer belastende symptomen.

De uitkomsten van dit systematische literatuuroverzicht zijn leidend geweest bij het verkrijgen van consensus, tussen sarcoïdose experts, over aanbevelingen ten aanzien van fysieke training als interventie bij sarcoïdosepatiënten met verschillende manifestaties van de ziekte (fase II en III). De meeste experts waren longartsen (82\%) en de meerderheid (70\%) had meer dan 10 jaar ervaring met sarcoïdosepatiënten. Fysieke training wordt gezien als een waardevolle en veilige interventie. Pulmonale betrokkenheid, vermoeidheid en spier- en extrapulmonale betrokkenheid werden gezien als de meest belangrijke indicaties voor fysieke training. Bijna $50 \%$ van de respondenten op de survey gaf aan dat specifieke situaties zijn waarin fysieke training mogelijk risico's met zich meebrengt, zoals bij onbehandelde cardiale ritmestoornissen. De verzamelde resultaten uit fase I en fase III werden gebruikt om 10 aanbevelingen voor het gebruik van fysieke training bij sarcoïdose op te stellen. Uiteindelijk werden deze aanbevelingen voorgelegd aan een panel van 15 leidende internationale sarcoïdose experts, bekend met fysieke training bij sarcoïdose. Aanbevelingen met een consensus minder dan $75 \%$ werden niet opgenomen in de definitieve selectie. Dit proces heeft geresulteerd in acht aanbevelingen ten aanzien van indicaties voor fysieke training, gestandaardiseerde evaluatie, inhoud van het trainingsprogramma, veiligheidsoverwegingen en monitoring tijdens training.

Hoofdstuk 8, bevat de Engelstalige samenvatting met daarin de belangrijkste bevindingen van dit proefschrift en de algemene discussie. Dit proefschrift beschrijft de gevolgen van de ziekte sarcoïdose en de effecten van een fysiek trainingsprogramma op de gevolgen van deze ziekte. Fysieke training is een goed beschreven, veel onderzochte, veilige en effectieve interventie voor de revalidatie bij chronische ziekten. Sarcoïdose heeft een heel divers karakter met verschillende fenotypen. Het kan zich presenteren met een breed spectrum aan symptomen, zoals verminderde inspanningstolerantie, algemene spierzwakte, vermoeidheid en verminderde KvL. Dit maakt dat dat behandeling op maat erg belangrijk is, dit geldt ook voor het inzetten van fysieke training modaliteiten. Kort gezegd, gesuperviseerde fysieke training bij sarcoïdose kan het inspanningsvermogen, de KvL verbeteren, vermoeidheid en kortademigheid verminderen. ledere patiënt met deze symptomen zou een fysiek trainingsprogramma aangeboden dienen te krijgen. Hierbij is het essentieel dat de fysieke status voorafgaand aan het trainingsprogramma gestructureerd en uitgebreid in kaart wordt gebracht. Vermoeidheid, kortademigheid, spierkracht en inspanningsvermogen zijn belangrijke onderdelen.

Om fysieke training bereikbaar te maken voor meer sarcoïdosepatiënten is het belangrijk dat er richtlijnen worden opgesteld. De heterogeniteit van de sarcoïdosepatiënten, met uiteenlopende symptomen, zorgt ervoor dat een fysiek trainingsprogramma op maat aangepast dient te worden. In dit proefschrift is getracht een begin te maken met de ontwikkeling van richtlijnen door middel van het vergroten 
van de wetenschappelijke kennis op het vlak van fysieke training bij sarcoïdose. Daarnaast zijn aanbevelingen voor de implementatie van fysieke training bij deze patiëntengroep opgesteld. Het is echter nog niet bekend welke patiënten het meest baat hebben bij fysieke training, welke trainingsmodaliteiten het meest effectief zijn bij het verminderen van sarcoïdose-gerelateerde vermoeidheid. Ook de optimale frequentie, intensiteit en duur van het trainingsprogramma zijn onbekend. Dit zijn belangrijke vragen om te beantwoorden in toekomstig onderzoek, om behandelstrategieën te optimaliseren.

\section{Hoofdpunten}

- Naast farmacologische interventies dient de begeleiding van symptomatische sarcoïdosepatiënten behandelstrategieën gericht op een gezonde leefstijl en verbetering van de fysieke fitheid te bevatten.

- Kennis van trainingsprincipes en de pathofysiologie van sarcoïdose zijn essentieel voor het optimaal kunnen begeleiden van een effectief fysiek trainingsprogramma.

- Ondanks de complexiteit van de aanwezige symptomen bij sarcoïdosepatiënten is gesuperviseerde fysieke training een veilige en effectieve interventie gebleken ter bevordering van klinische verbetering.

- Het volgen van een fysiek trainingsprogramma leidt tot verbetering van het inspanningsvermogen, vermoeidheid en kwaliteit van leven bij patiënten met sarcoïdose. 
Dankwoord 



\section{Dankwoord}

In dit dankwoord maak ik graag gebruik van de gelegenheid om een aantal mensen te bedanken voor hun bijdrage aan de totstandkoming van dit proefschrift. Veel personen hebben, op verschillende manieren, bijgedragen aan het tot stand komen van dit proefschrift.

Allereerst gaat in het bijzonder mijn dank uit naar mijn promotoren: Prof. dr. Marjolein Drent en Prof. dr. Jolanda de Vries.

Beste Marjolein, het eerste woord van deze zin is essentieel, want een betere promotor had ik me niet kunnen wensen. Toen je in het ZGV ging werken heb je met veel enthousiasme de afdeling Fysiotherapie en mij voor je te weten te winnen. Gedreven zijn we binnen het toenmalige ILD care team met sarcoïdose- en longfibrosepatiënten gestructureerd aan het trainen geslagen. Met goed resultaat en enthousiasme bij alle partijen. Ik weet nog goed dat je zei: "Laten we dit eens proberen op te schrijven..." Jouw enthousiasme, heldere blik en bevlogenheid voor onderzoek, maar vooral voor de patiënt, zijn inspirerend. Jouw toegankelijkheid en bereikbaarheid hebben er voor gezorgd dat de samenwerking erg prettig was. Mijn mailbox puilde continue uit met alle mailtjes die je me stuurde. Veelal goede ideeën, nuttige tips, waardevolle correcties en aanvullingen van de manuscripten, maar ook...nieuwe opdrachten en extra werk. Zonder jouw bevlogenheid, behulpzaamheid en steun had dit proefschrift niet in deze hoedanigheid en op dit moment hier gelegen, bedankt!

Beste Jolanda, ook jou ben ik veel dank verschuldigd. Voor het kritisch lezen en voorzien van scherpe feedback op mijn manuscripten en statische hulp ben je erg belangrijk geweest. Nog steeds maak ik gebruik van jouw opmerkingen als ik gevraagd word feedback op andermans stukken te geven (is de inleiding in relatie tot de vraagstelling wel logisch, is de vraagstelling concreet, wordt er wel echt antwoord gegeven op de centrale vraag...). Bedankt voor de fijne samenwerking.

Een ander belangrijk persoon in de totstandkoming van dit proefschrift is Marjon Elfferich geweest. Heel erg bedankt voor je hulp bij het bijeenzoeken, uitpluizen en verwerken van alle patiëntgegevens om tot een complete digitale database te komen. Ook je hulp bij het opstellen en uitzetten van de verschillende surveys heb ik enorm gewaardeerd. We hebben vast alle geheimen van Survey Monkey weten te ontrafelen tijdens ons gepuzzel met de verschillende surveys. Ook wil ik je bedanken voor je kritische eindredactionele blik op alle stukken.

I would also like to thank Lesley Ann Saketkoo very much. Your help with preparing the survey and manuscript (chapter 7) was inspiring. The process of content analysis, deconstructing text and extracting key concepts in order to prepare representative survey questions was new territory for me, your experience and feedback was very helpful. Inviting me to participate in the New Orleans FSR patient conference 'Tackling 
the Trickster' and introducing me to the leading sarcoidosis experts was a valuable experience for me, and I also enjoyed the lovely city of New Orleans.

Also, I want to thank Jeff Swigris for his support and great help in preparing my first manuscript. Your clear view and extensive feedback was very helpful. 'Less is more' and 'stick with the essence' were two important lessons I still try to apply in my work.

Dank ben ik ook verschuldigd aan Mirjam van Manen voor de samenwerking die geleid heeft tot het artikel over de King's Sarcoidosis Questionnaire. Heel veel succes gewenst bij het afronden van je eigen promotietraject.

Ook wil ik graag op deze manier de leden van de beoordelingscommissie, Prof. dr. R.A. de Bie, Prof. dr. A. Bast, Prof. dr. J. Grutters, Prof. dr. H. Kuipers en Prof. dr. W. Wuyts, bedanken voor het kritisch lezen en beoordelen van het manuscript.

Al mijn co-auteurs wil ik hartelijk danken voor hun kritische en waardevolle feedback op al mijn (concept)manuscripten, heel erg bedankt!

I would like to thank all my co-authors for their feedback and help in the preparation of the manuscripts, thank you very much!

Een speciaal woord van dank gaat uit naar mijn leidinggevende, Ton Knevel. Persoonlijke ontwikkeling, groei en werktevredenheid zijn voor jou belangrijke pijlers in het 'managen' van onze afdeling Fysiotherapie. Deze pijlers hebben het voor mij mogelijk gemaakt hier nu te staan.

Ook mijn collega's van de Afdeling Fysiotherapie van Ziekenhuis Gelderse Vallei wil ik hierbij graag bedanken, voor jullie interesse en het aanhoren van mijn onderzoeksresultaten op menig afdelingsoverleg. Ik kan niet beloven dat ik jullie in de toekomst niet meer lastig zal vallen op de vergaderingen, er is nog veel te ontdekken op ons vakgebied in het verlengde van dit proefschrift...

In het bijzonder wil ik Soraya, Irene, Marcella en Flora bedanken voor de essentiële hulp bij de dataverzameling, zonder jullie hulp was ik nu waarschijnlijk nog steeds data aan het verzamelen...

Ook het secretariaat verdient een vermelding in dit dankwoord. Maria, Elsbeth, Marjolein, Ilse en Annet, heel erg bedankt voor jullie hulp bij het maken (en verzetten) van alle benodigde afspraken met de patiënten. 
De onderzoeken in dit proefschrift zijn mogelijk gemaakt door financiële ondersteuning van de ild care foundation en de Sarcoïdosebelangenvereniging Nederland (SBN), hen ben ik veel dank verschuldigd.

Ook wil ik alle, bij de onderzoeken in dit proefschrift, betrokken patiënten en sarcoïdose experts enorm bedanken. De patiënten waren zeer gemotiveerd deel te nemen en bijzonder geïnteresseerd. Daarnaast kwamen ze uit alle hoeken en gaten van het land (en buitenland) om te kunnen participeren, dit stel ik zeer op prijs.

Dr. Petal Wijnen, ook jouw inspanningen mogen niet ongenoemd blijven. Allereerst bedankt voor de spoedcursus 'Endnote voor Dummies' op een zaterdagochtend bij Marjolein thuis. Deze heeft enige vruchten afgeworpen, echter ik heb je toch nog veelvuldig nodig gehad om ICT-gerelateerde problemen het hoofd te bieden, bedankt voor al je hulp.

Jan Klerkx, ook u ben ik ook grote dank verschuldigd voor het beoordelen en corrigeren van alle Engelse tekst in dit proefschrift. Bedankt voor de zorgvuldige en supersnelle hulp.

Tiny Wouters, ik wil je hierbij heel erg bedanken voor je belangrijke bijdrage aan dit proefschrift. Alle losse onderdelen heb je vakkundig tot een geheel weten op te maken. Daarnaast bewonder ik de snelheid waarmee dit steeds gebeurde, iedere mail werd binnen zeer korte tijd beantwoord en voorzien van het gevraagde. Bedankt voor al je hulp.

Beste Rik, niet alleen was je mijn directe voorganger als promovendus bij Marjolein, je hebt in samenwerking met Marjolein een heel belangrijk gebied voor de sarcoïdosepatiënt ontgonnen. Nog weinig was er voor jouw promotietraject objectief bepaald over de fysieke beperkingen die deze patiënten kunnen ervaren. Je hebt dit echt op de kaart gezet en daarbij een enorme voorzet voor de richting van mijn promotietraject gegeven. Ook bedankt voor de feedback op een tweetal manuscripten en je persoonlijke interesse.

Ik wil ook mijn familie en vrienden bedanken voor de interesse die zij hebben getoond in mijn werkzaamheden. De tijd die ik met jullie heb doorgebracht op feestjes, op visites, op het voetbalveld, heeft er voor gezorgd dat ik op die momenten helemaal met mijn hoofd weg was bij sarcoïdose, longfibrose, onderzoek, patiënten, statistiek en meer van dit soort zaken. Op deze wijze zijn jullie erg belangrijk geweest. Wellicht dat de komende tijd meer tijd vrij laat voor feestjes, borrels en andere gezellige festiviteiten! 
Een speciaal bedankje moet er zijn voor mijn ouders. Pap en mam, ik wil jullie bedanken voor alles wat jullie voor mij hebben gedaan en nog steeds doen! Vanuit praktisch oogpunt is het steunen van mijn keuze, om na de opleiding Fysiotherapie, direct door te gaan met Fysiotherapiewetenschap aan de Universiteit Utrecht erg belangrijk geweest. Deze stap heeft het wetenschappelijke vuurtje in me behoorlijk aangewakkerd, en is essentieel geweest om dit alles mogelijk te maken.

Ook wil ik mijn paranimfen hierbij bedanken.

René, mijn kleine, niet meer zo kleine broer. Ondanks dat we op professioneel vlak op geheel andere werkgebieden beland zijn, maken jouw humor en hulpvaardigheid je tot mijn beste broer en uitermate geschikte paranimf. We moeten binnenkort snel nog maar eens naar het mooiste stadion van Nederland afreizen om een leuke wedstrijd te aanschouwen!

Roy, regelmatig lekker op stap, het geluk beproeven in een casino (waar jij altijd de jackpot lijkt te bemachtigen, hoe doe je dat toch?) heeft bij mij voor de nodige ontspanning gezorgd. Laten we dit na deze plechtigheid maar weer snel een vervolg geven.

Ik ben blij dat jullie me bij deze promotieplechtigheid terzijde staan.

En dit laatste deel wil ik wijden aan de meest belangrijke personen voor mij. Flora, heel erg bedankt voor al je liefde en steun tijdens deze periode. Door allereerst me de kans te geven dit promotietraject aan te gaan in deze drukke tijd van ons nog prille gezin. Daarnaast, wil ik je bedanken omdat je er altijd voor mij en de kinderen bent. Ook moet ik je bedanken voor alle praktische hulp bij de totstandkoming van dit proefschrift, het lezen van kladjes, aanhoren van gedachten, feedback geven op concept-concept titels heeft me erg geholpen. Je bent voor mij de allerliefste, ik hou van je!

En natuurlijk Julian en Benjamin, de liefste kindjes ter wereld. Overdag vroegen, maar gaven jullie mij zo ontzettend veel energie. Hierdoor kon ik iedere beschikbare avond (na jullie bedtijd, half acht 's avonds) goed aan de slag. Doordat jullie veelal lekker in dromenland verbleven was het heerlijk werken aan de keukentafel. Nu heeft papa weer alle tijd van de wereld om met jullie spannende avonturen te beleven... 
Curriculum vitae 



\section{Curriculum vitae}

Bert Strookappe was born on November 13, 1981, in Deventer, The Netherlands. After training to become a physical therapist he consecutively worked in three hospitals. In the same year (2005) he started the Master's degree program in physical therapy at the University of Utrecht, from which he graduated in 2009. Since December 2007 he has been working at the Department of Physical Therapy of Gelderse Vallei Hospital, Ede, The Netherlands as a physical therapist, focusing on the treatment of patient in the surgical ward (vascular surgery) and Intensive Care. Clinical rehabilitation of critically ill patients (with a wide range

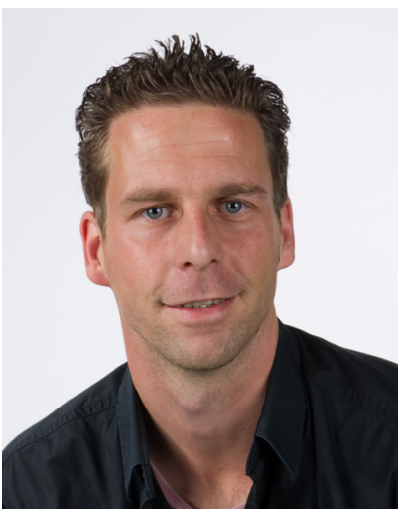
of conditions and comorbidities) has been his main interest. He considers the management of the rehabilitation process of critically ill patients, from 'bedridden' to 'walking out of the hospital', to be the most inspiring aspect of his work. The integration of scientific evidence in daily patient care is an important part of his tasks. Since 2012 he has been involved in the management of outpatients with interstitial lung disease (ILD). The research project described in this thesis started in 2014 at Gelderse Vallei Hospital, with Prof. Marjolein Drent and Prof. Jolanda De Vries as his supervisors. He is a member of the ILD care foundation research team and ILD Expertise Center of the St. Antonius Hospital Nieuwegein, The Netherlands.

The results of the studies reported on in this thesis have been presented at the European Respiratory Society's (ERS) 2015 International Annual Congress in Amsterdam, as well as at the American Association of Sarcoidosis and Other Granulomatous Disorders' (AASOG) 2015 conference in Denver, USA, at the Foundation for Sarcoidosis Research's (FSR) Patients 2015 Conference in New Orleans, USA, and the WASOG 2016 meeting in Gdansk, Poland. In 2015 he received a research grant from the ILD Care Foundation and the 'Research Support 2016' grant from the Sarcoïdose Belangenvereniging Nederland (SBN: Dutch Sarcoidosis Patients Association) to support the research-project entitled 'Physical Training in Sarcoidosis'.

He lives with his wife, Flora Strookappe-Kokenberg, and two sons, Julian and Benjamin in Huissen, The Netherlands. 

List of publications 



\section{List of publications}

Strookappe B, Elfferich M, Swigris J, Verschoof A, Veschakelen J, Knevel T, Drent M. Benefits of physical training in patients with idiopathic or end-stage sarcoidosis-related pulmonary fibrosis: a pilot study. Sarcoidosis Vasc Diffuse Lung Dis 2015;32:43-52.

Strookappe B, Swigris J, De Vries J, Elfferich M, Knevel T, Drent M. Benefits of Physical Training in Sarcoidosis. Lung 2015;193:701-708.

Drent M, Strookappe B, Hoitsma E, De Vries J. Consequences of Sarcoidosis. Clin Chest Med 2015;36(4):727-737.

Van Manen MJ, Wapenaar M, Strookappe B, Drent M, Elfferich M, De Vries J, Gosker HR, Birring SS, Patel AS, Van den Toorn L, Van den Blink B, Boomars K, Hoitsma E, Wijsenbeek MS. Validation of the King's Sarcoidosis Questionnaire (KSQ) in a Dutch sarcoidosis population. Sarcoidosis Vasc Diffuse Lung Dis 2016;33:75-82.

Strookappe B, De Vries J, Elfferich M, Kuijpers P, Knevel T, Drent M. Predictors of fatigue in sarcoidosis: The value of exercise testing. Respir Med 2016;116:49-54.

Strookappe B, Saketkoo LA, Elfferich M, Holland A, De Vries J, Knevel T, Drent M. Physical activity and training in sarcoidosis: review and experience-based recommendations. Expert Rev Respir Med 2016;10:1057-1068. 

Abbreviations 



\section{Abbreviations}

$\%$ pred percentage of predicted

$\Delta \quad$ difference

18-FDG-PET fluorine-18 fluorodexyglocose position emission tomography

6MWD six minute walking distance

6MWT six minute walk test

AASOG American Association of Sarcoidosis and other Granulomatous Disorders

ANOVA analysis of variance

ATS

American Thoracic Society

BAL bronchoalveolar lavage

BHL bilateral hilar lymphadenopathy

BMI body mass index

BS Bert Strookappe

CBT cognitive behavioral therapy

$\mathrm{Cl} \quad$ confidence interval

COPD chronic obstructive pulmonary disease

CPET cardiopulmonary exercise testing

CRP C-reactive protein

CRT chair rise time

CXR chest X-ray

DLCO diffusion capacity of the lungs for carbon monoxide

E eyes

EFMS elbow flexor muscle strength

ERS European Respiratory Society

Euroqol-5D-5L Euroqol-5D-5 level

$\mathrm{F}$

F-statistic

FAS

Fatigue Assessment Scale

$\mathrm{FEV}_{1} \quad$ forced expiratory volume in one second

FFM fat-free mass

Fig figure

FVC forced vital capacity

GHS general health status

GoR Grade of Recommendations

GRC-QoL Global Rating of Change-Quality of Life

HGF hand grip force

HGS hand grip strength

HRCT high-resolution computed tomography

HS health status

ICC intraclass correlations

IENFD intra-epidermal nerve fiber density

IL interleukin 


\begin{tabular}{|c|c|}
\hline ILD & interstitial lung disease \\
\hline IPF & idiopathic pulmonary fibrosis \\
\hline KSQ & King's Sarcoidosis Questionnaire \\
\hline KvL & Kwaliteit van leven \\
\hline L & lung \\
\hline LAS & Lesley Ann Saketkoo \\
\hline LoE & Levels of Evidence \\
\hline M & medication \\
\hline MCID & minimal clinically important difference \\
\hline MD & Marjolein Drent \\
\hline MD & Medical Doctor \\
\hline MSc & Master of Science \\
\hline MEC & medics ethics committee \\
\hline $\mathrm{MeSH}$ & Medical Subject Headings \\
\hline MicroFET & Micro Force Evaluating and Testing \\
\hline MRC & Medical Research Council \\
\hline MTX & methotrexate \\
\hline $\mathrm{N}$ & Newton \\
\hline $\mathrm{n}$ & number \\
\hline NA & not applicable \\
\hline NEI-VFQ25 & National Eye Institute Visual Function Questionnaire \\
\hline NSAID & non-steroidal anti-inflammatory drugs \\
\hline $\mathrm{p}$ & p-value \\
\hline PA & pathological anatomy \\
\hline $\mathrm{PAH}$ & pulmonary arterial hypertension \\
\hline PET & positron emission tomography \\
\hline PhD & Doctor of Philosophy \\
\hline PImax & maximal inspiratory mouth pressure \\
\hline PR & pulmonary rehabilitation \\
\hline PROMs & patient related outcome measures \\
\hline QOL & quality of life \\
\hline r & Pearson correlation coefficient \\
\hline$r^{2}$ & coefficient of determination \\
\hline RPE & rating of perceived exertion \\
\hline rpm & revolutions per minute \\
\hline S & skin \\
\hline SAT & Sarcoidosis Assessment Tool \\
\hline SD & standard deviation \\
\hline SEM & standard error of mean \\
\hline SF-36 & Medical Outcomes Study 36-item Short Form Health Survey \\
\hline SFN & small fiber neuropathy \\
\hline SFNSL & small fiber neuropathy screening list \\
\hline
\end{tabular}




\begin{tabular}{|c|c|}
\hline SGRQ & St. George Respiratory Questionnaire \\
\hline SHQ & Sarcoidosis Health Status Questionnaire \\
\hline SIL-2R & soluble interleukin-2 receptor \\
\hline SPSS & Statistical Package for the Social Sciences \\
\hline SRT & steep ramp test \\
\hline $\mathrm{t}$ & t-value \\
\hline TNF & tumor necrosis factor \\
\hline USA & United States of America \\
\hline VC & vital capacity \\
\hline $\mathrm{VO}_{2} \max$ & maximal oxygen uptake \\
\hline WASOG & World Association of Sarcoidosis and other Granulomatous Disorders \\
\hline \multicolumn{2}{|c|}{ WHOQOL-Bref World Health Organization Quality of Life assessment instrument-BREF } \\
\hline$x^{2}$ & chi-squared test \\
\hline yrs & years \\
\hline ZGV & $\begin{array}{l}\text { Hospital Gelderse Vallei (Ziekenhuis Gelderse Vallei), Ede, The } \\
\text { Netherlands }\end{array}$ \\
\hline
\end{tabular}


